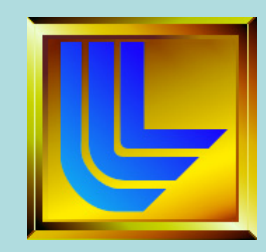

\title{
THERMODYNAMICS AND KINETICS OF PHASE TRANSFORMATIONS IN PLUTONIUM ALLOYS - PART I \\ UCRL-TR-206658
}

\author{
Patrice E. A. Turchi
}

Lawrence Livermore National Laboratory (L-353), P. O. Box 808, Livermore, CA 94551

\section{Larry Kaufman}

Dept. of Mater. Sci. and Eng., MIT, Cambridge, MA 02139

\section{Zi-Kui Liu and Shihuai Zhou}

Dept. of Mater. Sci. and Eng., The Pennsylvania State University, University Park, PA 16803
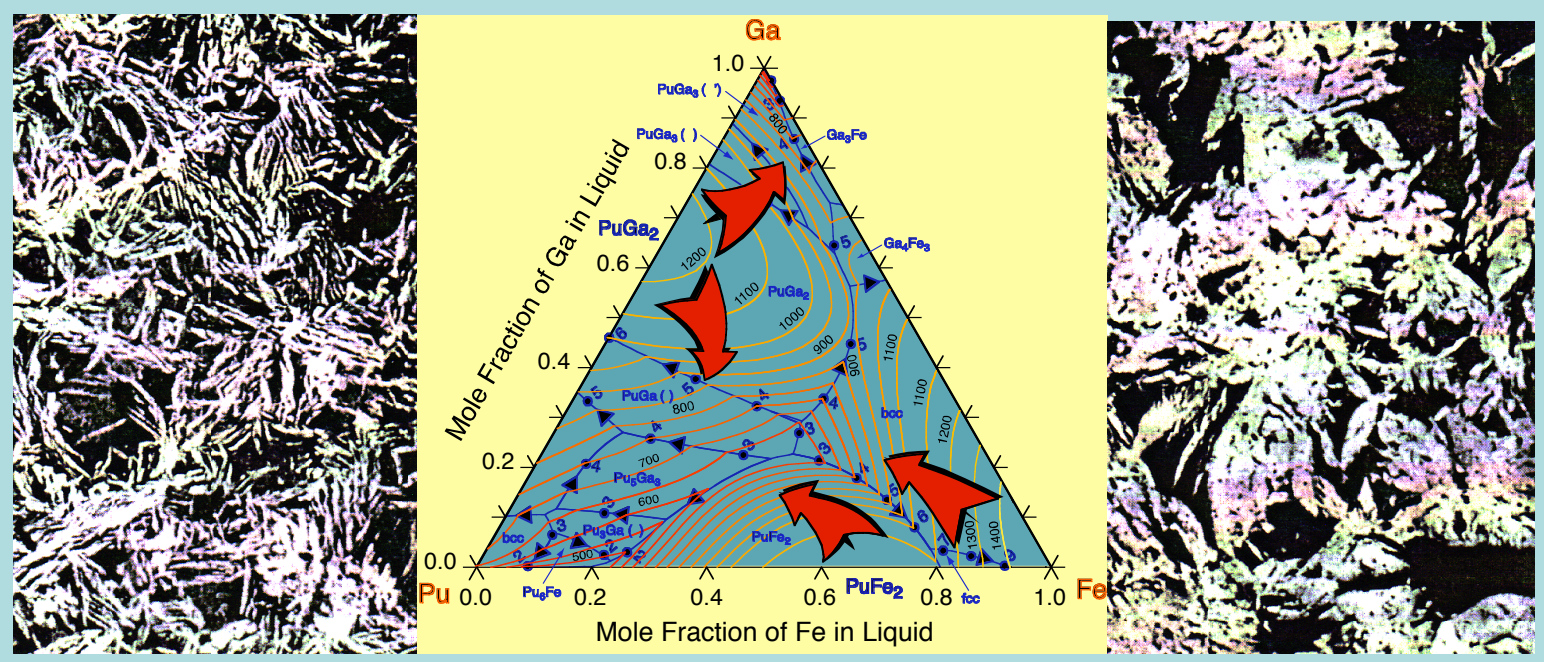

\section{PURPOSE}

To clarify and enhance our theoretical understanding of the effects of crystallography, alloying, and thermo-chemistry of actinide alloys on stability, meta-stability, phase transformations and aging. 


\section{DISCLAIMER}

This document was prepared as an account of work sponsored by an agency of the United States Government. Neither the United States Government nor the University of California nor any of their employees, makes any warranty, express or implied, or assumes any legal liability or responsibility for the accuracy, completeness, or usefulness of any information, apparatus, product, or process disclosed, or represents that its use would not infringe privately owned rights. Reference herein to any specific commercial product, process, or service by trade name, trademark, manufacturer, or otherwise, does not necessarily constitute or imply its endorsement, recommendation, or favoring by the United States Government or the University of California. The views and opinions of authors expressed herein do not necessarily state or reflect those of the United States Government or the University of California, and shall not be used for advertising or product endorsement purposes.

Cover: Micrograph of $\alpha$ ' in a $\delta$ matrix of Pu-Ga 1.2 at.\% treated at $-180{ }^{\circ} \mathrm{C}$ (left) and $-50{ }^{\circ} \mathrm{C}$ (right) for $30 \mathrm{mns}$, taken from P. Deloffre, J. L. Truffier and A. Falanga, "Phase transformation in Pu-Ga alloys at low temperature and under pressure: limit stability of the $\delta$ phase", J. of Alloys and Compounds 271-273, 370-373 (1998). The central picture shows the liquidus-surface projection for the ternary Pu-Ga-Fe system discussed in section VIII.1 (pp. 43) of this work. 


\section{CONTENTS}

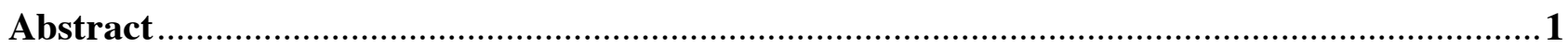

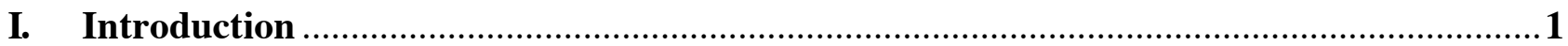

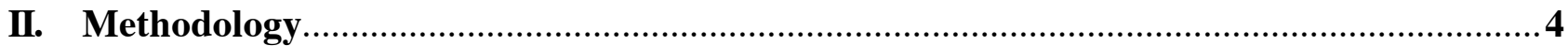

II.1. Computer Coupling of Phase Diagrams and Thermo-chemistry: CALPHAD ...........5

II.2. Solidification According to the Scheil-Gulliver Approach........................................

II.3. Diffusion Modeling of Phase Transformations ……………………………………...

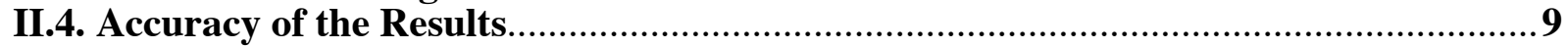

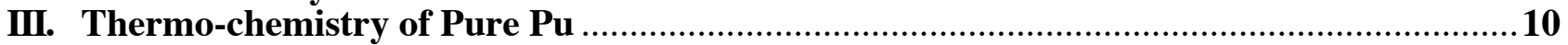

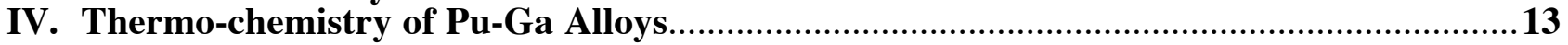

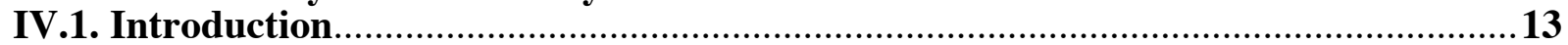

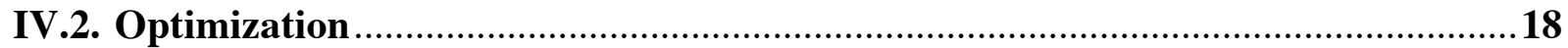

IV.3. Statics of Phase Transformations in Pu-Ga Alloys: Results.................................19

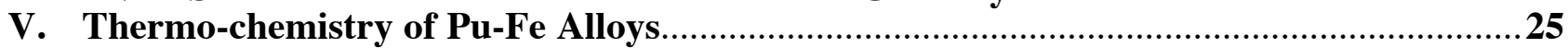

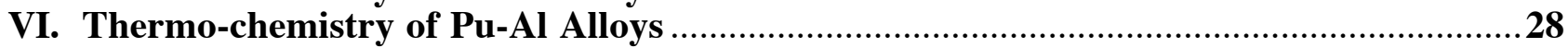

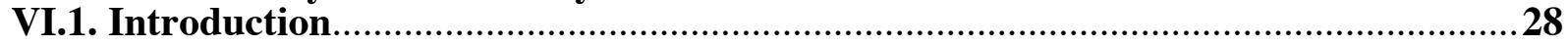

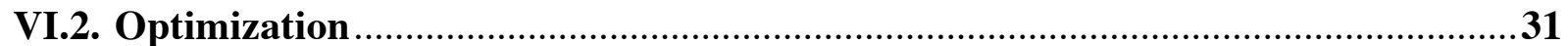

VI.3. Statics of Phase Transformations in Pu-Al Alloys: Results.................................32

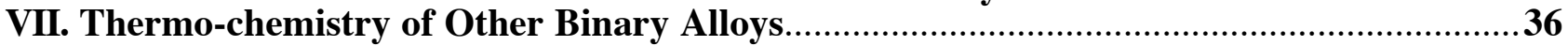

VII.1. Thermo-chemistry of Al-Fe Alloys ...........................................................................36

VII.2. Thermo-chemistry of Al-Ga Alloys ……………….............................................38

VII.3. Thermo-chemistry of Fe-Ga Alloys …………....................................................

VIII. Thermo-chemistry of Higher-Order Component Alloys ................................................42

VIII.1. Thermo-chemistry of Fe-Ga-Pu Alloys ..................................................................43

VIII.2. Thermo-chemistry of Al-Fe-Pu Alloys........................................................... 47

IX. Kinetics of Phase Transformations in Pu-Ga Alloys …………………….................52

IX.1. Scheil-Gulliver Results of Solidification in Pu-Ga-Fe Alloys ..............................53

IX.2. Kinetics of Formation of $\mathrm{Pu}_{3} \mathrm{Ga}$ from the fcc-based ( $\delta$ ) Matrix in Pu-Ga Alloys ..53

IX.3. Kinetics of the $\delta$ to $\alpha$ Transformation in Pu-rich Pu-Ga Alloys.............................57

IX.4. Eutectoid Phase Decomposition in Pu-Ga Alloys................................................59

IX.5. Martensitic Phase Transformation in Pu-Ga Alloys: Aging Properties .................64

X. Thermo-chemistry of other Actinide-based and Related Alloys .......................................72

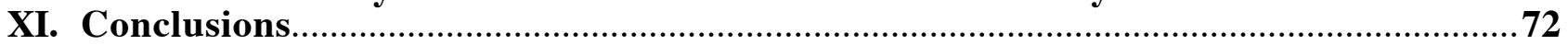

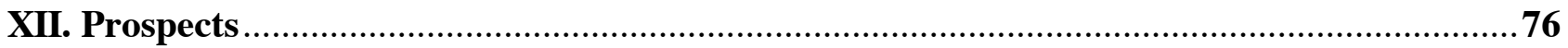

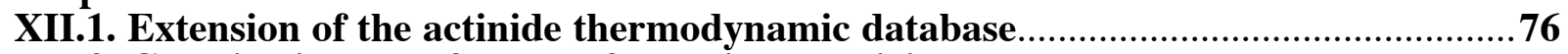

XII.2. Constitutive laws for transformation plasticity …….........................................77

XII.3. Composition-pressure-temperature phase diagrams .............................................77

XII.4. Phase-field modeling ......................................................................................

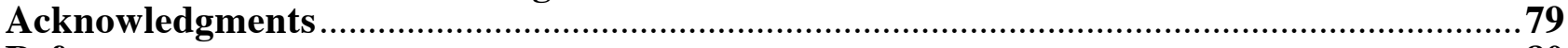

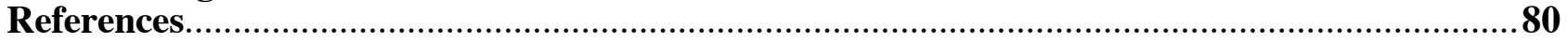

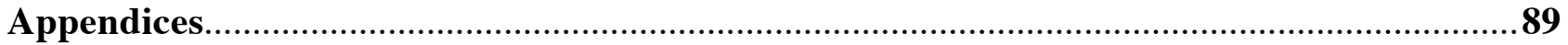

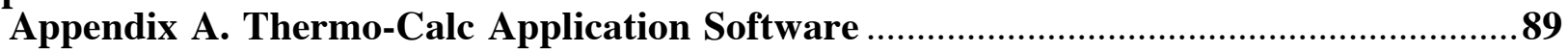

Appendix B. DICTRA Application Software ………………...................................89

Appendix C. Description of the Thermo-chemical Database ............................................90

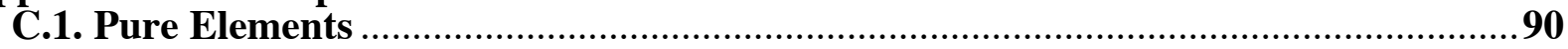

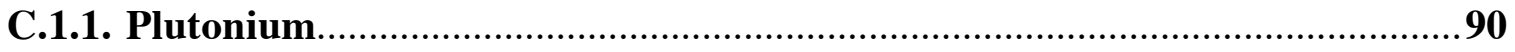

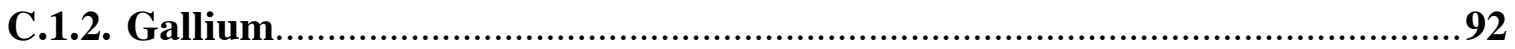

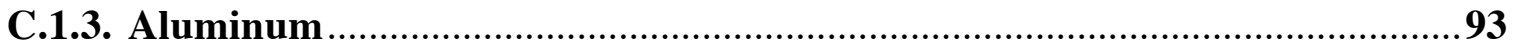

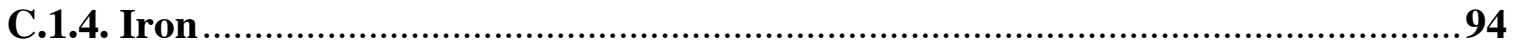

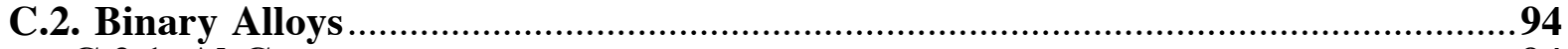

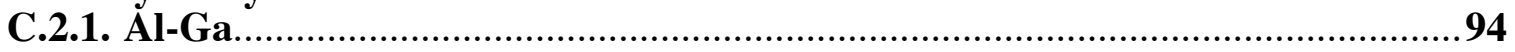

C.2.2. Al-Fe

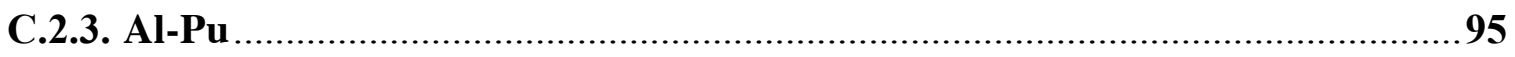




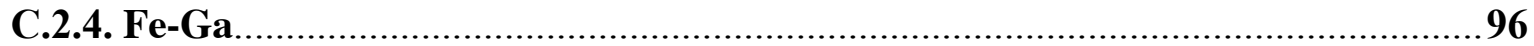

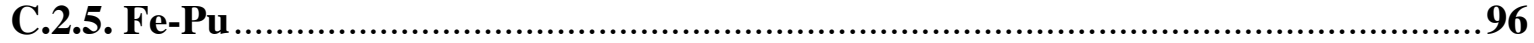

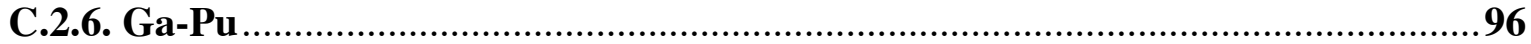

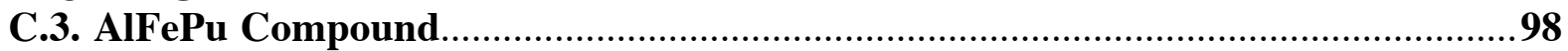

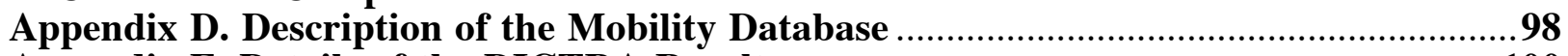

Appendix E. Details of the DICTRA Results ....................................................100

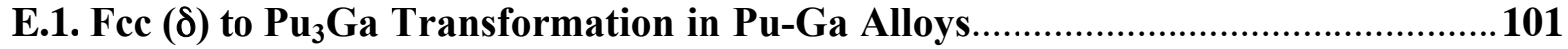

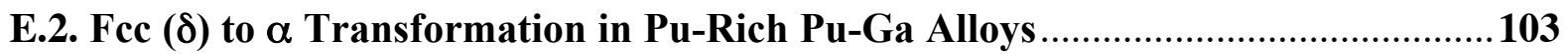

E.3. Fec ( $\delta$ ) to $\alpha$ and to $\mathrm{Pu}_{3} \mathrm{Ga}$ Transformations in Pu-Rich Pu-Ga Alloys at an

Equilibrium Rate of Transformation of $5 \%$ 


\title{
Statics and Kinetics of Phase Transformations in Plutonium Alloys - Part I
}

\author{
Patrice E. A. Turchi ${ }^{1}$, Larry Kaufman ${ }^{2}$, Zi-Kui Liu ${ }^{3}$, and Shihuai Zhou ${ }^{3}$ \\ ${ }^{1}$ Lawrence Livermore National Laboratory (L-353), P. O. Box 808, Livermore, CA 94551. \\ ${ }^{2}$ Dept. of Mater. Sci. and Eng., MIT, Cambridge, MA 02139. \\ ${ }^{3}$ Dept. of Mater. Sci. and Eng., The Pennsylvania State University, University Park, PA 16803.
}

\begin{abstract}
In this report we investigate order, stability, and phase transformations for a series of actinidebased alloys. The statics and kinetics of precipitation and ordering in this class of alloys are modeled with a scheme that couples fundamental information on the alloy energetics obtained from experimental and assessed thermo-chemical data to the CALPHAD approach commonly used in industry for designing alloys with engineering specificity with the help of the Thermo-Calc software application. The CALPHAD approach is applied to the study of the equilibrium thermodynamic properties of $\mathrm{Pu}$-based alloys, $\mathrm{Pu}-\mathrm{X}$, where $\mathrm{X}=\mathrm{Al}, \mathrm{Fe}, \mathrm{Ga}$. The assessment of the equilibrium phase diagrams in the whole range of alloy composition has been performed with the PARROT module of the Thermo-Calc application software. Predictions are made on the low temperature and Pu-rich side of the phase diagrams of $\mathrm{Pu}-\mathrm{Ga}$ and $\mathrm{Pu}-\mathrm{Al}$ for which controversy has been noted in the past. The validity of the assessed thermo-chemical database will be discussed by comparing predicted heats of transformation for pure $\mathrm{Pu}$ with measured values from differential scanning calorimetry analysis. An overall picture for the stability properties of $\mathrm{Pu}-\mathrm{Ga}$ and $\mathrm{Pu}-\mathrm{Al}$ that reconciles the results of past studies carried out on these alloys is proposed. Results on phase stability in the ternary Fe-Ga-Pu and Al-Fe$\mathrm{Pu}$ alloys are discussed. The information collected in this study is then used to model metastability, long-term stability and aging for this class of alloys by coupling Thermo-Calc with DICTRA, a series of modules that allow the analysis of DIffusion Controlled TRAnsformations. Kinetics information is then summarized in so-called TTT (temperature-time-transformations) diagrams for the most relevant phases of actinide alloys. Specifically, results are presented on kinetics of phase transformations associated with the eutectoid-phase decomposition reaction occurring at low temperature, and with the martensitic transformation that takes place at low $\mathrm{Ga}$ content in $\mathrm{Pu}-\mathrm{Ga}$ alloys. Finally, after a summary of the most salient results, suggestions are made for further studies at the micro- and mesoscales.
\end{abstract}

\section{INTRODUCTION}

The existence of six crystallographic allotropes from room temperature up to the solid-liquid transition just above $913 \mathrm{~K}$ at atmospheric pressure makes solid Plutonium unique among the elements in the periodic table. Among these phases (labeled $\alpha, \beta, \gamma, \delta, \delta$, and $\varepsilon$ ), the $\delta$ phase, stable between $593 \mathrm{~K}$ and $736 \mathrm{~K}$, has commanded considerable interest in the metallurgical and solid state communities $[1,2]$. In contrast to the low-temperature monoclinic $\alpha$ phase, which is strong and brittle, 
the face-centered cubic (fcc) $\delta$ phase is weak and ductile, a property that makes it convenient for engineering applications. This phase can also be stabilized through alloying with a number of other elements ( $\delta$-stabilizer or “deltagen”) such as Al, Am, Ce, Ga, In, Sc, Tl, Zn, and Zr, although only four of them (Al, Am, Ce, and $\mathrm{Ga}$ ) stabilize the $\delta$ phase at and below room temperature.

The low-symmetry and small atomic volume of the low-temperature phases of $\mathrm{U}, \mathrm{Np}$, and $\mathrm{Pu}$ is attributed to the role played by the $f$-electrons in determining the bonding in these materials. The unusually large $24 \%$ volume increase in going from the $\alpha$ to the $\delta$ phase of $\mathrm{Pu}[3,4]$ has been argued on phenomenological grounds to be the result of decreased $f$ bonding. Many attempts have been made to study this transition from the point of view of first-principles electronic structure calculations [5-8]

These calculations have been carried out within the framework of density-functional theory (DFT) and its local-density approximation (LDA), as well as the generalized gradient approximation (GGA) [5] designed to account for non-local effects of the electron density. In spite of these attempts, a fundamental understanding of the electronic structure properties of $\mathrm{Pu}$, and the mechanisms responsible for the $\delta$ to $\alpha$ volume collapse is still lacking. As a direct consequence of this lack of understanding, the phase stability properties of $\mathrm{Pu}$ alloys are still poorly described from a fundamental standpoint [9-13]. For example [14,15], the solubility limits of Ga in $\delta$ and $\varepsilon \mathrm{Pu}$ (respectively 12.5 and 20 at.\%), and the definite tendency toward ordering and phase formation (with the existence of six intermediate phases stable at room temperature) still need to be explained. More recently a constrained version of the LDA in which the $f$-electrons were confined to core states, and finally the so-called $\mathrm{LDA}+\mathrm{U}$ method, both within the ab inito full-potential linear muffin orbital (FP-LMTO) electronic structure methodology has been applied to pure $\mathrm{Pu}$ and $\mathrm{Pu}-\mathrm{Ga}$ alloys [14]. This latter treatment was able to shed some light on the role of the partially localized $f$-electrons on properties, and also emphasized the need for an $a b$ initio treatment that accounts not only for spectral properties, but also for equilibrium properties, phase stability, and energetics of correlated metals and alloys. Indeed, despite its encouraging results, the $\mathrm{LDA}+\mathrm{U}$ approach is still in essence phenomenological. More recent attempts have been made based on spin-polarized first-principles DFT calculations within the GGA to describe some of the properties of pure $\mathrm{Pu}$ [15]. Despite agreements with experimental facts, it remains to be seen if the predicted magnetic properties can in fact be validated experimentally. Possibly the most promising electronic structure approach that accounts for electron correlations in metals such as Ce or Pu is the so-called Dynamical Mean-Field Theory (DMFT) [16]. Indeed, recent applications of DMFT to structural transformation [17] and vibrational properties of pure $\mathrm{Pu}$ [18] produced encouraging results that have been in part recently confirmed experimentally [19]. However, in essence, DMFT also remains a phenomenological method with parameters obtained form LDA calculations. Furthermore its extension to multi-component alloys is not clear at this time. Finally no $a b$ initio electronic structure method has been able to describe the energetics and predict the heats of transformation of pure $\mathrm{Pu}$. And the situation is even more hopeless at this time regarding alloys.

For these reasons, since the goal of this work is to describe the statics and kinetics of phase transformations as accurately as possible, another route was considered. The theoretical component of the work utilizes the so-called CALPHAD (CALculation of PhAse Diagrams) approach [20-24] 
supplemented by experimental and assessed information. Note that the same approach can be used to validate some of the predictions on the energetics when available from electronic-structure-based calculations. The CALPHAD approach introduced in the seventies and used in several commercial software involves the coupling of phase diagrams calculations for multi-component alloy systems with other forms of thermo-chemical inputs to address detailed thermodynamic questions that are relevant for this project. One of the major steps in the CALPHAD approach is the full characterization of a phase diagram, which includes all available thermodynamic data. Even in binary systems, difficulties often occur in answering all these questions solely by reference to an experimentally determined phase diagram. These difficulties arise from kinetic limitations on reaching equilibrium at low temperatures, and from inherent limitations on the accuracy of some of the available experimental techniques. By supplementing the existing thermodynamic databank with experimental information collected from experiments, a detailed analysis of alloys can be undertaken. Although the long-term goal of this project is the development of a thermodynamic database for actinide alloys, in this project special emphasis was put on the role of solutes such as Fe on ordering, precipitation, and stability in Pu-Ga alloys. This project will build on previous studies that addressed thermodynamic equilibrium and kinetics in restricted regions of phase and concentration space by using modern thermodynamic modeling and an improved description of diffusion and kinetics.

Prediction and analysis of the thermo-chemical behavior of materials in nuclear reactors and weapons, heavy element isotopic heat sources and separation facilities, and scrap recovery/waste element processes require knowledge of key thermodynamic properties of actinides elements and their alloys. This study represents a first step in the development of a thermodynamic database that combines all possible combinations of actinide elements $\{\mathrm{U}, \mathrm{Np}, \mathrm{Pu}, \mathrm{Am}\}$ with $\{\mathrm{Al}, \mathrm{C}, \mathrm{Fe}, \mathrm{Ga}, \mathrm{Ni}, \mathrm{O}$, $\mathrm{Zr}$ \} so that questions on stability, aging and other properties that strongly depend on this knowledge can be addressed.

The paper is organized as follows. In section II, the methodology is described. The theoretical modeling is expressed within the CALPHAD framework. Stability properties are predicted with the Thermo-Calc application with the thermo-chemistry given by the CALPHAD methodology (section II.1). Solidification according to the Scheil-Gulliver approach is described in section II.2 whereas the aging properties based on the classical diffusion equations are predicted with the DICTRA application, and discussed in section II.3. In section III, the results of the thermo-chemistry of pure $\mathrm{Pu}$ are presented. In sections IV-VI, the results of the statics of phase transformations in Pu-based alloys are discussed. These include the detailed study of $\mathrm{Pu}-\mathrm{Ga}, \mathrm{Pu}-\mathrm{Fe}$, and $\mathrm{Pu}-\mathrm{Al}$. In section VII, we present the results of additional thermodynamic assessments for Al-Fe, Al-Ga, and Fe-Ga that were necessary to describe ternary alloys. In section VIII, the analysis focuses on the ternary $\mathrm{Fe}-\mathrm{Ga}-\mathrm{Pu}$ and $\mathrm{Al}-\mathrm{Fe}-\mathrm{Pu}$ alloys with a complete description of phase relation assessment, and of the prediction of isothermal sections and liquidus surfaces of the ternary phase diagrams. In section IX, we briefly discuss ScheilGulliver results and present the results of phase-transformation kinetics in $\mathrm{Pu}-\mathrm{Ga}$ alloys with special emphasis on the formation of the $\mathrm{Pu}_{3} \mathrm{Ga}$ compound from a fcc matrix, the $\delta$ to $\alpha$ reaction, and the lowlying eutectoid-phase decomposition $\delta \rightarrow \alpha+\mathrm{Pu}_{3} \mathrm{Ga}$. In section IX.5, the martensitic transformation 
that takes place at low temperature for $\mathrm{Pu}$-rich $\mathrm{Pu}-\mathrm{Ga}$ alloys is studied as a function of temperature, time and alloy composition, and time-temperature-transformation diagrams are compared with those determined experimentally. In section $\mathrm{X}$ we briefly review the thermodynamic data on other actinide alloys that are available in the scientific literature. A summary of the most salient results obtained in this work is presented in section XI together with some concluding remarks. Finally in section XII, suggestions are made for future work in four different areas: thermodynamic assessment, modeling of constitutive relations for transformation plasticity, composition-pressure-temperature phase diagrams, and modeling of solidification and microstructure evolution in the presence or not of defects, and under specific external conditions of temperature, pressure, and applied stress.

\section{METHODOLOGY}

The questions that have been raised on phase stability and long-term aging of actinide alloys are addressed with the use of the Thermo-Calc and DICTRA application software [25]. Currently, no other software application or combination of software applications has been identified to perform these functions. These two applications have been used by the scientific community and by the industry since the 80 's, and have generated data that has been presented in peer reviewed journals.

Both software are based on the so-called CALPHAD [20-24] approach introduced in the seventies by Larry Kaufman [23,24], that involves the coupling of phase diagrams calculations for multi-component alloy systems with other forms of thermo-chemical inputs to address questions which are relevant for this project, in particular:

1) What phases are going to form at a particular combination of temperature and composition?

2) What are the proportions of the various phases?

3) What heat treatments can be used to optimize structures and properties?

4) What stable or metastable phases should be avoided?

5) At what critical temperatures do other phases appear or disappear by solid-state transformation?

6) What is the effect of solute addition and variability from the nominal alloy composition on stability?

Even in binary systems, difficulties often occur in answering all these questions solely by reference to an experimentally determined phase diagram. These difficulties arise from kinetic limitations on reaching equilibrium at low temperatures, and from inherent limitations on the accuracy of some of the available experimental techniques. One of the major steps in the Thermo-Calc application is a full characterization of a phase diagram that includes all available thermodynamic information. This, in turn, offers a reliable overall assessment that also allows the calculation of ancillary properties from the same database. In going to higher order multi-component alloys, the Thermo-Calc application avoids thermodynamic inconsistencies with built-in safeguards that ensure that phase boundaries are drawn in accordance with the fundamental rules of classical thermodynamics. 


\section{II.1. Computer Coupling of Phase Diagrams and Thermochemistry: CALPHAD Modeling}

Computer coupling of phase diagrams and thermo-chemistry is capable of predicting the phase behavior in experimentally uninvestigated regions of a multi-component system from the extrapolation of their lower-order systems. This is a real test for the applicability of experimental and theoretical studies of thermo-chemistry and phase equilibrium to the real world since most commercial materials have six or more important alloying elements.

In the CALPHAD approach, the Gibbs energy of individual phases is modeled, and the model parameters are collected in a thermodynamic database. It is the modeling of the Gibbs energy of individual phases and the coupling of phase diagram and thermo-chemistry that make the CALPHAD a powerful technique in computational thermodynamics of multi-component materials. Models for the Gibbs energy are based on the crystal structures of the phases. For pure elements and stoichiometric compounds, the most commonly used model is the one suggested by the Scientific Group Thermodata Europe (SGTE) [26] and has the following form (for simplicity, the pressure dependence and the magnetic contribution are not shown here),

$$
G_{m}^{\Phi}(T)={ }^{0} G_{m}^{\Phi}(T)-H_{m}^{\text {SER }}(298.15 K)=a+b T+c T \ln (T)+\sum d_{n} T^{n}
$$

The left-hand side of Eq. (1) is defined as the Gibbs energy of element $m$ in a specific structure $\Phi$ relative to a standard element reference state (SER), where $\mathrm{H}_{\mathrm{m}}^{\mathrm{SER}}$ is the enthalpy of the element $\mathrm{m}$ in its stable state at $298.15 \mathrm{~K}$ and $10^{5} \mathrm{~Pa}$. Coefficients, a, b, c, and $\mathrm{d}_{\mathrm{i}}$ are the model parameters. The SGTE data for all the pure elements of the periodic table have been compiled by Dinsdale [27].

For multi-component solution phases, the Gibbs energy has the following general expression [20],

$$
G^{\Phi}-\sum_{I} c_{I} H_{I}^{S E R}(298.15 K)={ }^{0} G^{\Phi}+{ }^{\text {ideal }} G_{m i x}^{\Phi}+{ }^{x s} G_{m i x}^{\Phi}
$$

where ${ }^{0} G$ is the contribution from the mechanical mixing of the pure components, ${ }^{\text {ideal }} G_{m i x}$ is the ideal mixing contribution, and ${ }^{x s} G_{m i x}$ is the excess Gibbs energy of mixing due to non-ideal interactions. Sublattice models have been widely used to describe solution phases [20,28-30]. For example, for a simple phase with two sublattices in an A-B binary system where the two components enter both sublattices, the sublattice model is written as $(A, B)_{p}(A, B)_{q}$, where subscripts $p$ and $q$ denote the number of sites of each sublattice. More specifically, the three terms in Eq. (2) are written as,

$$
\begin{aligned}
{ }^{0} G^{\Phi} & =y_{A}^{I} y_{A}^{I I}{ }^{0} G_{A: A}^{\Phi}+y_{A}^{I} y_{B}^{I I}{ }^{0} G_{A: B}^{\Phi}+y_{B}^{I} y_{A}^{I I}{ }^{0} G_{B: A}^{\Phi}+y_{B}^{I} y_{B}^{I I} \quad G_{B: B}^{\Phi} \\
{ }^{i d e a l} G_{m i x}^{\Phi} & =p R T\left(y_{A}^{I} \ln y_{A}^{I}+y_{B}^{I} \ln y_{B}^{I}\right)+q R T\left(y_{A}^{I I} \ln y_{A}^{I I}+y_{B}^{I I} \ln y_{B}^{I I}\right) \\
{ }^{x s} G_{m i x}^{\Phi}= & y_{A}^{I} y_{B}^{I}\left(y_{A}^{I I} \sum_{k=0}{ }^{k} L_{A, B: A}\left(y_{A}^{I}-y_{B}^{I}\right)^{k}+y_{B}^{I I} \sum_{k=0}^{k} L_{A, B: B}\left(y_{A}^{I}-y_{B}^{I}\right)^{k}\right) \\
& +y_{A}^{I I} y_{B}^{I I}\left(y_{A}^{I} \sum_{k=0}{ }^{k} L_{A: A, B}\left(y_{A}^{I I}-y_{B}^{I I}\right)^{k}+y_{B}^{I} \sum_{k=0}{ }^{k} L_{B: A, B}\left(y_{A}^{I I}-y_{B}^{I I}\right)^{k}\right)
\end{aligned}
$$


where $\mathrm{y}^{\mathrm{I}}$ and $\mathrm{y}^{\mathrm{II}}$ are the site fractions of $\mathrm{A}$ or $\mathrm{B}$ in the first and second sublattices, respectively. ${ }^{0} G_{I: J}$ is the Gibbs energy of the compound $\mathrm{I}_{\mathrm{p}} \mathrm{J}_{\mathrm{q}}$, expressed by Eq. (1). ${ }^{k} L_{A, B: *}\left({ }^{k} L_{*: A, B}\right)$ is the $\mathrm{k}^{\text {th }}$ order interaction parameter between component $\mathrm{A}$ and $\mathrm{B}$ in the first (second) sublattice. In this notation, a column separates components occupying different sublattices, and a comma separates interacting components in the same sublattice. These equations can be generalized for phases with multicomponents and multi-sublattices, and they reduce to a random substitutional model when there is only one sublattice.

For a multi-component solution in a particular phase $\Phi$ described with a single sublattice model, the three contributions to the total Gibbs energy reduce to [20]:

$$
\begin{aligned}
& { }^{0} G^{\Phi}=\sum_{I} c_{I}\left[{ }^{0} G_{I}^{\Phi}-H_{I}^{S E R}(298.15 K)\right] \\
& { }^{\text {ideal }} G_{\text {mix }}^{\Phi}=R T \sum_{I} c_{I} \ln c_{I} \\
& { }^{x s} G_{m i x}^{\Phi}=\sum_{I} \sum_{J>I} c_{I} c_{J} \sum_{k}{ }^{k} L_{I, J}^{\Phi}\left(c_{I}-c_{J}\right)^{k}
\end{aligned}
$$

where the molar Gibbs energy of mixing is expressed by a Redlich-Kister expansion [31]. In these expressions $c_{I}$ is the composition of the alloy in species I, and ${ }^{k} L_{I, J}^{\Phi}$ is the $\mathrm{k}^{\text {th }}$-order binary interaction parameter between species I and $\mathrm{J}$, and associated with the phase $\Phi$, expressed as a polynomial in temperature T. Note that in both sets of expressions the excess Gibbs energy due to non-ideal contributions is expressed within the Muggianu approximation [32].

For stoichiometric compounds, the Gibbs energy only depends on temperature, and is given by:

$$
G^{\text {Comp }}={ }^{0} G^{\text {Comp }}(T)-\sum_{I} c_{I} H_{I}^{\text {SER }}(298.15 K)=a+b T+\sum_{I} c_{I}\left[{ }^{0} G_{I}^{\Phi_{I}}(T)-H_{I}^{\text {SER }}(298.15 K)\right]
$$

where $(\mathrm{a}+\mathrm{bT})$ represents the Gibbs energy of formation of a specific compound formed from the pure elements considered in their states $\Phi_{\mathrm{I}}$. These states $\Phi$ can be a given phase, identical to the one of the compound, or the SER state of each element. The parameters a and b represent the enthalpy and the entropy of formation of the compound, respectively.

Thermodynamic modeling begins with the evaluation of the thermodynamic descriptions of unary and binary systems. By combining the thermodynamic descriptions of constitutive binary systems and ternary experimental data, a thermodynamic description of ternary systems is developed, and so forth. These descriptions cover the whole composition and temperature ranges including the experimentally uninvestigated regions. For this work, the original SSOL thermodynamic database has been developed using the CALPHAD technique. The computer program, Thermo-Calc, developed at the Royal Institute of Technology in Stockholm, Sweden, is then used (cf. Appendix A). It is the most general and powerful program in computational thermodynamics of multi-component alloys [20-24].

The CALPHAD approach is, in fact, the most successful method used at present in addressing specific materials questions of practical importance to industry and technology [22]. 


\section{II.2. Solidification according to the Scheil-Gulliver approach}

In all practical cases, solidification during most processing routes occurs in a non-equilibrium manner and gives rise to significant variations in the chemistry and the occurrence of secondary phases. Using a CALPHAD approach based on Scheil-Gulliver simulations, solidification can be studied and predictions on the amount of undercooling can be made [20,33]. Within this approach, a liquid of composition $\mathrm{c}_{0}$ is cooled to a small amount below its liquidus temperature $\mathrm{T}_{1}$. The solid precipitates out of the liquid with a composition $c_{1}^{S}$ whereas the composition of the liquid becomes $c_{1}^{L}$. On further cooling to the temperature $\mathrm{T}_{2}$, the initial solid cannot change its composition (since backdiffusion in the solid phase is neglected in this approach). A local equilibrium is then established, and the liquid of composition $c_{1}^{\mathrm{L}}$ transforms in a liquid of composition $\mathrm{c}_{2}^{\mathrm{L}}$, and a solid with composition, and the process is repeated upon further cooling (see Fig. 1). As solidification proceeds, the solid phase becomes lean in solute in the center of the dendrite whereas the liquid is enriched in solute until the composition of the liquid reaches the eutectic composition, and solidification is finally completed. Inside the Thermo-Calc application software a Scheil module is available to perform these simulations.

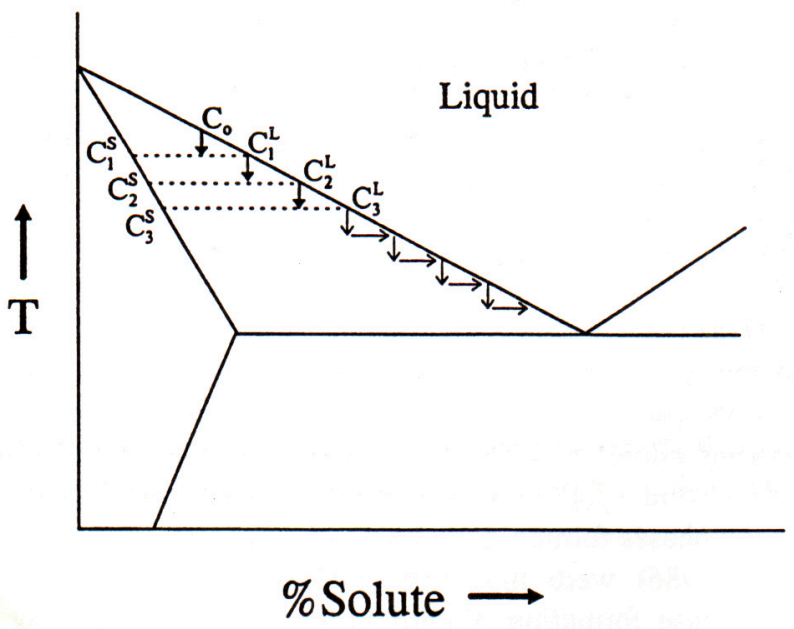

Figure 1. Schematic description of solidification according to the Scheil-Gulliver approach (taken from Ref. [20]).

\section{II.3. Diffusion Modeling of Phase Transformations}

Process simulations require the development of a kinetic description of alloy systems, i.e., the knowledge of the mobility of the species in individual phases [20-23,34,35]. The models that relate the mobility and diffusivity are based on the generalized Onsager flux equation. As an example, for a phase consisting of a substitutional sublattice and an interstitial sublattice, the intrinsic diffusion coefficient, $\mathrm{D}_{\mathrm{kj}}$ (the diffusivity of component $\mathrm{k}$ with respect to the gradient of component $\mathrm{j}$ ), is related to the atomic mobility $\mathrm{M}_{\mathrm{i}}$ (i for all the elements in a phase) with the following formula

$$
\begin{aligned}
& D_{k j}=\sum_{i \in S}\left(\delta_{i k}-u_{k}\right) u_{i} M_{i} \frac{\partial \mu_{i}}{\partial u_{j}}+\sum_{i \notin S} \delta_{i k} u_{i} y_{V a} M_{i} \frac{\partial \mu_{i}}{\partial u_{j}} \\
& \text { with } u_{k}=\frac{x_{k}}{\sum_{i \in S} x_{i}} \text { and } \delta_{i \mathrm{k}}= \begin{cases}1 & \mathrm{i}=\mathrm{k} \\
0 & i \neq \mathrm{k}\end{cases}
\end{aligned}
$$


where $i \in S(i \notin \subset S)$ denotes that component $i$ is substitutional (interstitial), $x_{k}$ is the mole fraction of component $\mathrm{k}, \mu_{\mathrm{i}}$ is the chemical potential of component $\mathrm{i}$ derived from the Gibbs energy of the phase, $y_{V a}$ represents the site fraction of vacancy in the interstitial sublattice. The mobility $\mathrm{M}_{\mathrm{i}}$ associated with species $\mathrm{i}$ is further related to a frequency factor $\mathrm{M}_{\mathrm{i}}^{0}$ and composition with the following equations

$$
\begin{aligned}
& M_{i}=\frac{M_{i}^{0}}{R T} \exp \left(\frac{\Delta G_{i}}{R T}\right) \\
& \Delta G_{i}=\sum_{j} \sum_{m} y_{j}^{I} y_{m}^{I I} \Delta G_{i}^{j: m}+\sum_{j} \sum_{k>j} \sum_{m} y_{j}^{I} y_{k}^{I} y_{m}^{I I} \Delta G_{i}^{j, k: m}+\sum_{j} \sum_{n} \sum_{m>n} y_{j}^{I} y_{n}^{I I} y_{m}^{I I} \Delta G_{i}^{j: n, m}
\end{aligned}
$$

$\Delta \mathrm{G}_{\mathrm{i}}$ is the activation Gibbs energy of component $\mathrm{i}$, and $\Delta G_{i}^{j: m}$ is the activation Gibbs energy of component $\mathrm{i}$ with components $\mathrm{j}$ and $\mathrm{m}$ located on the first and second sublattices, respectively. The interaction terms $\Delta G_{i}^{j, k: m}$ and $\Delta G_{i}^{j: n, m}$ are expressed with a polynomial similar to the summations in Eq. (5). The individual parameters are evaluated from chemical and tracer diffusion data.

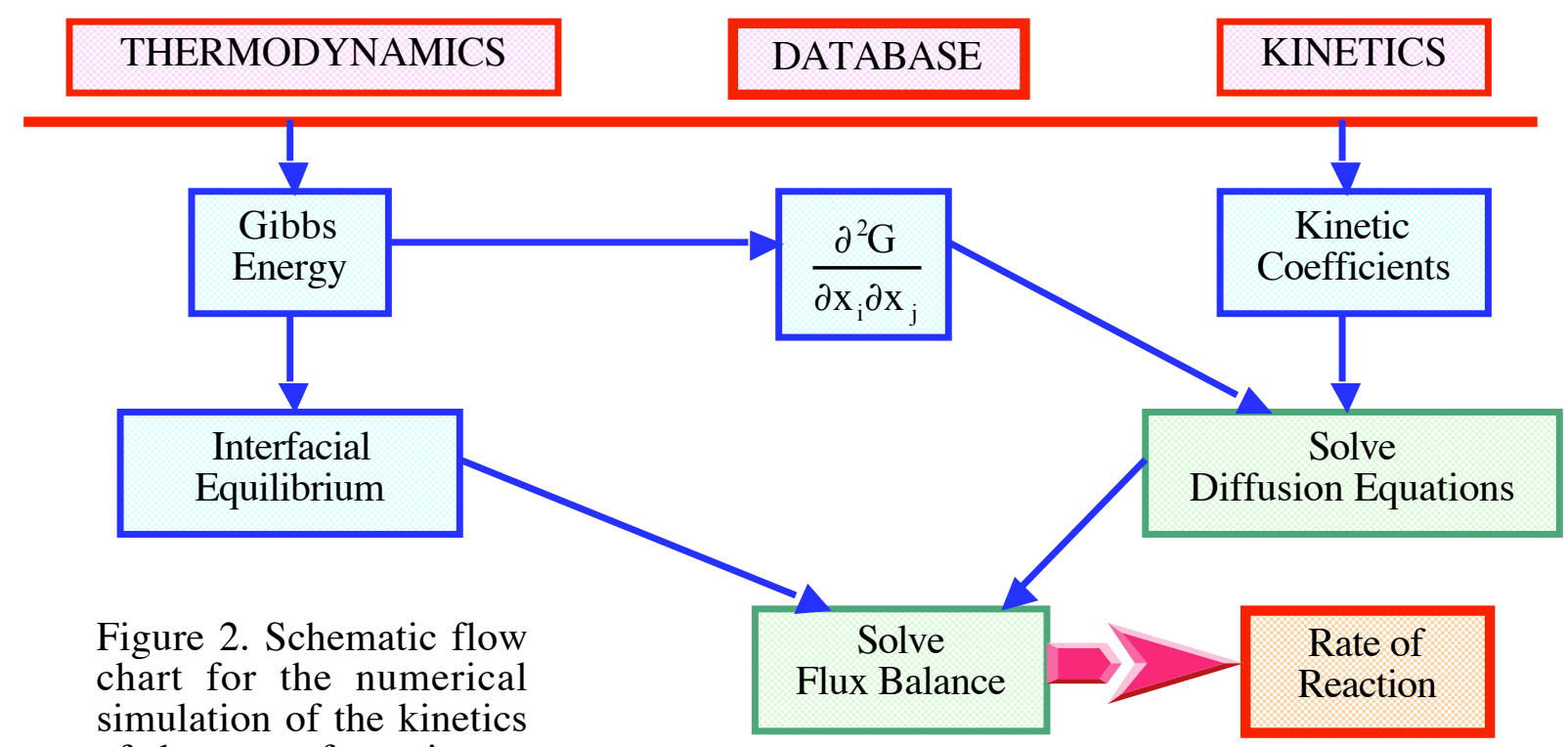
of phase transformations.

By combining the thermodynamic and kinetic descriptions of alloy systems, phase transformations can then be simulated. The schematic flow chart of the DICTRA simulation is shown in Fig. 2. The most significant feature of this simulation procedure is the coupling of thermodynamics and kinetics simultaneously.

DICTRA (see Appendix B) fulfills the need to provide critical modeling and analysis of data by solving the diffusion equations, calculating thermodynamic equilibrium (with Thermo-Calc), solving the flux-balance equations, and finally predicting the displacement of phase-interface positions. This application is used to analyze the kinetics of eutectoid phase decomposition in $\mathrm{Pu}-\mathrm{Ga}$ alloys from the $\delta-(\mathrm{Pu}, \mathrm{Ga})$ to $\alpha-\mathrm{Pu}+\mathrm{Pu}_{3} \mathrm{Ga}$. 
Starting with the thermo-chemical database provided by SGTE [26], a detailed analysis of the thermodynamics of the unary $\mathrm{Pu}$ element, the stability of the binary alloys $\mathrm{Pu}-\mathrm{Ga}, \mathrm{Pu}-\mathrm{Fe}, \mathrm{Fe}-\mathrm{Ga}, \mathrm{Pu}-\mathrm{Al}$, $\mathrm{Fe}-\mathrm{Al}$, and of the ternary $\mathrm{Pu}-\mathrm{Ga}-\mathrm{Fe}$ alloys has been undertaken. Then, kinetic and thermodynamic modeling have been combined and applied to the study of diffusion-controlled transformations with the use of the DICTRA application linked with Thermo-Calc for the study of eutectoid-phase decomposition. Thermodynamic analysis has been also carried out to study the martensitic phase transformation that occurs at low $\mathrm{Ga}$ content in $\mathrm{Pu}-\mathrm{Ga}$ and predict the TTT (Temperature-TimeTransformation) diagrams for this transformation as functions of $\mathrm{Ga}$ composition. The overall approach is summarized in the schematic flow chart presented in Fig. 3.

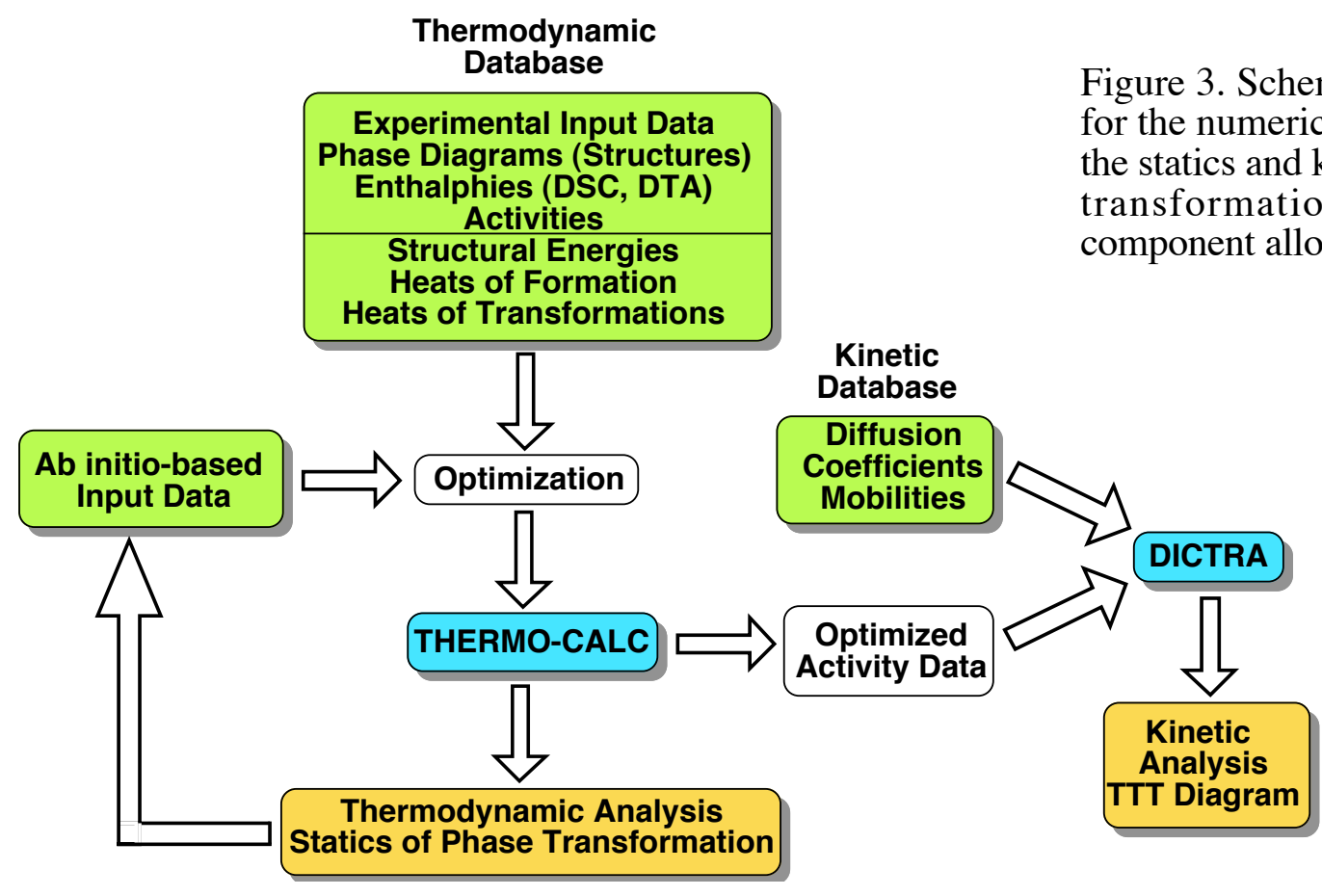

\section{II.4. Accuracy of the Results}

The analysis of the results on stability and aging are based on calculations carried out with the Thermo-Calc and DICTRA application software, respectively. These software make use of databases.

In the case of Thermo-Calc, the original thermo-chemical database that contains information on the energetics of all phases made of the six elements: $\mathrm{Al}, \mathrm{Fe}, \mathrm{Ga}, \mathrm{Ni}, \mathrm{Pu}, \mathrm{U}$, has been extracted from the SSOL database that is normally called by Thermo-Calc. The database will be re-evaluated based on experimental data specifically available for the Ni-based class of alloys. This re-evaluation will account for output information such as assessed phase diagrams, measured heats of formation and transformation for binary and ternary alloys. Once the database is validated, predictions can be made on phase stability information, such as property diagrams, isopleths, Scheil-Gulliver results on solidification. Hence, the accuracy of the output information is mostly the machine accuracy of the calculations, once the thermo-chemical database has been validated.

In the case of DICTRA, two databases are used, namely the thermo-chemical database associated 
with Thermo-Calc, and a database that contains information on diffusion coefficients and mobilities. The original MOB database that is normally called by DICTRA for the class of alloys considered here has to be supplemented with experimental data and validated with experimental information on TTT diagrams available for Pu-Ga alloys. Again, once validation is achieved, predictions can be made for the aging properties of various phases exhibited by multi-component alloys, and the accuracy of the TTT results is mostly the machine accuracy associated with the numerical resolution of the diffusion equations.

\section{THERMO-CHEMISTRY OF PURE Pu}

Six allotropes, besides the liquid state, exist for pure $\mathrm{Pu}$ : monoclinic $(\alpha-\mathrm{Pu})$, body-centered monoclinic $(\beta-\mathrm{Pu})$, face-centered orthorhombic $(\gamma-\mathrm{Pu})$, face-centered cubic $(\delta-\mathrm{Pu})$, body-centered tetragonal $\left(\delta^{\prime}-\mathrm{Pu}\right)$, and body-centered cubic $(\varepsilon-\mathrm{Pu})[1,2]$. The thermodynamics of pure Pu has been well established by the SGTE group [28], and the Gibbs functions that describe the six allotropes and the liquid state of $\mathrm{Pu}$ are reported in Appendix $\mathrm{C}$. With the use of Thermo-Calc the transition temperatures and the heats of transformation have been calculated, and the results are summarized in Table 1 and Fig. 4.

\begin{tabular}{|c|c|c|c|}
\hline Transition & $\mathrm{T}(\mathrm{K})$ & $\Delta \mathrm{H}^{\text {trans }}(\mathrm{J} / \mathrm{mol})$ & $\Delta \mathrm{H}^{\text {trans }}(\mathrm{mRy} / \mathrm{at})$ \\
\hline$\alpha \rightarrow \beta$ & 397.62 & $3,705.98$ & 2.823 \\
\hline$\beta \rightarrow \gamma$ & 487.90 & 477.99 & 0.364 \\
\hline$\gamma \rightarrow \delta$ & 593.07 & 713.02 & 0.543 \\
\hline$\delta \rightarrow \delta$ & 736.42 & 83.33 & 0.064 \\
\hline$\delta \delta^{\prime} \varepsilon$ & 755.67 & $1,841.06$ & 1.402 \\
\hline$\varepsilon \rightarrow$ Liquid & 913.00 & $2,824.03$ & 2.151 \\
\hline
\end{tabular}

Table 1. Temperature (in Kelvin) and heat of transformation (in $\mathrm{J} / \mathrm{mol}$ and $\mathrm{mRy} /$ atom) for each of the 6 transitions of $\mathrm{Pu}$.

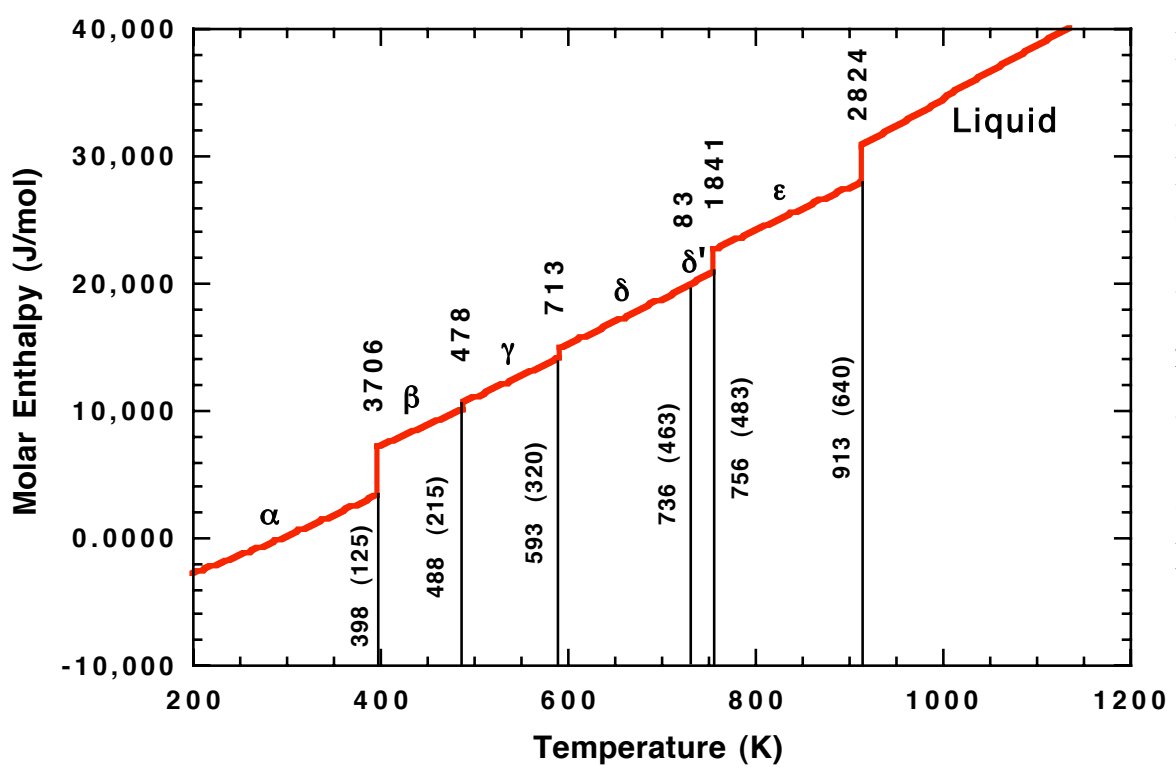

Figure 4. Molar enthalpy (in $\mathrm{J} / \mathrm{mol}$ ) versus temperature for pure $\mathrm{Pu}$. Each number above the curve indicates the value of the heat of transformation (in $\mathrm{J} / \mathrm{mol}$ ). Each number below the curve indicates the transition temperature (in Kelvin), with its conversion in ${ }^{\circ} \mathrm{C}$ in parenthesis. 
Table 2 gives the melting temperature of each individual allotrope. This information will be used at a later stage to perform kinetic calculations.

\begin{tabular}{|c|c|c|c|}
\hline Transition & $\mathrm{T}_{\mathrm{m}}(\mathrm{K})$ & $\Delta \mathrm{H}^{\text {trans }}(\mathrm{J} / \mathrm{mol})$ & $\Delta \mathrm{H}^{\text {trans }}(\mathrm{mRy} / \mathrm{at})$ \\
\hline$\alpha \rightarrow$ Liquid & 527.86 & $6,608.10$ & 5.034 \\
\hline$\beta \rightarrow$ Liquid & 742.52 & $4,511.55$ & 3.437 \\
\hline$\gamma \rightarrow$ Liquid & 794.25 & $4,053.37$ & 3.088 \\
\hline$\delta \rightarrow$ Liquid & 840.12 & $3,836.88$ & 2.923 \\
\hline$\delta^{\prime} \rightarrow$ Liquid & 840.85 & $3,895.56$ & 2.967 \\
\hline$\varepsilon \rightarrow$ Liquid & 913.00 & $2,824.03$ & 2.151 \\
\hline
\end{tabular}

Table 2. Melting temperature (in Kelvin) and heat of fusion (in $\mathrm{J} / \mathrm{mol}$ and $\mathrm{mRy} /$ atom) associated with each allotrope of pure $\mathrm{Pu}$.

It is also interesting to note the meta-stable transitions that may occur among the various allotropes of pure $\mathrm{Pu}$. Indeed, each temperature corresponds to the maximum $\mathrm{T}_{0}$ value associated with equal Gibbs energy between the two phases considered. The results are summarized in Table 3. Note that when ab inito results of energetics become available, this is typically this kind of information that can be compared with the CALPHAD data gathered in Tables 1 to 3 .

\begin{tabular}{|c|c|c|c|}
\hline Transition & $\mathrm{T}(\mathrm{K})$ & $\Delta \mathrm{H}^{\text {trans }}(\mathrm{J} / \mathrm{mol})$ & $\Delta \mathrm{H}^{\text {trans }}(\mathrm{mRy} / \mathrm{at})$ \\
\hline$\alpha \rightarrow \gamma$ & 406.72 & $4,207.81$ & 3.205 \\
\hline$\alpha \rightarrow \delta$ & 429.64 & $4,789.91$ & 3.649 \\
\hline$\alpha \rightarrow \delta$ & 431.01 & $4,909.38$ & 3.740 \\
\hline$\alpha \rightarrow \varepsilon$ & 495.81 & $6,865.40$ & 5.230 \\
\hline$\beta \rightarrow \delta$ & 546.91 & $1,196.80$ & 0.912 \\
\hline$\beta \rightarrow \delta$ & 560.33 & $1,325.09$ & 1.009 \\
\hline$\beta \rightarrow \varepsilon$ & 662.25 & $3,296.16$ & 2.511 \\
\hline$\gamma \rightarrow \delta$ & 610.07 & 830.96 & 0.633 \\
\hline$\gamma \rightarrow \varepsilon$ & 706.85 & $2,610.05$ & 1.988 \\
\hline$\delta \rightarrow \varepsilon$ & 754.92 & $1,907.70$ & 1.453 \\
\hline
\end{tabular}

Table 3. Transition temperature (in Kelvin) and heat of transformation (in $\mathrm{J} / \mathrm{mol}$ and $\mathrm{mRy} /$ atom) associated with every possible meta-stable transition that may occur in the case of pure $\mathrm{Pu}$.

Note that the results presented in Table 1 and Fig. 4 compare favorably with those obtained experimentally from Differential Scanning Calorimetry (DSC) summarized in Table 4.

\begin{tabular}{|c|c|c|c|c|c|c|c|c|c|c|}
\hline & \multicolumn{2}{|c|}{$\alpha \rightarrow \beta$} & \multicolumn{2}{|c|}{$\beta \rightarrow \gamma$} & \multicolumn{2}{|c|}{$\gamma \rightarrow \delta$} & \multicolumn{2}{|c|}{$\delta \rightarrow \delta^{\prime}$} & \multicolumn{2}{|c|}{$\delta^{\prime} \rightarrow \varepsilon$} \\
\hline & $\begin{array}{l}\mathrm{T}_{\text {onset }} \\
\left({ }^{\circ} \mathrm{C}\right)\end{array}$ & $\begin{array}{c}\Delta \mathrm{H} \\
(\mathrm{J} / \mathrm{g})\end{array}$ & $\begin{array}{l}\mathrm{T}_{\text {onset }} \\
\left({ }^{\circ} \mathrm{C}\right)\end{array}$ & $\begin{array}{c}\Delta \mathrm{H} \\
(\mathrm{J} / \mathrm{g})\end{array}$ & $\begin{array}{l}\mathrm{T}_{\text {onset }} \\
\left({ }^{\circ} \mathrm{C}\right)\end{array}$ & $\begin{array}{c}\Delta \mathrm{H} \\
(\mathrm{J} / \mathrm{g})\end{array}$ & $\begin{array}{l}\mathrm{T}_{\text {onset }} \\
\left({ }^{\circ} \mathrm{C}\right)\end{array}$ & $\begin{array}{c}\Delta \mathrm{H} \\
(\mathrm{J} / \mathrm{g})\end{array}$ & $\begin{array}{l}\mathrm{T}_{\text {onset }} \\
\left({ }^{\circ} \mathrm{C}\right)\end{array}$ & $\begin{array}{c}\Delta \mathrm{H} \\
(\mathrm{J} / \mathrm{g})\end{array}$ \\
\hline $16 \mathrm{mg}^{*}$ & 126.4 & 15.49 & 214.26 & 2.28 & 323.40 & 2.89 & 468.0 & 0.29 & 486.06 & 7.02 \\
\hline $22 \mathrm{mg}^{*}$ & 126.5 & 16.23 & 213.75 & 2.29 & 323.38 & 2.92 & 467.5 & 0.29 & 485.96 & 7.23 \\
\hline 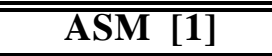 & 122 & $\overline{14.0}$ & 207 & $\overline{2.45}$ & $\overline{315}$ & 2.28 & 457 & $\overline{0.35}$ & $\overline{4880}$ & 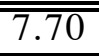 \\
\hline Foltyn [2] & 127 & 16.02 & 215 & 1.67 & 325 & 2.97 & 460 & - & 483 & 7.70 \\
\hline $\begin{array}{l}\text { Ward [3] } \\
\end{array}$ & 124.6 & 15.50 & 214.8 & 2.00 & 320.0 & 2.98 & 463.0 & 0.35 & 482.6 & 7.00 \\
\hline Rolon [4] & 126.4 & 14.65 & 216.6 & 2.03 & 319.4 & 2.74 & 462.8 & 0.43 & 482.6 & 6.76 \\
\hline Oetting [5] & 124.4 & 15.49 & 214.8 & 2.00 & 320.0 & 2.98 & & & & \\
\hline Allen [6] & 123 & 15.05 & 213 & 1.97 & 328 & 2.45 & 467 & 0.27 & 486 & 6.67 \\
\hline CALPHAD [7] & 124.6 & 15.19 & 214.9 & 1.96 & 320.1 & 2.92 & 463.4 & 0.34 & 482.7 & 7.55 \\
\hline
\end{tabular}

*D. S. Schwartz, T. G. Zocco, and J. Lashley: Recent measurements at LANL, unpublished (2003). 
1. R. Hultgren et al., Selected Values of the Thermodynamic Properties of the Elements (Amer. Soc. for Metals, OH, 1973), pp. 402-409.

2. E. M. Foltyn, J. Nuc. Mater. 172, pp. 180-183 (1990).

3. J. W. Ward et al., Thermochemical Properties of the Actinide Elements and Selected Actinide-Noble Metal Intermetallics (Handbook on the Physics and Chemistry of the Actinides, A. J. Freeman and C. Keller, eds. Elsevier, 1986) pp. 332-341.

4. C. E. Rolon, G. G. Gallegos, J. Thermal Anal. 21, 159-161 (1981).

5. F. L. Oetting, R. O. Adams, J. Chem. Thermodynamics 15, 537-554 (1983).

6. P. G. Allen, Recent measurements at LLNL, unpublished (2002).

7. Present CALPHAD results converted from Table 1 . ( $1 \mathrm{~J} / \mathrm{mol}=244 \mathrm{~J} / \mathrm{g}$.atom).

Table 4. Compilation of the literature data, and recent experimental work carried out at LANL and LLNL, together with the results from CALPHAD modeling. Temperature (in ${ }^{\circ} \mathrm{C}$ ) and heat of transformation (in $\mathrm{J} / \mathrm{g}$.atom) for the five transitions of $\mathrm{Pu}$ in the solid phase.

We present in Fig. 5 the DSC results upon heating from room temperature and in argon atmosphere (with an increment of $5^{\circ} \mathrm{C} / \mathrm{mn}$ ) obtained at LLNL [36] that clearly show the five structural transformations of pure Pu that occur in the solid phase.

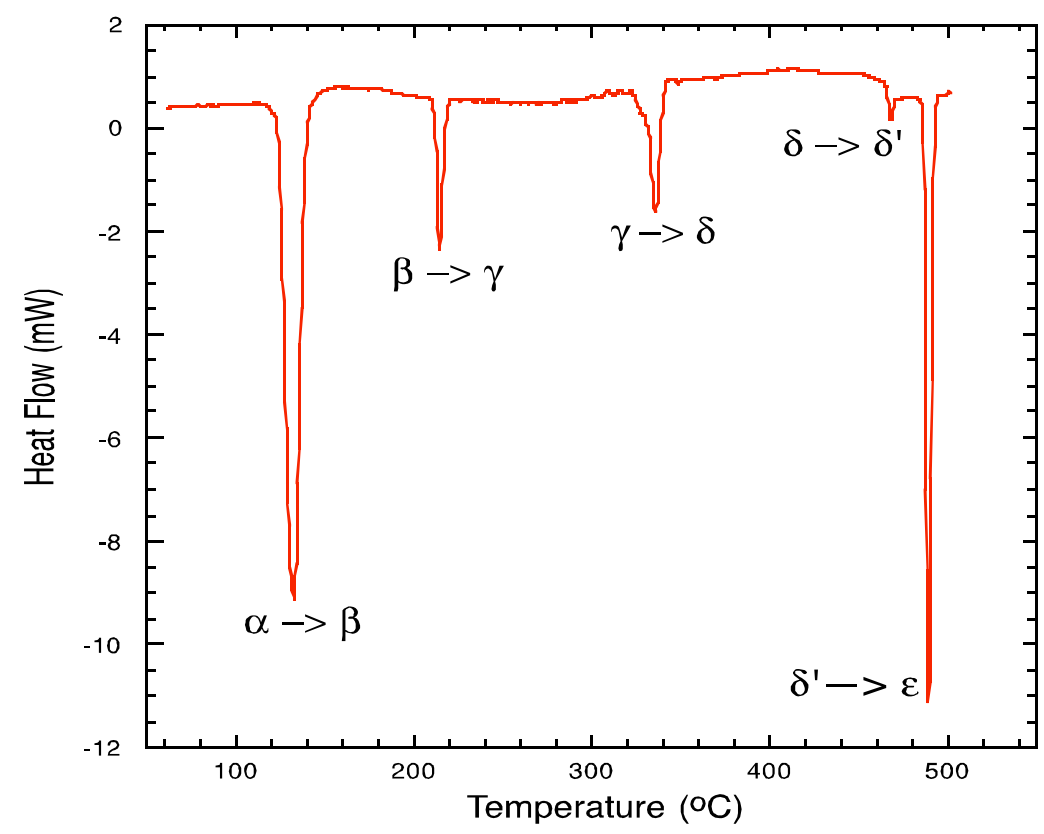

Figure 5. DSC results upon heating from room temperature for pure $\mathrm{Pu}$ obtained at LLNL [34].

In conclusion, the CALPHAD assessment of pure $\mathrm{Pu}$ is established on solid ground, and will be used to study the thermodynamics of higher-order systems with a high degree of confidence. As said before, there is a wealth of information collected during the assessment, i.e., all the thermodynamic functions, and in particular Gibbs energy, enthalpy, entropy, heat capacity among others for all six phases of $\mathrm{Pu}$, heats of transformation and structural energy differences. For example, from Eq. (1), the entropy, the enthalpy and the heat capacity at constant pressure are given by $[20,37,38]$ :

$$
S=-\frac{\partial G}{\partial T}=-b-c-c \ln (T)-\sum_{n} n d_{n} T^{n-1}
$$




$$
\begin{aligned}
& H=G+T S=a-c T-\sum_{n}(n-1) d_{n} T^{n} \\
& C_{p}=\frac{\partial H}{\partial T}=-c-\sum_{n} n(n-1) d_{n} T^{n-1}
\end{aligned}
$$

All theses thermodynamic results will be compared with those predicted from first-principles electronic structure calculations when thelatter become available.

\section{THERMO-CHEMISTRY OF Pu-Ga ALLOYS}

\section{IV.1. Introduction}

The phase diagram of $\mathrm{Pu}-\mathrm{Ga}$ has been highly controversial over the years. The dispute arose when Chebotarev et al. [39] presented evidence for the existence of a low lying eutectoid reaction at about $373 \mathrm{~K}: \delta \rightarrow \alpha+\mathrm{Pu}_{3} \mathrm{Ga}$. Previous work by Ellinger et al. [40] in 1964 and Hocheid et al. [41] in 1965 showed an extended domain of stability of $\delta$-stabilized Pu-Ga down to low temperature with no indication of any solid-phase transformation (besides the martensitic transformation that occurs at very low temperature). The most recent Pu-Ga phase diagram that was published in1986 in the ASM handbook of actinide alloy phase diagrams $[42,43]$ is essentially the one proposed by Ellinger et al. [40]. The long-standing controversy between the American and Russian version of the Pu-Ga phase diagram was finally put to rest recently in favor of the Russian version. Indeed during an International Conference held in Oxford, UK, in 1999, on "Aging Studies and Lifetime Extension of Materials", Timofeeva gave a clear presentation on plutonium phase diagrams [44], and the process used almost 30 years ago was clearly revealed and showed that the Russian phase diagram was indeed an equilibrium phase diagram. Prior to long annealing at atmospheric pressure, the use of pressure and plastic deformation was used to "precondition" plutonium alloys and enhance the kinetics of the $\delta$ phase decomposition. This was contrary to the thought that long-term annealing was performed under pressure and therefore was leading to non-equilibrium phase diagram at some unspecified pressure [45-48]. It is interesting to note that the study performed by Adler at LLNL in the early 90's, without the full knowledge of the experiments carried out in the Soviet Union, was predicting with a thermodynamic model the existence of an eutectoid decomposition in $\mathrm{Pu}-\mathrm{Ga}$ and $\mathrm{Pu}-\mathrm{Al}$ at low temperature [49]. It is worth noting that, using available thermodynamic data, Adler only constructed the Pu-rich side of the phase diagram using the FACT (Facility for the Analysis of Chemical Thermodynamics) software [50]. As it will be seen later, this assessment leads to an unreliable estimation of the thermodynamic properties. That should not come as a surprise since stability is a global property that requires the knowledge of the thermodynamics of all phases in the entire range of alloy composition. Based on this remark we conducted a full assessment of the phase diagram of $\mathrm{Pu}-$ Ga with the expectation that, by considering all the phases that are experimentally observed during the assessment, the Gibbs energy associated with each phase will be constrained and a self-consistent set of thermodynamic data will be generated. 
Let us first review the various phases that one has to consider for assessing the phase diagram of $\mathrm{Ga}-\mathrm{Pu}$ in the whole range of alloy composition. Besides the endpoints, there are three solution phases, denoted $\delta$, $\varepsilon$, and $\eta$, and sixteen compounds, namely (in increasing Ga composition): $\mathrm{Pu}_{3} \mathrm{Ga}(\zeta$ ', LT), $\mathrm{Pu}_{3} \mathrm{Ga}(\zeta, \mathrm{HT}), \mathrm{Pu}_{5} \mathrm{Ga}_{3}(\theta), \operatorname{PuGa}(\iota, \mathrm{LT}), \operatorname{PuGa}\left(\iota^{\prime}, \mathrm{HT}\right), \mathrm{Pu}_{2} \mathrm{Ga}_{3}(\kappa), \mathrm{PuGa}_{2}(\lambda), \mathrm{PuGa}_{3}(\mu$ ', LT), $\mathrm{PuGa}_{3}\left(\mu^{\prime}, \mathrm{MT}\right), \mathrm{PuGa}_{3}(\mu, \mathrm{HT}), \mathrm{Pu}_{2} \mathrm{Ga}_{7}, \mathrm{PuGa}_{3.7}, \mathrm{PuGa}_{4}, \mathrm{PuGa}_{6}$ ( $\xi$ ', LT), PuGa 6 ( $\xi, \mathrm{HT}$ ), and $\mathrm{Pu}_{2} \mathrm{Ga}_{15}$. Note that in the following, although some of these compounds are indicated with a limited solubility, $\mathrm{Pu}_{5} \mathrm{Ga}_{3}, \mathrm{PuGa}\left(\mathrm{l}, \mathrm{HT}\right.$ ), and $\mathrm{PuGa}_{2}$, they will be treated as line compounds like the others since their domain of stability is not well defined (indicated by dashed line in the phase diagram). A summary of all existing phases in the Pu-Ga phase diagram with crystallographic information is given in Table 5.

\begin{tabular}{|c|c|c|c|c|c|}
\hline & at. $\% \mathrm{Pu}$ & $\begin{array}{l}\text { Pearson } \\
\text { Symbol }\end{array}$ & $\begin{array}{l}\text { Space } \\
\text { Group }\end{array}$ & $\begin{array}{c}\text { Struktur- } \\
\text { bericht }\end{array}$ & Structure-type \\
\hline $\mathrm{Ga}$ & $0-21$ & oC8 & Cmca & A11 & $\mathrm{Ga}$ \\
\hline $\mathrm{Ga}_{15} \mathrm{Pu}_{2}$ & 11.8 & (c) & & & \\
\hline $\mathrm{Ga}_{6} \mathrm{Pu}(\xi)$ & 14.3 & $\mathrm{tP} 14$ & $\mathrm{P} 4 / \mathrm{nbm}$ & & $\mathrm{Ga}_{6} \mathrm{Pu}(\xi)$ \\
\hline $\mathrm{Ga}_{6} \mathrm{Pu}\left(\xi^{\prime}\right)$ & 14.3 & & & & \\
\hline $\mathrm{Ga}_{4} \mathrm{Pu}$ & 20 & oI20 & Imma & $\overline{\mathrm{D} 1_{\mathrm{b}}}$ & $\overline{\mathrm{Al}_{4} \mathrm{U}}$ \\
\hline $\mathrm{Ga}_{3,7} \mathrm{Pu}$ & 21.3 & & & & \\
\hline $\mathrm{Ga}_{7} \mathrm{Pu}_{2}$ & 22.2 & (c) & & & \\
\hline $\mathrm{Ga}_{3} \mathrm{Pu}(\mu)$ & 25 & & & & \\
\hline $\mathrm{Ga}_{3} \mathrm{Pu}\left(\mu^{\prime}\right)$ & 25 & hP8 & $\mathrm{P}_{3} / \mathrm{mmc}$ & $\mathrm{D} 0_{19}$ & $\mathrm{Ni}_{3} \mathrm{Sn}$ \\
\hline $\mathrm{Ga}_{3} \mathrm{Pu}\left(\mu^{\prime \prime}\right)$ & 25 & & $\mathrm{R} \overline{3} \mathrm{~m}$ & & \\
\hline $\mathrm{Ga}_{2} \mathrm{Pu}(\lambda)$ & 33.3 & $\overline{\mathrm{hP3}}$ & $\mathrm{P} 6 / \mathrm{mmm}$ & $\overline{\mathrm{C} 32}$ & $\overline{\mathrm{AlB}_{2}}$ \\
\hline $\mathrm{Ga}_{3} \mathrm{Pu}_{2}(\kappa)$ & 40 & (d) & & & \\
\hline $\mathrm{GaPu}(\mathrm{l})$ & 50 & tI16 & $\mathrm{I} 4 / \mathrm{mmm}$ & & \\
\hline GaPu (ı') & 50 & $\mathrm{cI} 2$ & $\operatorname{Im} \overline{3} \mathrm{~m}$ & $\overline{\mathrm{A} 2}$ & $\overline{\mathrm{W}}$ \\
\hline $\mathrm{Ga}_{3} \mathrm{Pu}_{5}(\theta)$ & $62.5-64$ & $\mathrm{tI} 32$ & $\mathrm{I} 4 / \mathrm{mcm}$ & $\mathrm{D} 8_{\mathrm{m}}$ & $\mathrm{W}_{5} \mathrm{Si}_{3}$ \\
\hline $\mathrm{GaPu}_{3}(\xi)$ & 75 & $\mathrm{cP} 4$ & $\operatorname{Pm} \overline{3} \mathrm{~m}$ & $\overline{\mathrm{L} 1_{2}}$ & $\mathrm{AuCu}_{3}$ \\
\hline $\mathrm{GaPu}_{3}\left(\zeta^{\prime}\right)$ & 75 & $\mathrm{tP} 4$ & $\mathrm{P} 4 / \mathrm{mmm}$ & & $\mathrm{SrPb}_{3}$ \\
\hline$\eta$ & $58-81.5$ & & $12_{1} 3(\mathrm{a})$ & & \\
\hline$\alpha-\mathrm{Pu}$ & 100 & mP16 & $\mathrm{P} 2_{1} / \mathrm{m}$ & & \\
\hline$\beta-\mathrm{Pu}$ & 100 & mC34 & $\mathrm{C} 2 / \mathrm{m}$ & & \\
\hline$\gamma-\mathrm{Pu}$ & 100 & oF8 & Fddd & & \\
\hline$\delta-\mathrm{Pu}$ & 100 & $\mathrm{cF} 4$ & $\mathrm{Fm} \overline{3} \mathrm{~m}$ & A1 & $\mathrm{Cu}$ \\
\hline$\delta^{\prime}-\mathrm{Pu}$ & 100 & $\mathrm{tI} 2$ & $\mathrm{I} 4 / \mathrm{mmm}$ & $\mathrm{A} 6$ & In \\
\hline$\varepsilon-\mathrm{Pu}$ & 100 & $\mathrm{cI} 2$ & $\operatorname{Im} \overline{3} \mathrm{~m}$ & $\overline{\mathrm{A} 2}$ & $\bar{W}$ \\
\hline
\end{tabular}

Table 5. Crystallographic structures of the condensed phases in the Ga-Pu binary system.

In Fig. 6 we present the phase diagram of Pu-Ga as shown in Refs. [42,43]. This diagram corresponds to the "American version", mostly based on the work of Ellinger et al. [40]. As a reminder, the dashed lines delineate regions of uncertainty. This is particular true for the domain of existence of the $\eta$ phase solid solution. A few unique features of this phase diagram require comments. 
First, Ga stabilizes the $\delta$ phase of $\mathrm{Pu}$ in a relatively wide range of $\mathrm{Ga}$ composition, like other diverse stabilizers such as Al, Sc, and Am. This stabilization, still not understood from first-principles electronic structure calculations, will not be addressed in this report.

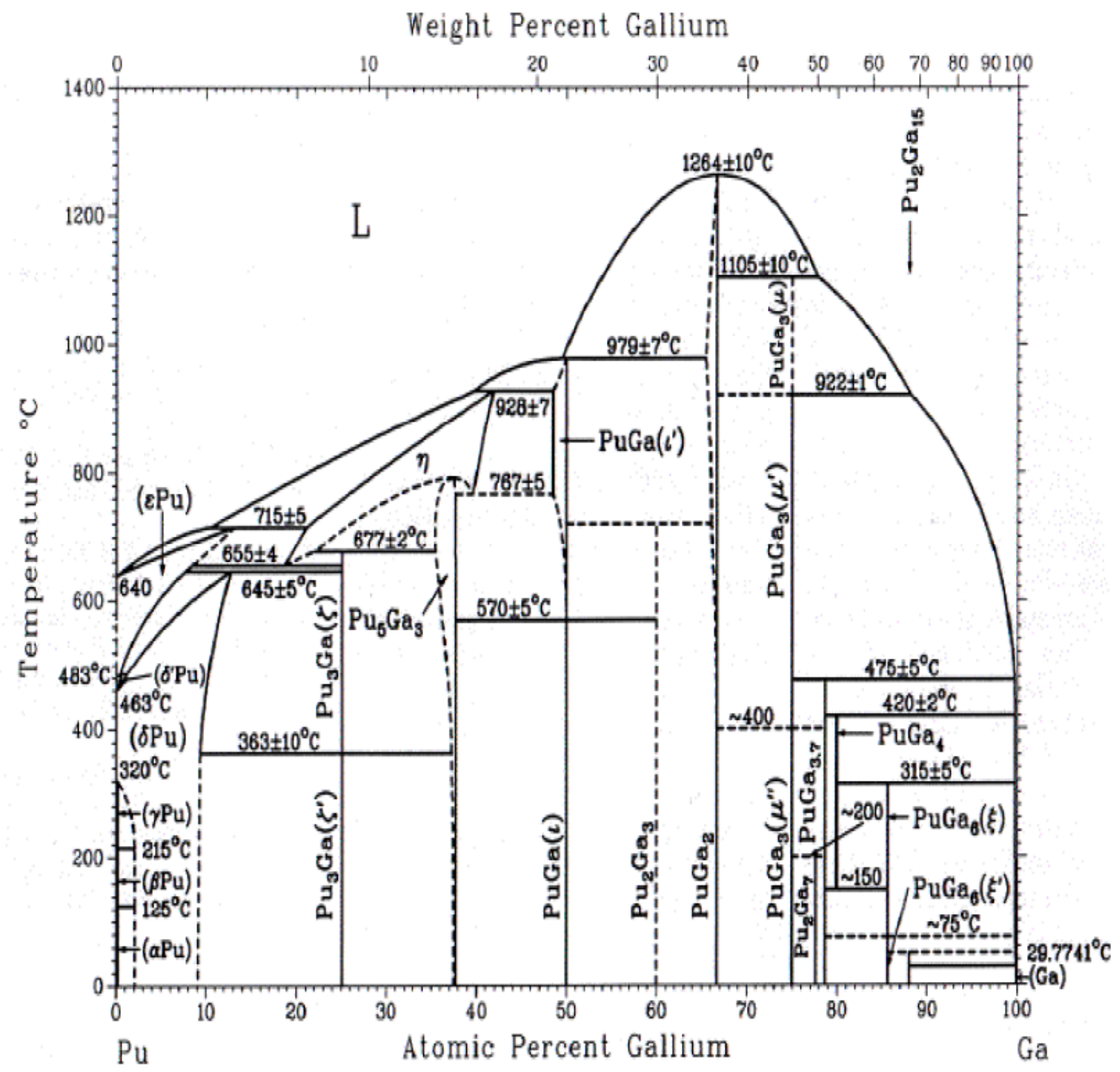

Figure 6. "American version" of the phase diagram of the Pu-Ga system mostly after the work of Ellinger et al. [40]. (From Refs. [42,43]).

Second, despite the low melting points of the endpoints, $\mathrm{Pu}$ at $640{ }^{\circ} \mathrm{C}$ and $\mathrm{Ga}$ at $29.77{ }^{\circ} \mathrm{C}$, the $\mathrm{PuGa}_{2}$ compound congruently melts at very high temperature $\left(1264{ }^{\circ} \mathrm{C}\right)$, and this leads to a very asymmetric phase diagram. This also indicates that the addition of $\mathrm{Pu}$ to $\mathrm{Ga}$ has a tremendous effect on stability, and that the Ga-Pu bonding is rather unique.

Third, there are a few points in the phase diagram (see Fig. 6) that do not comply with the rules of thermodynamic: at $363^{\circ} \mathrm{C}$ and $\mathrm{c}_{\mathrm{Ga}}=0.25,570{ }^{\circ} \mathrm{C}$ and $\mathrm{cGa}_{\mathrm{Ga}}=0.50$, and $922{ }^{\circ} \mathrm{C}$ and $\mathrm{c}_{\mathrm{Ga}}=0.75$. Indeed at these location there is a four-phase equilibrium. One simple way to correct for these artifacts is to assume that there is a limited solubility for the compound, and a probable solution is depicted in Fig. 7. 
Fourth, and foremost, the American version of the phase diagram indicate a domain of stability for the fcc solid solution between 4 and 9 at.\% Ga that seems to extend at low temperature, possibly at $0 \mathrm{~K}$.
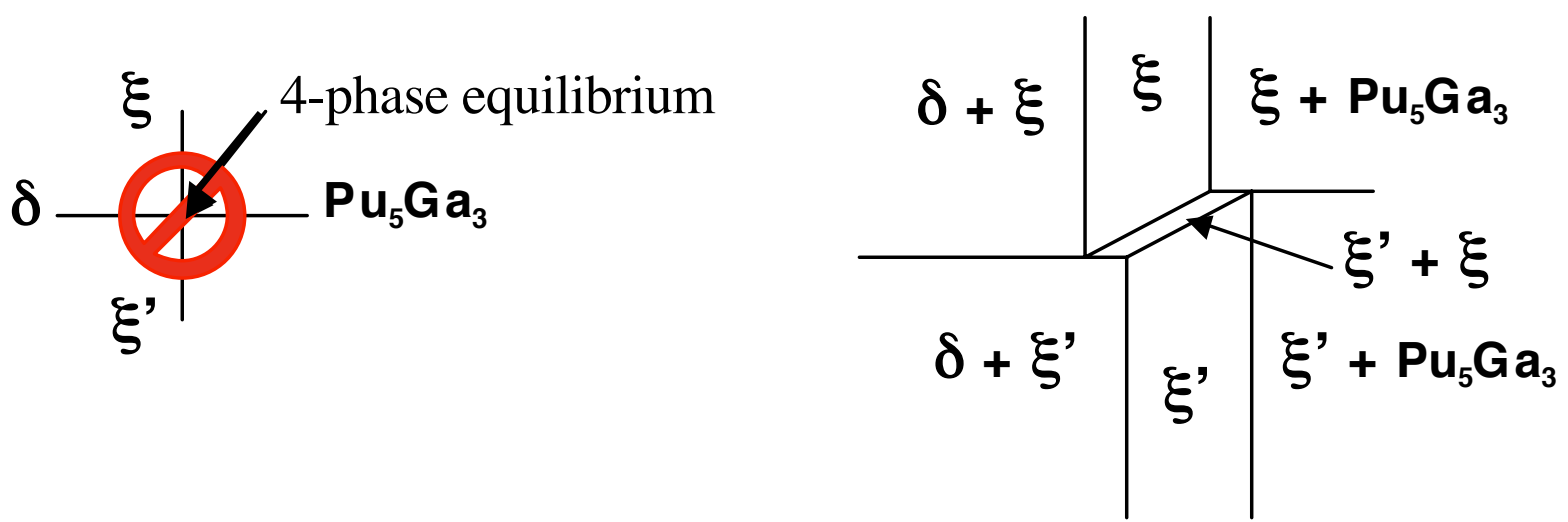

Figure 7. On the left, a feature of the phase diagram of $\mathrm{Pu}-\mathrm{Ga}$ is shown that violates the rules of classical thermodynamics, and on the right, a possible solution to it is proposed.

Hence a legitimate question to ask is: Is this feature in accordance with the known laws of thermodynamics? The answer is yes [51]. According to classical thermodynamics, the third law as proposed by Nernst (1906) says the following: "the entropy change in any isothermal process approaches zero as the temperature at which the process occurs approaches zero". Nernst's law was rephrased by Planck (1911) [52], and this new version is commonly referred to as third law of thermodynamics. It says the following: "the entropy (itself) goes to zero as the temperature approaches zero". Now, based on the relation between entropy S and number of accessible states w, $S=k_{B} \ln (w)$ where $k_{B}$ is Boltzmann's constant, one would conclude that if $S=0$ at $T=0 \mathrm{~K}$, this means that the macroscopic state of a system includes only one single micro-state $(\mathrm{w}=1)$, and therefore a solid solution cannot be stable at zero temperature. However, it is important to note that according to the Boltzmann statistical mechanics approach to thermodynamics, the first and second laws of classical thermodynamics are built in the derivation, and the third law in this context remains an open statement. In fact it is easy to find model systems that lead to the existence of several (even an infinity of) states with equal energy stable at zero temperature, therefore contradicting the implications of the third law. For example, a system that may order as ...ABABA... or ...BABAB... has two states with the same energy at $\mathrm{T}=0 \mathrm{~K}$. A similar example would be the ferromagnetic state of a system with the two stable configurations: all spins "up" or all spins "down". A slightly more involved example would be based on an Ising description of order disorder phenomena in A-B alloy given by the following Hamiltonian:

$$
H=J \sum_{n, m \neq n} \sigma_{n} \sigma_{m}
$$

where $\sigma_{n}$ is a spin variable that takes the value +1 or -1 depending on the occupation of the site $n$ by a B or A species. In this equation is an interaction parameter between first nearest neighbors, and therefore $\mathrm{n}$ and $\mathrm{m}$ are first neighbor sites. Consider the ordering (or anti-ferromagnetic) case $(\mathrm{J}>0)$ ). At low alloy composition, the ground state is the solid solution with non-zero residual entropy. Indeed, 
below the composition $\mathrm{c}_{\mathrm{B}}$ at which the $\mathrm{B}$ atoms are not first neighbors, there is an infinity of configurations with the same energy at $0 \mathrm{~K}$. With this model Hamiltonian, an alloy based on an fcc lattice would exhibit below the composition $\mathrm{c}_{\mathrm{B}}<1 / 12$ (since there are 12 first nearest neighbors to a given site on a fcc lattice), a solid solution. So to conclude this comment, according to classical thermodynamics, the third law of thermodynamics as presented by Nernst may be valid. However since the third law of thermodynamics is not proved (or disproved) in statistical thermodynamics, it is incorrect to jump to the conclusion that the third law implies the existence of one micro-state at zero temperature. Therefore, the existence of a solid solution at zero temperature would imply that the atomic interactions are short range and rather weak, if the solubility extend appreciably away from the pure species.

The thermodynamics of pure $\mathrm{Pu}$ and $\mathrm{Ga}$ has been well established by the SGTE group [28], and the Gibbs functions that describe these two unary phases are reported in Appendix C from Ref. [27]. Since the thermo-chemical database SSOL provided by the SGTE data group had no information on the $\mathrm{Pu}-\mathrm{Ga}$ system, a careful assessment of the available experimental data in the entire range of alloy composition was required. Two sets of data have been considered. First, phase diagram information that includes phase boundaries, invariant lines and special points has been tabulated for the assessment. The data are summarized in Fig. 6 and Table 6. Special emphasis has been put on the high temperature description of the phase diagram since the low temperature and $\mathrm{Pu}$-rich portion of the phase diagram has been the subject of debates over the years. Second, initial values of enthalpies of formation of various compounds [42,53-55], reported in Table 7, have been considered as initial values of the optimization with a large margin of error attached to them.

\begin{tabular}{|c|c|c|c|c|c|c|}
\hline \multirow{2}{*}{$\begin{array}{c}\text { Reaction Type } \\
\text { Congruent }\end{array}$} & \multirow{2}{*}{$\frac{\text { Reaction }}{\eta \leftrightarrow \mathrm{Pu}_{5} \mathrm{Ga}_{3}}$} & \multicolumn{3}{|c|}{ At. \% Ga } & \multirow{2}{*}{$\frac{\text { T }\left({ }^{\circ} \text { Celsius }\right)}{790 \pm 10}$} & \multirow{2}{*}{$\frac{T \text { (Kelvin) }}{1063}$} \\
\hline & & & 37.5 & & & \\
\hline & $\mathrm{L} \leftrightarrow \mathrm{PuGa}_{2}$ & & 66.7 & & $1264 \pm 10$ & 1537 \\
\hline \multirow{8}{*}{ Peritectic } & $\mathrm{L}+\eta \leftrightarrow(\varepsilon \mathrm{Pu})$ & 10 & 21 & 13 & $715 \pm 5$ & 988 \\
\hline & $\mathrm{L}+\mathrm{PuGa} \leftrightarrow \eta$ & 40 & 50 & 41.6 & $928 \pm 7$ & 1201 \\
\hline & $\mathrm{L}+\mathrm{PuGa}_{2} \leftrightarrow \mathrm{PuGa}$ & 49.5 & 66.7 & 50 & $979 \pm 7$ & 1252 \\
\hline & $\mathrm{PuGa}_{2}+\mathrm{L} \leftrightarrow \mathrm{PuGa}_{3}$ & 66.7 & 78 & 75 & $1105 \pm 10$ & 1378 \\
\hline & $\mathrm{PuGa}_{3}+\mathrm{L} \leftrightarrow \mathrm{PuGa}_{3.7}$ & 75 & 99.6 & 78.7 & $475 \pm 5$ & 748 \\
\hline & $\mathrm{PuGa}_{3,7}+\mathrm{L} \leftrightarrow \mathrm{PuGa}_{4}$ & 78.7 & 99.8 & 80 & $420 \pm 2$ & 693 \\
\hline & $\mathrm{PuGa}_{4}+\mathrm{L} \leftrightarrow \mathrm{PuGa}_{6}$ & 80 & 99.9 & 85.7 & $315 \pm 5$ & 588 \\
\hline & $\mathrm{PuGa}_{6}+\mathrm{L} \leftrightarrow \mathrm{Pu}_{2} \mathrm{Ga}_{15}$ & 85.7 & 99.9 & 88.2 & 50 & 323 \\
\hline \multirow[t]{5}{*}{ Peritectoid } & $(\varepsilon \mathrm{Pu})+\mathrm{Pu}_{3} \mathrm{Ga} \leftrightarrow(\delta \mathrm{Pu})$ & 7.5 & 25 & 12.5 & $645 \pm 5$ & 918 \\
\hline & $\eta+\left(\mathrm{Pu}_{5} \mathrm{Ga}_{3}\right) \leftrightarrow \mathrm{Pu}_{3} \mathrm{Ga}$ & 22 & 35.5 & 25 & $677 \pm 2$ & 950 \\
\hline & $\eta \leftrightarrow \mathrm{Pu}_{5} \mathrm{Ga}_{3}+\mathrm{PuGa}$ & 39.5 & 37.5 & 50 & $767 \pm 5$ & 1040 \\
\hline & $\mathrm{PuGa}+\mathrm{PuGa}_{2} \leftrightarrow \mathrm{Pu}_{2} \mathrm{Ga}_{3}$ & 50 & 66.7 & 60 & 720 & 993 \\
\hline & $\mathrm{PuGa}_{3}+\mathrm{PuGa}_{37} \leftrightarrow \mathrm{Pu}_{2} \mathrm{Ga}_{7}$ & 75 & 78.7 & 77.8 & 200 & 473 \\
\hline \multirow[t]{2}{*}{ Eutectoid } & $\eta \leftrightarrow(\varepsilon \mathrm{Pu})+\mathrm{Pu}_{3} \mathrm{Ga}$ & 18.5 & 8.5 & 25 & $655 \pm 4$ & 928 \\
\hline & $\mathrm{PuGa}_{4} \leftrightarrow \mathrm{PuGa}_{3}+\mathrm{PuGa}_{6}$ & 78.7 & 80 & 85.7 & 150 & 423 \\
\hline \multirow[t]{5}{*}{ Polymorphic } & $\mathrm{Pu}_{3} \mathrm{Ga} \leftrightarrow \mathrm{GaPu}_{3}$ & & 25 & & $363 \pm 10$ & 636 \\
\hline & $\mathrm{PuGa} \leftrightarrow \mathrm{GaPu}$ & & 50 & & $570 \pm 5$ & 843 \\
\hline & $\mathrm{PuGa}_{3} \leftrightarrow \mathrm{Ga}_{3} \mathrm{Pu}$ & & 75 & & $922 \pm 1$ & 1195 \\
\hline & $\mathrm{PuGa}_{3} \leftrightarrow \mathrm{Ga}_{3} \mathrm{Pu}$ & & 75 & & 400 & 673 \\
\hline & $\mathrm{PuGa}_{6} \leftrightarrow \mathrm{Ga}_{6} \mathrm{Pu}$ & & 85.7 & & 75 & 348 \\
\hline
\end{tabular}

Table 6. Special points and invariant lines of the Pu-Ga phase diagram and their characterisitics. 


\begin{tabular}{|l|l|c|l|l|c|}
\hline \multicolumn{1}{|c|}{ Compound } & $\begin{array}{c}\Delta \mathrm{H}_{\text {form }} \\
(\mathrm{kcal} / \mathrm{mol}) \\
{[42,53,54]}\end{array}$ & $\begin{array}{c}\Delta \mathrm{H}_{\text {form }} \\
(\mathrm{kcal} / \mathrm{g} . \mathrm{at}) \\
{[55]}\end{array}$ & $\begin{array}{c}\Delta \mathrm{H}_{\text {form }} \\
(\mathrm{kJ} / \mathrm{mol})\end{array}$ & $\begin{array}{c}\Delta \mathrm{H}_{\text {form }} \\
(\mathrm{mRy} / \mathrm{at})\end{array}$ & $\begin{array}{c}\Delta \mathrm{H}_{\text {form }} \\
(\mathrm{kJ} / \mathrm{mol}) \\
(\mathrm{CALPHAD})\end{array}$ \\
\hline $\mathrm{Pu}_{3} \mathrm{Ga}(\xi, \mathrm{HT})$ & $-37.8 \pm 5.0$ & -9.4 & $-39.565 \pm 5.233$ & -30.14 & -38.934 \\
\hline $\mathrm{Pu}_{5} \mathrm{Ga}_{3}$ & $-100 \pm 24$ & -13.0 & $-52.335 \pm 12.560$ & -39.87 & -48.394 \\
\hline $\mathrm{PuGa}(\mathrm{l}, \mathrm{LT})$ & $-28 \pm 7$ & -14.0 & $-58.615 \pm 14.654$ & -44.65 & -51.489 \\
\hline $\mathrm{Pu}_{2} \mathrm{Ga}_{3}$ & -65 & -13.0 & -54.428 & -41.46 & -54.260 \\
\hline $\mathrm{PuGa}_{2}$ & $-45.4 \pm 7.5$ & -12.0 & $-63.360 \pm 10.467$ & -48.26 & -58.000 \\
\hline $\mathrm{PuGa}_{3}(\mu, \mathrm{MT})$ & $-56 \pm 12$ & -9.2 & $-58.615 \pm 12.560$ & -44.65 & -59.714 \\
\hline $\mathrm{Pu}_{2} \mathrm{Ga}_{7}$ & & & & & -59.000 \\
\hline $\mathrm{PuGa}_{37}$ & & & & & -57.000 \\
\hline $\mathrm{PuGa}_{4}$ & $-56 \pm 8$ & -7.7 & $-46.892 \pm 6.699$ & -35.72 & -53.820 \\
\hline $\mathrm{PuGa}_{6}(\xi, \mathrm{HT})$ & $-56.9 \pm 9.0$ & -5.2 & $-34.041 \pm 5.383$ & -25.93 & -41.000 \\
\hline $\mathrm{Pu}_{2} \mathrm{Ga}_{13}$ & & & & & -38.000 \\
\hline
\end{tabular}

Table 7. Heat of formation of various compounds of the Pu-Ga system. The results of the $4^{\text {th }}$ and $5^{\text {th }}$ columns correspond to those of the $2^{\text {nd }}$ one divided by the number of atoms per formula unit, expressed in $\mathrm{kJ} / \mathrm{mol}$ and $\mathrm{mRy} / \mathrm{at}$, respectively $(1 \mathrm{cal} \approx 4.1868 \mathrm{~J}$ and $1 \mathrm{mRy} /$ atom $\approx 1312.760308$ $\mathrm{J} / \mathrm{mol})$. The $6^{\text {th }}$ column gives the results of the CALPHAD assessment.

Note that the values reported in Table 7 ( $2^{\text {nd }}$ column) for $\mathrm{Pu}_{3} \mathrm{Ga}, \mathrm{PuGa}_{2}$, and $\mathrm{PuGa}_{6}$ are from calorimetric measurements of the heats of solution, whereas for the other compounds a correlation between enthalpy of formation and melting temperature has been assumed for estimating the heats of formation $[42,53,54]$. The data reported in Table $7\left(3^{\text {rd }}\right.$ column $)$ are the results of a simple atomistic model originally derived by Miedema [55].

\section{IV.2. Optimization}

For the assessment, the following models were considered:

- a one Redlich-Kister parameter (with ${ }^{1} \mathrm{~L}_{\mathrm{Ga}, \mathrm{Pu}}$ ) model for the $\alpha$ and $\gamma$ "solid solutions".

- a two Redlich-Kister parameter (with ${ }^{0} \mathrm{~L}_{\mathrm{Ga}, \mathrm{Pu}}$ and ${ }^{1} \mathrm{~L}_{\mathrm{Ga}, \mathrm{Pu}}$ ) model for the $\delta$ solid solution.

- a three Redlich-Kister parameter (with ${ }^{\mathrm{k}} \mathrm{L}_{\mathrm{Ga}, \mathrm{Pu}}, \mathrm{k}=0,2$ ) model for the $\varepsilon$ and $\eta$ solid solutions, and the liquid phase.

- a first-order polynomial in $\mathrm{T}$ for the description of each of the 15 compounds of Pu-Ga (instead of 16, since we did not make the distinction between the LT and HT phases of $\mathrm{PuGa}_{6}$ ).

Since all the Redlich-Kister parameters are also expressed as first-order polynomials in T, there is a total of 56 parameters that need to be determined during the optimization process. Actually the task is simplified since the determination of the parameters for most of the compounds, except for $\mathrm{PuGa}_{2}$, is easy once the Gibbs energies for the solution phases and the liquid are known.

The optimization of the model parameters for all phases was carried out with the use of the PARROT module of Thermo-Calc [25]. This module allows the handling of experimental data of various sources, e.g., the information on invariant equilibria, enthalpies of phase formation, etc. The 
module can account for experimental errors and is flexible enough to consider different statistical weights depending on the experimental sets of data that are considered. The following input information was considered for the optimization:

- the set $\left\{\mathrm{c}_{\mathrm{Ga}}, \mathrm{T}\right\}$ that characterizes the HT part of the phase diagram with the associated experimental errors, cf. Fig. 6.

- the set of invariant lines and special points with the associated experimental errors, cf. Table 6.

- a set of initial values for the heats of formation of various compounds, cf. Table 7 ( $4^{\text {th }}$ column).

The optimization was carried out in steps. Since the liquid phase covers the entire composition range and $\mathrm{PuGa}_{2}$ melts congruently, these two phases were initially considered for the optimization. Then, the introduction of the $\varepsilon$ (bcc) solution phase added more constraints to the definition of the Gibbs energies of the two previous phases. In a third step, the $\eta$ solid solution was considered jointly with the surrounding compounds $\mathrm{Pu}_{3} \mathrm{Ga}(\xi), \mathrm{Pu}_{5} \mathrm{Ga}_{3}$. Then the $\delta$ (fcc) solid solution was introduced in the assessment, and all the previous Gibbs energies were re-optimized to produce a self-consistent set of thermodynamic data that reproduce within the experimental errors the HT part of the phase diagram. In the following step, the two HT compounds, $\mathrm{PuGa}\left(\mathrm{l}^{\prime}\right)$ and $\mathrm{PuGa}_{3}(\mu)$, were considered. The thermodynamic definition of the remaining line compounds was finally obtained from the knowledge of the HT part of the phase diagram and of the special points and invariant lines. It is important to stress that during the optimization, the emphasis (statistical weights) was put on the HT part of the phase diagram, and therefore, the LT part comes out as a prediction. Note also that, during the optimization, little emphasis was put on the $\eta$ phase since its crystallography is poorly characterized and its domain of stability as indicated in the assessed phase diagram is not precisely defined (Cf. dashed line in Fig. 6).

\section{IV.3 Statics of Phase Transformation in Pu-Ga Alloys: Results}

The final results of the optimization are reported in Appendix $\mathrm{C}$, and the calculated phase diagram is presented in Fig. 8. The overall features of the calculated and experimental phase boundaries are similar. More precisely we present in Table 8 the characteristics of the calculated invariant lines and special points that compare favorably with those given in Table 6 . The strong asymmetry of the phase diagram is a result of the variation of the heat of formation with alloy composition, as shown in Table 7 ( $6^{\text {th }}$ column $)$ and in Fig. 9.

\begin{tabular}{|c|c|c|c|c|c|c|}
\hline \multirow{3}{*}{\begin{tabular}{|c|} 
Reaction Type \\
Congruent \\
\end{tabular}} & Reaction & \multicolumn{3}{|c|}{ At. $\%$ Ga } & T ( $\left({ }^{\circ}\right.$ Celsius) & T (Kelvin) \\
\hline & $\eta \leftrightarrow \mathrm{Pu}_{15} \mathrm{Ga}_{3}$ & & 37.5 & & 778.15 & 1051.15 \\
\hline & $\mathrm{L} \leftrightarrow \mathrm{PuGa}_{2}$ & & 66.7 & & 1261.97 & 1534.97 \\
\hline \multirow[t]{6}{*}{ Peritectic } & $\mathrm{L}+\eta \leftrightarrow(\varepsilon \mathrm{Pu})$ & 10 & 21 & 13 & 715.83 & 988.83 \\
\hline & $\mathrm{L}+\mathrm{PuGa} \leftrightarrow \eta$ & 40 & 50 & 41.6 & 897.82 & 1170.82 \\
\hline & $\mathrm{L}+\mathrm{PuGa}_{2} \leftrightarrow \mathrm{PuGa}$ & 49.5 & 66.7 & 50 & 1000.07 & 1273.07 \\
\hline & $\mathrm{PuGa}_{2}+\mathrm{L} \leftrightarrow \mathrm{PuGa}_{3}$ & 66.7 & 78 & 75 & 1084.44 & 1357.44 \\
\hline & $\mathrm{PuGa}_{3}+\mathrm{L} \leftrightarrow \mathrm{PuGa}_{3.7}$ & 75 & 99.6 & 78.7 & 476.85 & 749.85 \\
\hline & $\mathrm{PuGa}_{3.7}+\mathrm{L} \leftrightarrow \mathrm{PuGa}_{4}$ & 78.7 & 99.8 & 80 & 425.44 & 698.44 \\
\hline
\end{tabular}




\begin{tabular}{|c|c|c|c|c|c|c|}
\hline & $\mathrm{PuGa}_{4}+\mathrm{L} \leftrightarrow \mathrm{PuGa}_{6}$ & 80 & 99.9 & 85.7 & 311.48 & 584.48 \\
\hline & $\mathrm{PuGa}_{6}+\mathrm{L} \leftrightarrow \mathrm{Pu}_{2} \mathrm{Ga}_{15}$ & 85.7 & 99.9 & 88.2 & 69.95 & 342.95 \\
\hline \multirow[t]{5}{*}{ Peritectoid } & $(\varepsilon \mathrm{Pu})+\mathrm{Pu}_{3} \mathrm{Ga} \leftrightarrow(\delta \mathrm{Pu})$ & 6.3 & 25 & 12.5 & 648.57 & 921.57 \\
\hline & $\eta+\left(\mathrm{Pu}_{5} \mathrm{Ga}_{3}\right) \leftrightarrow \mathrm{Pu}_{3} \mathrm{Ga}$ & 22 & 35.5 & 25 & 667.29 & 940.29 \\
\hline & $\eta \leftrightarrow \mathrm{P}_{5} \mathrm{Ga}_{3}+\mathrm{PuGa}_{5}$ & 39.5 & 37.5 & 50 & 778.15 & 1051.15 \\
\hline & $\mathrm{PuGa}+\mathrm{PuGa}_{2} \leftrightarrow \mathrm{Pu}_{2} \mathrm{Ga}_{3}$ & 50 & 66.7 & 60 & 719.11 & 992.11 \\
\hline & $\mathrm{PuGa}_{3}+\mathrm{PuGa}_{37} \leftrightarrow \mathrm{Pu}_{2} \mathrm{Ga}_{7}$ & 75 & 78.7 & 77.8 & 192.05 & 465.05 \\
\hline \multirow[t]{2}{*}{ Eutectoid } & $\eta \leftrightarrow(\varepsilon P u)+\mathrm{Pu}_{3} \mathrm{Ga}$ & 18.5 & 8.5 & 25 & 660.97 & 933.97 \\
\hline & $\mathrm{PuGa}_{4} \leftrightarrow \mathrm{PuGa}_{3.7}+\mathrm{PuGa}_{6}$ & 78.7 & 80 & 85.7 & 133.53 & 406.53 \\
\hline New & $(\delta \mathrm{Pu}) \leftrightarrow \alpha \mathrm{Pu}+\mathrm{Pu}_{3} \mathrm{Ga}\left(\zeta^{\prime}\right)$ & 7.84 & 0 & 25 & 57.44 & 330.44 \\
\hline \multirow[t]{5}{*}{ Polymorphic } & $\mathrm{Pu}_{3} \mathrm{Ga} \leftrightarrow \mathrm{GaPu}_{3}$ & & 25 & & 361.85 & 634.85 \\
\hline & $\mathrm{PuGa} \leftrightarrow \mathrm{GaPu}$ & & 50 & & 568.42 & 841.42 \\
\hline & $\mathrm{PuGa}_{3} \leftrightarrow \mathrm{Ga}_{3} \mathrm{Pu}$ & & 75 & & 923.07 & 1196.07 \\
\hline & $\mathrm{PuGa}_{3} \leftrightarrow \mathrm{Ga}_{3} \mathrm{Pu}$ & & 75 & & 322.73 & 595.73 \\
\hline & $\mathrm{PuGa}_{6} \leftrightarrow \mathrm{Ga}_{6} \mathrm{Pu}$ & & 85.7 & & N/A & N/A \\
\hline
\end{tabular}
diagram.

Table 8. Characteristics of the invariant lines and special points of the calculated Pu-Ga phase

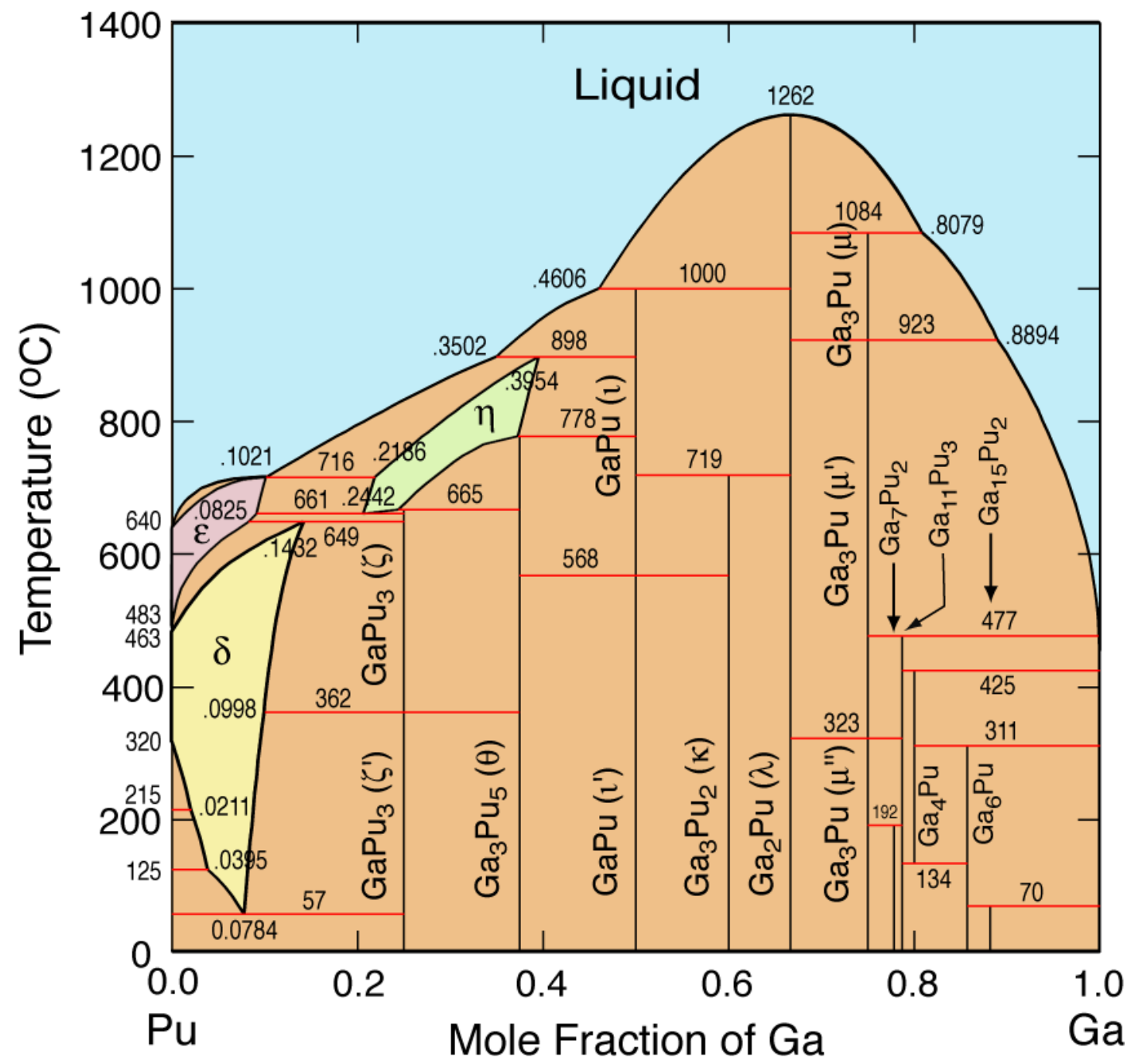

Figure 8. Calculated phase diagram of the Pu-Ga system based on a CALPHAD assessment. 


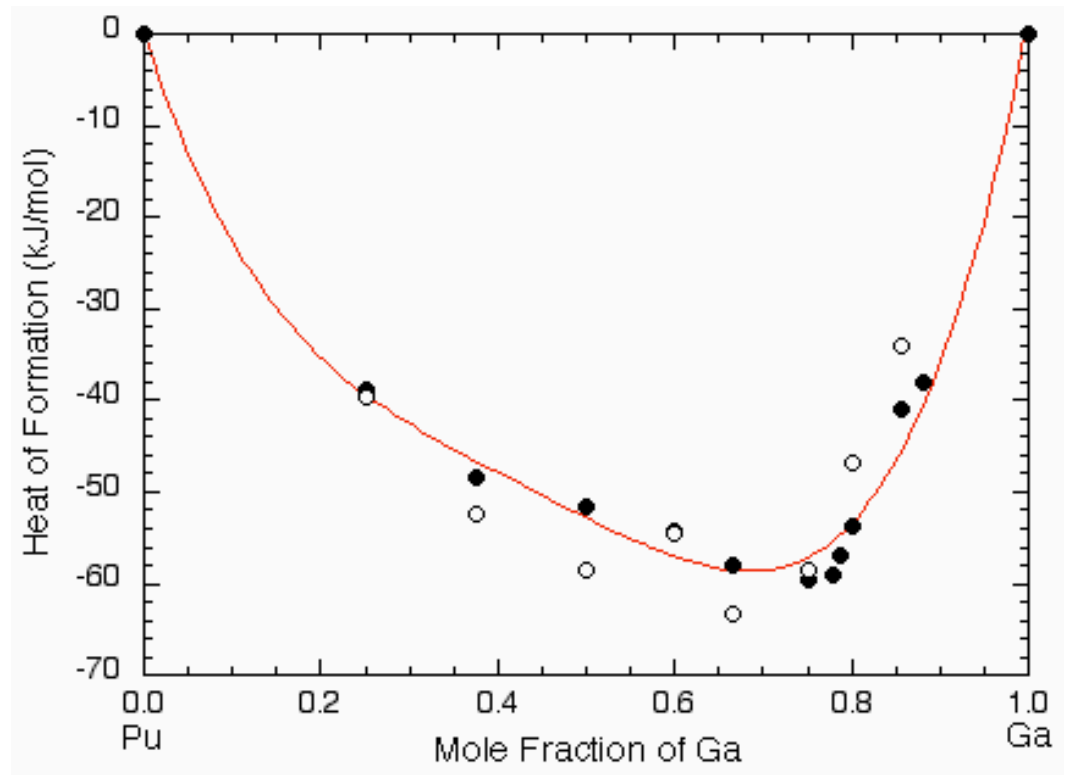

Figure 9. Heats of formation (filled circles) of the various compounds reported in Table 7 (in $\mathrm{kJ} / \mathrm{mol}$ ) resulting from the CALPHAD optimization for $\mathrm{Pu}-\mathrm{Ga}$ alloys. The reference states are $\alpha-\mathrm{Pu}$ and the orthorhombic (Cmca) structure of $\mathrm{Ga}$. The solid line serves as a guide to the eye. The open circles correspond to the experimental results given in Refs. [42,53-54].

Based on the present assessment of the $\mathrm{Pu}-\mathrm{Ga}$ phase diagram, the existence of a low lying eutectoid invariant line in the $\mathrm{Pu}$-rich region at about $57{ }^{\circ} \mathrm{C}$ is consisitent with the Russian experimental results [44-47] that have been at the origin of the controversy between the USA and the former Soviet Union. The eutectoid decomposition of $\delta \rightarrow \alpha+\mathrm{Pu}_{3} \mathrm{Ga}$ at $\mathrm{T}=57.44{ }^{\circ} \mathrm{C}$ and at a composition of $\mathrm{x}_{\mathrm{Ga}}=0.0784$ (about $2.37 \mathrm{wt} \% \mathrm{Ga}$ ) is predicted within CALPHAD. Although Adler drew similar conclusions $\left(\mathrm{T}=81^{\circ} \mathrm{C}\right.$ and $\left.\mathrm{x}_{\mathrm{Ga}}=0.079\right)$ [49], the underlying thermodynamics is quite arguable since his assessment was only performed for the Pu-rich portion of the phase diagram, thus leading to quite inaccurate numerical expressions for the Gibbs energies. Magnified regions of the Russian and assessed phase diagrams are shown in Fig. 10. It is worth noting that the CALPHAD boundary of the two-phase region $\left(\delta+\mathrm{Pu}_{3} \mathrm{Ga}\right)$ lies on the left (i.e., at lower Ga composition) of the experimental results. This result was expected since the slow kinetics of formation of $\mathrm{Pu}_{3} \mathrm{Ga}$ precipitates in the fcc matrix at low temperatures prevents the observation of small phase fraction of $\mathrm{Pu}_{3} \mathrm{Ga}$.

Hence, to conclude this part of the work, a complete thermodynamic assessment of the $\mathrm{Pu}-\mathrm{Ga}$ phase diagram in the entire range of alloy composition was performed. Excellent agreement between experiment and modeling was achieved for the upper part of the phase diagram, and for the energetics that has been derived from the optimization process. From the prediction of a low-temperature eutectoid phase decomposition in the Pu-rich portion of the phase diagram, we conclude that the $\delta$ (fcc) solid solution is metastable at room temperature, and the decomposition of $\delta$ into $\alpha-\mathrm{Pu}$ and the ordered phase $\mathrm{Pu}_{3} \mathrm{Ga}$ is expected under equilibrium conditions. In other words, a thermodynamic driving does exist and is promoting phase decomposition even if it occurs at low temperatures. Hence, if aging of the Pu-Ga alloys should occur, the study of the kinetics of phase decomposition (Cf. section IX.2) is crucial to estimate the time at which such decomposition should take place. Since large volume changes and a ductile to brittle transition ( $\delta$ is ductile whereas $\alpha$ and $\mathrm{Pu}_{3} \mathrm{Al}$ are brittle) accompany this decomposition and can compromise the structural integrity of the alloy (because of 
dimensional distortions), kinetic studies in the Pu-rich region of the phase diagram become even more relevant. Finally, on a more technical side, if new qualified experimental results or $a b$ initio data are made available, the optimization procedure can be used to fine-tune the present results.
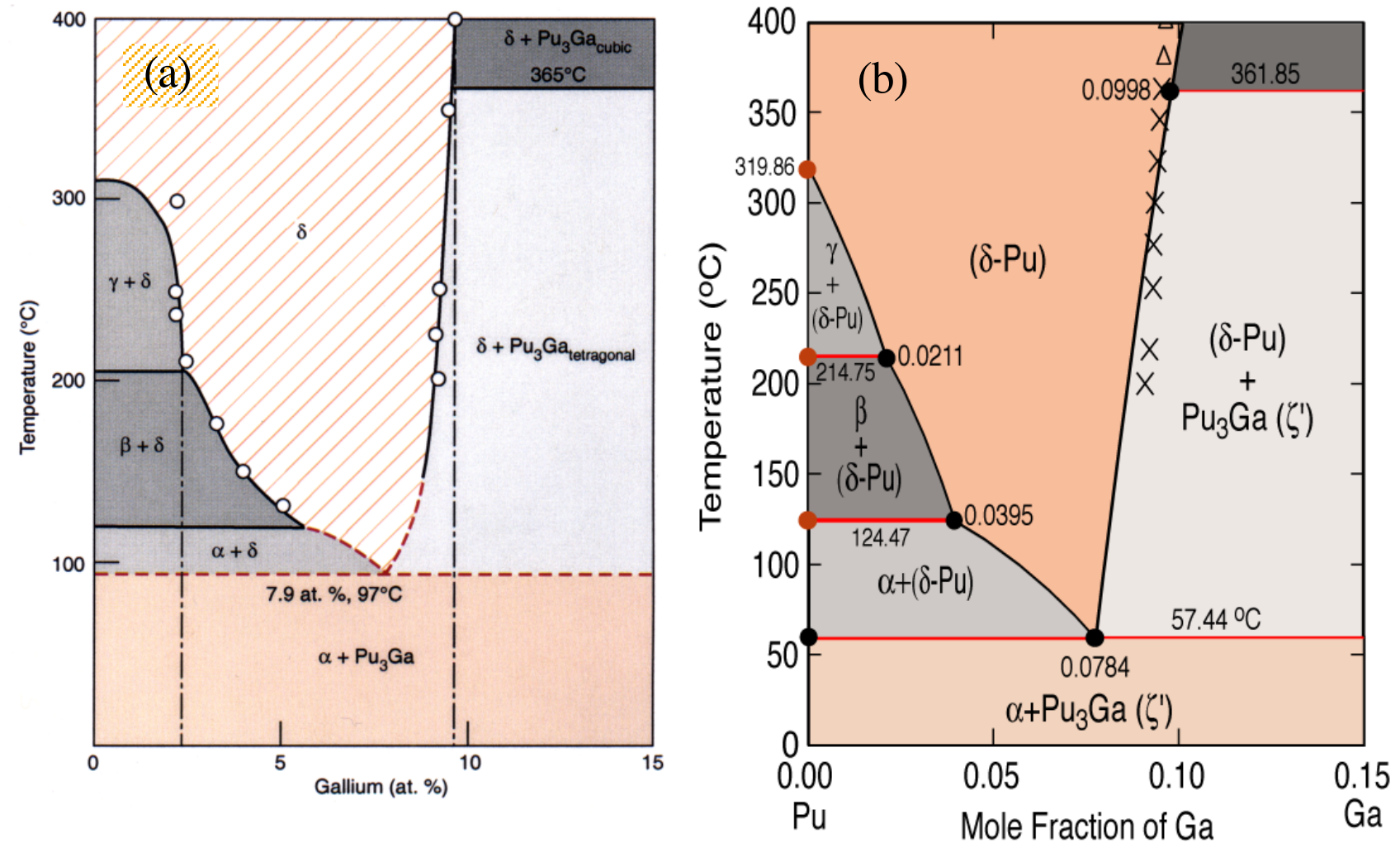

Figure 10. Russian [45] (a) and calculated (b) phase diagrams of the Pu-Ga system (to be compared with the U.S. equilibrium phase diagram shown in Fig. 6). Experimental results are indicated by empty circles in (a) and by crosses in (b), and in (a), the red dashed lines indicate extrapolation whereas in (b) the analogous lines are the results of the CALPHAD predictions.

In the low-temperature Pu-rich portion of the phase diagram, it is interesting to calculate the $\mathrm{T}_{0}$ curve that corresponds to the locus of the intersection of the Gibbs energy curves of two specific phases versus composition. In the present case, $\alpha(\beta$ or $\gamma)$ and $\delta$ are the phases that will be selected.

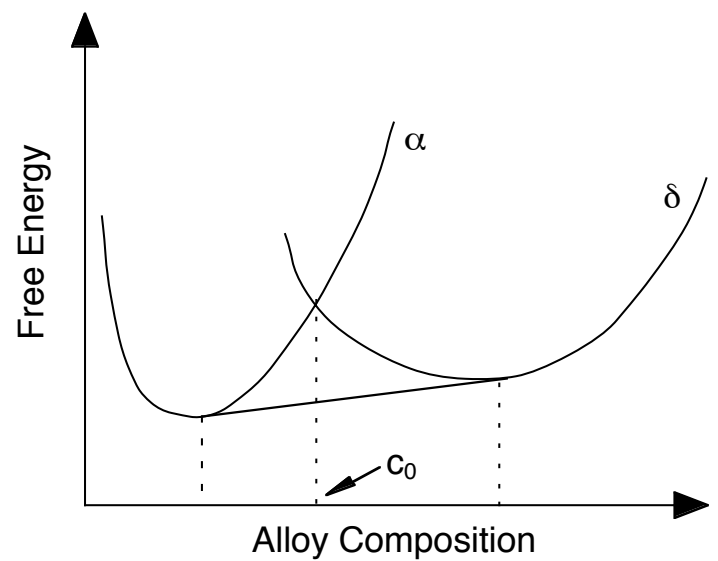

Figure 11. Schematic representation of free energy versus alloy composition for two representative phases $\alpha$ and $\delta$ at fixed temperature. The common tangent defines the composition of the two phases in equilibrium. The crossing of the two Gibbs energies at the fixed temperature $\mathrm{T}_{0}$ is associated with the composition $\mathrm{c}_{0}$ of the alloy. 
Consider the example of $\alpha$ and $\delta$, with $\delta$ being the high-temperature stable phase: below the associated $T_{0}$ curve, $G^{\alpha}<G^{\delta}$, and therefore the $\alpha$ phase satisfies the criterion of stability although thermodynamically this phase may not be the most stable one, as illustrated in Fig. 11.

The calculation of the $\mathrm{T}_{0}$ curve proceeds by defining at each selected temperature $\left(\mathrm{T}_{0}\right)$ the alloy composition $\mathrm{c}_{0}$ associated with equal free energies for two selected phases. The results are presented in Fig. 12 and the polynomial fits are expressed as follows:

$$
\begin{aligned}
& T_{0}^{\alpha-\delta}=156.64-9,121.060 x_{G a}+171,070.405 x_{G a}^{2}-8,209,480.252 x_{G a}^{3} \\
& T_{0}^{\beta-\delta}=273.91-78,246.028 x_{G a}+4,820,076.517 x_{G a}^{2}-1,671,624,863.409 x_{G a}^{3} \\
& T_{0}^{\gamma-\delta}=320.07-142,215.425 x_{G a}+68,728,844.938 x_{G a}^{2}-36,125,459,902.002 x_{G a}^{3}
\end{aligned}
$$

where $x_{G a}$ is the mole fraction of Ga.

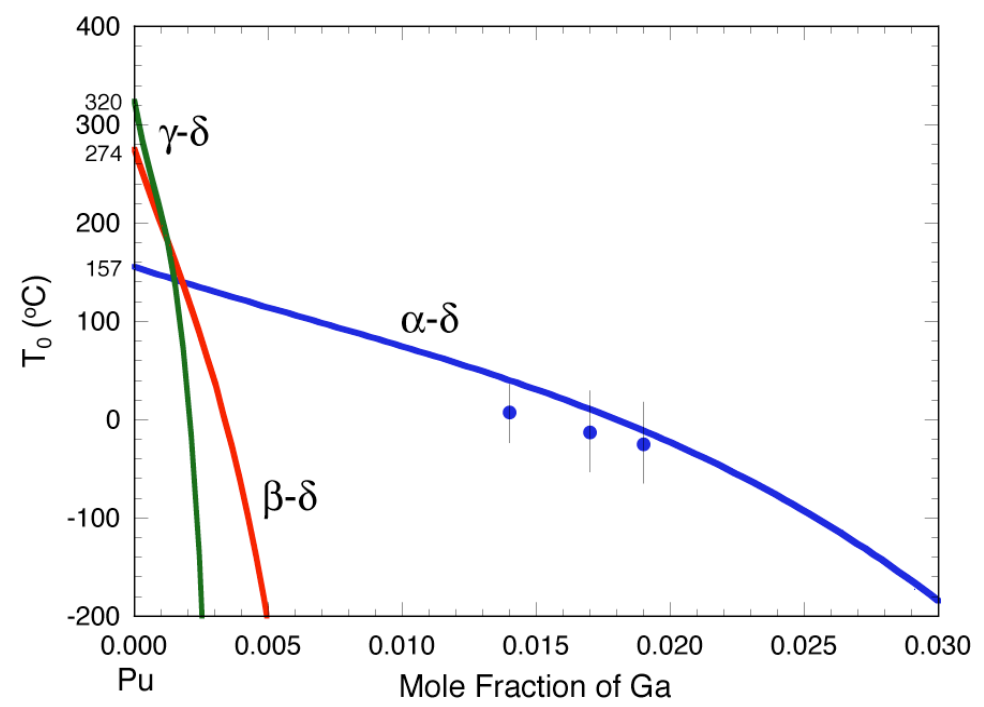

Figure 12. $\mathrm{T}_{0}$ versus mole fraction of $\mathrm{Ga}$ for the $\alpha-\delta$ (blue), $\beta-\delta$ (red), and $\gamma-\delta$ (green) phases of $\mathrm{Pu}-\mathrm{Ga}$ alloys. The dots with the experimental error bars are obtained from Eq. (15) $[49,56]$.

The results displayed in Fig. 12 for the $T_{0}^{\alpha-\delta}$ curve confirm those obtained from the approximate relation $[49,56]$ given by

$$
\mathrm{T}_{0}=\left(\mathrm{M}_{\mathrm{s}}+\mathrm{A}_{\mathrm{s}}\right) / 2
$$

where $\mathrm{M}_{\mathrm{s}}$ and $\mathrm{A}_{\mathrm{s}}$ correspond to the temperature at which the transformation starts and to the reversionstart temperature, respectively.

Finally, it is interesting to test the applicability of a universal relationship that was established for invariant transformations, and in particular for eutectoid transformations in binary alloy systems [57] to the Pu-Ga alloy system. Based on the work performed in the 60's and 70's in the Soviet Union correlations were proposed among the following factors: temperature of an invariant equilibrium, composition of the low-melting component at the invariant equilibrium point, and ratio of the melting points of the alloy components. The relations take the following simple form

$$
\begin{aligned}
& c_{n}\left(T_{A}-T_{n}\right)=T_{A}-T_{B} \text { if } T_{n}<T_{B}<T_{A} \\
& \left(T_{A}-T_{n}\right) / c_{n}=T_{A}-T_{B} \text { if }<T_{B}<T_{n}<T_{A}
\end{aligned}
$$

where $T_{n}$ is the invariant equilibrium temperature, $T_{A}$ and $T_{B}$ are te melting points (or temperatures of formation) of the alloy components taking part in the reaction, and $c_{n}$ is the composition of the low- 
melting component at the invariant equilibrium point. Eutectoid transformations, by definition, consist in the decomposition of one solid phase into two phases at different compositions, and therefore are represented by Eq. (17). If one defines $\mathrm{K}_{\mathrm{n}}$ given by

$$
\mathrm{K}_{\mathrm{n}}=\mathrm{c}_{\mathrm{n}}\left(\mathrm{T}_{\mathrm{A}}-\mathrm{T}_{\mathrm{n}}\right) / \mathrm{T}_{\mathrm{A}}
$$

as the invariant (or eutectoid) reaction coefficient (note that $c_{n}$ in the eutectoid case refers to the fraction of $\mathrm{B}$ phase associated with $\mathrm{T}_{\mathrm{B}}$ at the eutectoid point, according to the lever rule $[37,38]$ ), and $\mathrm{f}$ by

$$
\mathrm{f}=\mathrm{T}_{\mathrm{B}} / \mathrm{T}_{\mathrm{A}}
$$

as the temperature factor, with $T_{A}$ and $T_{B}$ being the maximum absolute temperatures where the phase of eutectoid decomposition is in equilibrium with the eutectoid phases, then for eutectoid reaction one would expect the simple relation

$$
\mathrm{K}_{\mathrm{n}}+\mathrm{f}=1
$$

This relation has been tested for a large number of binary alloy systems. In Table 9, the results of calculation of eutectoid reaction coefficients for transformation in $\mathrm{Pu}-\mathrm{X}$ binary systems, where $\mathrm{X}=\mathrm{Ga}$, $\mathrm{Al}, \mathrm{Fe}$, are presented. Deviations of less than $10 \%$ are observed for most selected reactions. The relation (20) can be used experimentally as well as in theoretical modeling

\begin{tabular}{|c|c|c|c|c|c|c|c|}
\hline Eutectoid Reaction & $\mathbf{T}_{\mathbf{n}}\left({ }^{\mathbf{0}} \mathbf{C}\right)$ & $\mathbf{T}_{\mathbf{B}}\left({ }^{\circ} \mathbf{C}\right)$ & $\mathbf{T}_{\mathbf{A}}\left({ }^{\mathbf{0}} \mathbf{C}\right)$ & $\mathbf{c}_{\mathbf{n}}$ & $\mathbf{f}$ & $\mathbf{K}_{\mathbf{n}}$ & $\mathbf{K}_{\mathbf{n}}+\mathbf{f}$ \\
\hline$(\delta-\mathrm{Pu}) \rightarrow(\alpha-\mathrm{Pu})+\mathrm{Pu}_{3} \mathrm{Ga}$ & 57.44 & 124.77 & 361.85 & $.689(\alpha-\mathrm{Pu})$ & .344 & .579 & .923 \\
\hline$\eta \rightarrow(\varepsilon-\mathrm{Pu})+\mathrm{Pu}_{3} \mathrm{Ga}$ & 660.97 & 667.29 & 715.83 & $.742 \mathrm{Pu}_{3} \mathrm{Ga}$ & .932 & .057 & .989 \\
\hline $\mathrm{GaPu} \rightarrow \mathrm{Ga}_{3} \mathrm{Pu}_{5}+\mathrm{Ga}_{3} \mathrm{Pu}_{2}$ & 568.42 & 667.29 & 719.11 & $.444 \mathrm{Ga}_{3} \mathrm{Pu}_{5}$ & .927 & .093 & 1.02 \\
\hline $\mathrm{Ga}_{3} \mathrm{Pu} \rightarrow \mathrm{Ga}_{2} \mathrm{Pu}+\mathrm{Ga}_{11} \mathrm{Pu}_{3}$ & 322.73 & 476.85 & 719.11 & .697 & .663 & .384 & 1.047 \\
\hline$(\delta-\mathrm{Pu}) \rightarrow(\alpha-\mathrm{Pu})+\mathrm{Pu}_{3} \mathrm{Al}$ & 95.02 & 124.47 & 200.95 & $.655(\alpha-\mathrm{Pu})$ & .619 & .345 & .964 \\
\hline $\mathrm{PuAl} \rightarrow \mathrm{Pu}_{3} \mathrm{Al}+\mathrm{PuAl}{ }_{2}$ & 200.95 & 571.04 & 620.79 & $.400 \mathrm{Pu}_{3} \mathrm{Al}$ & .920 & .271 & 1.191 \\
\hline$(\varepsilon-\mathrm{Pu}) \rightarrow \mathrm{FePu}_{6}+(\delta-\mathrm{Pu})$ & 404.02 & 415.01 & 479.46 & $.236 \mathrm{FePu}_{6}$ & .866 & .037 & .903 \\
\hline
\end{tabular}

Table 9. Eutectoid reaction coefficients for transformations occurring in the $\mathrm{Pu}-\mathrm{X}$ binary systems, where $\mathrm{X}=\mathrm{Ga}, \mathrm{Al}, \mathrm{Fe}$. Along with the value for $\mathrm{c}_{\mathrm{n}}$ the $\mathrm{B}$ compound is also indicated.

In conclusion, the phase diagram of the Pu-Ga binary system has been carefully assessed with CALPHAD methodology, and the results will be used to study the thermodynamics of higher-order systems with confidence. As in the case of pure $\mathrm{Pu}$, a wealth of information has been collected during the assessment, among others, all the thermodynamic functions, and in particular Gibbs energy, enthalpy, entropy, heat capacity, and also heats of transformation and $\mathrm{T}_{0}$ data. This study fully confirmed the existence of an eutectoid reaction taking place at low temperature in the Pu-rich part of the phase diagram as was proposed by the team from the Soviet Union during the Cold War era. If thermodynamic equilibrium could be reached, this would have important consequences since the $\alpha$ phase of pure $\mathrm{Pu}$ and the $\mathrm{Pu}_{3} \mathrm{Ga}$ compound are brittle, and also because of the important change in volume between the fcc $(\delta)$ solid solution and $\alpha-\mathrm{Pu}$ and $\mathrm{Pu}_{3} \mathrm{Ga}$. Obviously the question of "how long 
could it take for such a phase decomposition to take place?" is extremely appropriate and will be addressed in section X.2.

\section{THERMO-CHEMISTRY OF Pu-Fe ALLOYS}

The crystallographic information of the Fe-Pu system given in Table 10 is from Refs. [42,43]. The experimental results $[58,59]$ are rather sparse. The $\mathrm{Fe}_{2} \mathrm{Pu}$ and $\mathrm{FePu}_{6}$ compounds (analogous to $\mathrm{Fe}_{2} \mathrm{U}$ and $\mathrm{FeU}_{6}$ ) decompose congruently and peritectically (arguable), respectively. Although it was observed experimentally that $\mathrm{Fe}_{2} \mathrm{Pu}$ was transforming from $\alpha$ to $\beta$ at $771{ }^{\circ} \mathrm{C}$, and from $\beta$ to $\gamma$ at about $1020^{\circ} \mathrm{C}$, these structural transformations will be ignored in the CALPHAD assessment because of the lack of reliable information. The experimentally determined $\mathrm{Fe}-\mathrm{Pu}$ phase diagram taken from Ref. [42] is presented in Fig. 13. Note the existence of a few dashed lines and the relatively unusual shape of the line separating the liquid from the two-phase region $\mathrm{Fe}_{2} \mathrm{Pu}+$ liquid. We present in Table 11 the characteristics of the calculated invariant lines and special points. An initial CALPHAD assessment has been reported by Kurata et al. [60] and refined later on by the same authors. However modifications had to be made to the thermodynamic description of the $\mathrm{FePu}_{6}$ compound to fix an artifact associated with its formation in the domain of stability of the liquid phase in the Fe-rich part of the phase diagram. The final results of the optimization are reported in Appendix $\mathrm{C}$, and the calculated phase diagram is presented in Fig. 14a with a more detailed presentation of the Pu-rich part of the phase diagram in Figure 14b. The overall features of the calculated and experimental phase boundaries are similar as can be appreciated by comparing the results reported in Tables 11 and 12 . The most salient difference between the accepted and assessed phase diagrams of $\mathrm{Fe}-\mathrm{Pu}$ is the prediction of a congruent melting of the $\mathrm{FePu}_{6}$ compound at $422{ }^{\circ} \mathrm{C}$ (cf. Fig. 14b), instead of the perirectic reaction: $\mathrm{Liquid}+\mathrm{FePu}_{2}(\alpha) \leftrightarrow \mathrm{FePu}_{6}$ (cf. Fig. 13).

\begin{tabular}{|c|c|c|c|c|c|}
\hline & at.\% Pu & $\begin{array}{l}\text { Pearson } \\
\text { Symbol }\end{array}$ & $\begin{array}{l}\text { Space } \\
\text { Group }\end{array}$ & $\begin{array}{c}\text { Struktur- } \\
\text { bericht }\end{array}$ & Structure-type \\
\hline$\gamma-\mathrm{Fe}$ & 0 & $\mathrm{cF} 4$ & $\mathrm{Fm} \overline{3} \mathrm{~m}$ & $\overline{\mathrm{A} 1}$ & $\mathrm{Cu}$ \\
\hline$\alpha-\mathrm{Fe}$ & 0 & $\mathrm{cI} 2$ & $\operatorname{Im} \overline{3} \mathrm{~m}$ & $\mathrm{~A} 2$ & $\overline{\mathrm{W}}$ \\
\hline$\alpha-\mathrm{Fe}_{2} \mathrm{Pu}$ & 33.3 & $\mathrm{cF} 24$ & $\mathrm{Fd} \overline{3} \mathrm{~m}$ & $\overline{C 15}$ & $\mathrm{Cu}_{2} \mathrm{Mg}$ \\
\hline$\beta-\mathrm{Fe}_{2} \mathrm{Pu}$ & 33.3 & hP24 & $\mathrm{P}_{3} / \mathrm{mmc}$ & $\bar{C} 36$ & $\mathrm{MgNi}_{2}$ \\
\hline$\gamma-\mathrm{Fe}_{2} \mathrm{Pu}$ & 33.3 & $\mathrm{c}^{*}$ & & & \\
\hline $\mathrm{FePu}_{6}$ & 85.7 & tI28 & $\mathrm{I} \overline{4} / \mathrm{mcm}$ & $\mathrm{D} 2_{\mathrm{c}}$ & $\mathrm{MnU}_{6}$ \\
\hline$\alpha-\mathrm{Pu}$ & 100 & mP16 & $\mathrm{P} 2_{1} / \mathrm{m}$ & & \\
\hline$\beta-\mathrm{Pu}$ & 100 & $\mathrm{mC} 34$ & $\mathrm{C} 2 / \mathrm{m}$ & & \\
\hline$\gamma-\mathrm{Pu}$ & 100 & oF8 & Fddd & & \\
\hline$\delta-\mathrm{Pu}$ & 100 & $\mathrm{cF} 4$ & $\mathrm{Fm} \overline{3} \mathrm{~m}$ & $\overline{\mathrm{A} 1}$ & $\mathrm{Cu}$ \\
\hline$\delta^{\prime}-\mathrm{Pu}$ & 100 & $\mathrm{tI2}$ & $\mathrm{I} 4 / \mathrm{mmm}$ & A6 & In \\
\hline$\varepsilon-\mathrm{Pu}$ & 100 & $\mathrm{cI} 2$ & $\operatorname{Im} \overline{3} \mathrm{~m}$ & $\mathrm{~A} 2$ & $\overline{\mathrm{W}}$ \\
\hline
\end{tabular}

Table 10. Crystallographic structures of the condensed phases in the Fe-Pu binary system. 


\begin{tabular}{|c|c|c|c|c|c|c|}
\hline Reaction Type & Reaction & \multicolumn{3}{|c|}{ At.\% Fe } & T ( ${ }^{\circ}$ Celsius) & T (Kelvin) \\
\hline Congruent & $\mathrm{L} \leftrightarrow \mathrm{Fe}_{2} \mathrm{Pu}(\gamma)$ & & 66.67 & & 1240 & 1513 \\
\hline Peritectic & $\mathrm{L}+\mathrm{Fe}_{2} \mathrm{Pu}(\alpha) \leftrightarrow \mathrm{FePu}_{6}$ & 87 & 66.67 & 14.29 & 428 & 701 \\
\hline Catatectic & $\mathrm{L}+(\delta \mathrm{Fe}) \leftrightarrow(\gamma \mathrm{Fe})$ & 94 & 99 & $\sim 100$ & $\sim 1400$ & $\sim 1673$ \\
\hline Eutectoid & $(\gamma \mathrm{Fe}) \leftrightarrow(\alpha \mathrm{Fe})+\mathrm{Fe}_{2} \mathrm{Pu}(\beta)$ & 99 & $\sim 100$ & 66.67 & 907 & 1180 \\
\hline & $\mathrm{L}+(\delta \mathrm{Pu} \leftrightarrow \leftrightarrow(\varepsilon \mathrm{Pu})$ & 10 & 0.5 & 2.2 & 430 & 703 \\
\hline Eutectic & $\mathrm{L} \leftrightarrow(\gamma \mathrm{Fe})+\mathrm{Fe}_{2} \mathrm{Pu}(\gamma)$ & 82 & 98 & 66.67 & 1165 & 1438 \\
\hline & $\mathrm{L} \leftrightarrow(\delta \mathrm{Pu})+\mathrm{Fe} \mathrm{Pu}$ & 10 & 0.4 & 14.29 & 413 & 686 \\
\hline Polymorphic & $\mathrm{Fe}_{2} \mathrm{Pu}(\beta) \leftrightarrow \mathrm{Fe}_{2} \mathrm{Pu}(\gamma)$ & & 66.67 & & 1020 & 1293 \\
\hline & $\mathrm{Fe}_{2} \mathrm{Pu}(\alpha) \leftrightarrow \mathrm{Fe}_{2} \mathrm{Pu}(\beta)$ & & 66.67 & & 771 & 1044 \\
\hline Allotropic & $(\gamma \mathrm{Fe}) \leftrightarrow(\delta \mathrm{Fe})$ & & 100 & & 1394 & 1667 \\
\hline & $(\alpha \mathrm{Fe}) \leftrightarrow(\gamma \mathrm{Fe})$ & & 100 & & 912 & 1185 \\
\hline Melting & $\mathrm{L} \leftrightarrow \delta \mathrm{Fe}$ & & 100 & & 1538 & 1811 \\
\hline
\end{tabular}

Table 11. Special points and invariant lines of the $\mathrm{Pu}-\mathrm{Fe}$ phase diagram and their characteristics.

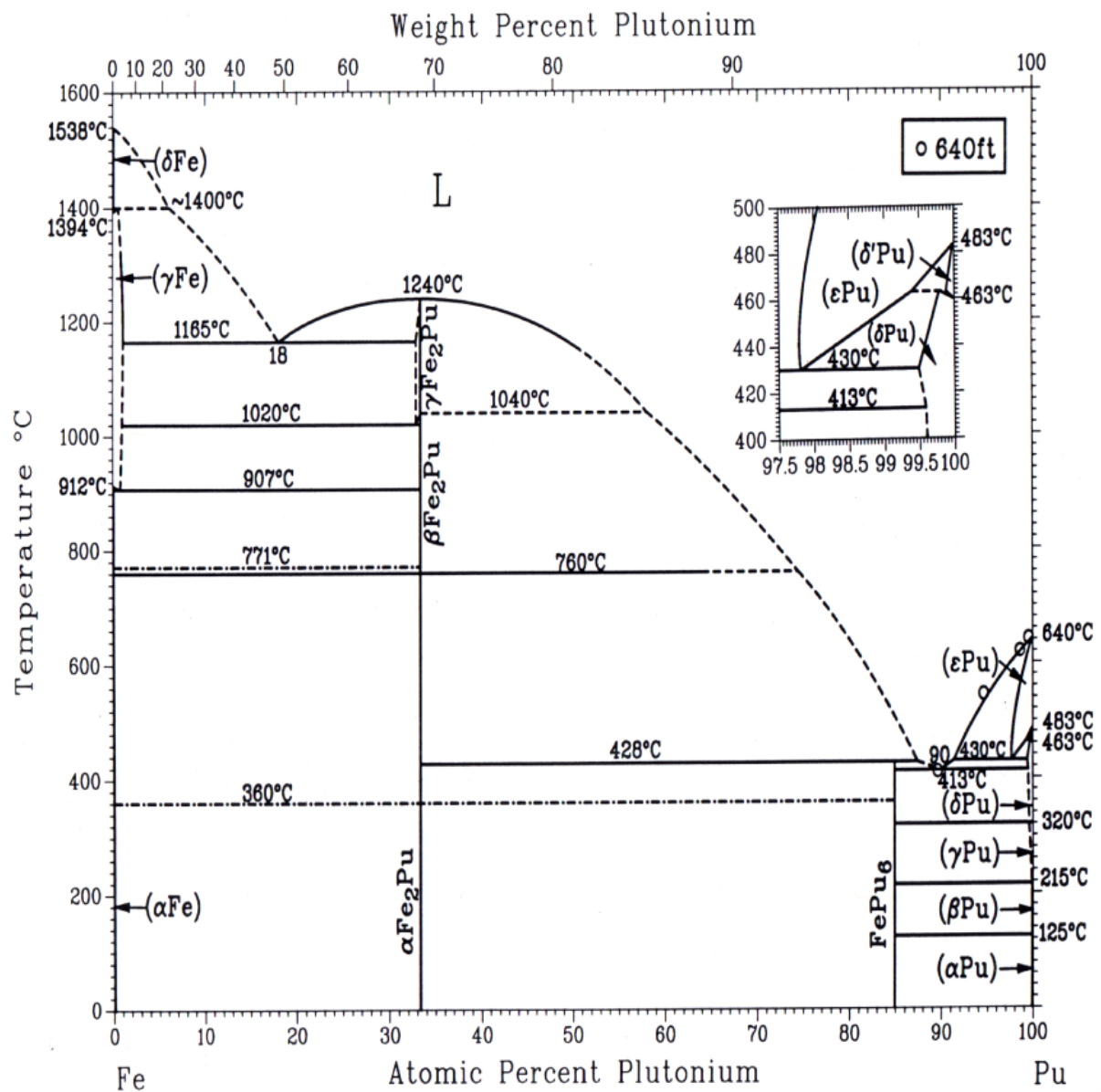

Figure 13. Experimental assessment of the phase diagram of the Fe-Pu system (From Ref. [42]).

\begin{tabular}{|c|c|c|c|c|c|c|}
\hline \multirow{3}{*}{$\frac{\text { Reaction Type }}{\text { Congruent }}$} & \multirow{2}{*}{$\frac{\text { Reaction }}{\mathrm{L} \leftrightarrow \mathrm{Fe}_{2} \mathrm{Pu}}$} & \multicolumn{3}{|c|}{ At. \% Fe } & \multirow{2}{*}{$\frac{T\left({ }^{\circ} \text { Celsius }\right)}{1243.09}$} & \multirow{2}{*}{$\frac{\text { T (Kelvin) }}{1516.09}$} \\
\hline & & \multicolumn{3}{|c|}{66.67} & & \\
\hline & $\mathrm{L} \leftrightarrow \mathrm{FePu}_{6}$ & & 14.29 & & 422 & 695 \\
\hline Catatectic & $\mathrm{L}+(\delta \mathrm{Fe}) \leftrightarrow(\gamma \mathrm{Fe})$ & 92.64 & 99.04 & $\sim 100$ & 1392.55 & 1665.55 \\
\hline Eutectoid & $(\gamma \mathrm{Fe}) \leftrightarrow(\alpha \mathrm{Fe})+\mathrm{Fe}_{2} \mathrm{Pu}$ & 90 & 99.5 & 66.94 & 890.07 & 1163.07 \\
\hline & $(\varepsilon \mathrm{Pu}) \leftrightarrow(\delta \mathrm{Pu})+\mathrm{FePu}_{6}$ & 4.14 & 0.98 & 14.4 & 404.02 & 677.02 \\
\hline Eutectic & $\mathrm{L} \leftrightarrow(\gamma \mathrm{Fe})+\mathrm{Fe}_{2} \mathrm{Pu}$ & 80.6 & 96.9 & 66.67 & 1111.89 & 1384.89 \\
\hline
\end{tabular}




\begin{tabular}{|c|c|c|c|c|c|c|}
\hline & $\mathrm{L} \leftrightarrow(\varepsilon \mathrm{Pu})+\mathrm{FePu}_{6}$ & 10.45 & 4.74 & 14.29 & 415.01 & 688.01 \\
\hline Allotropic & $(\gamma \mathrm{Fe}) \leftrightarrow(\delta \mathrm{Fe})$ & & 100 & & 1394.33 & 1667.33 \\
\hline & $(\alpha \mathrm{Fe}) \leftrightarrow(\gamma \mathrm{Fe})$ & & 100 & & 911.65 & 1184.65 \\
\hline Melting & $\mathrm{L} \leftrightarrow \delta \mathrm{Fe}$ & & 100 & & 1537.75 & 1810.75 \\
\hline
\end{tabular}

Table 12. Special points and invariant lines of the calculated Pu-Fe phase diagram as obtained from the CALPHAD assessment.
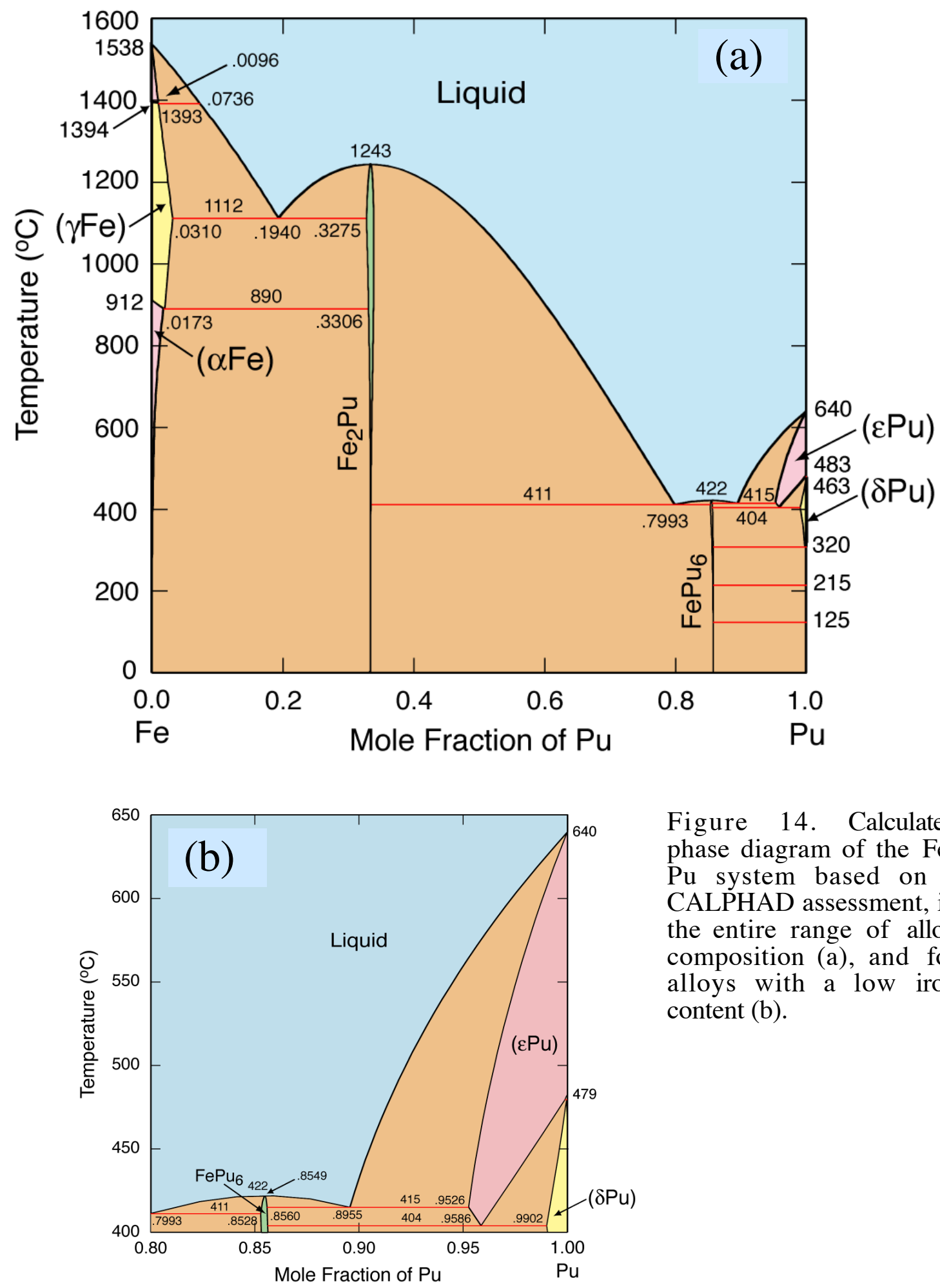

Figure 14. Calculated phase diagram of the Fe$\mathrm{Pu}$ system based on a CALPHAD assessment, in the entire range of alloy composition (a), and for alloys with a low iron content (b). 


\section{THERMO-CHEMISTRY OF Pu-Al ALLOYS}

\section{VI.1. Introduction}

The $\mathrm{Pu}-\mathrm{Al}$ phase diagram originally proposed by Schonfeld in 1957 [61] and followed by the one of Bochvar et al. in 1958 [62] generated a dispute similar to the one discussed in the case of the $\mathrm{Pu}-\mathrm{Ga}$ phase diagram. The phase boundaries of the low temperature $\mathrm{Pu}$-rich part of the diagram were the contended features. In the "American version" the $\delta$ phase is indicated stable at low temperature whereas in the Bochvar et al. version an eutectoid reaction $\delta \rightarrow \beta+\mathrm{Pu}_{3} \mathrm{Al}$ at $448 \mathrm{~K}$ is proposed. The most recent $\mathrm{Pu}-\mathrm{Al}$ phase diagram that was published in1986 in the ASM handbook of actinide alloy phase diagrams $[42,43]$ was essentially the one proposed by Ellinger et al. [63,64], see Fig. 15 . The long-standing controversy between the American and Russian version of the Pu-Al phase diagram was finally put to rest recently in favor of the Russian version. Indeed during an International Conference held in Oxford, UK, in 1999, on “Aging Studies and Lifetime Extension of Materials", Timofeeva gave a clear presentation on plutonium phase diagram [44], and the process used almost 30 years was clearly revealed and showed that the Russian phase diagram was an equilibrium phase diagram. Prior to long annealing at atmospheric pressure, the use of pressure and plastic deformation was used to "precondition" plutonium alloys and enhance the kinetics of the $\delta$-phase decomposition. This was contrary to the thought that long-term annealing was performed under pressure and therefore was leading to non-equilibrium phase diagram at some unspecified pressure [45-48]. It is interesting to note that the study performed by Adler at LLNL in the early 90's, without the full knowledge of the experiments carried out in the Soviet Union, was predicting with a thermodynamic model the existence of an eutectoid decomposition in $\mathrm{Pu}-\mathrm{Al}$ at low temperature [49]. We conducted a full re-assessment of the phase diagram of $\mathrm{Pu}-\mathrm{Al}$ with the expectation that, by considering all the phases that are experimentally observed during the assessment procedure, the Gibbs energy associated with each phase will be constrained and a self-consistent set of thermodynamic data will be generated.

Let us first review the various phases that one has to consider for assessing the phase diagram of $\mathrm{Al}-\mathrm{Pu}$ in the whole range of alloy composition. Besides the endpoints, there are two solution phases, denoted $\delta$ and $\varepsilon$, and twelve compounds, namely (in increasing $\mathrm{Al}$ composition): $\mathrm{Pu}_{3} \mathrm{Al}$ ( $\zeta$ ', LT), $\mathrm{Pu}_{3} \mathrm{Al}$

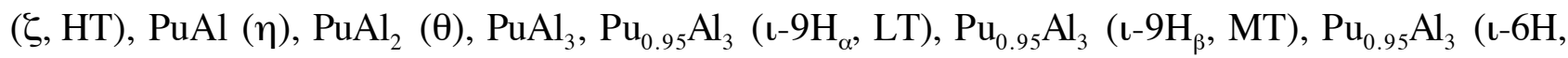
MT), $\mathrm{Pu}_{0.95} \mathrm{Al}_{3}(\mathrm{l}-3 \mathrm{H}, \mathrm{HT}), \mathrm{PuAl}_{4}, \mathrm{Pu}_{0.90} \mathrm{Al}_{4}\left(\mathrm{~K}_{\alpha}, \mathrm{LT}\right)$, and $\mathrm{Pu}_{0.90} \mathrm{Al}_{4}\left(\mathrm{~K}_{\beta}, \mathrm{HT}\right)$. Note that in the following, we will ignore the slight departures from the stoichiometries at 75 and 80 at.\% Al, and all compounds will be treated as line compounds. A summary of all existing phases in the $\mathrm{Pu}-\mathrm{Al}$ phase diagram with crystallographic information is given in Table 13.

\begin{tabular}{|l|c|c|c|c|c|}
\hline & at.\% Al & $\begin{array}{c}\text { Pearson } \\
\text { Symbol }\end{array}$ & $\begin{array}{c}\text { Space } \\
\text { Group }\end{array}$ & $\begin{array}{c}\text { Struktur- } \\
\text { bericht }\end{array}$ & Structure-type \\
\hline $\mathrm{Al}$ & $99.99-100$ & $\mathrm{cF} 4$ & $\mathrm{Fm} \overline{3} \mathrm{~m}$ & $\mathrm{~A} 1$ & $\mathrm{Cu}$ \\
\hline $\mathrm{Al}_{4} \mathrm{Pu}_{0.90}\left(\mathrm{~K}_{\alpha}\right)$ & 81.6 & $\mathrm{OI} 20$ & $\mathrm{Imma}$ & $\mathrm{D} 1_{\mathrm{b}}$ & $\mathrm{Al}_{4} \mathrm{U}$ \\
\hline $\mathrm{Al}_{4} \mathrm{Pu}_{0.90}\left(\mathrm{~K}_{\beta}\right)$ & 81.6 & $\mathrm{O} 20$ & $\mathrm{Imma}$ & $\mathrm{D} 1_{\mathrm{b}}$ & $\mathrm{Al}_{4} \mathrm{U}$ \\
\hline $\mathrm{Al}_{4} \mathrm{Pu}$ & 80 & $\mathrm{OI} 20$ & $\mathrm{Imma}$ & $\mathrm{D} 1_{\mathrm{b}}$ & $\mathrm{Al}_{4} \mathrm{U}$ \\
\hline $\mathrm{Al}_{3} \mathrm{Pu}_{0.95}\left(\mathrm{l}-9 \mathrm{H}_{\alpha}\right)$ & 76 & & $\mathrm{R} \overline{3} \mathrm{~m}$ & & \\
\hline
\end{tabular}




\begin{tabular}{|c|c|c|c|c|c|}
\hline $\mathrm{Al}_{3} \mathrm{Pu}_{0.95}\left(\mathrm{l}-9 \mathrm{H}_{\beta}\right)$ & 76 & & $\mathrm{R} \overline{3} \mathrm{~m}$ & & \\
\hline $\mathrm{Al}_{3} \mathrm{Pu}_{0.95}(\mathrm{l}-6 \mathrm{H})$ & 76 & & $\mathrm{P}_{3} / \mathrm{mmc}$ & & \\
\hline $\mathrm{Al}_{3} \mathrm{Pu}_{0.95}(\mathrm{l}-3 \mathrm{H})$ & 76 & $\mathrm{cP} 4$ & $\operatorname{Pm} \overline{3} \mathrm{~m}$ & $\mathrm{L1}_{2}$ & $\mathrm{AuCu}_{3}$ \\
\hline $\mathrm{Al}_{3} \mathrm{Pu}$ & 75 & hP24 & $\mathrm{P}_{3} / \mathrm{mmc}$ & & \\
\hline $\mathrm{Al}_{2} \mathrm{Pu}(\theta)$ & 66.7 & $\mathrm{cF} 24$ & $\mathrm{Fd} \overline{3} \mathrm{~m}$ & C15 & $\mathrm{Cu}_{2} \mathrm{Mg}$ \\
\hline $\mathrm{AlPu}(\eta)$ & 50 & cI58 & & & \\
\hline $\mathrm{AlPu}_{3}(\xi, \mathrm{HT})$ & 25 & $\mathrm{tP} 4$ & $\mathrm{P} 4 / \mathrm{mmm}$ & & $\mathrm{SrPb}_{3}$ \\
\hline $\mathrm{AlPu}_{3}\left(\zeta^{\prime}, \mathrm{LT}\right)$ & 25 & (a) & & & \\
\hline$\alpha-\mathrm{Pu}$ & $\overline{0}$ & $\mathrm{mP} 16$ & $\mathrm{P} 2_{1} / \mathrm{m}$ & & \\
\hline$\overline{\beta-P u}$ & 0 & $\mathrm{mC} 34$ & $\mathrm{C} 2 / \mathrm{m}$ & & \\
\hline$\gamma-\mathrm{Pu}$ & 0 & oF8 & Fddd & & \\
\hline$\delta-\mathrm{Pu}$ & $0-14.5$ & $\mathrm{cF} 4$ & $\mathrm{Fm} \overline{3} \mathrm{~m}$ & A1 & $\mathrm{Cu}$ \\
\hline$\delta^{\prime}-\mathrm{Pu}$ & 0.25 & $\mathrm{tI} 2$ & $\mathrm{I} / \mathrm{mmm}$ & A6 & In \\
\hline$\varepsilon-\mathrm{Pu}$ & $0-12$ & $\mathrm{cI} 2$ & $\operatorname{Im} \overline{3} \mathrm{~m}$ & $\mathrm{~A} 2$ & $\overline{\mathrm{W}}$ \\
\hline
\end{tabular}

Table 13. Crystallographic structures of the condensed phases in the Al-Pu binary system.

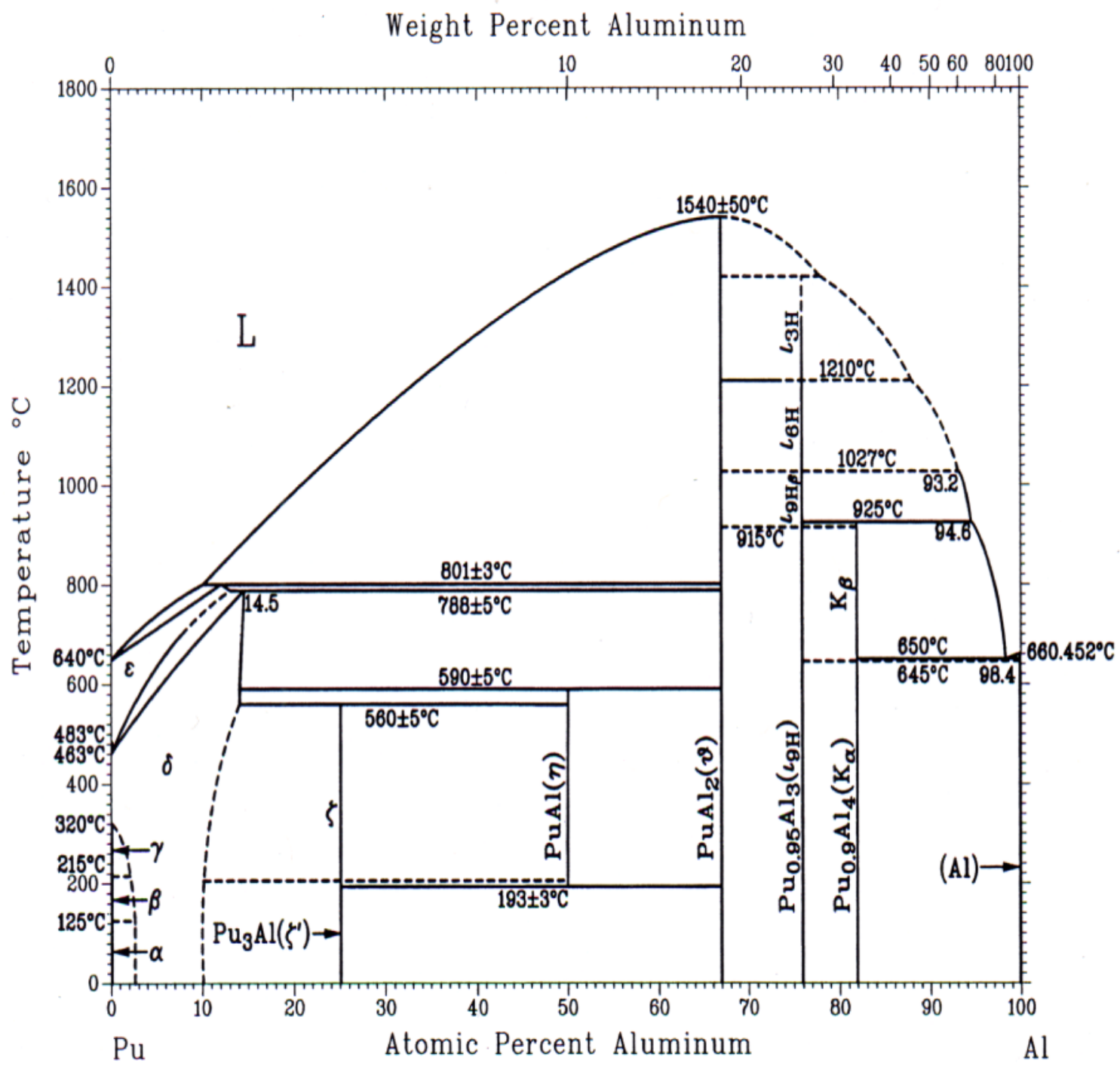

Figure 15. Experimental assessment of the phase diagram of the Pu-Al system (From Ref. [42]). 
In Fig. 15 we present the phase diagram of $\mathrm{Pu}-\mathrm{Al}$ as shown in Refs. [42,43]. This diagram corresponds to the "American version", mostly based on the work of Ellinger et al. [63,64]. As a reminder, the dashed lines delineate regions of uncertainty. This is particular true for the domain of existence of the $\delta$ phase solid solution. A few unique features of this phase diagram require comments. First, $\mathrm{Al}$ stabilizes the $\delta$ phase of $\mathrm{Pu}$ in a relatively wide range of $\mathrm{Al}$ composition, like other "deltagens", as mentioned in section I. This stabilization, still not understood from firstprinciples electronic structure calculations, will not be addressed in this report. Second, despite the low melting points of the endpoints, $\mathrm{Pu}$ at $640{ }^{\circ} \mathrm{C}$ and $\mathrm{Al}$ at $660.452{ }^{\circ} \mathrm{C}$, the $\mathrm{PuAl}_{2}$ compound congruently melts at very high temperature $\left(1540{ }^{\circ} \mathrm{C}\right)$, and this leads to a very asymmetric phase diagram, as in the $\mathrm{Pu}-\mathrm{Ga}$ case. This also indicates that the addition of $\mathrm{Pu}$ to $\mathrm{Al}$ has a tremendous effect on stability, and that the Al-Pu bonding is rather unique. Finally, the remarks made about the third law of thermodynamics in the Pu-Ga case in section IV.1 also apply here.

The thermodynamics of pure Pu and $\mathrm{Al}$ has been well established by the SGTE group [28], and the Gibbs functions that describe these two unary phases are reported in Appendix C from Ref. [27]. Since the thermo-chemical database SSOL provided by the SGTE data group had no information on the $\mathrm{Pu}-\mathrm{Al}$ system, a careful assessment of the available experimental data in the entire range of alloy composition was required. Two sets of data have been considered. First, phase diagram information that includes phase boundaries, invariant lines and special points has been tabulated for the assessment. The data are summarized in Fig. 15 and Table 14. Special emphasis has been put on the high temperature description of the phase diagram since the low temperature and Pu-rich portion of the phase diagram has been the subject of debates over the years. Second, initial values of enthalpies of formation of various compounds [42,53-55], reported in Table 15, have been considered as initial values of the optimization with a large margin of error attached to them.

\begin{tabular}{|c|c|c|c|c|c|c|}
\hline \multirow{2}{*}{$\begin{array}{c}\begin{array}{c}\text { Reaction } \\
\text { Type }\end{array} \\
\text { Congruent } \\
\end{array}$} & \multirow{2}{*}{$\begin{array}{l}\text { Reaction } \\
\mathrm{L} \leftrightarrow \mathrm{PuAl}_{2}(\theta)\end{array}$} & \multicolumn{3}{|c|}{ At. \% Al } & \multirow{2}{*}{$\frac{\text { T ( }}{\left(^{\circ} \text { Celsius) }\right.}$} & \multirow{2}{*}{$\begin{array}{c}\text { T (Kelvin) } \\
1813 \\
\end{array}$} \\
\hline & & & 66.7 & & & \\
\hline \multirow[t]{3}{*}{ Peritectic } & $\mathrm{L}+\mathrm{PuAl}_{2}(\theta) \leftrightarrow(\varepsilon \mathrm{Pu})$ & 10 & 12 & 66.7 & $801 \pm 3$ & 1074 \\
\hline & $\mathrm{PuAl}_{2}(\theta)+\mathrm{L} \leftrightarrow \mathrm{Pu}_{0.95} \mathrm{Al}_{3}$ & 66.7 & 79 & 76 & 1420 & 1693 \\
\hline & $\mathrm{L}+\mathrm{Pu}_{0.95} \mathrm{Al}_{3} \leftrightarrow \mathrm{Pu}_{0.90} \mathrm{Al}_{4}$ & 94.7 & 76 & 81.6 & 925 & 1198 \\
\hline \multirow[t]{3}{*}{ Peritectoid } & $(\varepsilon \mathrm{Pu})+\mathrm{PuAl} l_{2}(\theta) \leftrightarrow(\delta \mathrm{Pu})$ & 13 & 66.7 & 14.5 & $788 \pm 5$ & 1061 \\
\hline & $(\delta \mathrm{Pu})+\mathrm{PuAl}(\eta) \leftrightarrow \mathrm{Pu}_{3} \mathrm{Al}(\zeta)$ & 14 & 50 & 25 & $560 \pm 5$ & 833 \\
\hline & $(\delta \mathrm{Pu})+\mathrm{PuAl}_{2}(\theta) \leftrightarrow \mathrm{PuAl}(\eta)$ & 14 & 66.7 & 50 & $590 \pm 5$ & 863 \\
\hline Eutectic & $\mathrm{L} \leftrightarrow \mathrm{Al}(\alpha)+\mathrm{Pu}_{0.90} \mathrm{Al}_{4}$ & 99.99 & 98.4 & 88.6 & 650 & 923 \\
\hline \multirow[t]{2}{*}{ Eutectoid } & $(\varepsilon \mathrm{Pu}) \leftrightarrow\left(\delta^{\prime} \mathrm{Pu}\right)+(\delta \mathrm{Pu})$ & $\sim 0.1$ & $\sim 0.05$ & $\sim 0.25$ & 460 & 733 \\
\hline & $\operatorname{PuAl}(\eta) \leftrightarrow \mathrm{Pu}_{3} \mathrm{Al}+\mathrm{PuAl}_{2}(\theta)$ & 50 & 25 & 66.7 & $193 \pm 3$ & 466 \\
\hline \multirow[t]{5}{*}{ Polymorphic } & $\mathrm{Pu}_{3} \mathrm{Al}(\zeta) \leftrightarrow \mathrm{AlPu}_{3}\left(\zeta^{\prime}\right)$ & & 25 & & 195 & 468 \\
\hline & $\mathrm{Pu}_{0.95} \mathrm{Al}_{3} \leftrightarrow \mathrm{Al}_{3} \mathrm{Pu}_{0.95}$ & & 76 & & $1210 \pm 3$ & 1483 \\
\hline & $\mathrm{Pu}_{0.95} \mathrm{Al}_{3} \leftrightarrow \mathrm{Al}_{3} \mathrm{Pu}_{0.95}$ & & 76 & & $1027 \pm 3$ & 1300 \\
\hline & $\mathrm{Pu}_{0.95} \mathrm{Al}_{3} \leftrightarrow \mathrm{Al}_{3} \mathrm{Pu}_{0.95}$ & & 76 & & $915 \pm 3$ & 1188 \\
\hline & $\mathrm{Pu}_{0.90} \mathrm{Al}_{4} \leftrightarrow \mathrm{Al}_{4} \mathrm{Pu}_{0.95}$ & & 81.6 & & 645 & 918 \\
\hline
\end{tabular}

Table 14. Special points and invariant lines of the $\mathrm{Pu}-\mathrm{Al}$ phase diagram and their characteristics. 


\begin{tabular}{|l|c|c|c|c|c|}
\hline \multicolumn{1}{|c|}{ Compound } & $\begin{array}{c}\Delta \mathrm{H}_{\text {form }} \\
(\mathrm{kcal} / \mathrm{mol}) \\
{[42,65]}\end{array}$ & $\begin{array}{c}\Delta \mathrm{H}_{\text {form }} \\
(\mathrm{kcal} / \mathrm{g} . \mathrm{at})\end{array}$ & $\begin{array}{c}\Delta \mathrm{H}_{\text {form }} \\
(\mathrm{kJ} / \mathrm{mol})\end{array}$ & $\begin{array}{c}\Delta \mathrm{H}_{\text {form }} \\
(\mathrm{mRy} / \mathrm{at})\end{array}$ & $\begin{array}{c}\Delta \mathrm{H}_{\text {form }} \\
(\mathrm{kJ} / \mathrm{mol}) \\
(\mathrm{CALPHAD})\end{array}$ \\
\hline $\mathrm{Pu}_{3} \mathrm{Al}(\zeta)$ & & -9.6 & & & $-16,375$ \\
\hline $\mathrm{PuAl}(\eta)$ & & & & & $-34,128$ \\
\hline $\mathrm{PuAl}_{2}(\theta)$ & $-34.0 \pm 2.4$ & -13.0 & $-47.450 \pm 3.349$ & -36.15 & $-46,000$ \\
\hline $\mathrm{PuAl}_{3}\left(\mathrm{l}-9 \mathrm{H}_{\alpha}\right)$ & $-43.2 \pm 2.4$ & -10.0 & $-45.217 \pm 2.523$ & -34.44 & $-45,000$ \\
\hline $\mathrm{PuAl}_{3}\left(\mathrm{l}-9 \mathrm{H}_{\beta}\right)$ & & & & & $-28,200$ \\
\hline $\mathrm{PuAl}_{3}(\mathrm{l}-6 \mathrm{H})$ & & & & & $-25,600$ \\
\hline $\mathrm{PuAl}_{3}(\mathrm{l}-3 \mathrm{H})$ & & & & & $-24,150$ \\
\hline $\mathrm{PuAl}_{4}(\kappa)$ & $-43.2 \pm 2.4$ & -8.7 & $-36.174 \pm 2.009$ & -27.56 & $-36,000$ \\
\hline
\end{tabular}

Table 15. Heat of formation of various compounds of the $\mathrm{Pu}-\mathrm{Al}$ system. The results of the $4^{\text {th }}$ and $5^{\text {th }}$ columns correspond to those of the $2^{\text {nd }}$ one divided by the number of atoms per formula unit, expressed in $\mathrm{kJ} / \mathrm{mol}$ and $\mathrm{mRy} / \mathrm{at}$, respectively $(1 \mathrm{cal} \approx 4.1868 \mathrm{~J}$ and $1 \mathrm{mRy} /$ atom $\approx 1312.760308$ $\mathrm{J} / \mathrm{mol}$ ). The $6^{\text {th }}$ column gives the results of the CALPHAD assessment.

Note that the values reported in Table 15 ( $2^{\text {nd }}$ column) for $\mathrm{PuAl}_{2}, \mathrm{PuAl}_{3}$ and $\mathrm{PuAl}_{4}$ are from calorimetric measurements of the heats of solution $[42,65]$. The data reported in Table 15 ( $3^{\text {rd }}$ column) are the results of a simple atomistic model originally derived by Miedema [55].

\section{VI.2. Optimization}

For the assessment, the following models were considered:

- a one Redlich-Kister parameter (with ${ }^{0} L_{A l, P u}$ ) model for the $\alpha$ "solid solution".

- a two Redlich-Kister parameter (with ${ }^{0} L_{A l, P u}$ and ${ }^{1} L_{A l, P u}$ ) model for the $\varepsilon$ and $\delta$ solid solutions.

- a three Redlich-Kister parameter (with ${ }^{k} L_{A l, P u}, \mathrm{k}=0,2$ ) model for the liquid phase.

- a first-order polynomial in T for the description of the Redlich-Kister parameters (except for the $\alpha$ solid solution, for which case a constant was considered) and for each of the 8 (instead of 12) compounds of $\mathrm{Pu}-\mathrm{Al}$.

The optimization was carried out in steps. Since the liquid phase covers the entire composition range and $\mathrm{PuAl}_{2}$ melts congruently, these two phases were initially considered for the optimization. Then, the introduction of the $\varepsilon$ (bcc) solution phase added more constraints to the definition of the Gibbs energies of the two previous phases. In a third step, the $\delta$ (fcc) solid solution was introduced in the assessment, and all the previous Gibbs energies were re-optimized to produce a self-consistent set of thermodynamic data that reproduce within the experimental errors the HT part of the phase diagram. In the following step, the compounds, $\mathrm{PuAl}(\eta)$ and $\mathrm{PuAl}_{3} \mathrm{PuAl}_{3}(\mathrm{l}-3 \mathrm{H})$, were considered. The thermodynamic definition of the remaining line compounds was finally obtained from the knowledge of the HT part of the phase diagram and of the special points and invariant lines. It is important to stress that during the optimization, the emphasis (statistical weights) was put on the HT 
part of the phase diagram, and therefore, the LT part comes out as a prediction. Note also that, during the optimization, little emphasis was put on the low-temperature stability of the $\delta$ phase since its domain of existence as indicated in the assessed phase diagram is not precisely defined (Cf. dashed line in Fig. 15).

\section{VI.3 Statics of Phase Transformation in Pu-Al Alloys: Results}

The final results of the optimization are reported in Appendix C, and the calculated phase diagram is presented in Fig. 16. The overall features of the calculated and experimental phase boundaries are similar. More precisely we present in Table 16 the characteristics of the calculated invariant lines and special points that compare favorably with those given in Table 14. The strong asymmetry of the phase diagram is a result of the variation of the heat of formation with alloy composition, as shown in Table 13 ( $6^{\text {th }}$ column $)$ and in Fig. 17.

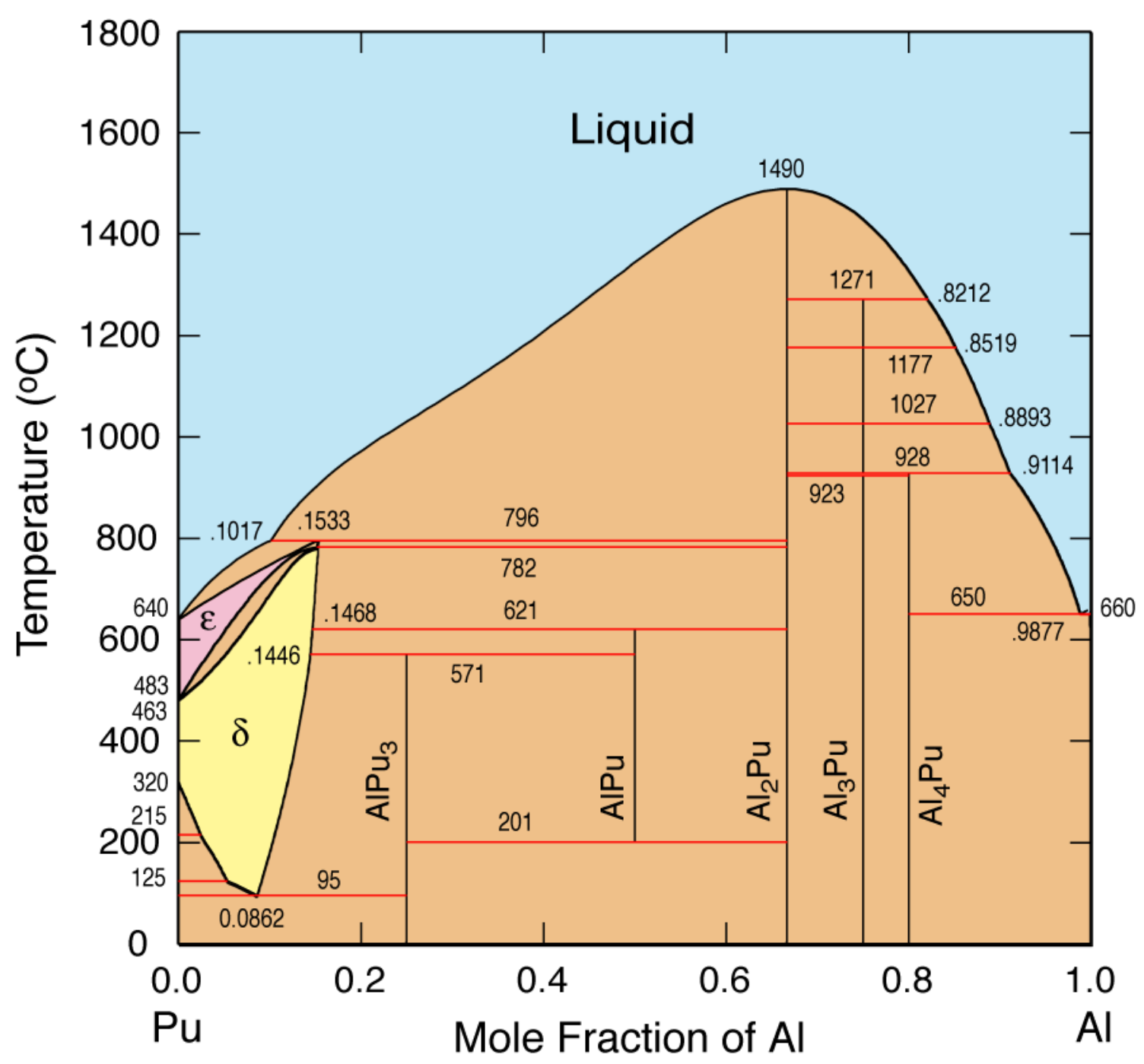

Figure 16. Calculated phase diagram of the $\mathrm{Pu}-\mathrm{Al}$ system based on a CALPHAD assessment. 


\begin{tabular}{|c|c|c|c|c|c|c|}
\hline Reaction Type & Reaction & \multicolumn{3}{|c|}{ At. $\%$ Al } & T $\left({ }^{\circ}\right.$ Celsius $)$ & T (Kelvin) \\
\hline Congruent & $\mathrm{L} \leftrightarrow \mathrm{PuAl}_{2}(\theta)$ & & 66.7 & & 1490.27 & 1763.27 \\
\hline \multirow[t]{3}{*}{ Peritectic } & $\mathrm{L}+\mathrm{PuAl}_{2}(\theta) \leftrightarrow(\varepsilon \mathrm{Pu})$ & 10.17 & 15.33 & 66.7 & 796.04 & 1069.04 \\
\hline & $\mathrm{PuAl}_{2}(\theta)+\mathrm{L} \leftrightarrow \mathrm{Pu}_{0.95} \mathrm{Al}_{3}$ & 66.7 & 82.12 & 75 & 1271.49 & 1544.49 \\
\hline & $\mathrm{L}+\mathrm{PuAl}_{3} \leftrightarrow \mathrm{PuAl}_{4}$ & 91.14 & 75 & 80 & 928.41 & 1201.41 \\
\hline \multirow[t]{3}{*}{ Peritectoid } & $(\varepsilon \mathrm{Pu})+\mathrm{PuAl}_{2}(\theta) \leftrightarrow(\delta \mathrm{Pu})$ & 15.17 & 66.7 & 15.32 & 782.30 & 1055.30 \\
\hline & $(\delta \mathrm{Pu})+\mathrm{PuAl}(\eta) \leftrightarrow \mathrm{Pu}_{3} \mathrm{Al}(\zeta)$ & 14.46 & 50 & 25 & 571.04 & 844.04 \\
\hline & $(\delta \mathrm{Pu})+\mathrm{PuAl}_{2}(\theta) \leftrightarrow \mathrm{PuAl}(\eta)$ & 14.88 & 66.7 & 50 & 620.79 & 893.79 \\
\hline Eutectic & $\mathrm{L} \leftrightarrow \mathrm{Al}(\alpha)+\mathrm{PuAl} l_{4}$ & 99.99 & 98.87 & 80 & 650.38 & 923.38 \\
\hline \multirow[t]{2}{*}{ Eutectoid } & $\mathrm{PuAl}(\eta) \leftrightarrow \mathrm{Pu}_{3} \mathrm{Al}+\mathrm{PuAl}_{2}(\theta)$ & 50 & 25 & 66.7 & 200.95 & 473.95 \\
\hline & $(\delta \mathrm{Pu}) \leftrightarrow \mathrm{Pu}_{3} \mathrm{Al}(\zeta)+(\alpha \mathrm{Pu})$ & 8.62 & 25 & $\sim 0$ & 95.02 & 368.02 \\
\hline \multirow[t]{3}{*}{ Polymorphic } & $\mathrm{PuAl}_{3} \leftrightarrow \mathrm{Al}_{3} \mathrm{Pu}$ & & 75 & & 1176.85 & 1449.85 \\
\hline & $\mathrm{PuAl}_{3} \leftrightarrow \mathrm{Al}_{3} \mathrm{Pu}$ & & 75 & & 1026.85 & 1299.85 \\
\hline & $\mathrm{PuAl}_{3} \leftrightarrow \mathrm{Al}_{3} \mathrm{Pu}$ & & 75 & & 923.42 & 1196.42 \\
\hline
\end{tabular}

Table 16. Characteristics of the invariant lines and special points of the calculated $\mathrm{Pu}-\mathrm{Al}$ phase diagram.

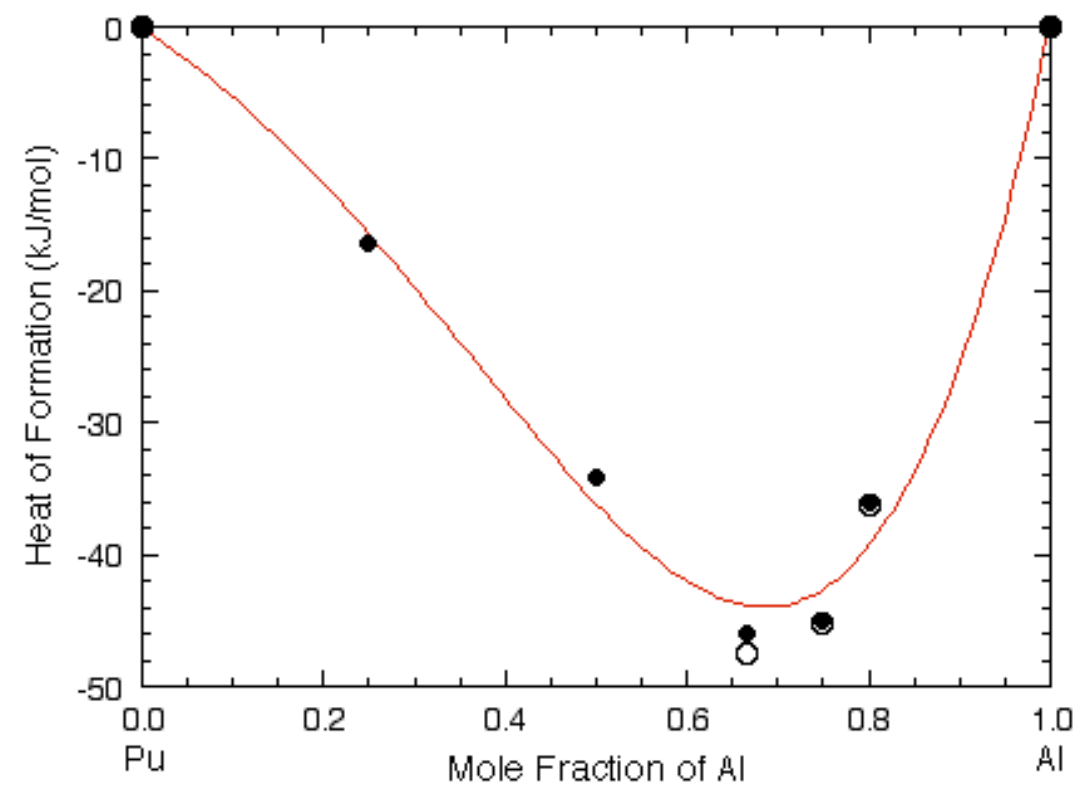

Figure 17. Heats of formation (filled circles) of the various compounds reported in Table 15 (in $\mathrm{kJ} / \mathrm{mol}$ ) resulting from the CALPHAD optimization for Pu-Al alloys. The reference states are $\alpha-\mathrm{Pu}$ and the fcc structure of Al. The solid line serves as a guide to the eye. The open circles correspond to the experimental results given in Refs. [42,65].

Based on the present assessment of the $\mathrm{Pu}-\mathrm{Al}$ phase diagram, the existence of a low lying eutectoid invariant line in the Pu-rich region is consistent with the Russian experimental findings $[44,45]$ that have been at the origin of the controversy between the USA and the former Soviet Union. The eutectoid decomposition of $\delta \rightarrow \alpha+\mathrm{Pu}_{3} \mathrm{Al}$ at $\mathrm{T}=95.02{ }^{\circ} \mathrm{C}$ and at a composition of $\mathrm{x}_{\mathrm{Ga}}=0.0862$ (about $1.03 \mathrm{wt} . \% \mathrm{Al}$ ) is predicted within CALPHAD compares remarkably well to the experimental extrapolation of $93{ }^{\circ} \mathrm{C}$ and $0.089[44,45]$. Although Adler drew similar conclusions $\left(\mathrm{T}=62{ }^{\circ} \mathrm{C}\right.$ and $\mathrm{x}_{\mathrm{Ga}}=0.092$ ) [49], the underlying thermodynamics is quite arguable since his assessment was only performed for the Pu-rich portion of the phase diagram, thus leading to quite inaccurate numerical expressions for the Gibbs energies. Magnified regions of the Russian and assessed phase diagrams are shown in Fig. 18.

Hence, to conclude this part of the work, a complete thermodynamic assessment of the Pu-Al phase diagram in the entire range of alloy composition was performed. Satisfactorily agreement 
between experiment and theory was achieved for the upper part of the phase diagram, and for the energetics that has been derived from the optimization process. From the prediction of a lowtemperature eutectoid phase decomposition in the Pu-rich portion of the phase diagram, we conclude that the $\delta$ (fcc) solid solution is metastable at room temperature, and the decomposition of $\delta$ into $\alpha-\mathrm{Pu}$ and the ordered phase $\mathrm{Pu}_{3} \mathrm{Al}$ is expected under equilibrium conditions. In other words, a thermodynamic driving does exist and is promoting phase decomposition even if it occurs at low temperatures. As in the Pu-Ga case, since large volume changes and a ductile to brittle transition ( $\delta$ is ductile whereas $\alpha$ and $\mathrm{Pu}_{3} \mathrm{Al}$ are brittle) accompany this decomposition and can compromise the structural integrity of the alloy (because of dimensional distortions), kinetic studies in the Pu-rich region of the phase diagram become extremely relevant. Finally, on a more technical side, if new qualified experimental results or ab initio data are made available, the optimization procedure can be used to fine-tune the present results.
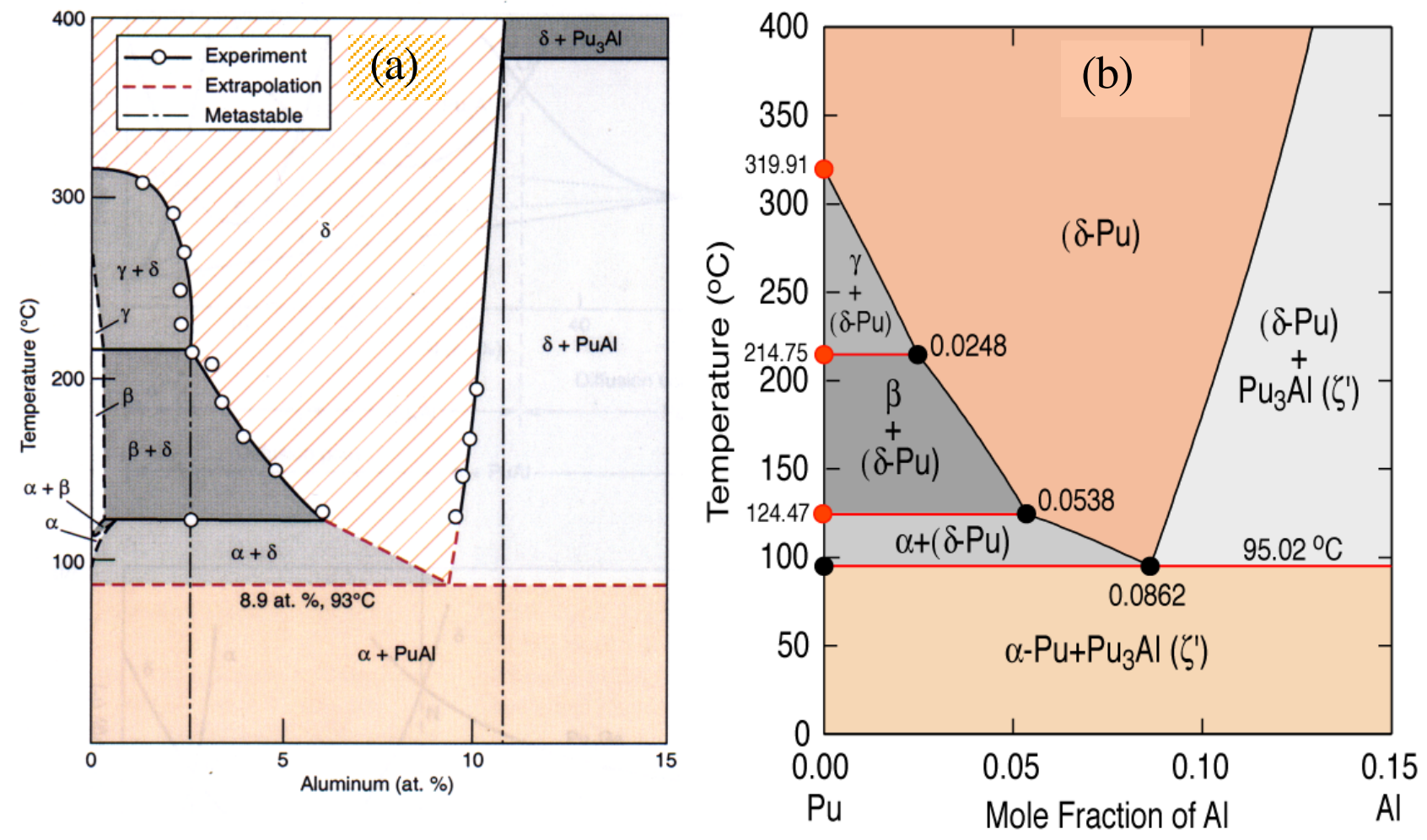

Figure 18. Russian [44,45] (a) and calculated (b) phase diagrams of the Pu-Al system (to be compared with the U.S. equilibrium phase diagram shown in Fig. 15). Experimental results are indicated by empty circles in (a), and in (a), the red dashed lines indicate extrapolation whereas in (b) the analogous lines refer to calculated lines.

In the low-temperature $\mathrm{Pu}$-rich portion of the phase diagram, it is interesting to calculate the $\mathrm{T}_{0}$ curve that corresponds to the locus of the intersection of the Gibbs energy curves of two specific phases versus composition (Cf. section IV.3 and Fig. 11). In the present case, $\alpha(\beta$ or $\gamma$ ) and $\delta$ are the phases that will be considered. The calculation of the $\mathrm{T}_{0}$ curve proceeds by defining at each selected 
temperature $\left(\mathrm{T}_{0}\right)$ the alloy composition $\mathrm{c}_{0}$ associated with equal free energies for two selected phases. The results are presented in Fig. 19 and the polynomial fits are expressed as follows:

$$
\begin{aligned}
& T_{0}^{\alpha-\delta}=156.64-11,322.449 x_{A l}+180,489.838 x_{A l}^{2}-5,451,608.005 x_{A l}^{3} \\
& T_{0}^{\beta-\delta}=273.91-42,259.360 x_{A l}+1,399,640.238 x_{A l}^{2}-131,164,050.147 x_{A l}^{3} \\
& T_{0}^{\gamma-\delta}=320.07-74,760.373 x_{A l}+12,924,947.037 x_{A l}^{2}-3,160,802,832.475 x_{A l}^{3}
\end{aligned}
$$

where $\mathrm{x}_{\mathrm{Al}}$ is the mole fraction of $\mathrm{Al}$.

The results displayed in Fig. 19 for the $T_{0}^{\alpha-\delta}$ curve confirm those obtained from the approximate relation given by Eq. (16) and data from Refs. [49,56].

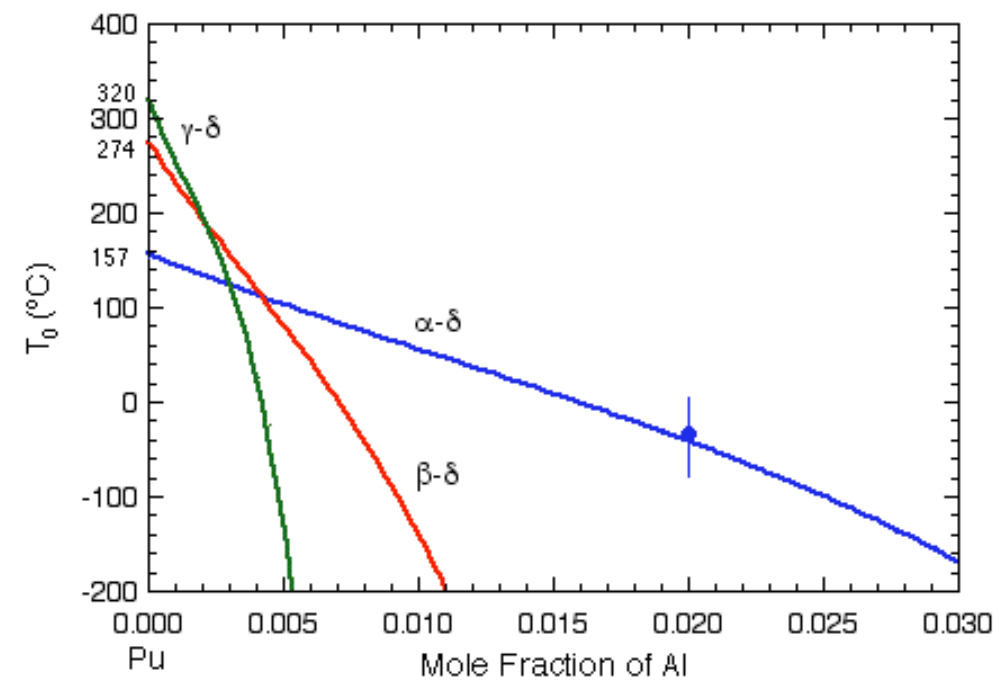

Figure 19. $\mathrm{T}_{0}$ versus mole fraction of $\mathrm{Al}$ for the $\alpha-\delta$ (blue), $\beta-\delta$ (red), and $\gamma-\delta$ (green) phases of $\mathrm{Pu}-\mathrm{Al}$ alloys. The dot with the experimental error bars are obtained from Eq. (15) $[49,56]$.

Finally, the applicability of a universal relationship mentioned at the end of section IV.3 to eutectoid transformations in the $\mathrm{Pu}-\mathrm{Al}$ alloy system has been tested and the results have been reported in Table 9. It was confirmed that relation (20) can be used experimentally as well as in theoretical modeling.

In conclusion, the phase diagram of the $\mathrm{Pu}-\mathrm{Al}$ binary system has been carefully assessed with CALPHAD methodology, and the results will be used to study the thermodynamics of higher-order systems with confidence. As in the case of pure $\mathrm{Pu}$, a wealth of information has been collected during the assessment, among others, all the thermodynamic functions, and in particular Gibbs energy, enthalpy, entropy, heat capacity, and also heats of transformation and $\mathrm{T}_{0}$ data. This study fully confirmed the existence of an eutectoid reaction taking place at low temperature in the Pu-rich part of the phase diagram as was proposed by the team from the Soviet Union during the Cold War era. If thermodynamic equilibrium could be reached, this would have important consequences since the $\alpha$ phase of pure $\mathrm{Pu}$ and the $\mathrm{Pu}_{3} \mathrm{Al}$ compound are brittle, and also because of the important change in volume between the fcc $(\delta)$ solid solution and $\alpha-\mathrm{Pu}$ and $\mathrm{Pu}_{3} \mathrm{Al}$. However based on the kinetic study performed for $\mathrm{Pu}-\mathrm{Ga}$ in section $\mathrm{X}$ it is anticipated that for kinetic reasons, this decomposition has very little chance to occur in $\mathrm{Pu}-\mathrm{Al}$ alloys as well. 


\section{THERMO-CHEMISTRY OF OTHER BINARY ALLOYS}

\section{VII.1. Thermo-Chemistry of AI-Fe Alloys}

The assessed phase diagram of the Al-Fe system shown in Fig. 20 has been described in Ref. [66]. As indicated in the published phase diagram, although the existence of the equilibrium intermediate phases is reliably established, work remains to be done to refine the reaction temperatures and the phase boundaries. The crystallographic information and the characteristics of the special points and invariant lines are summarized in Tables 17 and 18, respectively.

The thermodynamics of pure $\mathrm{Al}$ and Fe has been established by the SGTE group [28], and the Gibbs functions that describe these two unary phases are taken without modifications from Ref. [27]. For the Al-Fe system, we considered the data from the thermo-chemical database SSOL provided by the SGTE data group and summarized in Appendix C. Note that because of the lack of experimental information, the $\mathrm{Fe}_{3} \mathrm{Al}\left(\mathrm{DO}_{3}\right)$ ordered phase that exists at low temperature has not been considered in the CALPHAD assessment. The calculated phase diagram as obtained from Thermo-Calc is presented in Fig. 21. The characteristics of the special points and invariant lines given in Table 19 compare favorably with those known experimentally.

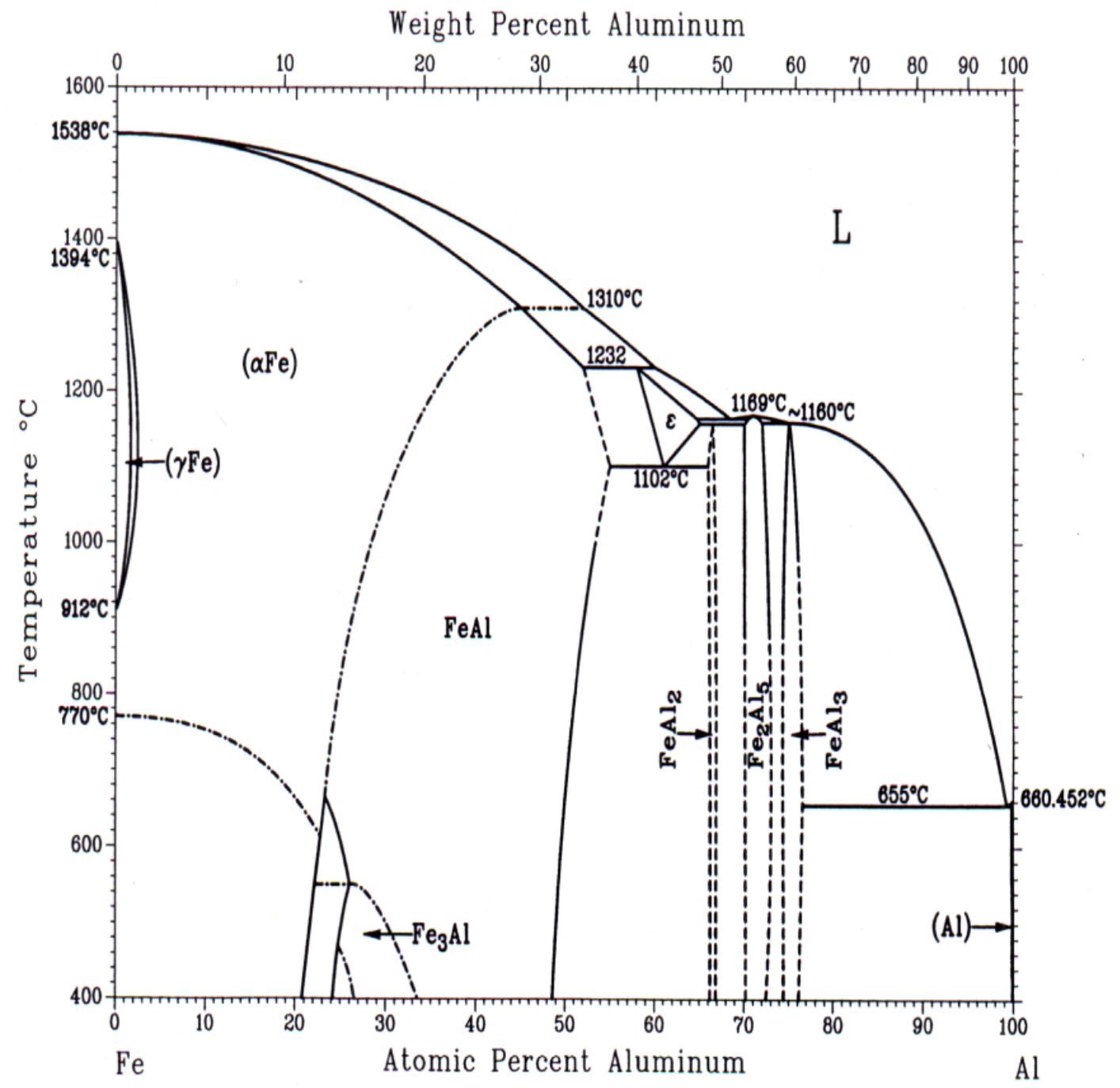

Figure 20. Experimental assessment of the phase diagram of the Fe-Al system (From Ref. [66]). 


\begin{tabular}{|l|c|c|c|c|c|}
\hline & at.\% Al & $\begin{array}{c}\text { Pearson } \\
\text { Symbol }\end{array}$ & $\begin{array}{c}\text { Space } \\
\text { Group }\end{array}$ & $\begin{array}{c}\text { Struktur } \\
\text {-bericht }\end{array}$ & Structure-type \\
\hline $\mathrm{Al}$ & 100 & $\mathrm{cF}^{*}$ & $\mathrm{Fm} \overline{3} \mathrm{~m}$ & $\mathrm{~A} 1$ & $\mathrm{Cu}$ \\
\hline $\mathrm{Al}_{3} \mathrm{Fe}$ & $74.5-76.6$ & $\mathrm{mC} 102$ & $\mathrm{C} 2 / \mathrm{m}$ & & \\
\hline $\mathrm{Al}_{5} \mathrm{Fe}{ }_{2}$ & $70-73$ & $\mathrm{oC}$ & $\mathrm{Cmcm}$ & & \\
\hline $\mathrm{Al}_{2} \mathrm{Fe}$ & $66-67$ & $\mathrm{aP} 18$ & $\mathrm{P} 1$ & & $\mathrm{Al}_{2} \mathrm{Fe}$ \\
\hline$\varepsilon$ & $58-65$ & $\mathrm{cl} 16 ?$ & & & \\
\hline $\mathrm{AlFe}_{3}$ & $23-34$ & $\mathrm{cF} 16$ & $\mathrm{Fm} \overline{3} \mathrm{~m}$ & $\mathrm{D} 0_{3}$ & $\mathrm{BiF}_{3}$ \\
\hline $\mathrm{AlFe}$ & $23-55$ & $\mathrm{cP} 8$ & $\mathrm{Pm} \overline{3} \mathrm{~m}$ & $\mathrm{~B} 2$ & $\mathrm{CsCl}$ \\
\hline$\gamma-\mathrm{Fe}$ & $0-1.3$ & $\mathrm{cF} 4$ & $\mathrm{Fm} \overline{3} \mathrm{~m}$ & $\mathrm{~A} 1$ & $\mathrm{Cu}$ \\
\hline$\alpha-\mathrm{Fe}$ & $0-45$ & $\mathrm{cI}$ & $\mathrm{Im} \overline{3} \mathrm{~m}$ & $\mathrm{~A} 2$ & $\mathrm{~W}$ \\
\hline
\end{tabular}

Table 17. Crystallo-graphic structures of the condensed phases in the Al-Fe binary system.

\begin{tabular}{|c|c|c|c|c|c|c|}
\hline Reaction Type & Reaction & \multicolumn{3}{|c|}{ At. \% Al } & T ( $\left({ }^{\circ}\right.$ Celsius) & T (Kelvin) \\
\hline Congruent & $\mathrm{L} \leftrightarrow \mathrm{Fe}_{2} \mathrm{Al}_{5}$ & & 71 & & 1169 & 1442 \\
\hline Peritectic & $\mathrm{L}+\mathrm{FeAl} \leftrightarrow \varepsilon$ & 60 & 52 & $\sim 58$ & 1232 & 1505 \\
\hline Peritectoid & $\varepsilon+\mathrm{Fe}_{2} \mathrm{Al}_{5} \leftrightarrow \mathrm{FeAl}_{2}$ & $\sim 65$ & $\sim 70$ & $\sim 66.5$ & 1156 & 1429 \\
\hline Eutectic & $\mathrm{L} \leftrightarrow \varepsilon+\mathrm{Fe}_{2} \mathrm{Al}_{5}$ & 68.5 & $\sim 70.5$ & $\sim 64.5$ & 1165 & 1438 \\
\hline & $\mathrm{L} \leftrightarrow \mathrm{FeAl}_{3}+(\mathrm{Al})$ & 99.1 & 76.6 & 99.97 & 655 & 928 \\
\hline Eutectoid & $\varepsilon \leftrightarrow \mathrm{FeAl}+\mathrm{FeAl}{ }_{2}$ & $\sim 61$ & $\sim 55$ & $\sim 66$ & 1102 & 1375 \\
\hline Unknown & $\mathrm{L}+\mathrm{Fe}_{2} \mathrm{Al}_{5} \leftrightarrow \mathrm{FeAl}_{3}$ & $\sim 75$ & $\sim 72$ & $\sim 75$ & $\sim 1160$ & $\sim 1433$ \\
\hline Allotropic & $(\gamma \mathrm{Fe}) \leftrightarrow(\alpha \mathrm{Fe})$ & & 0 & & 1394 & 1667 \\
\hline & $(\alpha \mathrm{Fe}) \leftrightarrow(\gamma \mathrm{Fe})$ & & 0 & & 912 & 1185 \\
\hline Melting & $\mathrm{L} \leftrightarrow \delta \mathrm{Fe}$ & & 0 & & 1538 & 1811 \\
\hline & $\mathrm{L} \leftrightarrow \mathrm{Al}$ & & 100 & & 660.452 & 933.452 \\
\hline
\end{tabular}

Table 18. Special points and invariant lines of the experimentally assessed Al-Fe phase diagram and their characteristics.

\begin{tabular}{|c|c|c|c|c|c|c|}
\hline Reaction Type & Reaction & \multicolumn{3}{|c|}{ At. \% Al } & T ( $\left({ }^{\circ}\right.$ Celsius $)$ & T (Kelvin) \\
\hline Congruent & $\mathrm{L} \leftrightarrow \mathrm{Fe}_{2} \mathrm{Al}_{5}$ & & 71.40 & & 1161.02 & 1434.02 \\
\hline Peritectic & $\mathrm{L}+(\alpha \mathrm{Fe}) \leftrightarrow \mathrm{Fe}_{4} \mathrm{Al}_{5}(\varepsilon)$ & 56.94 & 49.78 & 55.78 & 1236.77 & 1509.77 \\
\hline & $\mathrm{L}+\mathrm{Fe}_{2} \mathrm{Al}_{5} \leftrightarrow \mathrm{Fe}_{4} \mathrm{Al}_{13}$ & 75.66 & 71.40 & 75.30 & 1151.48 & 1424.58 \\
\hline Peritectoid & $\varepsilon+\mathrm{Fe}_{2} \mathrm{Al}_{5} \leftrightarrow \mathrm{FeAl}_{2}$ & & & & 1156 & 1429 \\
\hline Eutectic & $\mathrm{L} \leftrightarrow \mathrm{Fe}_{4} \mathrm{Al}_{5}(\varepsilon)+\mathrm{Fe}_{2} \mathrm{Al}_{5}$ & 69.01 & 63.87 & 71.40 & 1158.12 & 1431.12 \\
\hline & $\mathrm{L} \leftrightarrow \mathrm{Fe}_{4} \mathrm{Al}_{13}+(\mathrm{Al})$ & 99.11 & 76.28 & 99.98 & 654.12 & 927.12 \\
\hline Eutectoid & $\mathrm{Fe}_{4} \mathrm{Al}_{5}(\varepsilon) \leftrightarrow(\alpha \mathrm{Fe})+\mathrm{Fe} \mathrm{Al}_{2}$ & 56.68 & 51.00 & 66.30 & 1022.73 & 1295.73 \\
\hline & $\mathrm{FeAl}_{2} \leftrightarrow \mathrm{Fe}_{4} \mathrm{Al}_{5}(\varepsilon)+\mathrm{Fe}_{2} \mathrm{Al}_{5}$ & 66.30 & 63.74 & 71.40 & 1155.34 & 1428.34 \\
\hline Allotropic & $(\gamma \mathrm{Fe}) \leftrightarrow(\alpha \mathrm{Fe})$ & & 0 & & 1393 & 1666 \\
\hline & $(\alpha \mathrm{Fe}) \leftrightarrow(\gamma \mathrm{Fe})$ & & 0 & & 911.67 & 1184.67 \\
\hline Melting & $\mathrm{L} \leftrightarrow \delta \mathrm{Fe}$ & & 0 & & 1537.81 & 1810.81 \\
\hline & $\mathrm{L} \leftrightarrow \mathrm{Al}$ & & 100 & & 660.45 & 933.45 \\
\hline
\end{tabular}

Table 19. Special points and invariant lines of the calculated Al-Fe phase diagram as obtained from the CALPHAD assessment. 


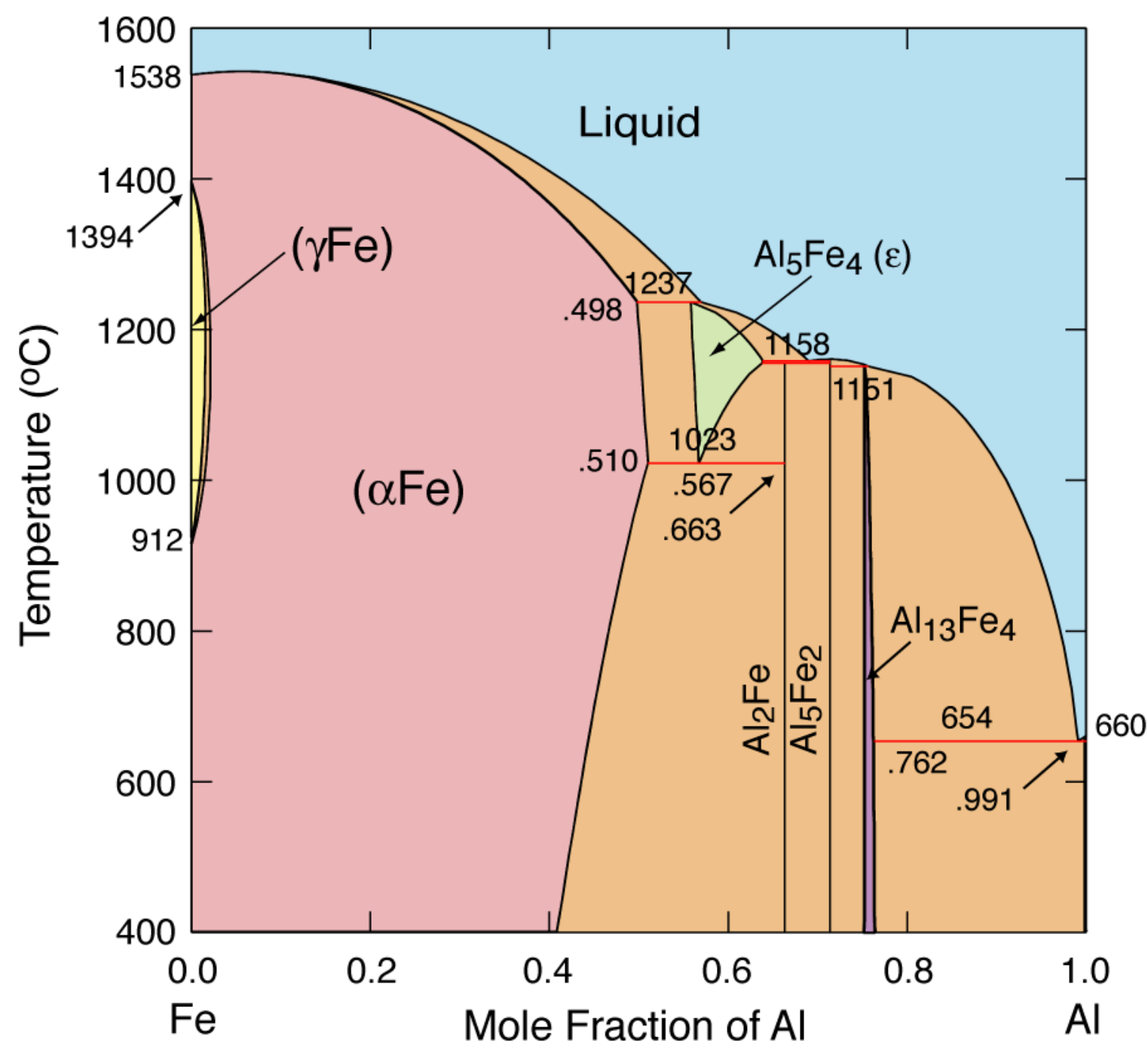

Figure 21. Calculated phase diagram of the Fe-Al system based on a CALPHAD assessment.

\section{VII.2. Thermo-Chemistry of Al-Ga Alloys}

The assessed phase diagram of Al-Ga shown in Fig. 22a has been described in Ref. [66]. The solubility of $\mathrm{Al}$ in $\mathrm{Ga}$ is very low whereas the solubility of $\mathrm{Ga}$ in $\mathrm{Al}$ is about 9 at.\%, with an eutectic reaction taking place at about $26.6{ }^{\circ} \mathrm{C}$. The special points of the Al-Ga system are summarized in Table 20.

\begin{tabular}{|c|c|c|c|c|c|c|}
\hline Reaction Type & Reaction & \multicolumn{3}{|c|}{ At. $\%$ Ga } & T ( $\left({ }^{\circ}\right.$ Celsius $)$ & T (Kelvin) \\
\hline Melting & $\mathrm{L} \leftrightarrow \mathrm{Al}$ & & 0 & & 660.452 & 933.452 \\
\hline & $\mathrm{L} \leftrightarrow \mathrm{Ga}$ & & 100 & & 29.7741 & 302.7741 \\
\hline Eutectic & $\mathrm{L} \leftrightarrow(\mathrm{Al})+(\mathrm{Ga})$ & $97.9 \pm 0.4$ & $\approx 9$ & $\approx 100$ & $26.6 \pm 0.1$ & 299.6 \\
\hline
\end{tabular}

Table 20. Special points and invariant lines of the Fe-Ga phase diagram and their characteristics.

The thermodynamics of pure $\mathrm{Al}$ and $\mathrm{Ga}$ has been established by the SGTE group [28], and the Gibbs functions that describe these two unary phases are taken without modifications from Ref. [27]. For the Al-Ga system, we considered the data from the thermo-chemical database SSOL provided by 
the SGTE data group and summarized in Appendix C. The calculated phase diagram, as obtained from Thermo-Calc, is presented in Fig. 22b. The characteristics of the calculated invariant line and special points compare favorably with those given in Table 20 .
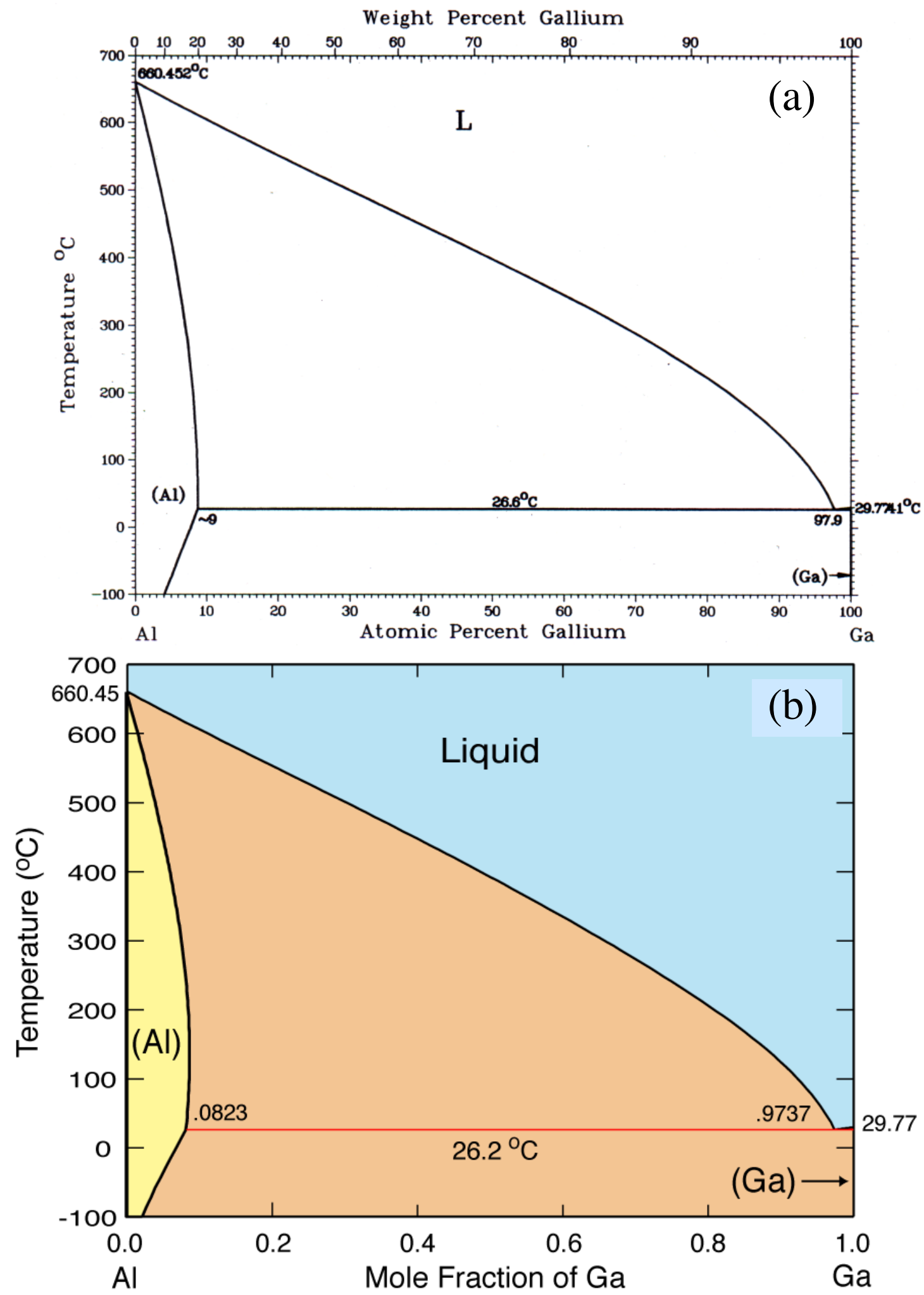

Figure 22. Phase Diagrams of the Al-Ga system: (a) experimentally assessed (taken from Ref. [66]), and (b) results of calculations based on a CALPHAD assessment. 


\section{VII.3. Thermo-Chemistry of Fe-Ga Alloys}

The assessed phase diagram of Fe-Ga reported in Ref. [66] is primarily based on the work of Koster and Godecke [67]. Let us first review the various phases that one has to consider for assessing the phase diagram of Fe-Ga in the whole range of alloy composition. Besides the endpoints, there are two solution phases, denoted $\alpha$ (bcc) and $\gamma$ (fcc), and four compounds, namely (in increasing Ga composition): $\mathrm{Fe}_{3} \mathrm{Ga}, \mathrm{Fe}_{6} \mathrm{Ga}_{5}, \mathrm{Fe}_{3} \mathrm{Ga}_{4}$, and $\mathrm{FeGa}_{3}$. Note that in the following, although the first three of these compounds exhibit limited solubility, they will be treated as line compounds. A summary of all existing phases in the Fe-Ga phase diagram with crystallographic information is given in Table 21.

\begin{tabular}{|c|c|c|c|c|c|}
\hline & at.\% Ga & $\begin{array}{l}\text { Pearson } \\
\text { Symbol }\end{array}$ & $\begin{array}{l}\text { Space } \\
\text { Group }\end{array}$ & $\begin{array}{c}\text { Struktur- } \\
\text { bericht }\end{array}$ & $\begin{array}{c}\text { Structure- } \\
\text { type }\end{array}$ \\
\hline$\gamma$-Fe & $0-2.8$ & $\mathrm{cF} 4$ & $\mathrm{Fm} \overline{3} \mathrm{~m}$ & $\overline{\mathrm{A} 1}$ & $\overline{\mathrm{Cu}}$ \\
\hline$\alpha-\mathrm{Fe}$ & $0-36$ & $\mathrm{cl} 2$ & $\operatorname{Im} \overline{3} \mathrm{~m}$ & $\overline{\mathrm{A} 2}$ & $\overline{\mathrm{W}}$ \\
\hline$\alpha^{\prime}$ & $31.5-47.5$ & $\mathrm{cP} 2$ & $\operatorname{Pm} \overline{3} \mathrm{~m}$ & $\overline{\mathrm{B} 2}$ & $\mathrm{CsCl}$ \\
\hline$\alpha^{\prime}$ & $22.8-32.1$ & cF16 & $\mathrm{Fm} \overline{3} \mathrm{~m}$ & & \\
\hline$\alpha^{\prime}$, & $22.8-25.9$ & cF16 & $\mathrm{Fm} \overline{3} \mathrm{~m}$ & $\overline{\mathrm{D} 0_{3}}$ & $\overline{\mathrm{BiF}_{3}}$ \\
\hline$\alpha-\mathrm{Fe}_{3} \mathrm{Ga}$ & $26.2-29.2$ & $\overline{c P 4}$ & $\operatorname{Pm} \overline{3} \mathrm{~m}$ & $\overline{\mathrm{L} 1_{2}}$ & $\mathrm{AuCu}_{3}$ \\
\hline$\beta-\mathrm{Fe}_{3} \mathrm{Ga}$ & $26-29$ & hP8 & $\mathrm{P}_{3} / \mathrm{mmc}$ & $\overline{\mathrm{D} 0_{19}}$ & $\mathrm{Ni}_{3} \mathrm{Sn}$ \\
\hline$\alpha-\mathrm{Fe}_{6} \mathrm{Ga}_{5}$ & $44.5-45.5$ & $\mathrm{mC} 44$ & $\mathrm{C} 2 / \mathrm{m}$ & & $\mathrm{Al}_{8} \mathrm{Cl}_{5}$ \\
\hline$\beta-\mathrm{Fe}_{6} \mathrm{Ga}_{5}$ & $44.5-45.5$ & hR26 & $\mathrm{R} \overline{3} \mathrm{~m}$ & & \\
\hline $\mathrm{Fe}_{3} \mathrm{Ga}_{4}$ & $56.5-58$ & $\mathrm{mC} 42$ & $\mathrm{C} 2 / \mathrm{m}$ & & \\
\hline $\mathrm{FeGa}_{3}$ & 75 & tP16 & $\mathrm{P} \overline{4} \mathrm{n} 2$ & & $\mathrm{CoGa}_{3}$ \\
\hline $\mathrm{Ga}$ & 100 & $\mathrm{oC} 8$ & Cmca & A11 & $\mathrm{Ga}$ \\
\hline
\end{tabular}

Table 21. Crystallographic structures of the condensed phases in the Fe-Ga binary system.

The thermodynamics of pure Fe and Ga has been well established by the SGTE group [28], and the Gibbs functions that describe these two unary phases are taken without modifications from Ref. [27]. Since the thermo-chemical database SSOL provided by the SGTE data group had no information on the Fe-Ga system, the assessment of the available experimental data in the entire range of alloy composition was required. Two sets of data have been considered. First, phase diagram information that includes phase boundaries, invariant lines and special points has been tabulated for the assessment. The data are summarized in Fig. 23a and Table 22. Second, because of the similarity between the Al-Fe and Ga-Fe phase diagrams, the thermo-chemistry of Al-Fe has been considered for the initial definition of the enthalpies of formation of the various compounds found in the case of $\mathrm{Fe}$ Ga with additional input on the heat of formation of the Fe-Ga compounds from Ref. [68] for the optimization.

\begin{tabular}{|c|c|c|c|c|c|c|}
\hline Reaction Type & Reaction & \multicolumn{3}{|c|}{ At. $\%$ Ga } & T ( $\left({ }^{\circ}\right.$ Celsius $)$ & T (Kelvin) \\
\hline Congruent & $\alpha^{\prime \prime} \leftrightarrow \beta \mathrm{FF}_{3} \mathrm{Ga}$ & & 27.5 & & 680 & 953 \\
\hline Peritectic & $\mathrm{L}+\alpha^{\prime} \leftrightarrow \mathrm{Fe}_{3} \mathrm{Ga}_{4}$ & 61.8 & 47.5 & 57 & 906 & 1173 \\
\hline & $\mathrm{L}+\mathrm{Fe}_{3} \mathrm{Ga}_{4} \leftrightarrow \mathrm{FeGa}_{3}$ & 81.5 & 58 & 75 & 824 & 1097 \\
\hline & $\mathrm{L}+\mathrm{FeGa}_{3} \leftrightarrow(\alpha \mathrm{Ga})$ & 99.9 & 75 & $?$ & 34 & 307 \\
\hline
\end{tabular}




\begin{tabular}{|c|c|c|c|c|c|c|}
\hline Peritectoid & $\alpha^{\prime}+\mathrm{Fe}_{3} \mathrm{Ga}_{4} \leftrightarrow \beta \mathrm{Fe}_{6} \mathrm{Ga}_{5}$ & 42 & 56.5 & 45 & 800 & 1073 \\
\hline & $\beta \mathrm{Fe}_{6} \mathrm{Ga}_{5}+\mathrm{Fe}_{3} \mathrm{Ga}_{4} \leftrightarrow \alpha \mathrm{Fe}_{6} \mathrm{Ga}_{5}$ & 46 & 56.5 & 46 & 778 & 1051 \\
\hline & $\beta \mathrm{Fe}_{3} \mathrm{Ga}_{+}+\mathrm{Fe}_{6} \mathrm{Ga}_{5} \leftrightarrow \alpha \mathrm{Fe}_{3} \mathrm{Ga}$ & 29 & 44.5 & 29.2 & 619 & 892 \\
\hline Eutectoid & $\beta \mathrm{Fe}_{6} \mathrm{Ga}_{5} \leftrightarrow \alpha^{\prime}+\alpha \mathrm{Fe}_{6} \mathrm{Ga}_{5}$ & 44.5 & 41 & 44.5 & 770 & 1043 \\
\hline & $\alpha^{\prime} \leftrightarrow \beta \mathrm{Fe}_{3} \mathrm{Ga}+\mathrm{Fe}_{6} \mathrm{Ga}_{5}$ & 33.5 & 29 & 44.5 & 625 & 898 \\
\hline & $\beta \mathrm{Fe}_{3} \mathrm{Ga}^{\prime} \leftrightarrow \alpha^{\prime}+\alpha \mathrm{Fe}_{3} \mathrm{Ga}$ & 26 & 25 & 26.2 & 605 & 878 \\
\hline & $\alpha \prime \prime \leftrightarrow(\alpha \mathrm{Fe})+\alpha \mathrm{Fe}_{3} \mathrm{Ga}$ & 23.4 & 20.6 & 26.3 & 588 & 861 \\
\hline Allotropic & $(\gamma \mathrm{Fe}) \leftrightarrow(\alpha \mathrm{Fe})$ & & 0 & & 1394 & 1667 \\
\hline & $(\alpha \mathrm{Fe}) \leftrightarrow(\gamma \mathrm{Fe})$ & & 0 & & 912 & 1185 \\
\hline Melting & $\mathrm{L} \leftrightarrow \alpha \mathrm{Fe}$ & & 0 & & 1538 & 1811 \\
\hline & $\mathrm{L} \leftrightarrow \alpha \mathrm{Ga}$ & & 100 & & 29.7741 & 302.7741 \\
\hline
\end{tabular}

Table 22. Special points and invariant lines of the Fe-Ga phase diagram and their characteristics.

The final results of the optimization are reported in Appendix C, and the calculated phase diagram, as obtained from Thermo-Calc, is presented in Fig. 23b. The overall features of the calculated and experimental phase boundaries compare favorably.

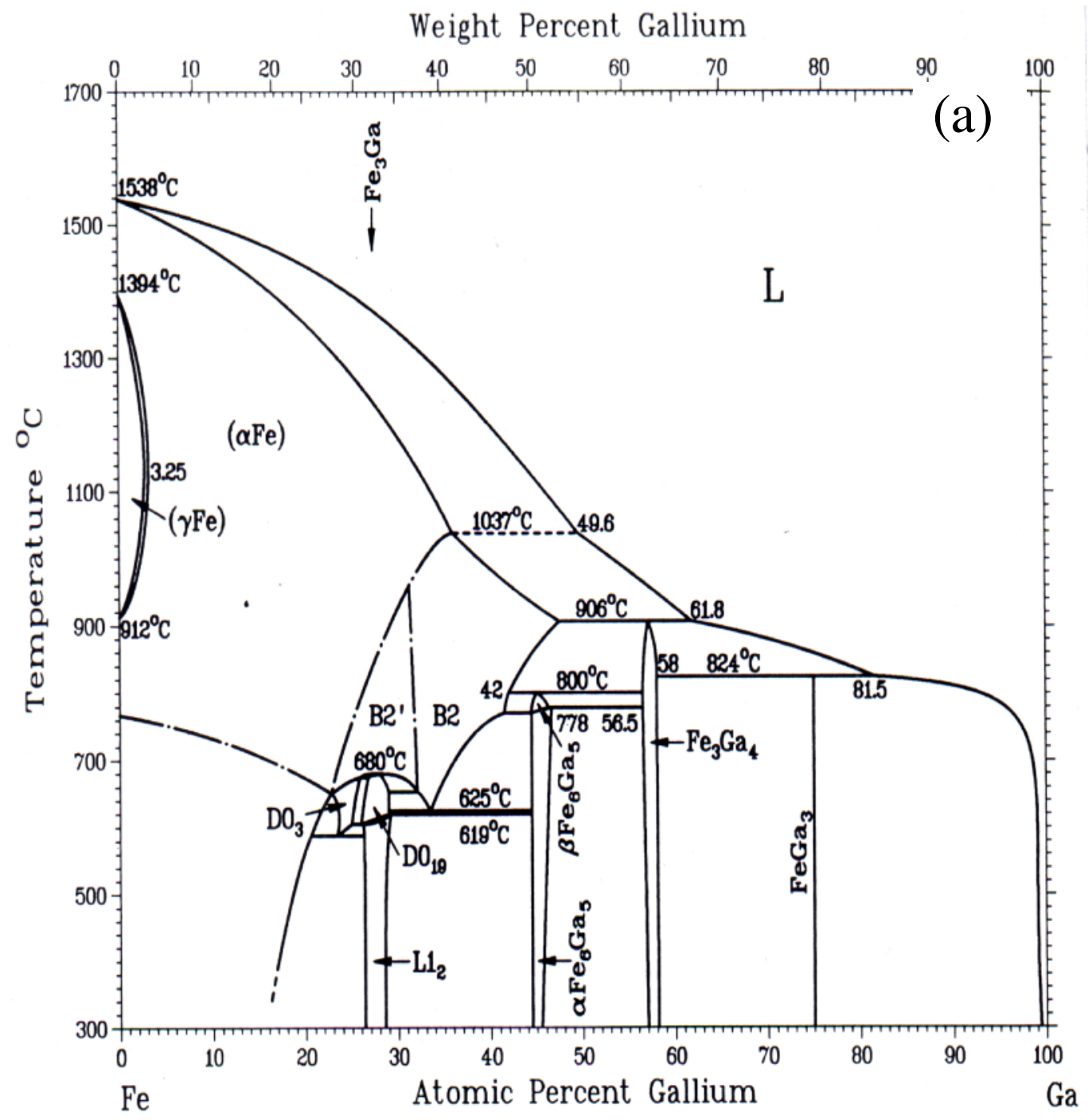




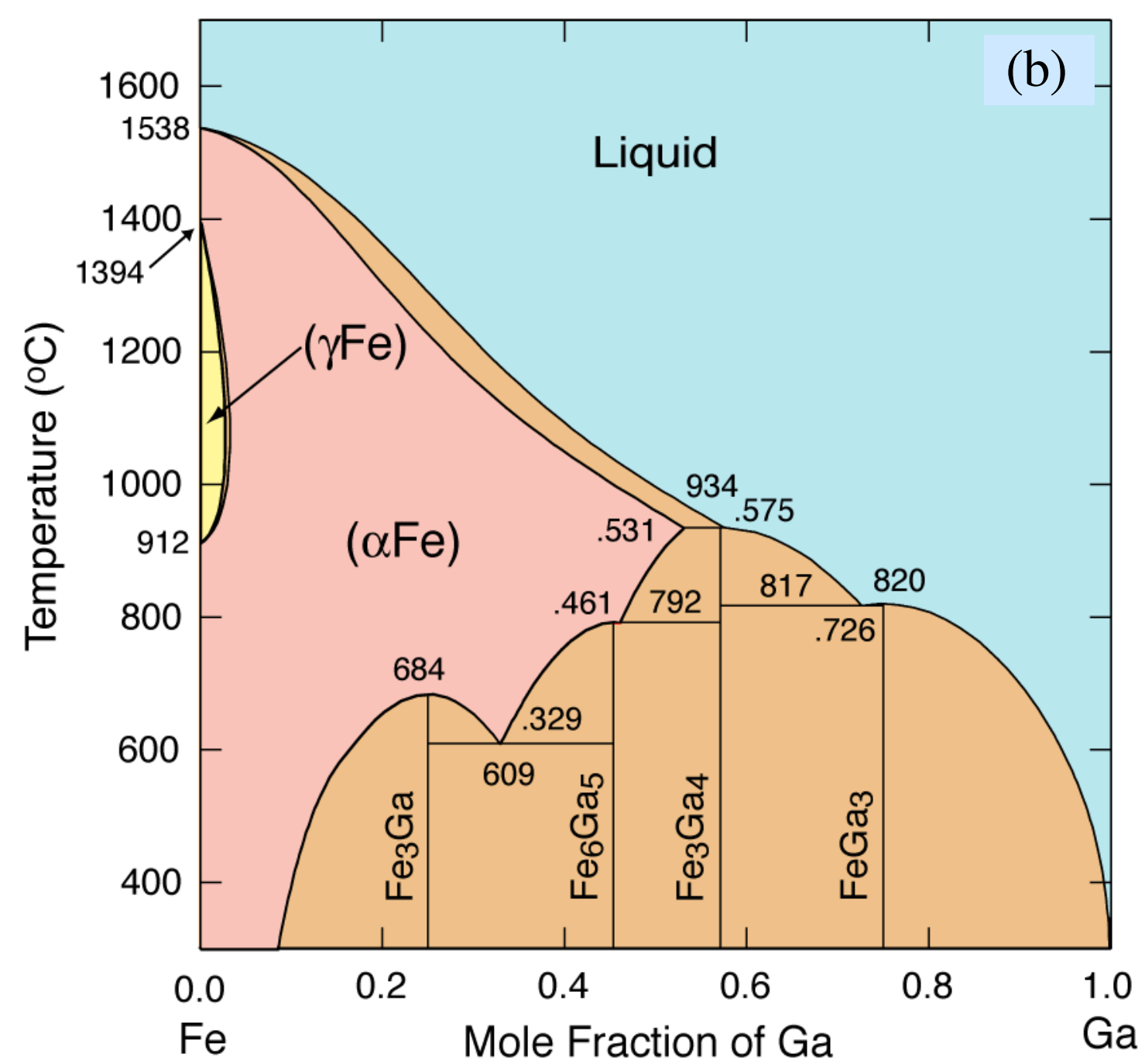

Figure 23. Phase Diagram of the Fe-Ga system: (a) experimentally assessed (taken from Ref. [66]), and (b) results of calculations based on a CALPHAD assessment.

\section{THERMO-CHEMISTRY OF HIGHER-ORDER COMPONENT ALLOYS}

To study ternary alloy systems ternary interactions between the species are neglected and the thermodynamics is given by the Muggianu expression [32] recalled in the third expression of Eqs. (6). Hence, from the assessed thermodynamics of the binary sub-systems, the calculation of all the thermodynamic functions, isothermal sections of ternary phase diagrams, and so-called property diagrams (i.e., phase fraction versus temperature) can directly proceed for ternary systems. In cases where known specific ternary compounds were observed experimentally, additional assessments were performed to evaluate their associated Gibbs energy. In the following we will consider the two ternary alloys $\mathrm{Fe}-\mathrm{Ga}-\mathrm{Pu}$ and $\mathrm{Al}-\mathrm{Fe}-\mathrm{Pu}$. In the isothermal sections of ternary phase diagrams that will be presented, the invariant lines and the tie lines will be colored in red and green, respectively. We will also present the liquidus surface projections within the entire composition range that could be confirmed experimentally by differential thermal analysis (DTA). 


\section{VIII.1. Thermo-Chemistry of Fe-Ga-Pu Alloys}

In the case of this alloy system, no additional compound that specifically forms in the ternary alloy is experimentally known, hence the ternary phase diagram is constructed from the three binary subsystems that were presented in Figs. 8, 23b, and 14a for $\mathrm{Pu}-\mathrm{Ga}, \mathrm{Fe}-\mathrm{Ga}$, and Fe-Pu, respectively, as summarized in Fig. 24. In the following we present isothermal sections of the phase diagram at various temperatures in Figs. 25 and 26.

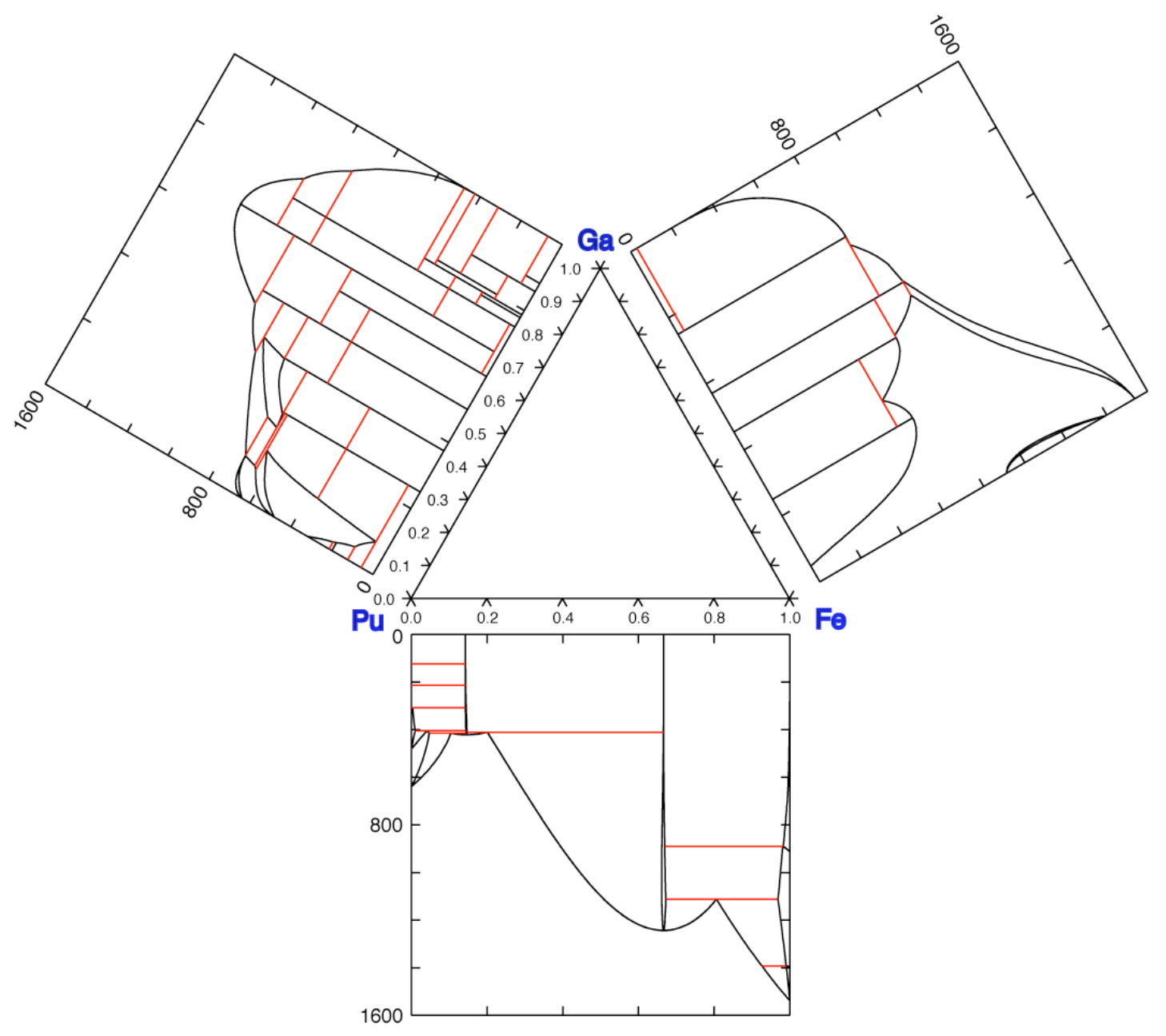

Figure 24. Summary of the CALPHAD assessment of the three binary phase diagrams that constitute the ternary $\mathrm{Pu}-\mathrm{Ga}-\mathrm{Fe}$ alloy phase diagram.

From what we know of the binary subsystems, it is clear that the first solid phase to form is pure iron with the bec structure $(\alpha \mathrm{Fe})$ followed by the compound $\mathrm{PuGa}_{2}$ as shown in Fig. 25. Also note that whatever the composition of $\mathrm{Fe}$ is (even at the ppm level) in a Pu-rich alloy of $\mathrm{Pu}-\mathrm{Ga}-\mathrm{Fe}$, the isothermal section of the ternary phase diagram displayed in Fig. 26 at the lowest temperature of 300 ${ }^{\circ} \mathrm{C}$ (right panel) clearly indicates that precipitation of $\mathrm{Pu}_{6} \mathrm{Fe}$ is unavoidable. Since $\mathrm{Pu}_{6} \mathrm{Fe}$ is a complex phase ( $\mathrm{D} 2_{\mathrm{c}}$ of $\mathrm{MnU}_{6}$ type), it is very likely that the nucleation of this phase will occur in a region where fluctuation of alloy composition exists, in particular at grain boundaries (as is usually the case with the formation of complex phases). 

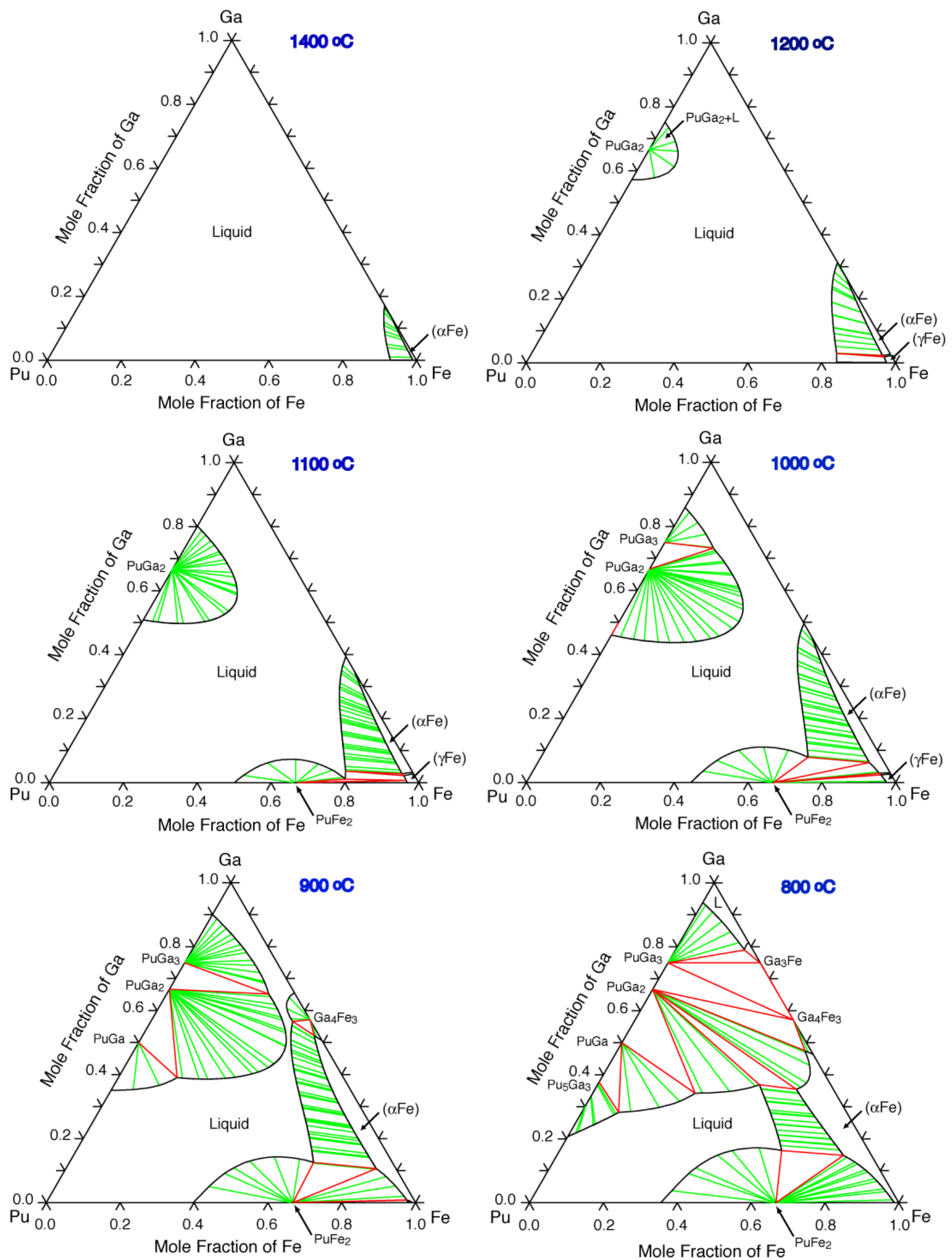

Figure 25. Calculated isothermal sections of the ternary Pu-Ga-Fe alloy phase diagram at 1400, $1300,1100,1000,900$, and $800{ }^{\circ} \mathrm{C}$. 

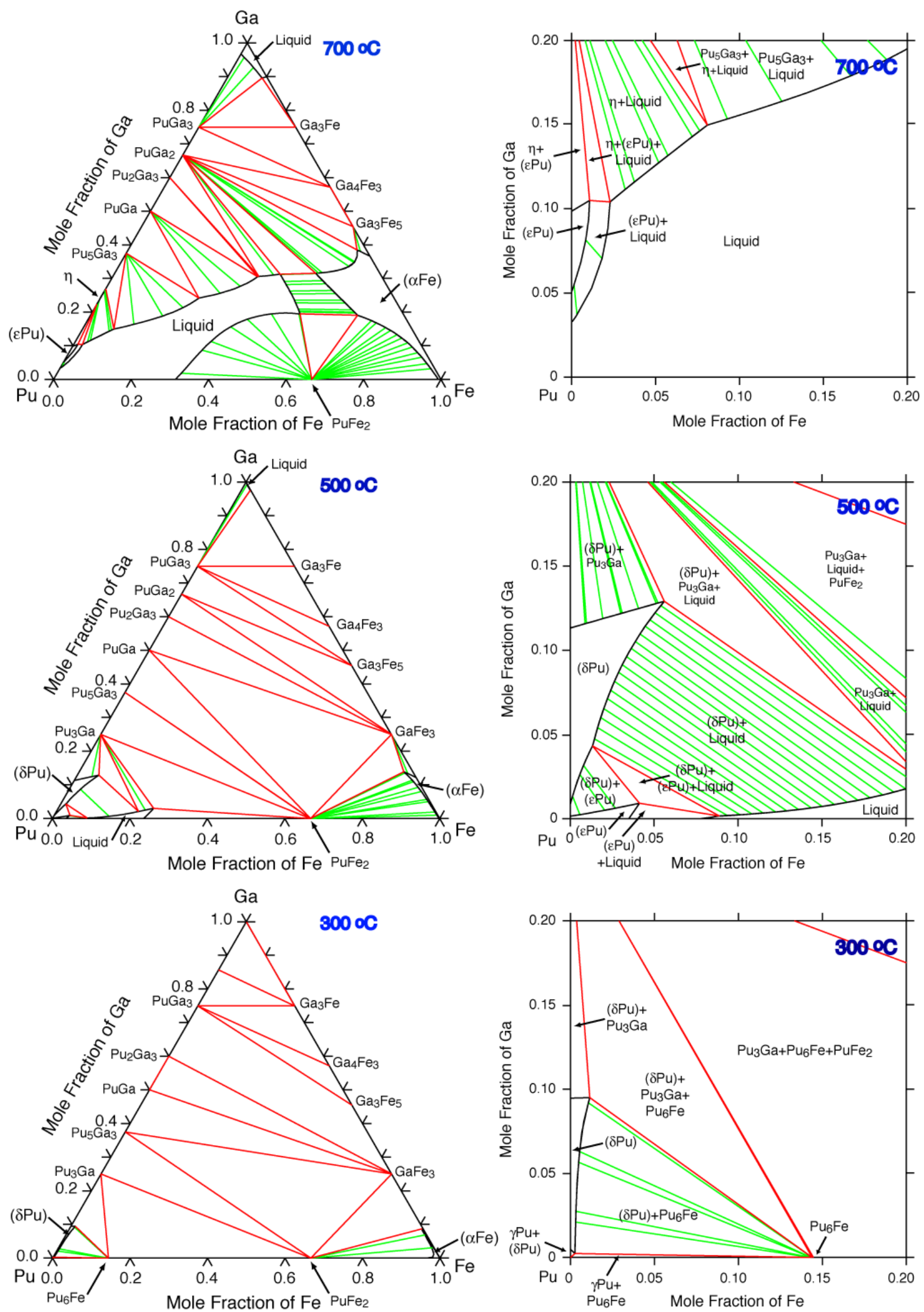

Figure 26. Calculated isothermal sections (left panels) and detailed representations around the $\mathrm{Pu}$ rich corner (right panels) of the ternary $\mathrm{Pu}-\mathrm{Ga}-\mathrm{Fe}$ alloy phase diagram at 700,500 , and $300{ }^{\circ} \mathrm{C}$. 
To complete the study of this ternary phase diagram we present in Fig. 27 the liquidus-surface projection with the primary fields of crystallization. The diagram shows the isotherms between 500 and $1200{ }^{\circ} \mathrm{C}$ as lines gradually colored from red to yellow. The liquidus valleys that separate the various fields of primary crystallization are shown as blue solid lines with arrows indicating the direction towards lower temperature. The liquidus surface is dominated by three large fields of primary crystallization of the two compounds $\mathrm{PuGa}_{2}$ and $\mathrm{PuFe}_{2}$ and of the bcc solid solution, and to some extent of the PuGa compound. These four fields converge toward a flat region in the temperature range $625-750{ }^{\circ} \mathrm{C}$ (cf. numbers 3 and 4 in Fig. 27 around 30 at. $\% \mathrm{Ga}$ and 50 at.\% Fe). The first phase to form, as discussed above, is $\alpha \mathrm{Fe}$ (bcc) at $1538^{\circ} \mathrm{C}$. The two compounds $\mathrm{PuGa}_{2}$ and $\mathrm{PuFe}_{2}$ shape the liquidus surface since they melt congruently at $1262^{\circ} \mathrm{C}$ and $1243{ }^{\circ} \mathrm{C}$, respectively. The last drop of liquid is located at about $411{ }^{\circ} \mathrm{C}$ at the composition $\mathrm{Pu}_{0.7933} \mathrm{Fe}_{0.2167}$, and ultimately at about $29.77^{\circ} \mathrm{C}$ at pure $\mathrm{Ga}$. Note that liquidus-surface projections are in general useful to predict the solidification path of alloys starting from a specific composition.

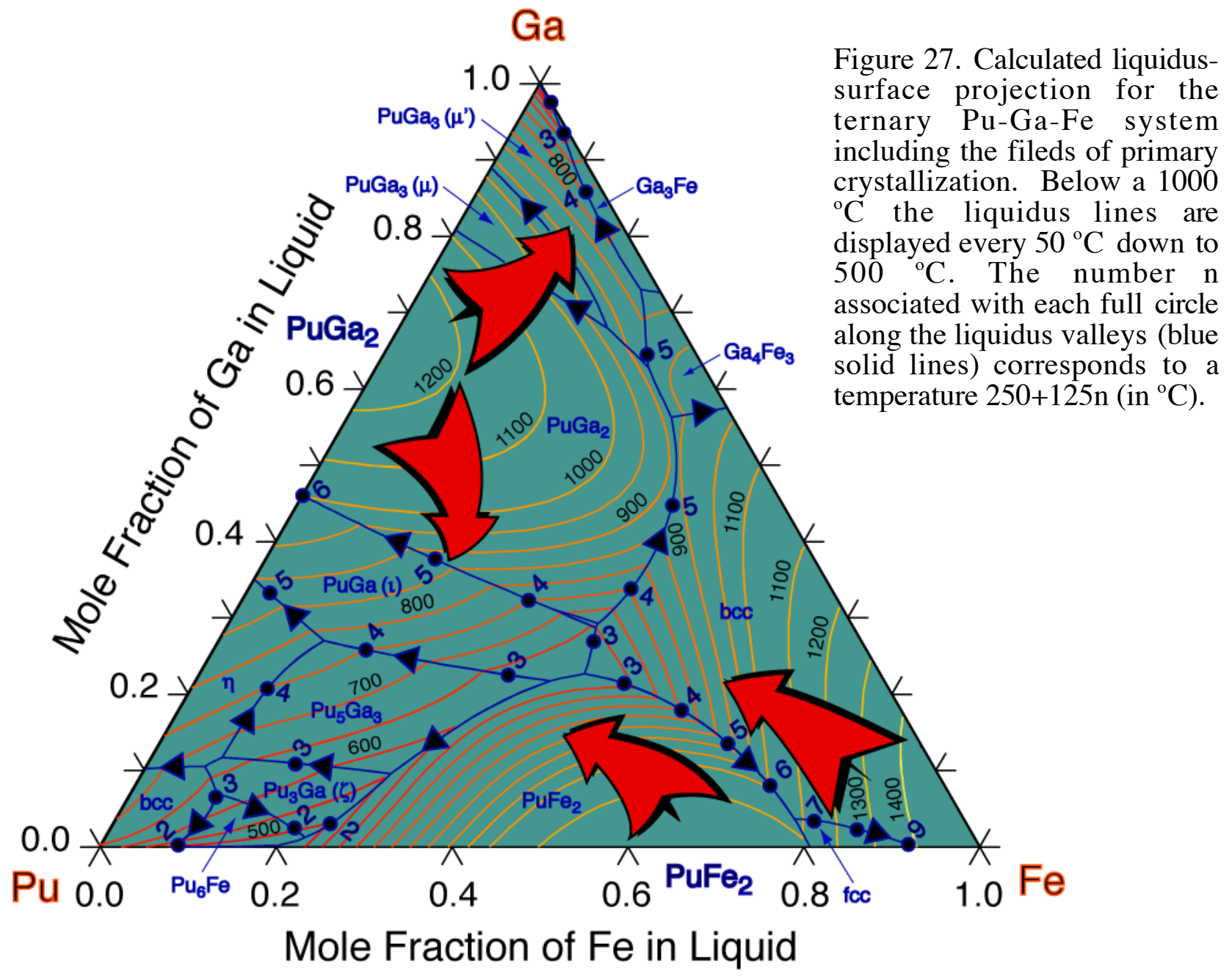

For the ternary Pu-Ga-Fe alloys, it is also interesting to plot property diagrams for specific alloy compositions. Such a diagram indicates the amount of phases formed (phase fractions) as a function of temperature at equilibrium, and corresponds to an incursion along a vertical line in the ternary phase 
diagram. As an illustration of these calculations, we show in Fig. 28, the property diagram associated with each of the three following alloy compositions: $\mathrm{Pu}_{0.90} \mathrm{Ga}_{0.05} \mathrm{Fe}_{0.05}, \mathrm{Pu}_{0.94} \mathrm{Ga}_{0.05} \mathrm{Fe}_{0.01}$, and $\mathrm{Pu}_{0.979} \mathrm{Ga}_{0.020} \mathrm{Fe}_{0.001}$. In all cases, the first solid phase to appear from the melt slightly below $700{ }^{\circ} \mathrm{C}$ is the bcc $(\varepsilon-\mathrm{Pu})$ phase followed by the fcc $(\delta-\mathrm{Pu})$ phase. At temperatures below $400{ }^{\circ} \mathrm{C}$, the ordered compound $\mathrm{Pu}_{6} \mathrm{Fe}$ appears, and finally at low temperatures below $100{ }^{\circ} \mathrm{C}$, there is a three-phase equilibrium among $(\alpha-\mathrm{Pu}), \mathrm{Pu}_{6} \mathrm{Fe}$, and $\mathrm{Pu}_{3} \mathrm{Ga}$. Note that the amount of each phase obviously depends on the alloy composition as seen in Fig. 28. These calculations that can be repeated for any alloy composition find useful applications during alloy processing to specify beneficial heat treatments that avoid the formation of undesirable phases, or to generate with a given phase fraction a specific compound or solid solution.
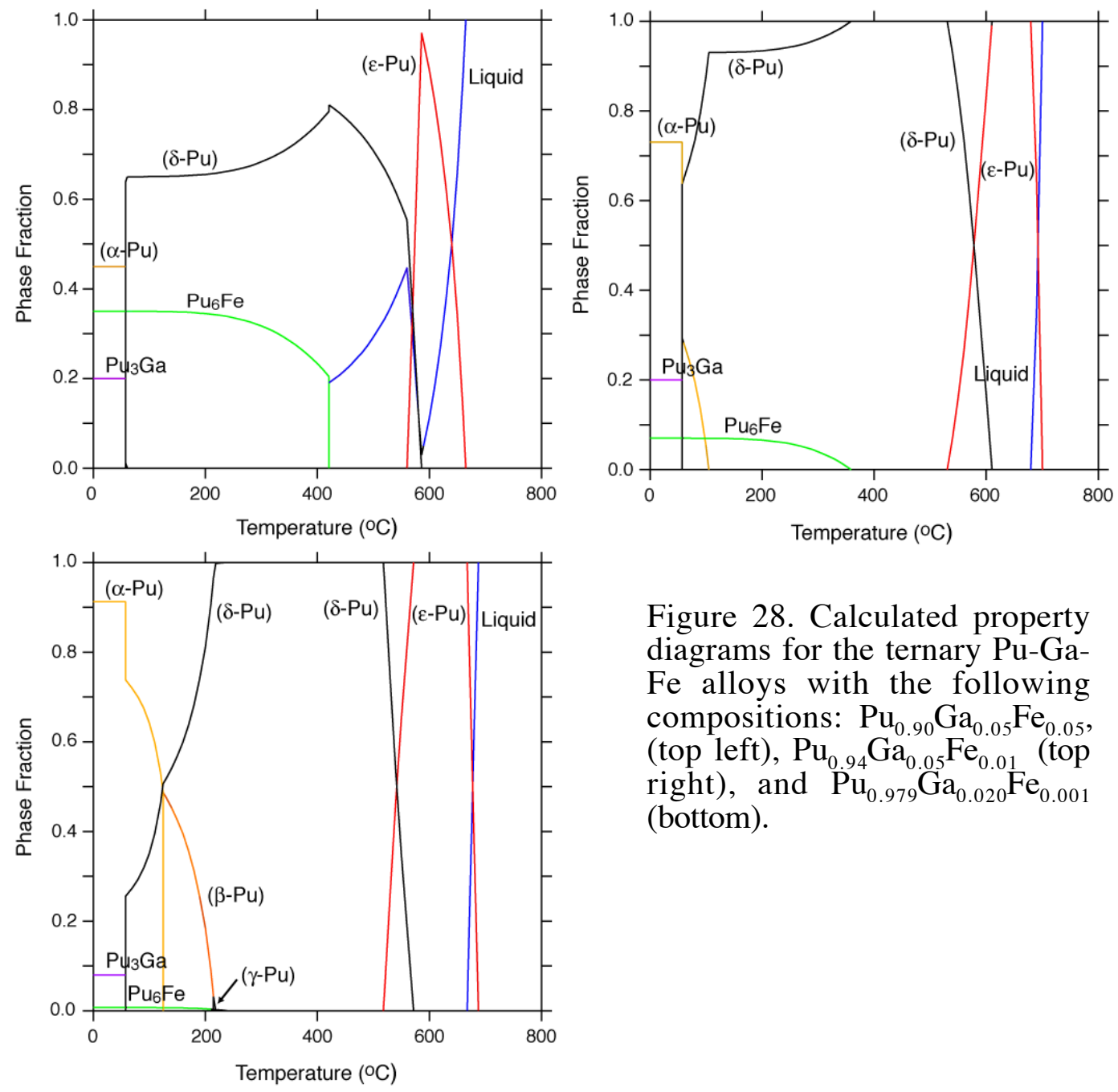

Figure 28. Calculated property diagrams for the ternary Pu-Ga$\mathrm{Fe}$ alloys with the following compositions: $\mathrm{Pu}_{0.90} \mathrm{Ga}_{0.05} \mathrm{Fe}_{0.05}$, (top left), $\mathrm{Pu}_{0.94} \mathrm{Ga}_{0.05} \mathrm{Fe}_{0.01}$ (top right), and $\mathrm{Pu}_{0.979} \mathrm{Ga}_{0.020} \mathrm{Fe}_{0.001}$ (bottom).

\section{VIII.2. Thermo-Chemistry of Al-Fe-Pu Alloys}

In the case of this alloy system, one additional compound that specifically forms in the ternary alloy has been reported in the literature at the composition PuFeAl [69]. Hence the ternary phase diagram is constructed from the thermodynamic information of the three binary subsystems that were presented in Figs. 16, 21, and 14a for Pu-Al, Fe-Al, and Fe-Pu, respectively, as summarized in Fig. 29. 
For PuFeAl the results of the simple assessment are given in Appendix $\mathrm{C}$ after having assumed no solubility for this compound (line compound). In the following we present isothermal sections of the phase diagram at various temperatures in Figs. 30 and 31.

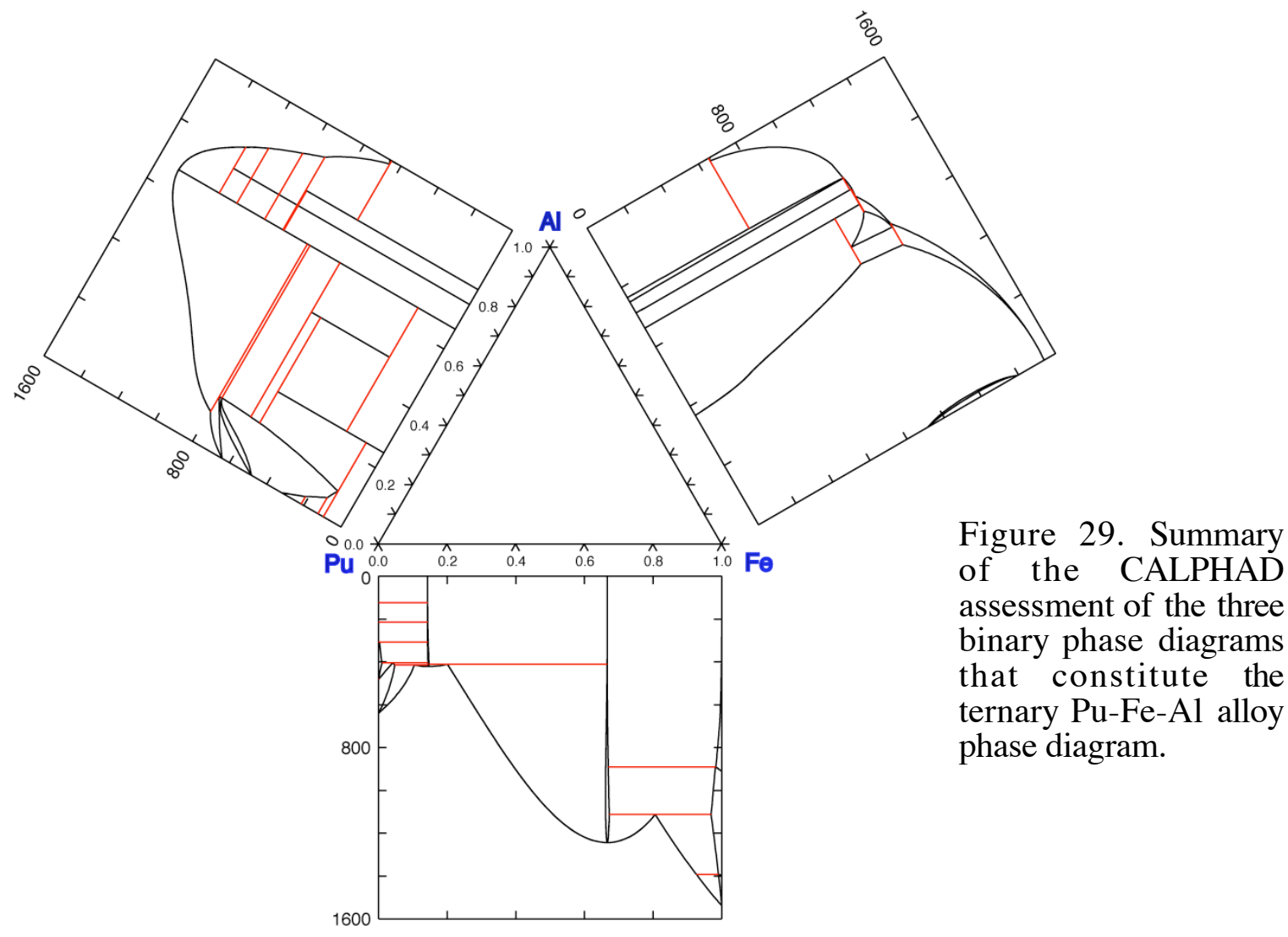

From what we know of the binary subsystems, it is clear that the first solid phase to form is pure iron with the bcc structure $(\alpha \mathrm{Fe})$ followed by the compound $\mathrm{PuAl}_{2}$ as shown in Fig. 30. Also note that whatever the composition of $\mathrm{Fe}$ is (even at the ppm level) in a $\mathrm{Pu}$-rich alloy of $\mathrm{Pu}-\mathrm{Fe}-\mathrm{Al}$, the isothermal section of the ternary phase diagram displayed in Fig. 31 at the lowest temperature of 300 ${ }^{\circ} \mathrm{C}$ (right panel) clearly indicates that precipitation of $\mathrm{Pu}_{6} \mathrm{Fe}$ is unavoidable.
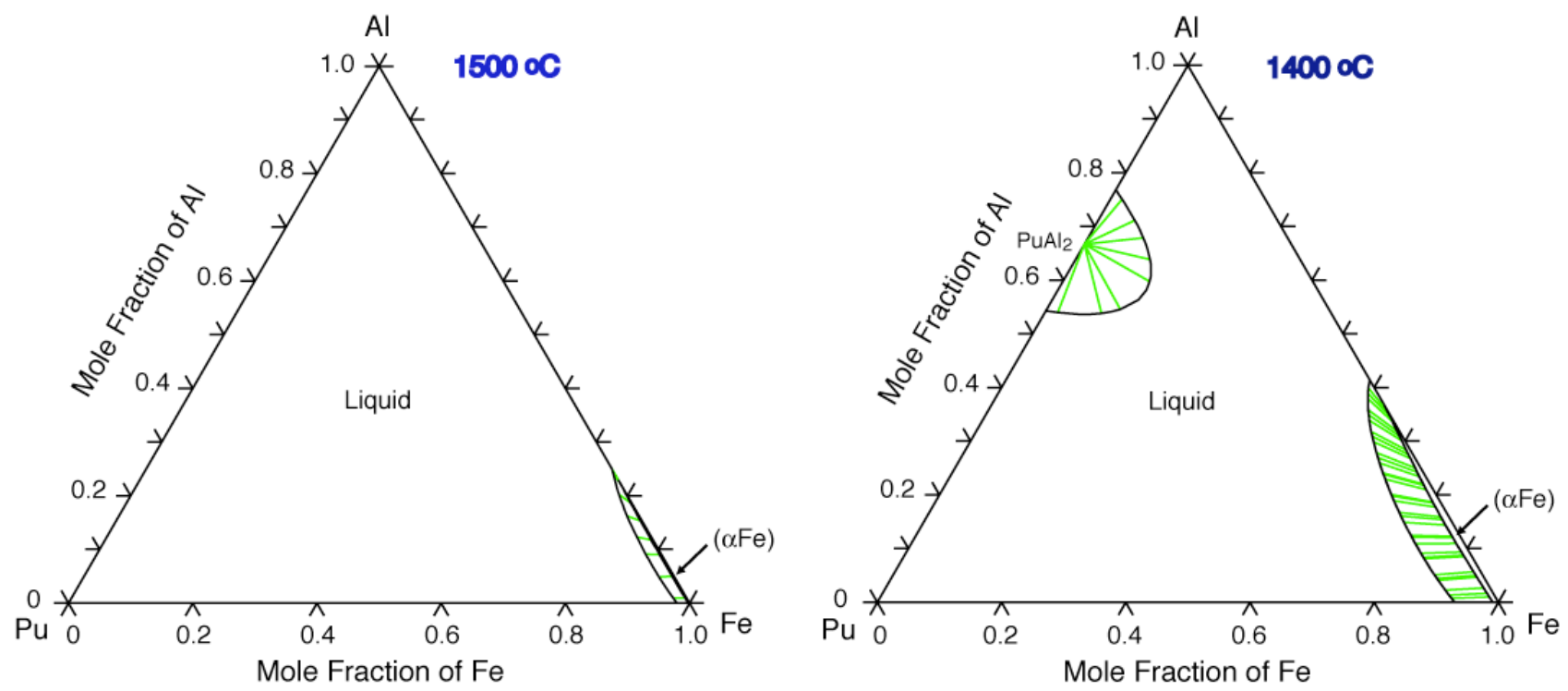

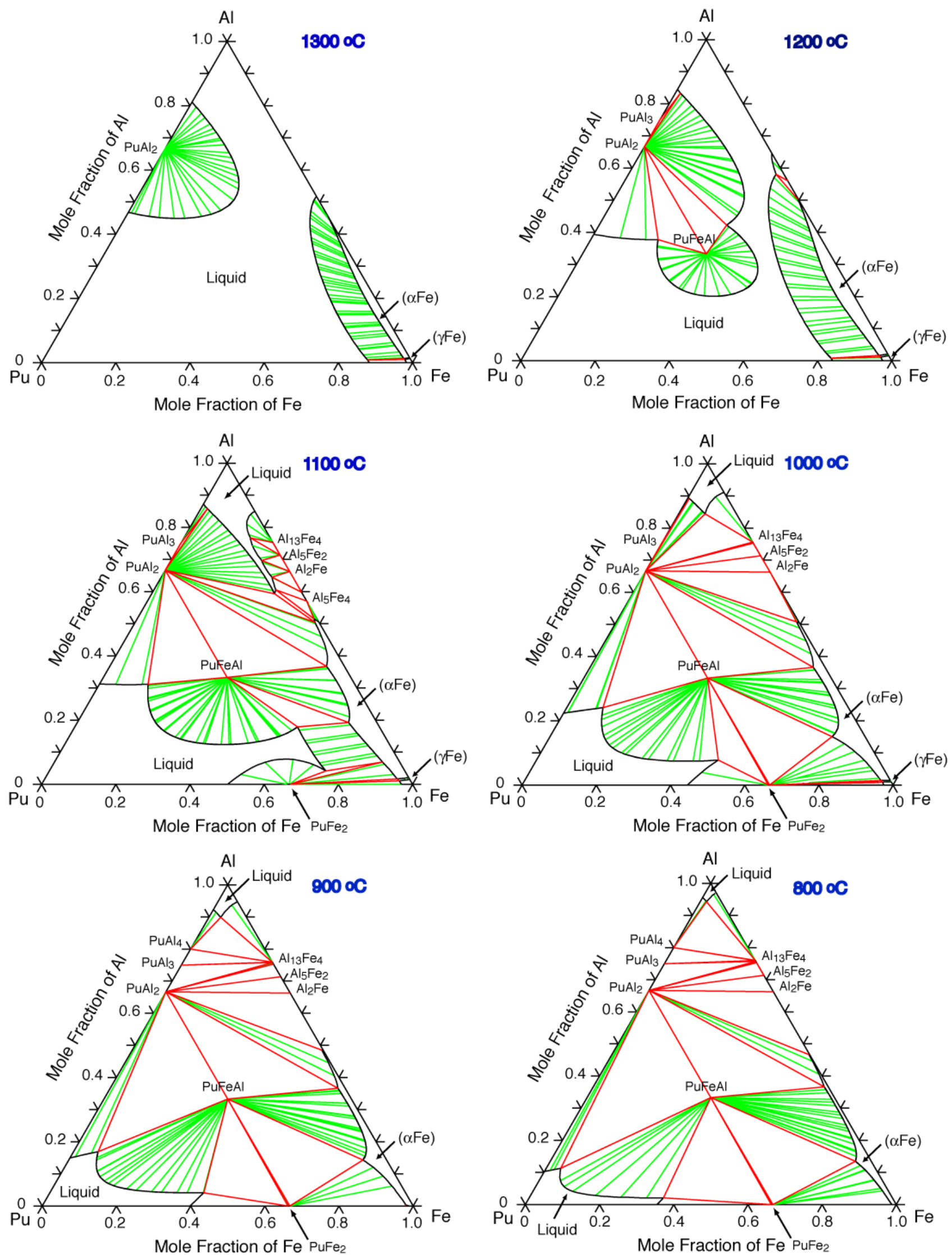

Figure 30. Calculated isothermal sections of the ternary Pu-Fe-Al alloy phase diagram at 1500, $1400,1300,1100,1000,900$, and $800{ }^{\circ} \mathrm{C}$. 

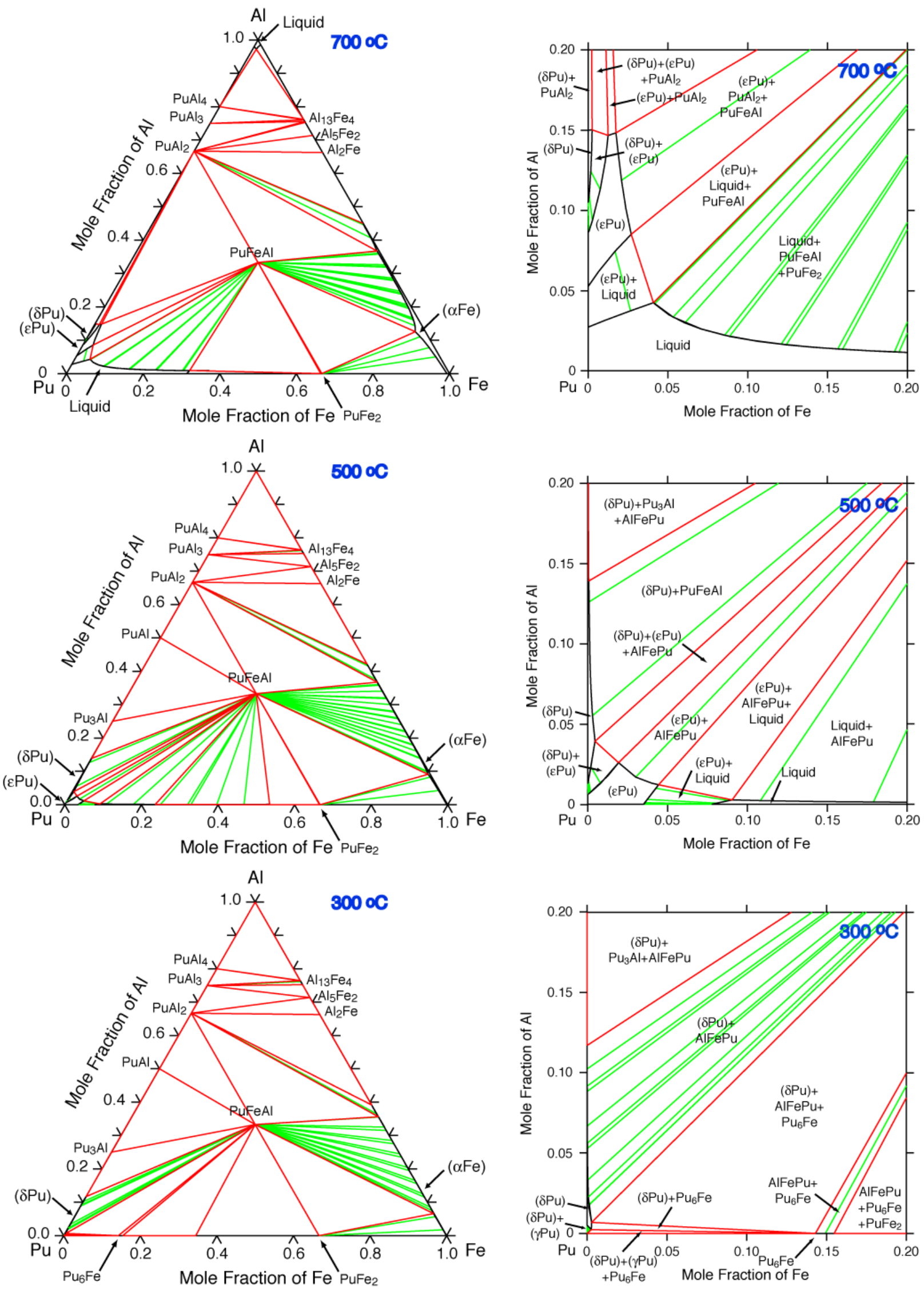

Figure 31. Calculated isothermal sections (left panels) and detailed representations around the $\mathrm{Pu}$ rich corner (right panels) of the ternary Pu-Fe-Al alloy phase diagram at 700, 500, and $300^{\circ} \mathrm{C}$. 
As for the $\mathrm{Pu}-\mathrm{Ga}-\mathrm{Fe}$ case, since $\mathrm{Pu}_{6} \mathrm{Fe}$ is a complex phase ( $\mathrm{D} 2_{\mathrm{c}}$ of $\mathrm{MnU}_{6}$ type), it is very likely that the nucleation of this phase will occur in a region where fluctuation of alloy composition exists, in particular at grain boundaries (as is usually the case with the formation of complex phases).

To complete the study of this ternary phase diagram we present in Fig. 32 the liquidus-surface projection with the primary fields of crystallization. The diagram shows the isotherms between 650 and $1400{ }^{\circ} \mathrm{C}$ as lines gradually colored from red to yellow. The liquidus valleys that separate the various fields of primary crystallization are shown as blue solid lines with arrows indicating the direction towards lower temperature. The liquidus surface is dominated by three large fields of primary crystallization of the two compounds $\mathrm{PuAl}_{2}$ and $\mathrm{PuFeAl}$ and of the bec solid solution, and to some extent of the $\mathrm{PuFe}_{2}$ compound. These four fields converge toward a flat region around $1125{ }^{\circ} \mathrm{C}$ (cf. number 7 in Fig. 32 around 30 at.\% $\mathrm{Al}$ and 60 at.\% Fe). The first phase to form, as discussed above, is $\alpha \mathrm{Fe}$ (bcc) at $1538{ }^{\circ} \mathrm{C}$. The two compounds $\mathrm{PuAl}_{2}$ and $\mathrm{PuFe}_{2}$ shape the liquidus surface since they melt congruently at $1490{ }^{\circ} \mathrm{C}$ and $1243{ }^{\circ} \mathrm{C}$, respectively. The last drop of liquid is located at about $660{ }^{\circ} \mathrm{C}$ at pure $\mathrm{Al}$, and ultimately at the composition $\mathrm{Pu}_{0.7933} \mathrm{Fe}_{0.2167}$, at about $411{ }^{\circ} \mathrm{C}$.

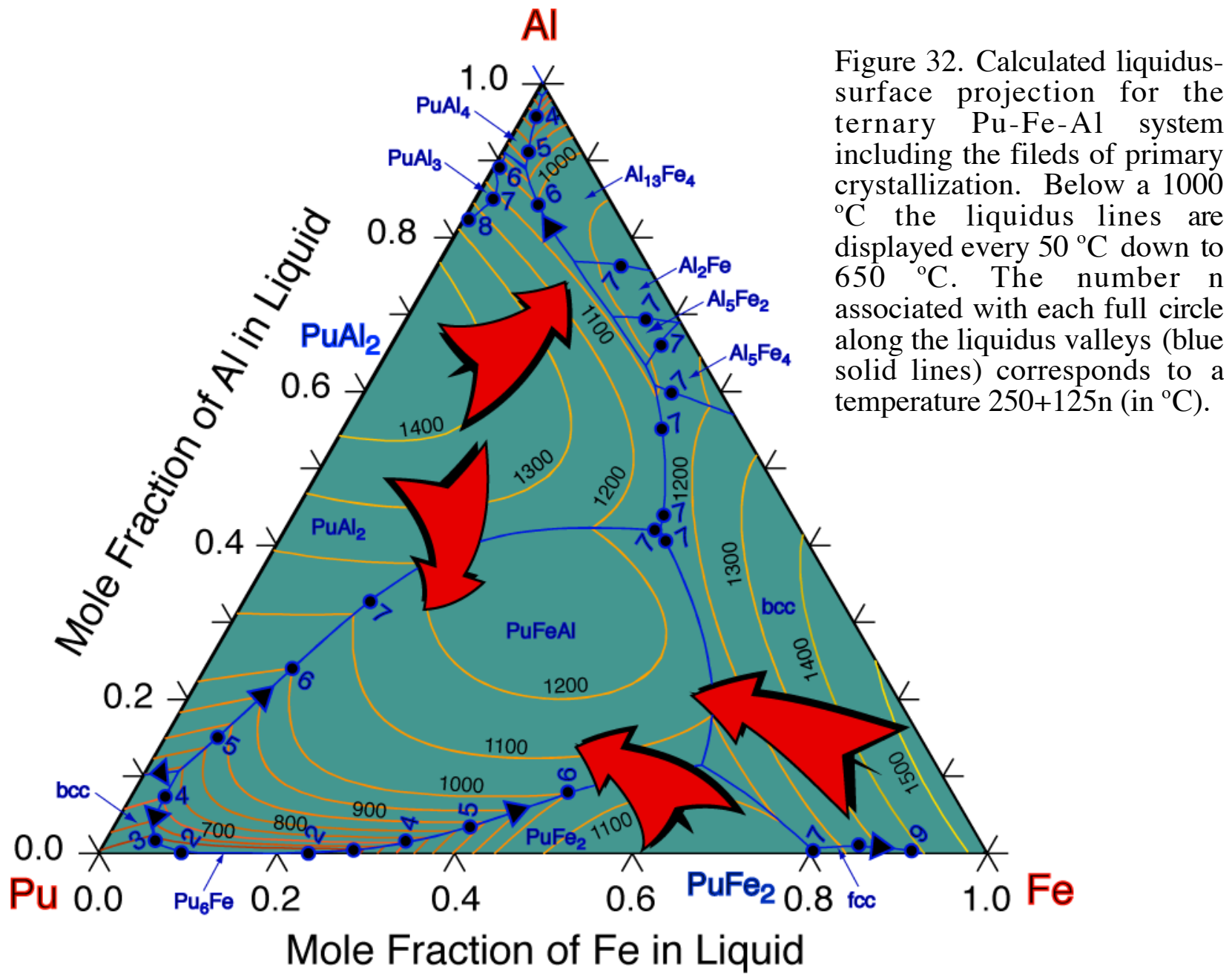

Finally, for the ternary $\mathrm{Pu}-\mathrm{Fe}-\mathrm{Al}$ alloys, it is also interesting to plot property diagrams for specific alloy compositions. As an illustration of these calculations, we show in Fig. 33, the property diagram 
associated with each of the three following alloy compositions: $\mathrm{Pu}_{0.90} \mathrm{Fe}_{0.05} \mathrm{Al}_{0.05}, \mathrm{Pu}_{0.94} \mathrm{Fe}_{0.01} \mathrm{Al}_{0.05}$, and $\mathrm{Pu}_{0.979} \mathrm{Fe}_{0.001} \mathrm{Al}_{0.020}$. In all cases, the first solid phase to appear from the melt slightly below $700{ }^{\circ} \mathrm{C}$ is the bcc $(\varepsilon-\mathrm{Pu})$ phase followed by the fcc $(\delta-\mathrm{Pu})$ phase. At low temperatures, the ordered compound $\mathrm{Pu}_{3} \mathrm{Al}$ is found in equilibrium with $(\alpha-\mathrm{Pu})$. It is worth mentioning that for the two highest Fe contents (0.05 and 0.01 at.\%), the compound PuFeAl, is found stable at low temperatures. Note that the amount of each phase obviously depends on the alloy composition as seen in Fig. 33.
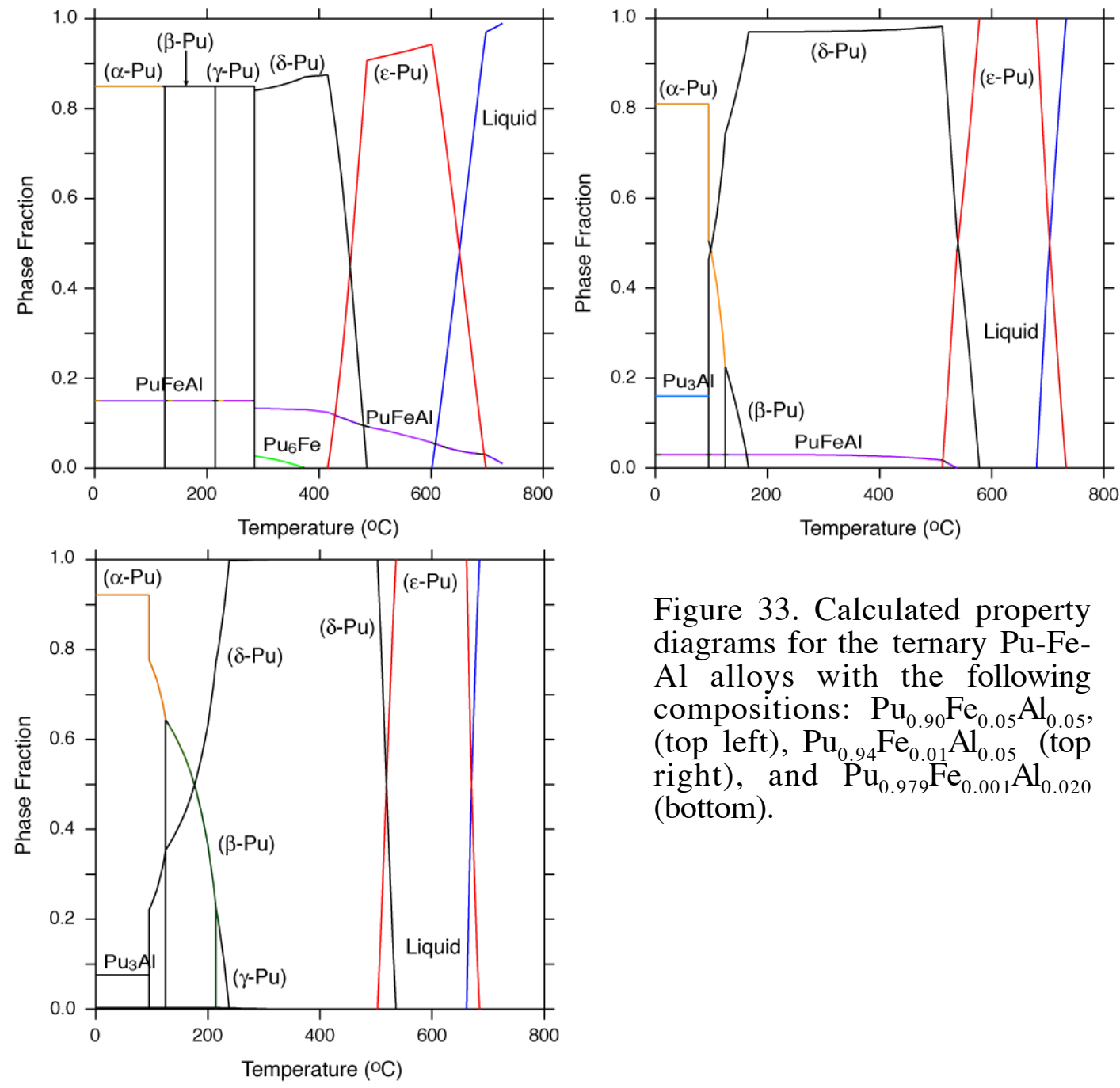

Figure 33. Calculated property diagrams for the ternary $\mathrm{Pu}-\mathrm{Fe}$ Al alloys with the following compositions: $\mathrm{Pu}_{0.90} \mathrm{Fe}_{0.05} \mathrm{Al}_{0.05}$, (top left), $\mathrm{Pu}_{0.94} \mathrm{Fe}_{0.01} \mathrm{Al}_{0.05}$ (top right), and $\mathrm{Pu}_{0.979} \mathrm{Fe}_{0.001} \mathrm{Al}_{0.020}$ (bottom).

\section{KINETICS OF PHASE TRANSFORMATIONS IN Pu-Ga ALLOYS}

In this section we first briefly examine the application of Scheil-Gulliver calculations to the study of solidification in the case of the ternary alloy $\mathrm{Pu}-\mathrm{Ga}-\mathrm{Fe}$, in the dilute regime, and to the prediction of phases that form first from the liquid phase, and the total amount of undercooling. Then, we study the kinetics of formation of the $\mathrm{Pu}_{3} \mathrm{Ga}$ compound from the fcc-based ( $\delta$ ) matrix in Pu-Ga alloys, and of the transformation $\delta$ to $\alpha$ in $\mathrm{Pu}$-rich $\mathrm{Pu}-\mathrm{Ga}$ alloys, and finally of the eutectoid phase decomposition in $\mathrm{Pu}-\mathrm{Ga}$ that takes place at low Ga content and at low temperatures (see section IV.3, and Fig. 10), as an application of the DICTRA software [34]. At the end of this section, we present a study on the 
kinetics of martensitic phase transformation that occurs in $\mathrm{Pu}-\mathrm{Ga}$ alloys at very low $\mathrm{Ga}$ content well below room temperature. For the first three studies, the kinetic equations were solved with the DICTRA software together with Thermo-calc and its thermodynamic database. The information that enters the mobility database in use with DICTRA has been generated from a critical assessment of available data in the scientific literature [70-74], and is discussed in Appendix D.

\section{IX.1 Scheil-Gulliver Results of Solidification for Pu-Ga-Fe Alloys}

Most Pu-Fe-Al alloys display a small amount of under-cooling, of the order of $25{ }^{\circ} \mathrm{C}$ (or less), and this result has been confirmed with Scheil-Gulliver simulations, see Fig. 34, in the case of the three dilute alloys $\mathrm{Pu}_{0.90} \mathrm{Ga}_{0.05} \mathrm{Fe}_{0.05}, \mathrm{Pu}_{0.94} \mathrm{Ga}_{0.05} \mathrm{Fe}_{0.01}$, and $\mathrm{Pu}_{0.979} \mathrm{Ga}_{0.020} \mathrm{Fe}_{0.001}$. In these three cases, from the liquid phase, the only solid phase to occur is the bcc matrix $(\varepsilon-\mathrm{Pu})$ under the Scheil,-Gulliver conditions (that assume local equilibrium, infinite diffusion in the liquid phase, and no back diffusion in the solid phase, cf. section II.2). These results clearly indicate that these alloys can be properly annealed in a relatively narrow region of temperatures and quenched to retain the single bcc phase.

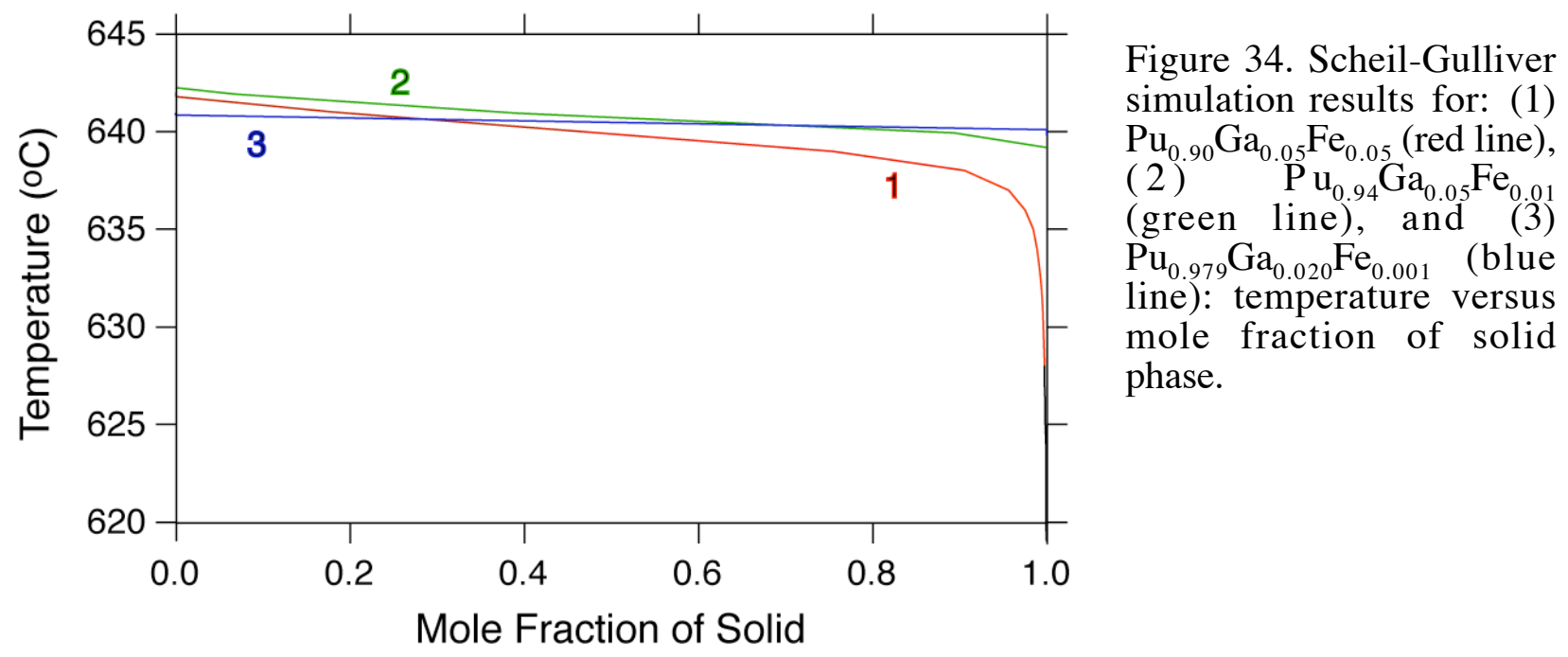

\section{IX.2. Kinetics of Formation of $\mathrm{Pu}_{3} \mathrm{Ga}$ from the fcc-based ( $\delta$ ) Matrix in Pu-Ga Alloys}

Kinetic and thermodynamic modeling have been combined and applied to the study of diffusioncontrolled transformations with the use of the DICTRA application linked to Thermo-Calc [25,34]. DICTRA fulfills the need to provide critical modeling and analysis of data by solving the diffusion equations, calculating thermodynamic equilibrium (with Thermo-Calc), solving the flux-balance equations, and finally by predicting the displacement of phase-interface positions (cf. section II.3).

For this study we only consider the fcc $(\delta)$ solid solution and the two compounds $\mathrm{Pu}_{3} \mathrm{Ga}(\zeta)$ and $\mathrm{Pu}_{3} \mathrm{Ga}\left(\zeta^{\prime}\right)$ that form at high temperatures (above $362{ }^{\circ} \mathrm{C}$ ) and low temperatures (between 57 and 362 ${ }^{\circ} \mathrm{C}$ ), respectively. All other phases have been ignored (suspended) during the calculations. The calculations are performed at fixed temperature and alloy composition, and the equilibrium (maximum) phase fraction can be obtained from the calculation of property diagrams, i.e., phase fraction versus 
temperature. In Fig. 35 we present the property diagrams of four Pu-Ga alloys for each of the four phases, namely the fcc $(\delta)$ solid solution, the $\alpha$ phase (that only occurs below $57{ }^{\circ} \mathrm{C}$ ), and the $\mathrm{Pu}_{3} \mathrm{Ga}$ ( $\zeta$ and $\left.\zeta^{\prime}\right)$ compounds. Note that the equilibrium phase fraction at a specific temperature and for a given alloy composition can be directly obtained from the straightforward application of the lever rule as discussed in Appendix E.1.
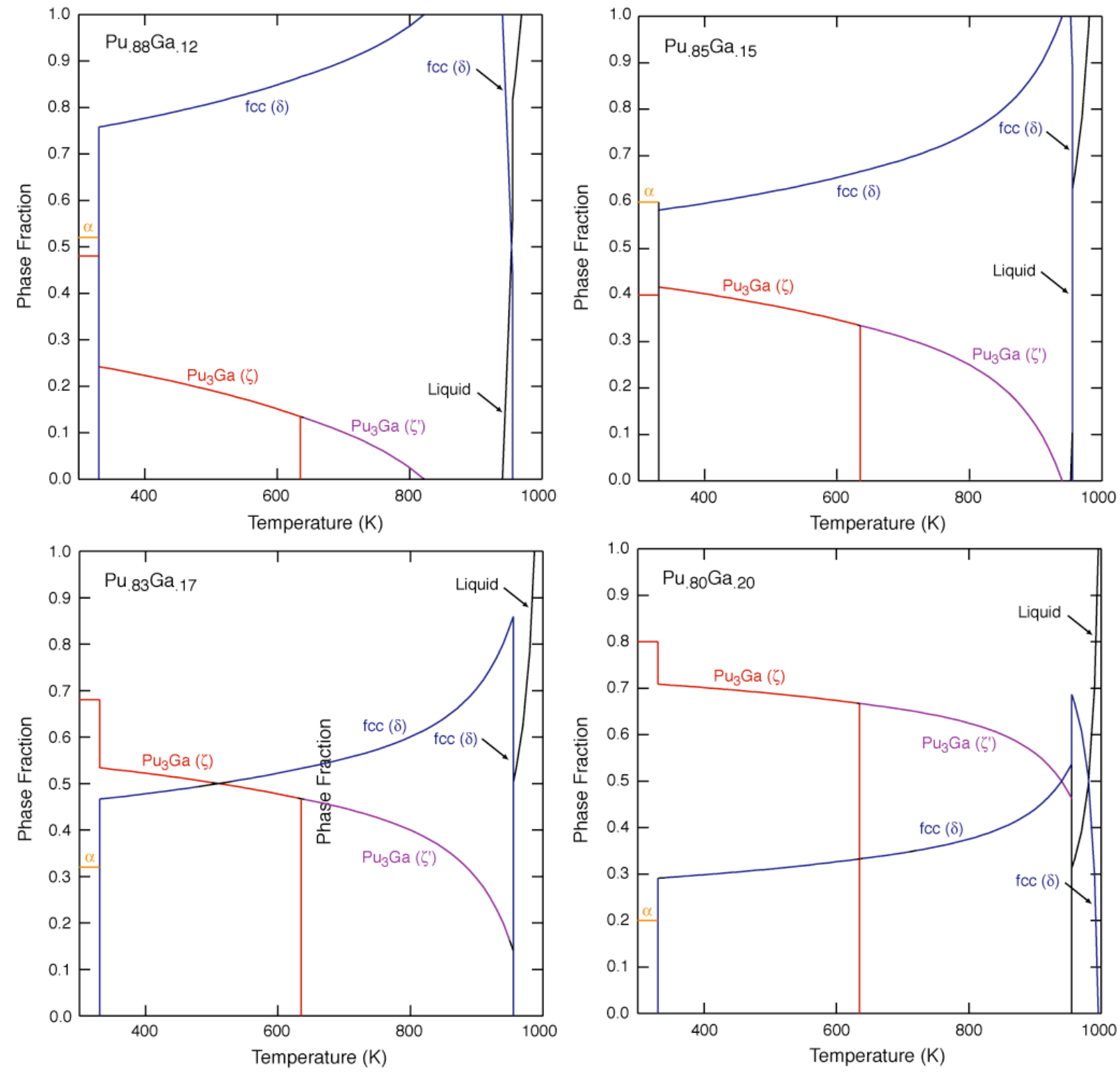

Figure 35. Property diagram of a $\mathrm{Pu}_{1-\mathrm{x}} \mathrm{Ga}_{\mathrm{x}}$ alloys $(\mathrm{x}=0.12,0.15,0.17$, and 0.20$)$. The fcc $(\delta), \alpha$, and $\mathrm{Pu}_{3} \mathrm{Ga}\left(\zeta\right.$ and $\left.\zeta^{\prime}\right)$ compounds are the only phases considered, and all other phases are ignored during the calculations.

The four selected alloy compositions are noted in Fig. 36 together with the temperatures that have been selected for the DICTRA calculations. For subsequent calculations the Pu-rich side of the $\mathrm{Pu}-\mathrm{Ga}$ 


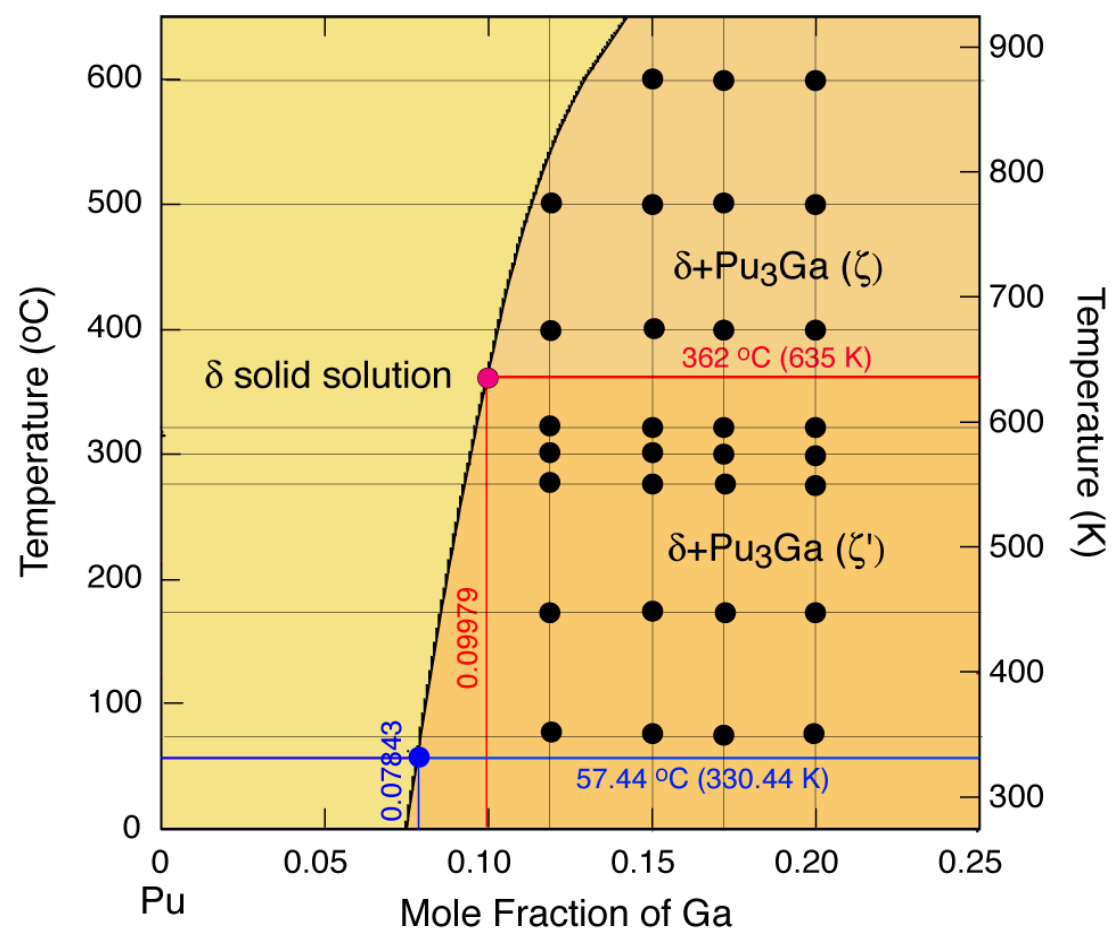

Figure 36. Alloy compositions and temperatures selected for the study of the kinetics of formation of $\mathrm{Pu}_{3} \mathrm{Ga}$ from the fcc-based $(\delta)$ matrix in $\mathrm{Pu}-\mathrm{Ga}$ alloys. The fcc $(\delta)$ solid solution and the two $\mathrm{Pu}_{3} \mathrm{Ga}(\zeta$ and ' $\zeta$ ') compounds are the only phases that have been considered for the determination of this phase diagram.

phase diagram (cf. Fig. 10b) that involves the $\alpha$ phase of pure Pu, the fcc-solid solution ( $\delta$ ), and the low-temperature $\mathrm{Pu}_{3} \mathrm{Ga}\left(\zeta^{\prime}\right)$ compound has been fitted according to

$$
100 x_{1}=244.16662+0.02667578 . T-4.1433872 .10^{-5} \cdot T^{2}+2.8284883 .10^{-8} \cdot T^{3}
$$

for the $\delta-\mathrm{Pu}_{3} \mathrm{Ga}\left(\zeta^{\prime}\right)$ line

$$
100 x_{2}=402.97877-3.2537171 . T+9.0285351 .10^{-3} \cdot T^{2}-8.4733763 .10^{-6} \cdot T^{3}
$$

for the $\delta$ - $\alpha$ line, where $x_{1}$ and $x_{2}$ correspond to the mole fraction of $\mathrm{Ga}$, and $\mathrm{T}$ is the temperature expressed in K. The results of the fit are shown in Fig. 37.

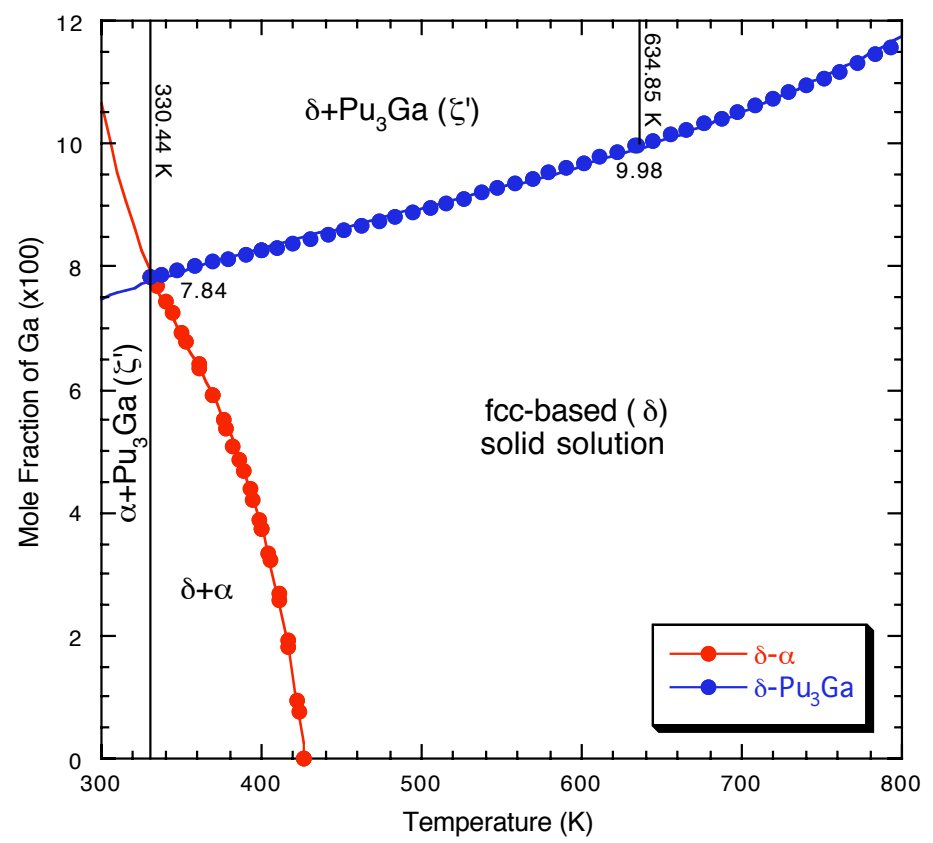

Figure 37. Results of the fit of the low-temperature $\mathrm{Pu}$ rich side of the $\mathrm{Pu}-\mathrm{Ga}$ phase diagram. 
The results from DICTRA are reported in Table E.1 of Appendix E.1. For $\mathrm{x}_{\mathrm{Ga}} \geq 0.0784$, at each selected temperature, the alloy composition is kept fixed and we record the phase fraction of, let say, $\delta$ phase versus time. The associated TTT curves for the $\delta$ to $\mathrm{Pu}_{3} \mathrm{Ga}$ transformation at fixed transformation rate and as a function of temperature and time are shown in Fig. 38 for four alloy compositions $(12,15,17$, and 20 at. $\% \mathrm{Ga})$ and four transformation rates $(5,10,15$, and $20 \%)$.
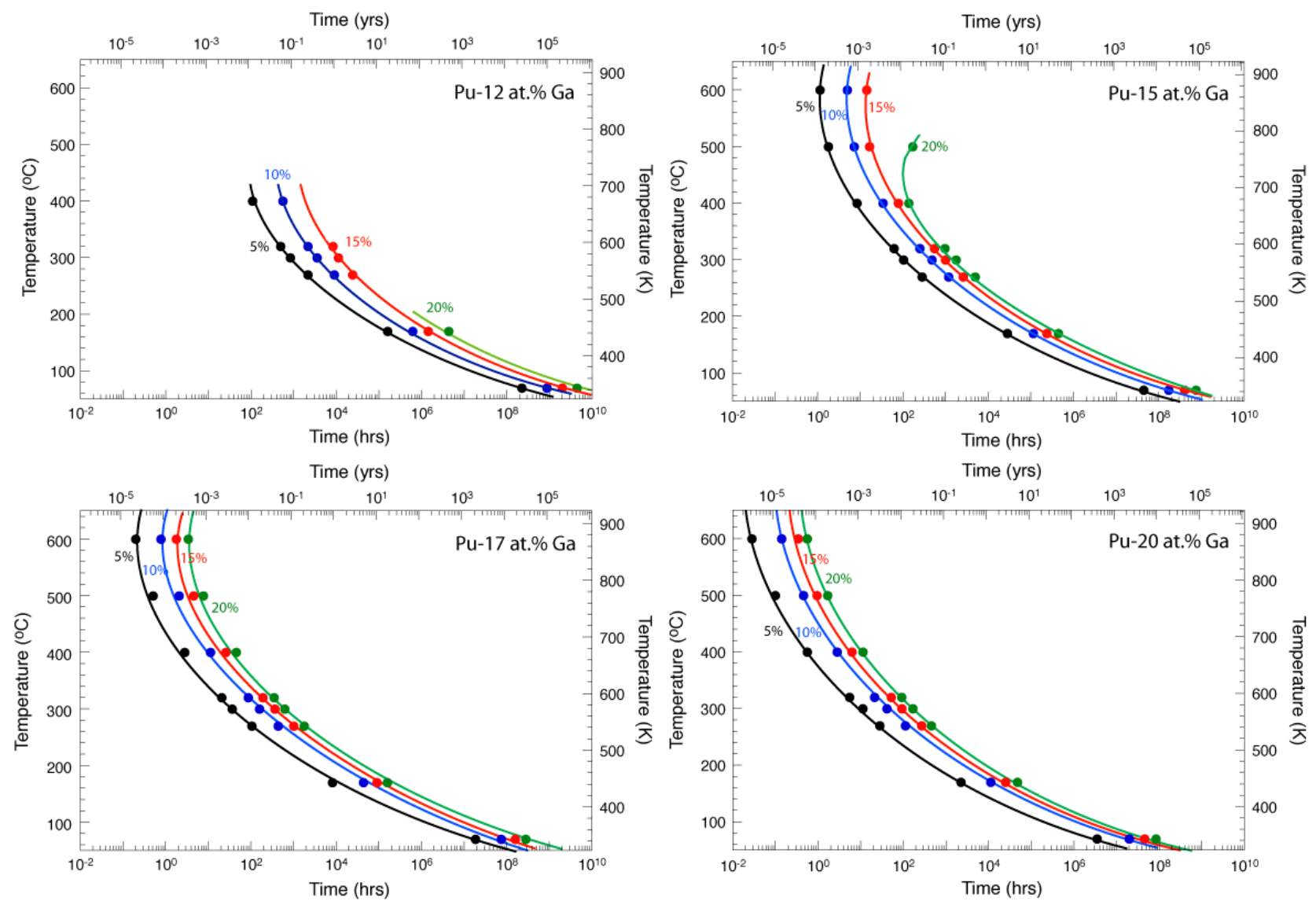

Figure 38. Calculated TTT curves for a fcc-based matrix of $\mathrm{Pu}_{1-\mathrm{x}} \mathrm{Ga}_{\mathrm{x}}$ alloys $(\mathrm{x}=.12, .15, .17, .20)$ transforming into the $\mathrm{Pu}_{3} \mathrm{Ga}$ compound ( $\zeta$ ' between 57 and $362{ }^{\circ} \mathrm{C}$, and $\zeta$ above $362{ }^{\circ} \mathrm{C}$ ), with transformation rates of $5,10,15$, and $20 \%$. The fcc-based $(\delta)$ solid solution and the $\mathrm{Pu}_{3} \mathrm{Ga}\left(\xi\right.$ or $\zeta^{\prime}$ ) compound are the only phases considered, and all other phases are ignored during the calculations. The lines are just guides to the eye.

Note that the higher the Ga content is, the lower the time for transformation is. This is simply attributed to the thermodynamic driving force that increases with the Ga content. In addition, the higher the temperature is, the lower the time for transformation is since, for obvious reasons, atomic diffusion takes place more efficiently. From the kinetics that is predicted for the formation of the $\mathrm{Pu}_{3} \mathrm{Ga}$ compound, it is clear that below 200-300 ${ }^{\circ} \mathrm{C}$ (depending on alloy composition) the long-range diffusion of solute atoms takes a prohibitive time and therefore equilibrium conditions cannot be reached. This was experimentally observed by Ellinger et al. [40]. Indeed, time for homogenization substantially increases with a decrease in temperature at which equilibration-heat treatments are perfor- 


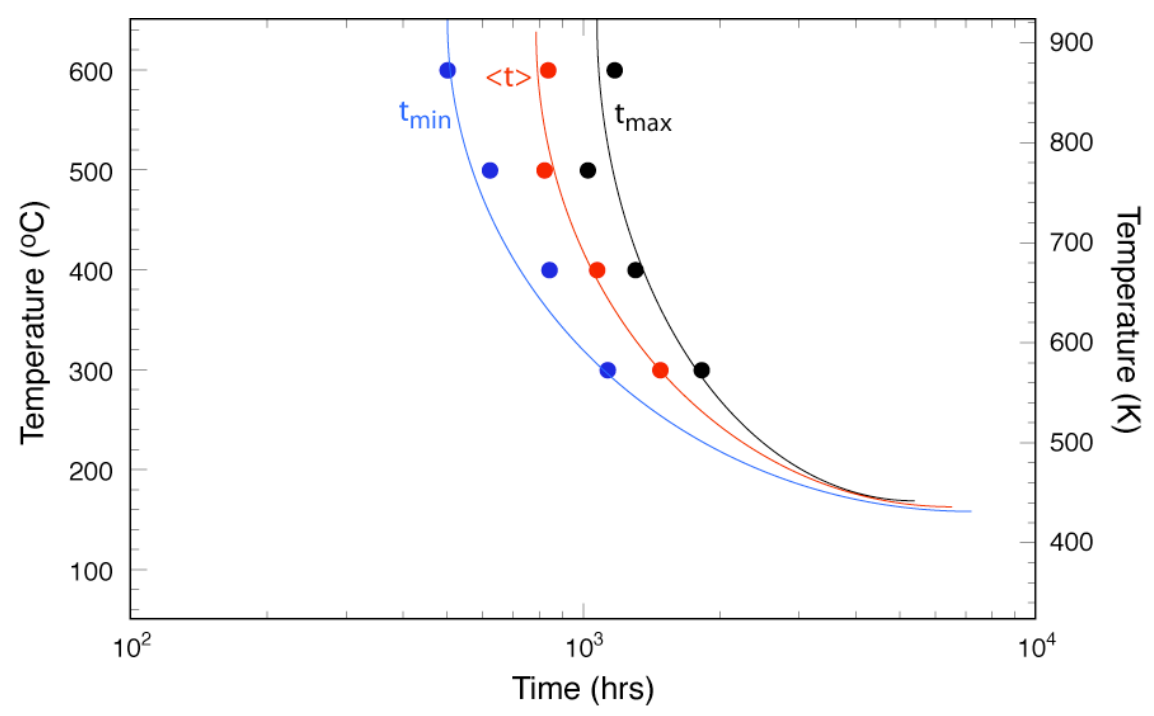

Figure 39. Homogenization time versus temperature of $\mathrm{Pu}-$ Ga alloys (with $\mathrm{Ga}$ contents ranging from 8 to 24 at.\%) heat-treated at various temperatures. The times $t_{\text {min }}$, $\mathrm{t}_{\max }$ and $<\mathrm{t}>$ correspond to the minimum, maximum and average time, respectively. (from Ref. [40]).

med. The results of Table 4 of Ref. [40] are displayed in Fig. 39, and are compatible with those reported in Fig. 38. Experimentally [40], as-cast samples with Ga content in the range 8-24 at.\% (more precisely, 8, 10, 12, 15, 18, 20, 22.5, and 24 at.\% Ga ) were equilibrated at various temperatures, and the formation of $\mathrm{Pu}_{3} \mathrm{Ga}$ led to the existence of a two-phase region with the fcc $(\delta)$ matrix exhibiting a lattice parameter corresponding (supposedly) to the equilibrium composition; hence the possibility of deducing the $\mathrm{Ga}$ content of the $\delta$ phase in equilibrium with $\mathrm{Pu}_{3} \mathrm{Ga}$, i.e., the phase boundary of the two-phase region, at each temperature, as long as the lattice parameter/composition relationship is established and indeed equilibrium is reached.

\section{IX.3. Kinetics of the $\delta$ to $\alpha$ transformation in Pu-rich Pu-Ga Alloys}

For this study we only consider the fcc-based $(\delta)$ solid solution and the $\alpha$ phase of $\mathrm{Pu}$ with all other phases ignored (suspended) during the calculations. Note that in the equilibrium phase diagram (see Figs. 10 and 40), the two-phase region $\alpha+\delta$ exists between the eutectoid temperature of $57.44{ }^{\circ} \mathrm{C}$ $\left(\mathrm{x}_{\mathrm{Ga}}=0.0784\right)$ and $124.47{ }^{\circ} \mathrm{C}\left(\mathrm{x}_{\mathrm{Ga}}=0.0395\right)$. However in the present study the two-phase region is extended to pure $\mathrm{Pu}$ that corresponds to a temperature of $157{ }^{\circ} \mathrm{C}$ as indicated in Table 3 and in Figs. 12 and 40. The calculations are performed at fixed temperature and alloy composition and the equilibrium (maximum) phase fraction can be obtained from the calculation of property diagrams, i.e., phase fraction versus temperature, cf. Fig. 41, or directly from the straightforward application of the lever rule as discussed in Appendix E.2. The four selected alloy compositions are noted in Fig. 40 together with the temperatures that have been selected for the DICTRA calculations.

The results from DICTRA are reported in Table E.2 of Appendix E.2. For $\mathrm{x}_{\mathrm{Ga}} \leq 0.0784$, at each selected temperature, the alloy composition is kept fixed and we record the phase fraction of, let say, $\alpha$ phase versus time. The associated TTT curves for the $\delta$ to $\alpha$ transformation at fixed transformation rate and as a function of temperature and time are shown in Fig. 42 for four alloy compositions (2, 3, 4 , and 5 at. $\% \mathrm{Ga}$ ) and 4 transformation rates $(5,10,15$, and $20 \%)$. 

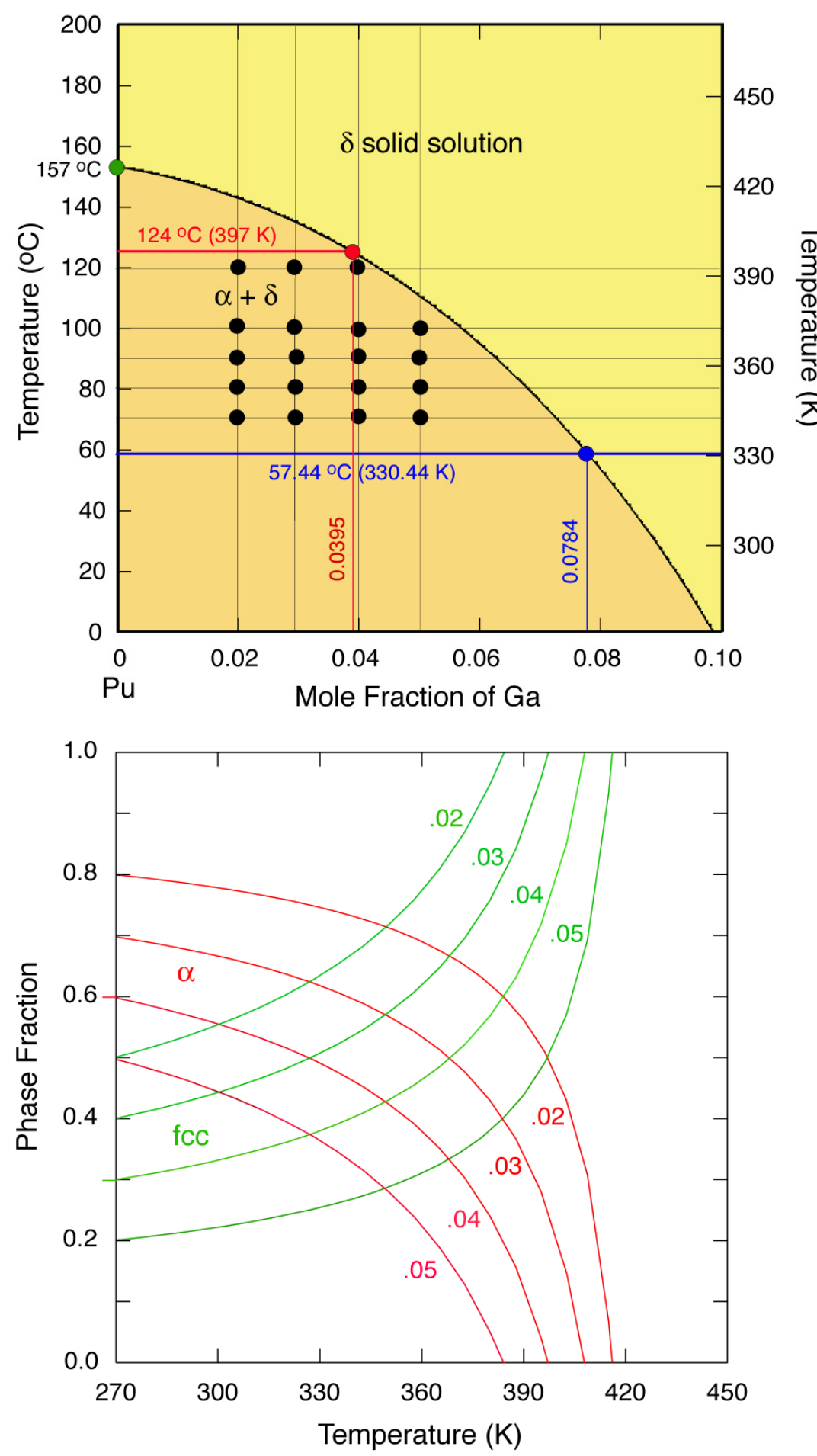

Figure 40. Alloy compositions and temperatures selected for the study of the kinetics of the $\delta$ to $\alpha$ transformation in $\mathrm{Pu}$-rich $\mathrm{Pu}$ Ga alloys. The fcc $(\delta)$ solid solution and $\alpha-\mathrm{Pu}$ are the only phases that have been considered for the determination of this phase diagram.
Figure 41. Property diagram of $\alpha$ and $\delta \quad \mathrm{Pu}_{1-\mathrm{x}} \mathrm{Ga}_{\mathrm{x}}$ alloys $(\mathrm{x}=0.02,0.03,0.04$, and 0.05$)$. The fcc $(\delta)$ solid solution and $\alpha-\mathrm{Pu}$ are the only phases considered, and all other phases are ignored during the calculations. The red (green) lines correspond to the amount of $\alpha(\delta)$.

Note that compared with the $\delta$ to $\mathrm{Pu}_{3} \mathrm{Ga}$ transformation the $\delta$ to $\alpha$ one is much slower. Even at the lowest Ga content for which the thermodynamic driving force is the highest, the nose of the transformation (at $5 \%$ transformation) is beyond 100 years above $100{ }^{\circ} \mathrm{C}$, and the higher the $\mathrm{Ga}$ content is, the slower the transformation occurs. For the Ga contents, 4 and 5 at.\% Ga, that lead to an equilibrium two-phase field $\alpha+\delta$, the time to transformation increases by one and two orders of magnitude, respectively. At all Ga contents, the experimental determination of the two-phase boundary 

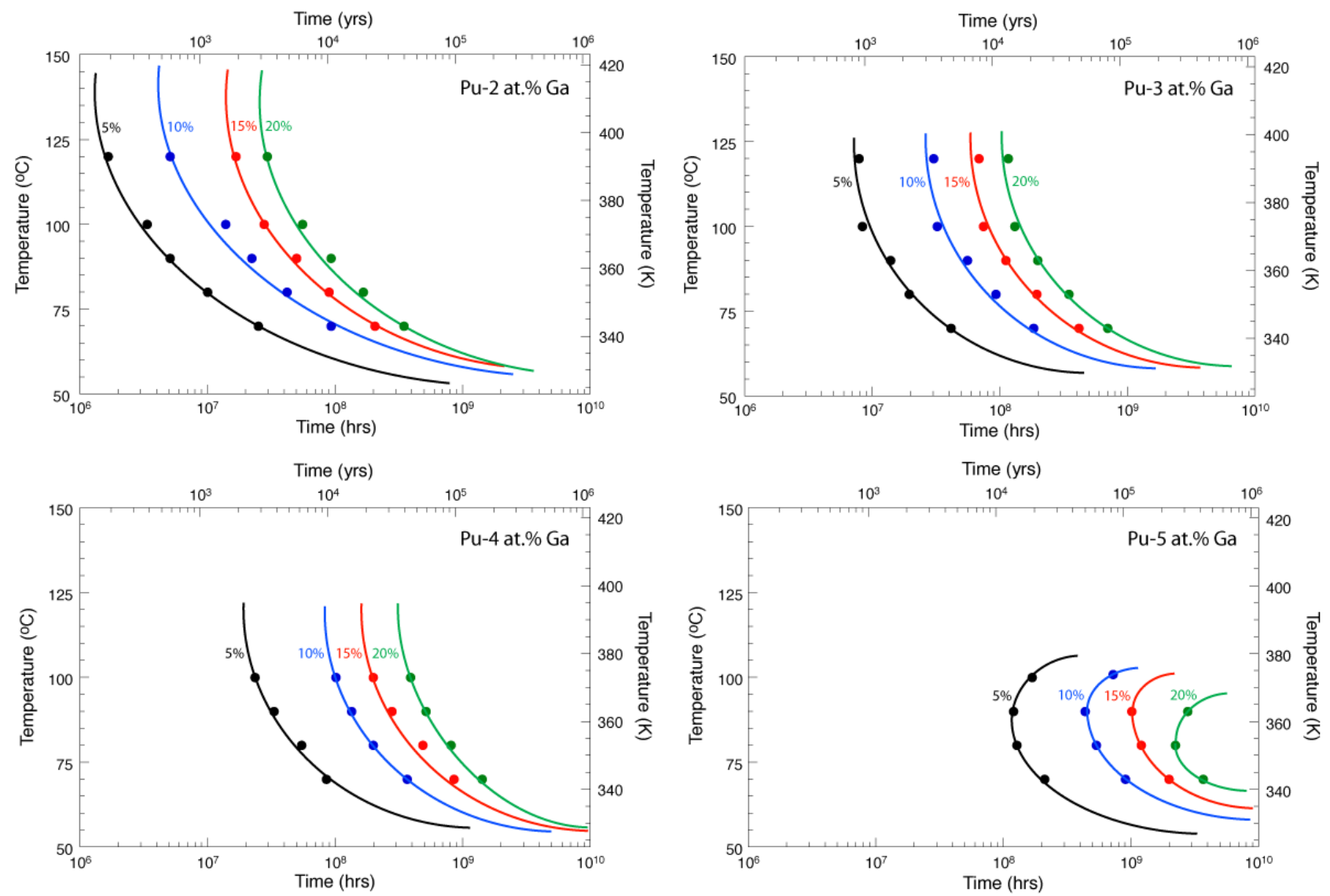

Figure 42. Calculated TTT curves for fcc-based $(\delta)$ matrix of $\mathrm{Pu}_{1-\mathrm{x}} \mathrm{Ga}_{\mathrm{x}}$ alloys $(\mathrm{x}=.02, .03, .04$, $.05)$ transforming into the $\alpha$ phase, with transformation rates of $5,10,15$, and $20 \%$. The fcc-based $(\delta)$ solid solution and $\alpha-\mathrm{Pu}$ are the only phases considered, and all other phases are ignored during the calculations. The lines are just guides to the eye.

is impossible since the diffusion of solute atoms is totally inhibited. As a consequence, the atomic configuration in the $\delta$ phase that is in equilibrium with $\alpha-\mathrm{Pu}$ is unaltered by the transformation.

\section{IX.4. Eutectoid Phase Decomposition in Pu-Ga Alloys}

DICTRA is used to analyze the kinetics of eutectoid phase decomposition $(\delta-\mathrm{Pu}) \rightarrow \alpha-\mathrm{Pu}+\mathrm{Pu}_{3} \mathrm{Ga}$ in $\mathrm{Pu}-\mathrm{Ga}$ alloys that is predicted to take place at $\mathrm{T}=57.44{ }^{\circ} \mathrm{C}$ and at a composition $\mathrm{x}_{\mathrm{Ga}}=0.0784$ from the CALPHAD assessment presented in section IV.3 (see also Fig. 10b). All the following results are based on the use of the assessed thermodynamic database (cf. Appendix C) and the mobility database that account for the diffusion of $\mathrm{Ga}$ and $\mathrm{Pu}$ in the phases in equilibrium (cf. Appendix D). To estimate the time it takes to observe the eutectoid phase decomposition two methods were considered.

First, let us consider alloys at compositions associated with a maximum equilibrium transformation rate of $5 \%$ that transform from $\delta$ to $\mathrm{Pu}_{3} \mathrm{Ga}$ and $\delta$ to $\alpha$, separately. The compositions 
were determined by making use of Eqs. (23) and (24), respectively. The results are shown in the phase diagram displayed in Fig. 43.

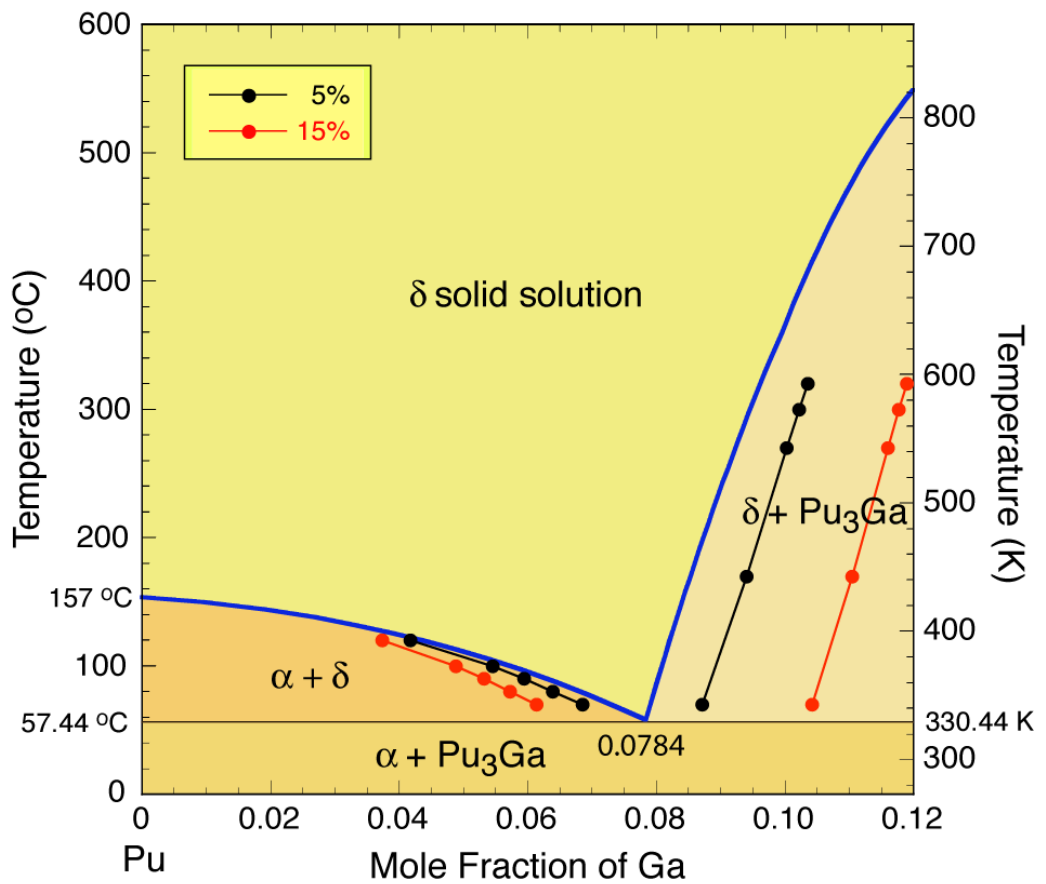

Figure 43. Low temperature rich-Pu portion of the $\mathrm{Pu}-\mathrm{Ga}$ phase diagram (blue lines) together with the 5\% (black line) and $15 \%$ (red line) transformation rates from $\delta$ to $\alpha$ (below $\mathrm{x}_{\mathrm{Ga}}=0.0784$ ) and from $\delta$ to $\mathrm{Pu}_{3} \mathrm{Ga}$ (above $\left.\mathrm{x}_{\mathrm{Ga}}=0.0784\right)$.

For these specific compositions, DICTRA calculations were performed and the numerical results are reported in Table E.3 of Appendix E.3. The associated TTT curves for the two transformations at the equilibrium transformation rate of $5 \%$ are shown in Fig. 44. (Note that along each line, the alloy composition varies, only the equilibrium phase fraction is kept fixed).

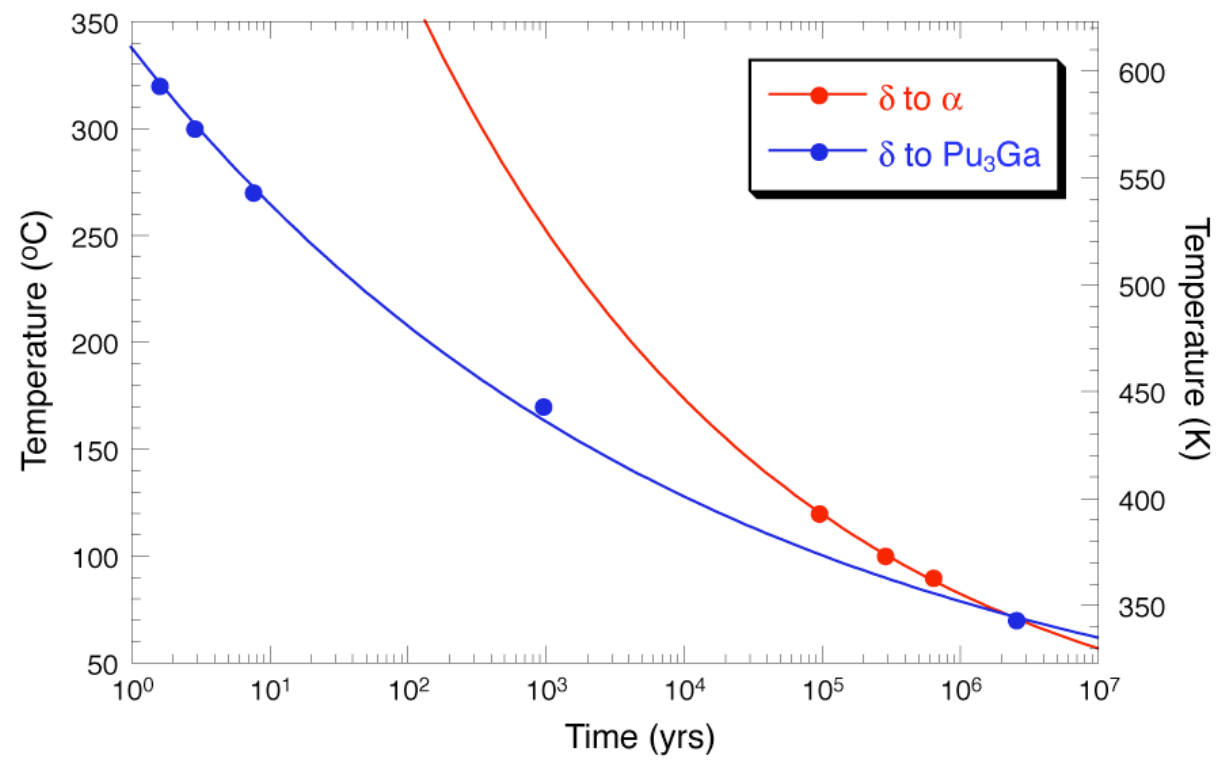

Figure 44. Calculated TTT curves for a fccbased $(\delta)$ matrix of $\mathrm{Pu}_{1-\mathrm{x}} \mathrm{Ga}_{\mathrm{x}}$ alloys transforming into the $\alpha$ phase, with a maximum equilibrium transformation rate of $5 \%$. The fcc-based ( $\delta)$ solid solution and $\alpha-\mathrm{Pu}$ are the only phases considered, and all other phases are ignored during the calculations. The lines are just guides to the eye.

As one would expect, close to the eutectoid temperature of about $57{ }^{\circ} \mathrm{C}$, the times for transformation should be similar for the two transformations. The two curves shown in Fig. 44 are well approximated by the following power laws: 


$$
T=776.558387 t^{-0.1626384}
$$

for the $\delta$ to $\alpha$ transformation, and

$$
T=337.6502470 t^{-0.1056391}
$$

for the $\delta$ to $\mathrm{Pu}_{3} \mathrm{Ga}$ transformation, where the temperature $T$ and the time $t$ are expressed in Kelvin and year, respectively.

As shown in Fig. 44, close to the temperature of eutectoid decomposition, the time for transformation is about $1.510^{6}$ years, and therefore by diffusion alone, the "simulated" eutectoid transformation is definitely inhibited.

Second, DICTRA simulations are performed to simulate the eutectoid phase decomposition $\delta \rightarrow \alpha+\mathrm{Pu}_{3} \mathrm{Ga}$ according to the scheme illustrated in Fig. 45. The calculations are done close to the

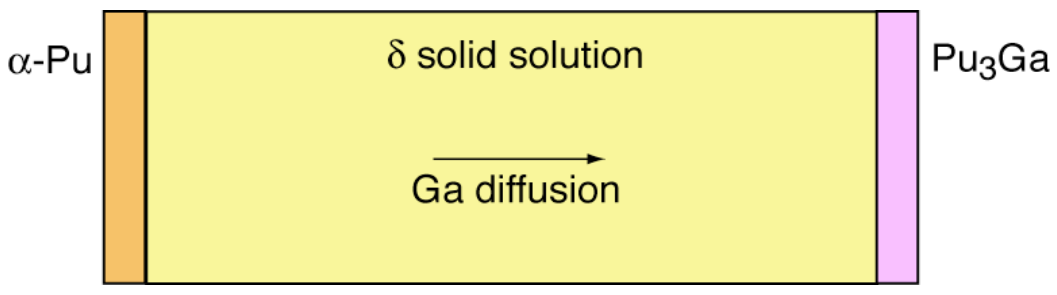

Figure 45. Sample configuration to simulate the kinetics of eutectoid decomposition in $\mathrm{Pu}-\mathrm{Ga}$ alloys.

eutectoid temperature of $57.44{ }^{\circ} \mathrm{C}$ at $57{ }^{\circ} \mathrm{C}(330 \mathrm{~K})$ and for an alloy compoistion of 7.8 at. $\% \mathrm{Ga}$.

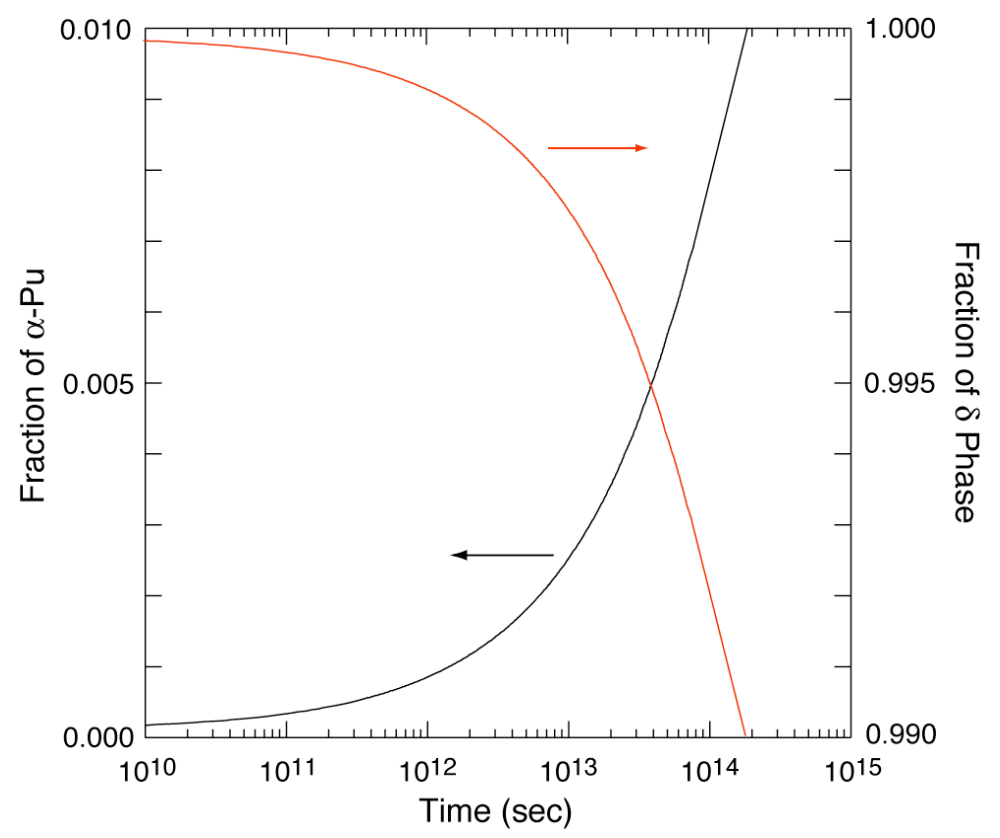

Figure 46. Phase fractions of $\alpha-\mathrm{Pu}$ (black line) and $\delta$ solid solution (red line) as functions of time (in sec), at $\mathrm{T}=330 \mathrm{~K}$ and for a $\mathrm{Pu}-7.8$ at. $\% \mathrm{Ga}$ alloy.

The results are shown in Fig. 46 for the incipient decomposition stage. Note that for the selected alloy composition, the equilibrium fraction of $\alpha$-Pu should be 0.688 . It is clear that the diffusion is too slow to observe the eutectoid-phase decomposition in $\mathrm{Pu}-\mathrm{Ga}$ alloys. 
In summary, it was shown that in Pu-Ga alloys long-range atomic diffusion at low temperature is totally inhibited. Therefore, although it has been established in section IV.3 that at equilibrium an eutectoid-phase decomposition takes place at low temperature, with the consequence that the $\delta$ solid solution is not a stable phase at low temperatures (below $57{ }^{\circ} \mathrm{C}$ according to our predictions), for all practical purposes the kinetics prevents such decomposition. Even at higher temperatures, i.e., above $130{ }^{\circ} \mathrm{C}$ where experiments have been carried out, diffusion is still a very slow process, cf. Figs. 38 and 42. Consequently it is likely that the experimentally determined phase boundaries $\alpha-\delta$ and $\delta-\mathrm{Pu}_{3} \mathrm{Ga} \underline{\mathrm{do}}$

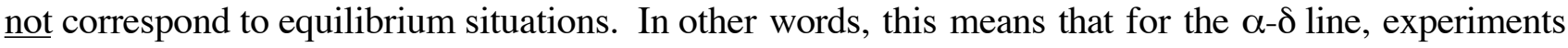
will tend to underestimate the $\mathrm{Ga}$ content, whereas for the $\delta-\mathrm{Pu}_{3} \mathrm{Ga}$ line, the $\mathrm{Ga}$ content will be overestimated, less so for the latter than for the former since the kinetics of transformation is faster in the $\left(\delta \rightarrow \delta+\mathrm{Pu}_{3} \mathrm{Ga}\right)$ case than in the $(\delta \rightarrow \delta+\alpha)$ one (cf. Figs. 38, 42, and 44). This is also illustrated in Fig. 47 where the predicted equilibrium phase-boundary lines between $\delta$ and $\gamma, \delta$ and $\beta, \delta$ and $\alpha$, and $\delta$ and $\mathrm{Pu}_{3} \mathrm{Ga}$ are shown.

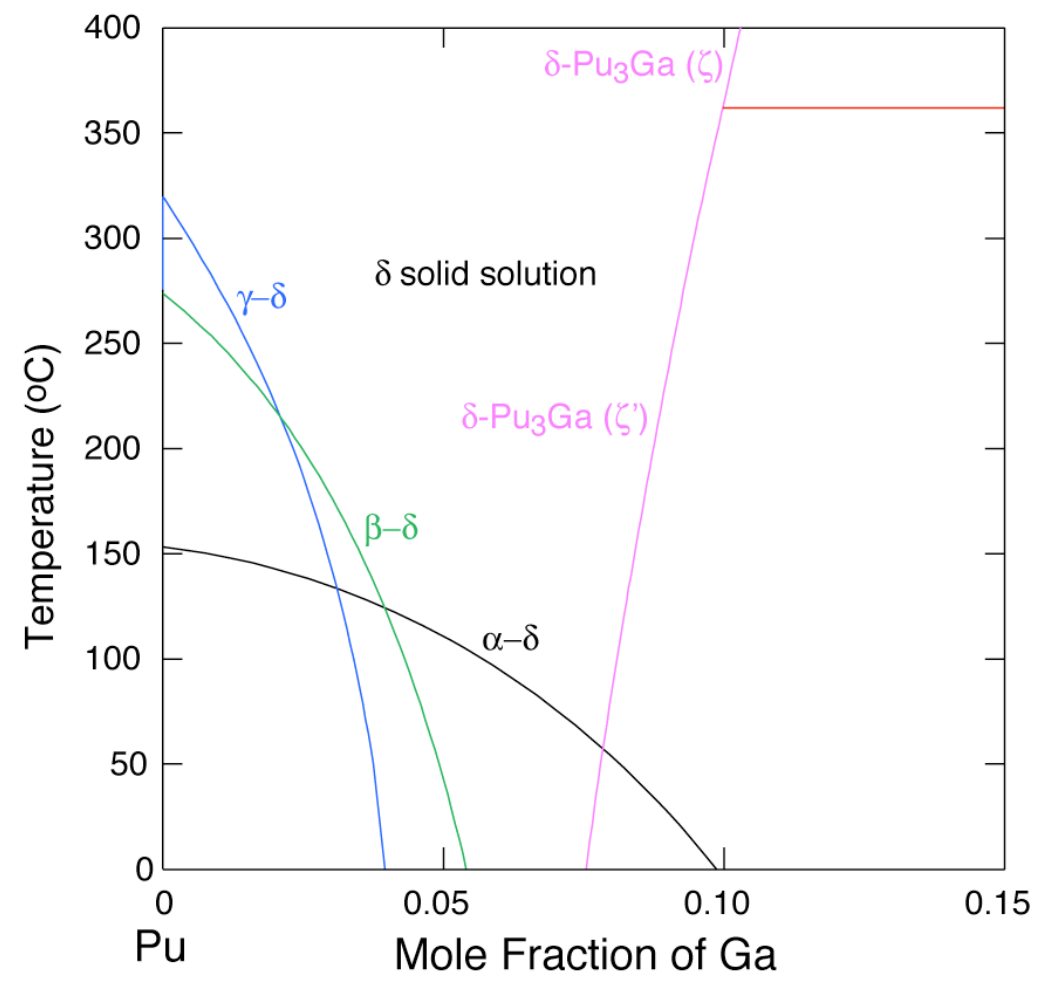

Figure 47. Pu-rich part of the low temperature region of the $\mathrm{Pu}-\mathrm{Ga}$ phase diagram. Each phaseboundary line has been calculated separately, i.e., with all other phases (than the ones involved in the two-phase equilibrium) suspended (or ignored) during the calculations.

It happens that the $\delta-\alpha$ and $\delta-\mathrm{Pu}_{3} \mathrm{Ga}$ lines cross near the eutectoid temperature (cf. Fig. 47), and therefore the "American version" of the Pu-Ga phase diagram (cf. Fig. 6) truly displays nonequilibrium (i.e., erroneous) phase boundaries at low temperatures, independently of the existence or not of an eutectoid invariant line. This observation is supported in Fig. 10 of section IV.3 where the experimental points evaluated by Timofeeva are located inside the assessed two-phase region $\delta+\mathrm{Pu}_{3} \mathrm{Ga}$ (more so at low temperature than at high temperature). For the same reasons, the time for eutectoid phase decomposition of several 10,000 years by Timofeeva is underestimated [44,45], since this time corresponds to lower fractions of product phases than those obtained at equilibrium. 
These conclusions will be unaltered by enhanced diffusion that can take place in alloys in general, and in $\mathrm{Pu}-\mathrm{Ga}$ in particular. Indeed, atomic diffusion at grain boundaries is usually faster than in the bulk, but even an increase of several orders of magnitude in the atomic mobility is not enough to prevent the inhibition of the eutectoid reaction solely on a kinetic ground. The same remark would apply to the role that impurities may play in enhancing diffusion. This has to be considered in the case of $\mathrm{Pu}$-based alloys because of the existence of products from self-irradiation caused by the radioactive nature of plutonium as shown in Fig. 48. The half-time of the major isotope ${ }^{239} \mathrm{Pu}$ is 24,390 years, and this element decays into uranium and helium by $\alpha$-particle decay with an energy release of $5.13 \mathrm{MeV}$.

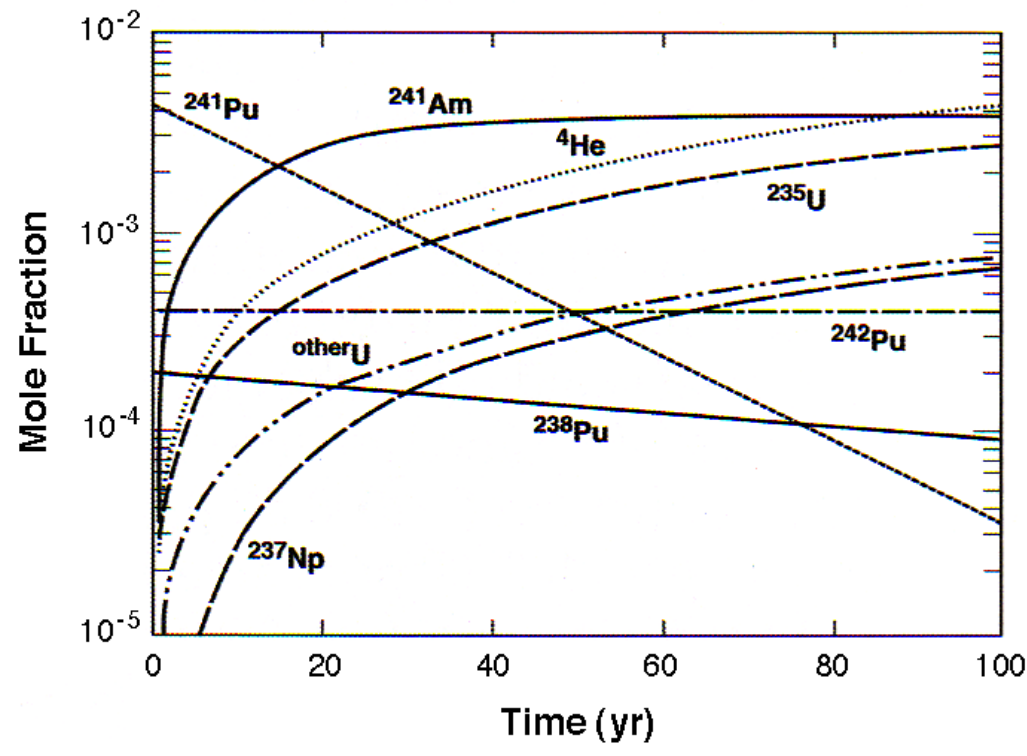

Figure 48. Temporal formation of transmutation products in ${ }^{239} \mathrm{Pu}$ (adapted from Ref. [46]).

This energy is partitioned among the two daughter products, with the helium nucleus receiving $5.04 \mathrm{MeV}$ and the recoiling uranium the remainder of $85.8 \mathrm{eV}$ (note that small amount of other $\mathrm{Pu}$ isotopes may have different half-lives, the energy of their $\alpha$-decays are very similar to ${ }^{239} \mathrm{Pu}$ ). The dissipation of the recoil energies of the daughter products results in heat that raises the local temperature, and in displacements of about $2500 \mathrm{Pu}$ atoms from their normal crystal lattice sites per decay. As a result, over a period of 10 years, each atom in the Pu crystal lattice is on average displaced once (whereas the rate of displacement is about 0.1 displacement per atom per year for $\mathrm{Pu}$, the rate of He production is 41 atomic parts per million per year). Hence, at ambient temperature, the vacancies and self-interstitials produced by the displacements as well as the He atoms are able to diffuse. Therefore it can be inferred that a higher internal temperature and the formation of micro-voids or He bubbles (or both) can enhance the long-range atomic diffusion in $\mathrm{Pu}$. However, once again, even an enhancement of several orders of magnitude in the atomic mobility is still not enough to promote the eutectoid decomposition in Pu-Ga alloys. Hence the only possibility for the alloy to lower its energy is to select another mechanism of transformation that does not rely on diffusion, and indeed in $\mathrm{Pu}-\mathrm{Ga}$ alloys a diffusionless-martensitic transformation has been observed. This constitutes the subject of the next section. 


\section{IX.5. Martensitic Transformation in Pu-Ga Alloys: Aging Properties}

The $\delta$ phase of $\mathrm{Pu}$, stable between $310{ }^{\circ} \mathrm{C}$ and $450{ }^{\circ} \mathrm{C}$ is retained down to room temperature by adding a small amount of $\delta$ stabilizer such as Ga because of the very long time required for homogenization as shown in the previous section. However, in the very dilute region, the fcc-based solid solution is metastable and may partially transform into the monoclinic $\alpha$ phase (usually referred to as $\alpha^{\prime}$, since the $\alpha$ phase contains a finite amount of $\delta$ stabilizer such as $\mathrm{Ga}$ ), by cooling below room temperature and under uniaxial or isobaric pressure with an accompanying volume decrease of about $20 \%$. Most studies conducted so far conclude that the $\delta \rightarrow \alpha$ ' transition proceeds via a martensitic mechanism. However it was noted [75,76] that this transformation might occur by a massive transformation under certain circumstances, and by a martensitic transformation under other conditions. As in the case of ferrous alloys, each martensitic unit grows very quickly to its final size, and since no diffusion or interchange of atoms is involved in the transformation the product phase inherits the composition, the atomic configuration, and the lattice defects of the parent phase (N.B.: in the literature, the product phase is often referred to as $\alpha$ ' to indicate the finite amount of Ga retained in the $\alpha$-based structure; the "prime" will be omitted in what follows).

More generally, two cases of martensites may be considered [77-80]. For athermal martensite, the number of units depends on temperature, and time has no effect. The transformation proceeds when new units are formed as the temperature is lowered. The transformation starts at $\mathrm{M}_{\mathrm{s}}$ and is completed well below $\mathrm{M}_{\mathrm{s}}$. In the case of isothermal martensite, there is also a critical temperature below which the martensite units can be triggered as a function of time. However this kind of transformation can be avoided by rapid cooling but can occur gradually as a function of time with the accompanying formation of an increasing number of units if the temperature is kept constant below the critical value. An isothermal transformation can be described by $\mathrm{C}$ curves that are similar to those observed in the case of diffusional transformations. For non-thermoelastic alloys that will be considered here, heterogeneous-nucleation is the rate-controlling factor, as it occurs in steel. In the present study we will adopt the model developed by Cohen and Kaufman (CK) and successfully applied to Fe-Ni alloys [81]. In this model, the critical barrier for nucleation is crossed by a single event of thermal activation and the growth process is very fast. The rate-controlling equation is given by

$$
\frac{d V}{d t}=n v V_{M} \exp \left(\Delta W^{*} / R T\right)
$$

where $\mathrm{V}$ is the volume of martensite, $\mathrm{n}$ is the number of favorable nucleation sites per unit volume, $v$ is the nucleation frequency (i.e., a typical lattice vibration frequency), $\mathrm{V}_{\mathrm{M}}$ is the average volume of martensite units, $\Delta \mathrm{W}^{*}$ is an activation energy (note that a minus sign has been absorbed in the definition of $\Delta \mathrm{W}^{*}$ ), and $\mathrm{R}$ is the gas constant. The exponential term corresponds to the "successful" fraction of nucleation attempts. Note that, although Eq. (27) looks similar to the equation derived in classical homogeneous nucleation theory, there are important differences: not all sites are considered as potential nucleation sites (cf. definition of $n \neq N$, where $\mathrm{N}$ is the Avogadro number), and the 
activation energy that is defined in a particular model of nucleation has to be much smaller than the one associated with the overall free energy for embryo growth. In the $\mathrm{CK}$ model, several assumptions are made. First, the growth of embryos into martensite that is triggered by thermal fluctuations is sufficient to nucleate dislocation loops. Second, the embryos of martensite are surrounded by dislocation loops (mostly screw in nature). Third, there is a repeated formation of dislocation loops at the parent/martensite interface, instead of successive transfer of atoms. Fourth, the energy to form and expand the dislocation loops (i.e., the interfacial energy) is supplied by the chemical driving force, as is the case for the strain energy set up by the displacement. Fifth, heterogeneous nucleation is assumed, i.e., all embryos that are activated at some temperature have an initial size above the critical size. Finally, the chemical driving force must exceed the required interfacial and strain energies. The nonchemical free energy is made up of two terms, the interfacial free energy given by

$$
\Delta G_{i}=2 \pi r^{2} \sigma
$$

where $2 \pi r^{2}$ is the approximate surface area of the martensite plate and $\sigma$ is the specific interfacial free energy per unit surface, and the strain energy that takes the form

$$
\Delta G_{s}=\frac{4 \pi r^{2} c}{3} \frac{c A}{r}
$$

where $4 \pi r^{2} c / 3$ is the approximate volume of the oblate spheroidal embryo and $c A / r$ is the strain energy referred to a unit volume of martensite. The characteristics $\mathrm{c}$ and $\mathrm{r}$ of the martensite embryo are depicted in Fig. 49.

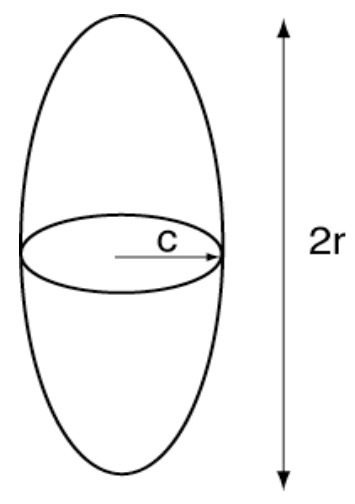

Figure 49. Schematic representation of an oblate spheroidal embryo of martensite.

Therefore the overall free energy is written as

$$
\Delta W=\Delta G_{c}+\Delta G_{i}+\Delta G_{s}
$$

where $\Delta G_{c}$ is the change in chemical free energy associated with the formation of a volume $\mathrm{V}_{\mathrm{M}}$ of martensite.

In the $\mathrm{CK}$ model, it is assumed that there is an embryo of radius $r_{c}$ such that when $r \geq r_{c}$ cataclysmic formation of martensite can occur, i.e., new dislocation loops can be generated athermally. If $r_{c} \geq r^{*}$, where $r^{*}$ is the radius of an embryo of critical size, there exits a range of sizes $r^{*} \leq r \leq r_{c}$ for which the embryo can grow spontaneously (in which case the free energy $\Delta W$ associated with the growth decreases) if thermal fluctuations facilitate the formation of new dislocation loops (embryos 
with $r<r^{*}$ cannot grow because of the extremely high value of $\Delta W^{*}$ ). The formation of "giant" dislocation loops of Burger's vector approximately equal to $\mathrm{cb} / \mathrm{d}$ (where $\mathrm{d}$ is the spacing between dislocations, and $b$ is the Burger vector) that follow the edge of the embryo provides the condition under which an embryo can grow cataclysmically. The activation energy per unit step during isothermal growth from $r\left(r \geq r^{*}\right)$ to $r_{c}$ is expressed as

$$
\Delta W^{l}=\frac{2.5 \pi b^{2}}{d^{2}}\left(\frac{\sigma}{A}\right)^{1 / 2}\left(3 \sigma r^{3 / 2}+\Delta g_{c}\left(\frac{\sigma}{A}\right)^{1 / 2} r^{2}\right) \text { per unit growth of loop }
$$

where $\Delta g_{c}$ is the chemical free energy per unit volume, $\Delta g_{c}=\Delta G_{c} / V$, where $\mathrm{V}$ is the molar volume of the parent phase. This activation energy has a maximum value given by

$$
\Delta W_{\max }^{l}=0.11 \pi \frac{\sigma^{3} V^{3} A}{-\Delta G_{c}^{3}}
$$

that corresponds to an embryo of size $r_{\max }$ such that

$$
r_{\max }^{1 / 2}=\frac{2.25(\sigma A)^{1 / 2}}{-\Delta g_{c}}
$$

In summary, Eq. (27) is rewritten as

$$
\log f=\log t+\log \left(n v V_{M}\right)+\frac{\Delta W^{*}}{R T \ln 10}
$$

where $\mathrm{f}$ is the fraction of parent phase that has been transformed per $\mathrm{cm}^{3}, f=d N / d t V_{M}$ (where $d N / d t$ is the initial rate of nucleation), and $\mathrm{t}$ is the time (in seconds).

In the case of Pu-Ga alloys, in the mid seventies Orme et al. [76,48] observed that the TTT curve associated with the low temperature transformation exhibits a double C-shape at high Ga content (1.4 and 1.9 at. $\% \mathrm{Ga}$ ), and a single $\mathrm{C}$-shape at low $\mathrm{Ga}$ composition (0.6 and 0.7 at.\% Ga). The results have been confirmed in the late nineties by Deloffre et al. [82]. To capture these facts, we will assume that for the concentrated alloys (i.e., 1.4 and 1.9 at.\% Ga) at "high temperatures", the rate of transformation is controlled by the intermediate transformation $\delta \rightarrow \gamma$ (i.e., $\gamma$ '), whereas at "low temperatures" the rate is controlled by the $\delta \rightarrow \alpha$ transformation. Furthermore, the model should be capable of reproducing the observed phenomenon that at low Ga composition (i.e., 0.6 and 0.7 at.\% $\mathrm{Ga}$ ) the rate of transformation is only controlled by the $\delta \rightarrow \alpha$ (i.e., $\alpha^{\prime}$ ) transformation. In the following the model parameters will have to be estimated for the two transformations $\delta \rightarrow \alpha$ and $\delta \rightarrow \gamma$ (when not specified the parameters take the same values for both transformations).

The following values can be unambiguously estimated:

- the volume of a transformed plate of product phase: $\mathrm{V}_{\mathrm{M}}=2.5 \times 10^{-9} \mathrm{~cm}^{3}$,

- the number of nucleation sites: $\mathrm{n}=2 \times 10^{+12} \mathrm{~cm}^{-3}$ based on the metallographic analysis shown in Ref. [76] (this number corresponds to one nucleation site per grain), and

- the nucleation frequency: $v=10^{+13} \mathrm{~s}^{-1}$.

Therefore with $\Delta W^{*}$ expressed in $\mathrm{J} / \mathrm{g}$.atom Eq. (34) becomes

$$
\log f=16+\log 5+\log t+\Delta W^{*} / R T \ln 10
$$


with $\Delta W^{*}$ given by Eq. (32) where the parameters $\sigma$ and A were estimated based on the results for $\mathrm{Fe}$ Ni alloys discussed in Ref. [81] and the fact that in Pu-1.9 at.\% Ga the shear modulus is about one fifth that of iron (note that both quantities depend on the shear modulus, and that according to Frank's model $\sigma$ depends on the bulk modulus). For these two parameters we will assume a variation with alloy composition, $x_{G a}$, and with temperature, $T$. These two parameters take the following values at zero temperature:

- for the $\delta \rightarrow \gamma$ transformation:

the energy of the semi-coherent embryo-parent phase interface:

$$
\sigma_{0}=\left(0.938+15.73 x_{G a}+59.67 x_{G a}^{2}\right) 10^{-5}{\mathrm{~J} . \mathrm{cm}^{-2}}^{-2}
$$

the shear parameter

$$
A_{0}=\left(0.938+15.73 x_{G a}+59.67 x_{G a}^{2}\right) 10^{2} J \mathrm{~cm}^{-3}
$$

and the molar volume (of the parent phase):

$$
V=15.443 \mathrm{~cm}^{3} / \text { g.atom }
$$

- for the $\delta \rightarrow \alpha$ transformation:

the energy of the semi-coherent embryo-parent phase interface:

$$
\sigma_{0}=\left(2.582-80.49 x_{G a}\right) 10^{-5} J . \mathrm{cm}^{-2}
$$

the shear parameter

$$
A_{0}=\left(2.582-80.49 x_{G a}\right) 10^{2} J . \mathrm{cm}^{-3}
$$

For both quantities, $\mathrm{K}=\sigma, \mathrm{A}$, a linear dependence with temperature is considered, similar to what has been proposed in Ref. [81] for Fe-Ni alloys, i.e.,

$$
K(T)=K_{0}(1-\alpha T)
$$

where $\alpha=0.0016$ and 0.0012 for the $\delta \rightarrow \gamma$ and $\delta \rightarrow \alpha$ transformation, respectively.

In Eq. (32) $\Delta G_{c}$ is expressed in Joules per mole of event. The Gibbs energy difference between the parent and the product phases, $\Delta G_{c}$, has to be evaluated down to $0 \mathrm{~K}$ for the two transformations that have been considered. For this purpose, the Gibbs energies evaluated in the course of the study on phase stability in section IV have to be extrapolated down to $0 \mathrm{~K}$ in accordance with the third law of thermodynamics (Nernst's law), i.e., such that the entropy $S=0=-\partial G / \partial T)_{T=0 K}$. To satisfy this constraint the following polynomial form for the Gibbs energy

$$
\Delta G_{c}=a+b T^{2}+c T^{3}
$$

has been assumed, and indeed guarantees that $\mathrm{S}=0$ at $0 \mathrm{~K}$ (note that in the following, the subscript $c$ will be dropped).

Based on the determination of the Gibbs energies for $\delta$ (fcc) and $\alpha$-based Pu-Ga alloys from Appendix $\mathrm{C}$ at 6 temperatures (from 250 to $500 \mathrm{~K}$ by step of $50 \mathrm{~K}$ ), a least-square fit was applied at the four alloy compositions for which kinetics data were available [76] (see also Ref. [48] for a review). The results are plotted in Fig. 50, and the numerical expressions for the difference in Gibbs energies (in $\mathrm{J} / \mathrm{mol}$ ) at the four compositions are: 


$$
\begin{aligned}
& \Delta G^{\delta \rightarrow \alpha}=-2,964.943+3.21310^{-2} T^{2}-3.08310^{-5} T^{3}, \text { for Pu-0.6 at.\% Ga } \\
& \Delta G^{\delta \rightarrow \alpha}=-2,842.957+3.17610^{-2} T^{2}-3.04910^{-5} T^{3}, \text { for Pu-0.7 at.\% Ga } \\
& \Delta G^{\delta \rightarrow \alpha}=-1,990.202+2.92110^{-2} T^{2}-2.82310^{-5} T^{3}, \text { for Pu-1.4 at.\% Ga } \\
& \Delta G^{\delta \rightarrow \alpha}=-1,381.433+2.74210^{-2} T^{2}-2.66410^{-5} T^{3}, \text { for Pu- } 1.9 \text { at. } \% \mathrm{Ga}
\end{aligned}
$$

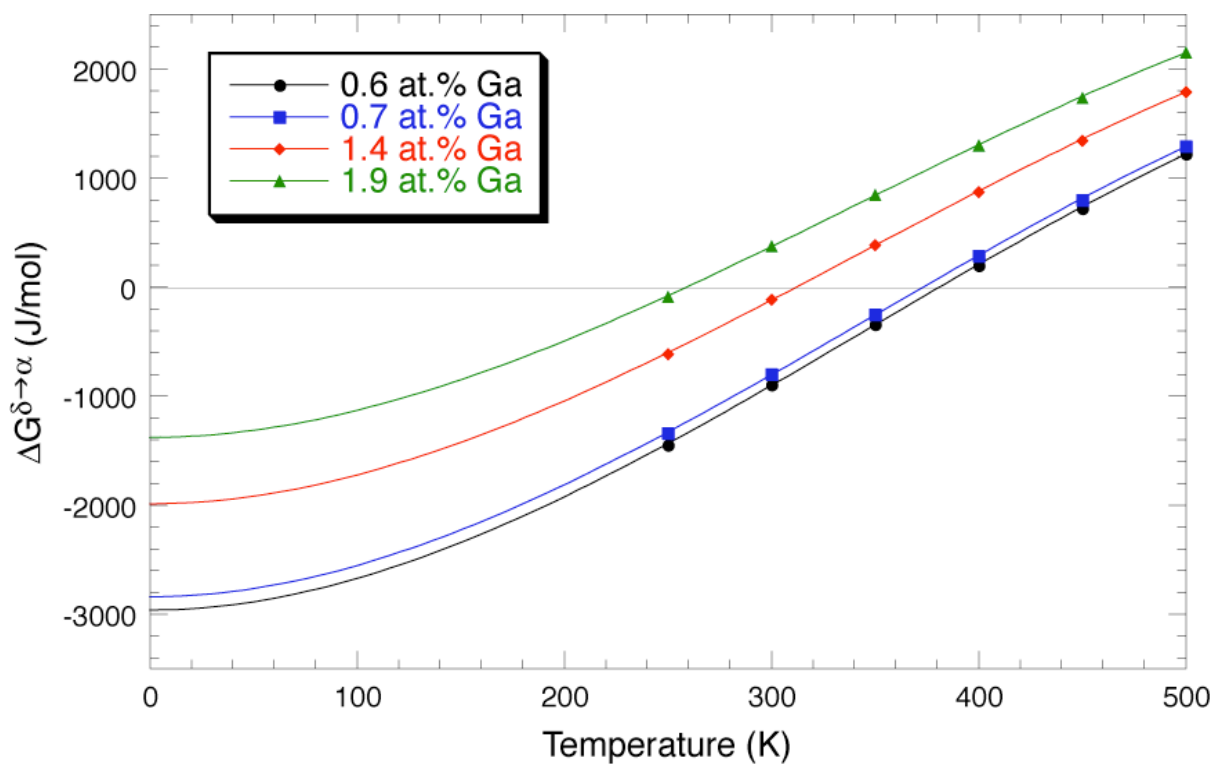

Figure 50. Gibbs energy difference (in $\mathrm{J} / \mathrm{mol}$ ) between $\alpha$ and $\delta$ $\mathrm{Pu}-\mathrm{Ga}$ alloys at four compositions as a function of temperature (in K). The lines correspond to the results from the leastsquare fit.

Note in Fig. 50 that at each composition the zero of Gibbs free energy corresponds to a temperature $\mathrm{T}_{0}$ by definition (cf. section IV.3). This means that above $\mathrm{T}_{0}$, the $\alpha$ phase is unstable. Based on Eq. (15) and Fig. 12, beyond the alloy composition of about 3.4 at. $\% \mathrm{Ga}, \Delta G^{\delta \rightarrow \alpha}>0$, and therefore no martensitic transformation should be observed.

To make these expression more general, each of the coefficients a, b, and c in Eq. (42) has been fitted by a third-order polynomial in mole fraction of $\mathrm{Ga}, \mathrm{x}_{\mathrm{Ga}}$, so that

$$
\begin{aligned}
& 10^{-3} \times a^{\delta \rightarrow \alpha}=-3.6983881+122.5070576 x_{G a}-51.1934067 x_{G a}^{2}+1,137.4542159 x_{G a}^{3} \\
& 10^{+2} \times b^{\delta \rightarrow \alpha}=+3.4385600-38.1419048 x_{G a}+97.1428572 x_{G a}^{2}-952.3809530 x_{G a}^{3} \\
& 10^{+5} \times c^{\delta \rightarrow \alpha}=-3.3038615+39.7805861 x_{G a}-575.2747252 x_{G a}^{2}+13,369.9633693 x_{G a}^{3}
\end{aligned}
$$

Similarly for the possible $\delta$ to $\gamma$ transformation in Pu-Ga alloys, the results for the difference in Gibbs energies (in $\mathrm{J} / \mathrm{mol}$ ) at the four compositions are plotted in Fig. 51, and the numerical expressions are given by

$$
\begin{aligned}
& \Delta G^{\delta \rightarrow \gamma}=-842.606+9.25010^{-3} T^{2}-7.32810^{-6} T^{3}, \text { for } \mathrm{Pu}-0.6 \text { at. } \% \mathrm{Ga} \\
& \Delta G^{\delta \rightarrow \gamma}=-900.676+1.04610^{-2} T^{2}-8.39910^{-6} T^{3}, \text { for } \mathrm{Pu}-0.7 \text { at. } \% \mathrm{Ga} \\
& \Delta G^{\delta \rightarrow \gamma}=-1,277.871+1.67510^{-2} T^{2}-1.57210^{-5} T^{3}, \text { for } \mathrm{Pu}-1.4 \text { at. } \% \mathrm{Ga} \\
& \Delta G^{\delta \rightarrow \gamma}=-1,515.102+2.44410^{-2} T^{2}-2.07410^{-5} T^{3}, \text { for } \mathrm{Pu}-1.9 \text { at. } \% \mathrm{Ga}
\end{aligned}
$$




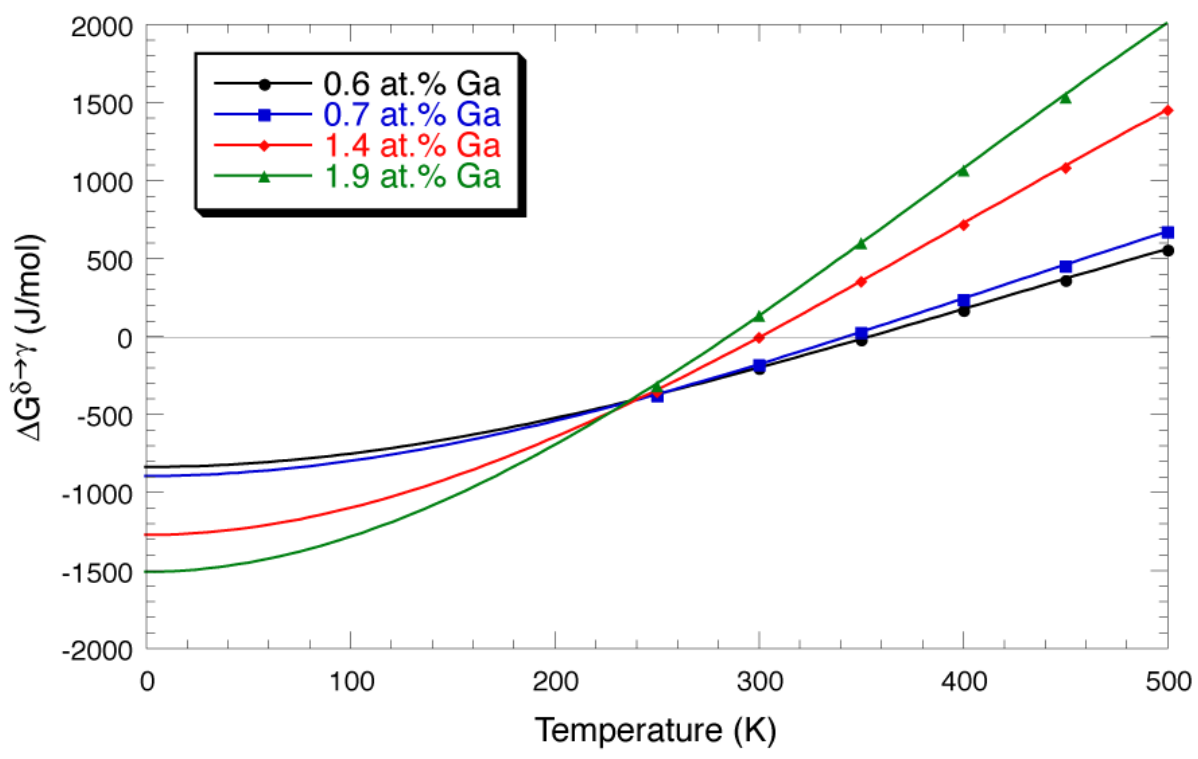

Figure 51. Gibbs energy difference (in $\mathrm{J} / \mathrm{mol}$ ) between $\gamma$ and $\delta$ $\mathrm{Pu}-\mathrm{Ga}$ alloys at four compositions as a function of temperature (in K). The lines correspond to the results from the leastsquare fit.

As in the previous case, to make these expression more general, each of the coefficients $a, b$, and $c$ in Eq. (42) has been fitted by a third-order polynomial in mole fraction of $\mathrm{Ga}, \mathrm{x}_{\mathrm{Ga}}$, so that

$$
\begin{aligned}
& 10^{-3} \times a^{\delta \rightarrow \gamma}=-0.4728333-64.6360749 x_{G a}+494.9706209 x_{G a}^{2}+1,039.8255492 x_{G a}^{3} \\
& 10^{+2} \times b^{\delta \rightarrow \gamma}=+0.1833317+125.4679448 x_{G a}-292.7870001 x_{G a}^{2}-2,634.2499981 x_{G a}^{3} \\
& 10^{+5} \times c^{\delta \rightarrow \gamma}=-0.0799080-110.1233839 x_{G a}+192.0336044 x_{G a}^{2}+4,196.9610793 x_{G a}^{3}
\end{aligned}
$$

In summary the equation that relates the time to the fraction of transformed phase is given by

$$
\log t=\log f-\log \left(n v V_{M}\right)-\frac{0.11 \pi \sigma_{0}^{3} A_{0}(1-\alpha T)^{4} N V^{3}}{\ln (10) R T \Delta G_{c}^{3}}
$$

where $\mathrm{N}$ is Avogadro's number $\left(6.0221367 \times 10^{23}\right)$ and $\mathrm{R}$ is the gas constant $(8.314510 \mathrm{~J} / \mathrm{mol} . \mathrm{K})$, and with the parameters that have been selected, i.e.,

- for the $\delta \rightarrow \gamma$ transformation:

$\sigma_{0}$ and $A_{0}$ from Eqs. (36) and (37), respectively, and $\alpha=0.0016$

$\Delta G_{c}$ from Eqs. (48) to (51)

- for the $\delta \rightarrow \alpha$ transformation:

$\sigma_{0}$ and $A_{0}$ from Eqs. (39) and (40), respectively, and $\alpha=0.0012$

$\Delta G_{c}$ from Eqs. (43) to (46)

It is worth noting that the location of the nose of the TTT curve, for any phase fraction $f$, is given by $\partial t / \partial T=0$, i.e.,

$$
-a-3 a \alpha T-7 b T^{2}+(3 b \alpha-10 c) T^{3}+6 c \alpha T^{4}=0
$$

where the parameters $\mathrm{a}, \mathrm{b}$, and $\mathrm{c}$ have been defined in Eq. (42).

For the four compositions that have been studied experimentally [48,76] TTT curves are shown in Figs. 52 and 53 together with the results from Orme et al. [76]. 

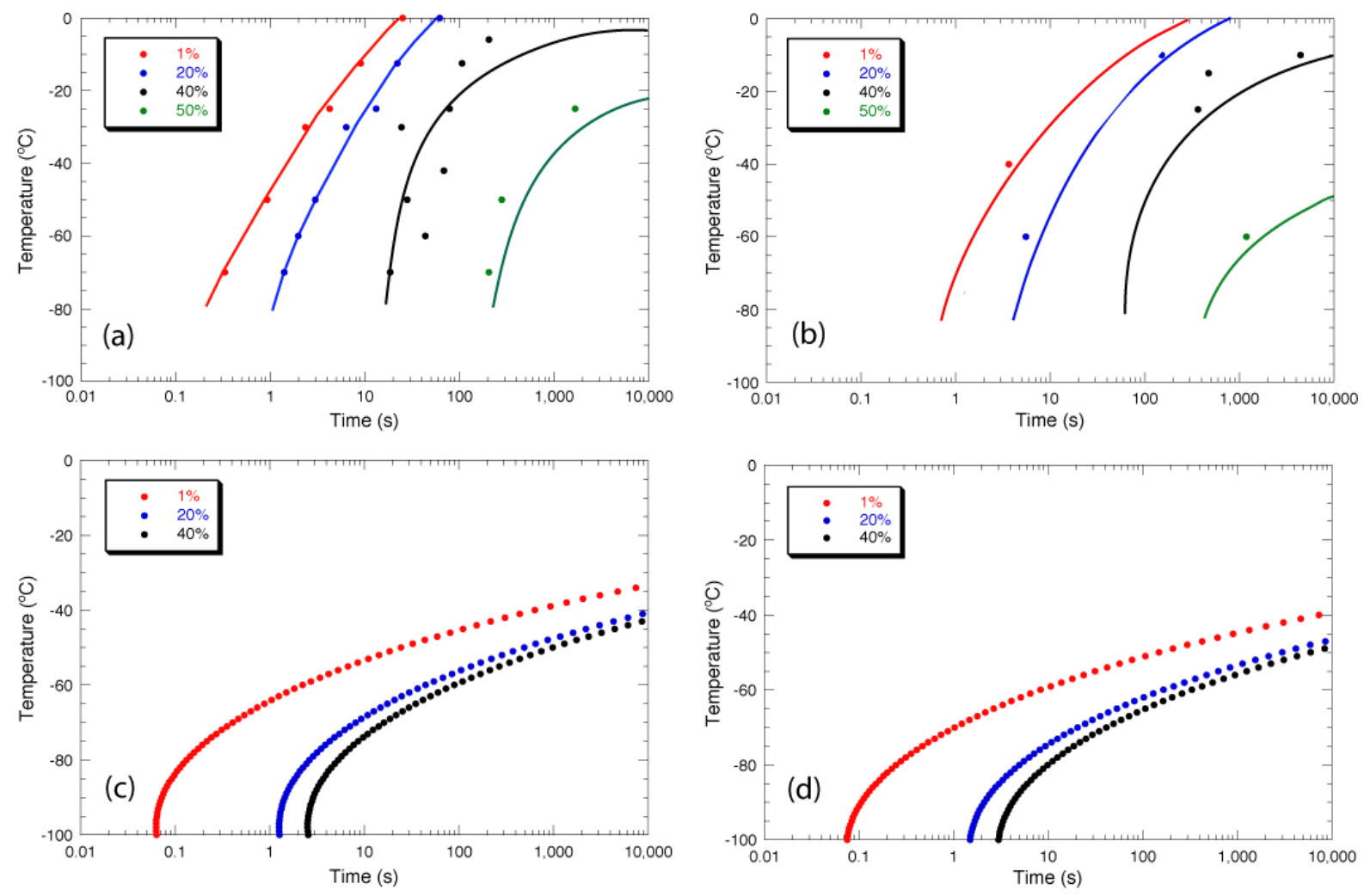

Figure 52. TTT curves associated with various rates of transformation for $\mathrm{Pu}-\mathrm{Ga}$ alloys with 0.6 ( $a$ and c) and 0.7 ( $b$ and d) at.\% Ga. The data points and curves in the upper panels (a and b) are redrawn from Orme et al. [76] whereas the results displayed in the lower panels (c and d) have been calculated from Eq. (53).
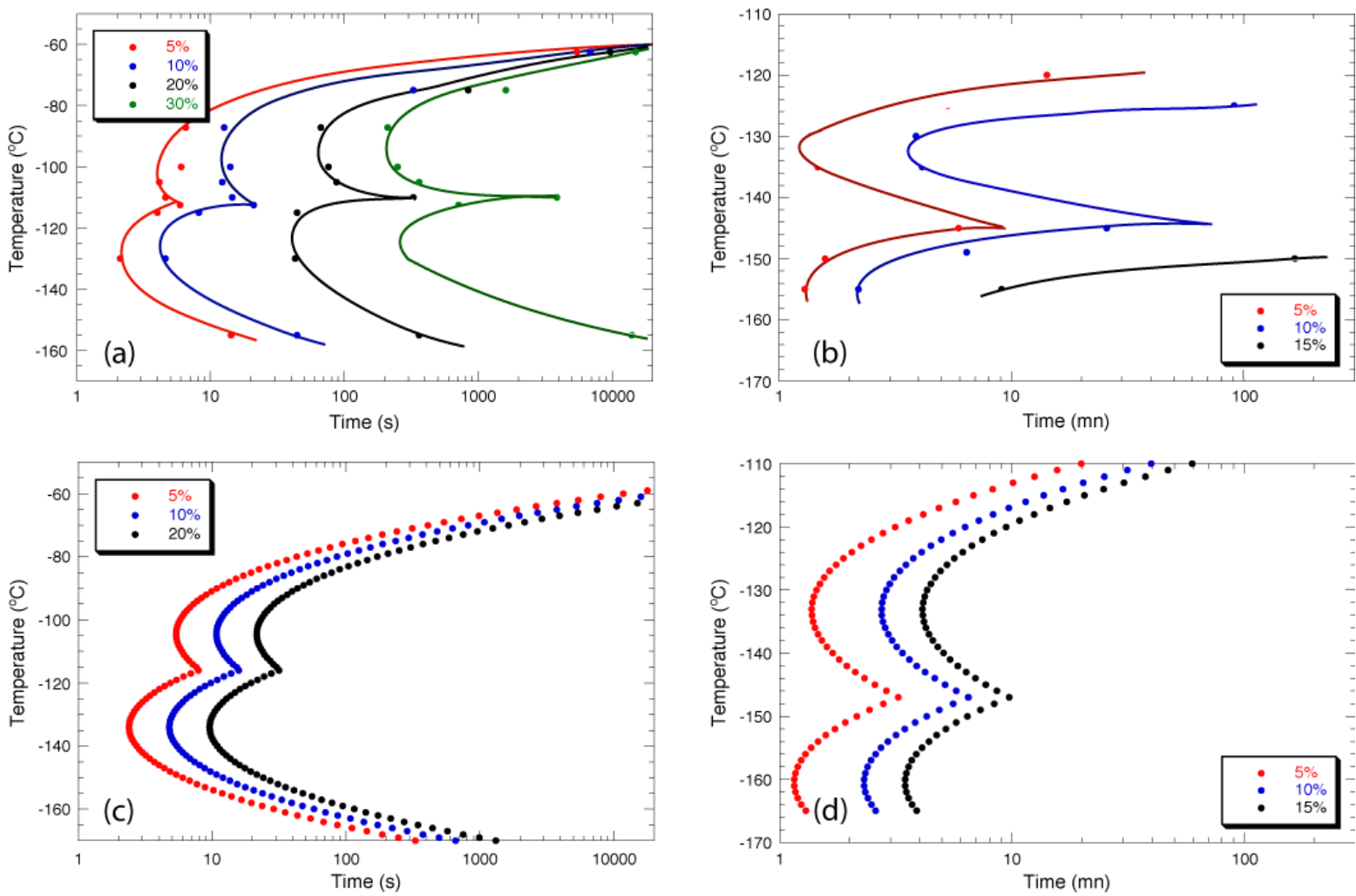

Figure 53. Same caption as for Fig. 52 but for Pu-Ga alloys with 1.4 (a and c) and 1.9 (b and d) at.\% Ga. 
Although differences can be noted in Figs. 52 and 53 between the experimental results and the calculated TTT curves obtained from the CK model the main features both in time and temperature have been captured. However it is worth noting that at all four alloy compositions the slow-down that seems to occur experimentally with an increase in the rate of transformation is not fully accounted for by the CK model. In this model, the main idea is that a heterogeneity, i.e. an embryo, must pre-exists beyond a critical size; and to grow fast into a martensite this embryo must go through a number of growth steps (or obstacles) that are thermally activated. In the CK model only one activation event is considered: the one that brings the embryo across the nearest obstacle. Instead of successive transfers of atoms as in early works this model assumes a repeated nucleation of dislocation loops at the parent/product interface. However, early on, it has been recognized that more than one obstacle should in principle be considered. Hence one would expect that after crossing a first obstacle, the embryo does not continue to grow instantly since a reverse reaction may be possible, and it is the detailed balance between the two reactions that should be considered in the overall mathematical description of the nucleation mechanism. This more accurate description of the martensite nucleation mechanism could explain why in the CK model the nucleation occurs faster at the highest rates of transformation. Recent progress along this line of reasoning has been made to improve on the original ideas and to contribute towards a unified description of athermal and isothermal nucleation of martensite [77-79].

In the present study the primary goal was to test the concept of martensite nucleation according to a model of nucleation of isothermal martensite that has been successfully applied to iron-nickel alloys. To account for the fundamental difference in TTT curves with Ga content (i.e., double versus single Cshape) it was assumed that at the highest Ga contents the rate-limited reaction in the $\delta \rightarrow \alpha$ transformation is controlled by the $\delta \rightarrow \gamma$ transformation at the highest temperatures whereas at the lowest temperatures the $\delta \rightarrow \alpha$ transformation proceeds with no intermediate reaction. Once these assumptions have been made, the thermodynamics of the $\gamma$ phase had to be adjusted to account for its thermodynamic stability in a narrow region of Ga composition at low temperatures (cf. the definition of the Redlich-Kister parameter for the definition of the $\gamma$ solid solution in Appendix C2.6). Indeed to paraphrase Morris Cohen [83]:“In order for a phase change to proceed spontaneously at a given temperature and pressure, it must be accompanied by a decrease in free energy. The martensitic transformation is no exception to this generalization... The excess in free energy of the parent phase over that of the martensite may be regarded as the "driving force" behind the martensitic transformation". It is worth mentoning that within the CK model, the absence of upper C-curve at low Ga content (cf. Fig. 52) is simply caused by the extremely slow $\delta \rightarrow \gamma$ transformation (caused by the rather small thermodynamic driving force calculated at low Ga content).

In a near future additional effort will be put to improve the modeling of the nucleation mechanism as it takes place in a martensite transformation, and to better account for the slow-down at higher transformation rate. Further testing will be done by comparison with experimental data that have been collected for $\mathrm{Pu}-\mathrm{Al}$ alloys for which a similar transformation has been observed $[48,84]$. 


\section{THERMO-CHEMISTRY OF OTHER ACTINIDE-BASED AND RELATED ALLOYS}

The results discussed above represent a first step toward building a thermodynamic database that combines all possible combinations of the following actinide elements $\{\mathrm{U}, \mathrm{Np}, \mathrm{Pu}, \mathrm{Am}\}$ and $\mathrm{Ce}$ with $\{\mathrm{Al}, \mathrm{C}, \mathrm{Fe}, \mathrm{Ga}, \mathrm{Ni}, \mathrm{O}, \mathrm{Zr}\}$ so that questions on stability, aging and other properties that strongly depend on this knowledge can be addressed. This set of selected elements generates 66 binaries, since if $\mathrm{n}$ is the number of unaries, and $\mathrm{m}=2$ refers to binary combination, the total number of binary alloys is given by $\mathrm{n} ! /[\mathrm{m} !(\mathrm{n}-\mathrm{m}) !]$. In this study, 6 binary alloys were fully assessed: Al-Fe, Al-Ga, Al-Pu, Fe$\mathrm{Ga}, \mathrm{Fe}-\mathrm{Pu}$, and $\mathrm{Ga}-\mathrm{Pu}$. As a result of an extended literature search thermodynamic assessments are available for the following binaries:

Al-Ni [85-87], Al-Pu [88], Al-Zr [89], C-Fe [90], Fe-Ni [25], Fe-Np [91], Fe-Pu [92,93], Fe-U [94,95], Fe-Zr [90,93-96], Ga-Ni [97,98], O-Pu [99,100], O-U [101,102], O-Zr [99,101,102], Pu-U [92,103-105], Pu-Zr [99,104,105], U-Zr [93,94,101-105].

In addition, experimental information (and in some cases, thermodynamic assessments) exists for the following ternary and quaternary alloys:

Al-Fe-U [106], C-Fe-Zr [90], Fe-Pu-U [92], Fe-Pu-Zr [107], Fe-Si-U [108], Fe-Sn-U [109], Fe-U-Zr [93,94,110], O-Pu-Zr [99], O-U-Zr [101,102], Pu-U-Zr [103-105], and the quaternary U-Pu-Fe-Zr system [111,112].

It is also worth mentioning general information contained in Ref. [113] on a systematic study of compound formation in actinides (and lanthanides) -based materials, and the characterization of specific compounds occurring in the binary U-Al alloy [114] and the ternary Al-Fe-U system [115]. In addition, for comparison purposes, the Al-Ce-Mg [116] and Al-Ce-Nd [117,118] systems have been thermodynamically assessed. The prospects of this topic of thermo-chemistry of actinide alloys is further discussed in section XII.1.

\section{CONCLUSIONS}

The CALPHAD methodology has been applied to the study of the statics (stability) and kinetics (aging) of phase formation and evolution in Pu-based alloys. A new thermodynamic database has been generated to account for the stability properties of several binary alloys, including $\mathrm{Al}-\mathrm{Fe}, \mathrm{Al}-\mathrm{Ga}$, $\mathrm{Al}-\mathrm{Pu}, \mathrm{Fe}-\mathrm{Ga}, \mathrm{Fe}-\mathrm{Pu}$, and $\mathrm{Ga}-\mathrm{Pu}$, and of the ternary Al-Fe-Pu and $\mathrm{Fe}-\mathrm{Ga}-\mathrm{Pu}$ alloys. A kinetic database has also been created to account for the kinetics of phase transformations in Ga-Pu alloys.

For pure $\mathrm{Pu}$, the thermodynamic assessment is in excellent agreement with available experimental data. This is in a sense a self-gratifying remark since the thermodynamic assessment of the various phases of pure $\mathrm{Pu}$ was based on experimental information gathered mostly during the 60's and 70's on heats of formation and transformation, transition temperatures, activities, and heat capacity data. The most recent DSC measurements have confirmed the reliability of the thermodynamic information. However, based on this assessment, additional information (in a sense predictions) on actual and hypothetical heats of formation and transformation among the various allotropes of pure $\mathrm{Pu}$ as functions of temperature are made available together with transition temperatures for further compari- 
son with experiment or quantum mechanical-based values.

For $\mathrm{Ga}-\mathrm{Pu}$ and $\mathrm{Al}-\mathrm{Pu}$ alloys, phase diagram assessment in the entire composition range was performed with input from high-temperature phase diagrams and estimates of heats of formation of various compounds. These two assessments constitute definite improvements over those done in the past on reduced portions in composition and temperature of the phase diagrams. An eutectoid-phase decomposition is predicted for both alloys at low temperature in the $\mathrm{Pu}$-rich portion of the phase diagram, as summarized in Fig. 54, in agreement with the experimental results obtained in the former Soviet Union.
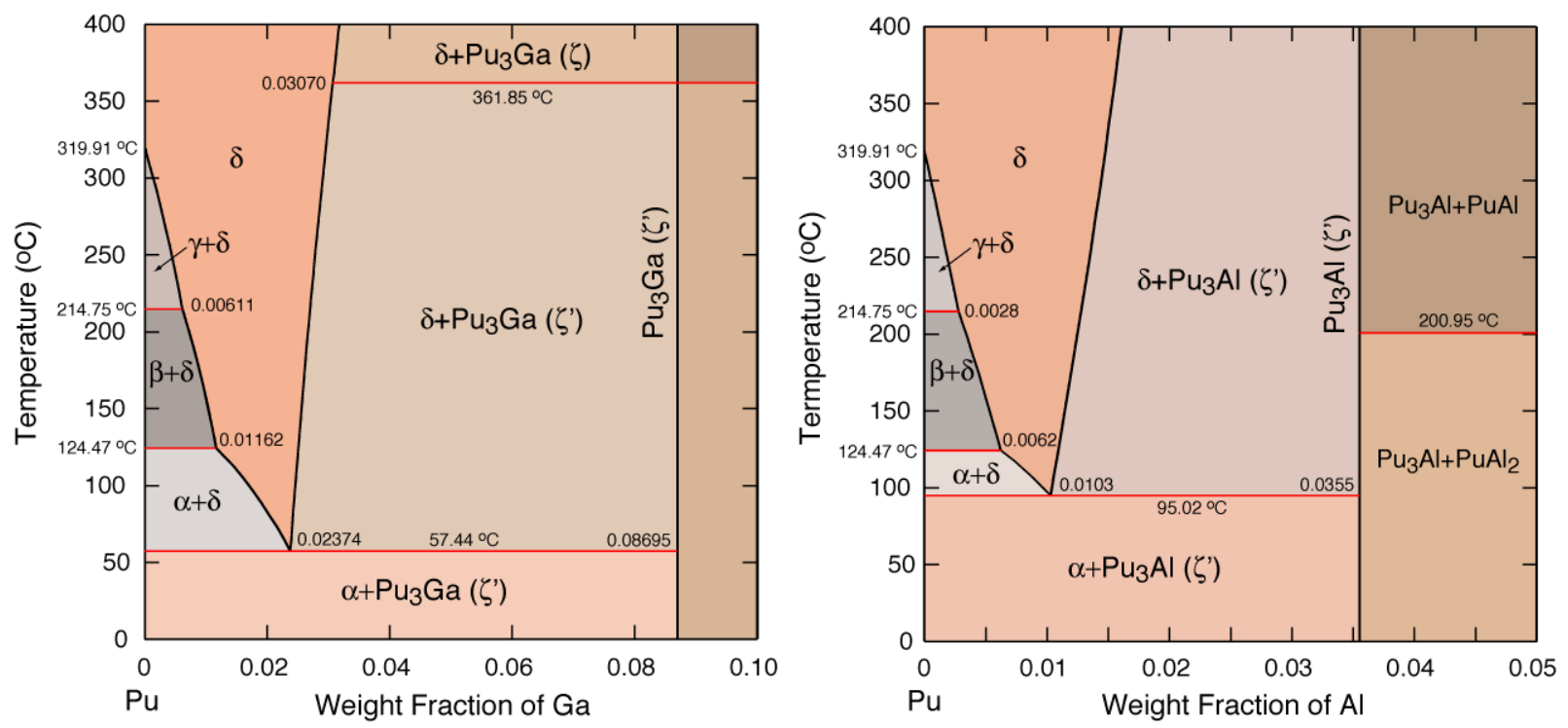

Figure 54. Pu-rich and low-temperature portion of the calculated phase diagrams of Pu-Ga (left) and $\mathrm{Pu}-\mathrm{Al}$ (right) where along the horizontal axis the weight fraction of $\mathrm{Ga}$ and $\mathrm{Al}$ are reported.

For $\mathrm{Fe}-\mathrm{Pu}$, the congruent melting of the $\mathrm{FePu}_{6}$ compound is predicted in contradistinction with the peritectic reaction that was tentatively suggested from incomplete experimental data.

With assessments of additional subsystems, the thermodynamic properties of the two ternary alloys, $\mathrm{Al}-\mathrm{Fe}-\mathrm{Pu}$ and $\mathrm{Fe}-\mathrm{Ga}-\mathrm{Pu}$ have been obtained, and the liquidus surfaces and isothermal sections of the ternary phase diagrams have been predicted for the first time. In the case of $\mathrm{Fe}-\mathrm{Ga}-\mathrm{Pu}$ alloys, even with a small Fe content (tens of ppm), a two-phase alloy is found stable at low temperatures with precipitation of $\mathrm{Pu}_{6} \mathrm{Fe}$ in the fcc-based $\mathrm{Pu}-\mathrm{Ga}$ solid solution.

The results on the statics of phase transformation for the various alloys discussed in this study constitute a small fraction of what can be made available. For example the possibility of suspending (i.e., ignoring) phases during phase diagram calculations provides a simple way of identifying domains of existence of "metastable" phases that may be confirmed experimentally under particular circumstances. This can find useful applications since specific physical and mechanical properties are associated to each phase. As an example Fig. 55 shows the "partial" Pu-Ga phase diagram that is associated with $\alpha, \delta$, and the two $\mathrm{Pu}_{3} \mathrm{Ga}$ compounds ( $\zeta$ and $\xi^{\prime}$ ), with all other phases ignored during 
the calculations. The present results based on a restricted set of phases can be repeated for any other combination of phases. Incidentally this type of calculations is highly recommended during an assessment to check the overall consistency of the thermodynamic data (indeed, it is very unlikely that phases appear in an erratic fashion in temperature and alloy composition since the Gibbs energy for

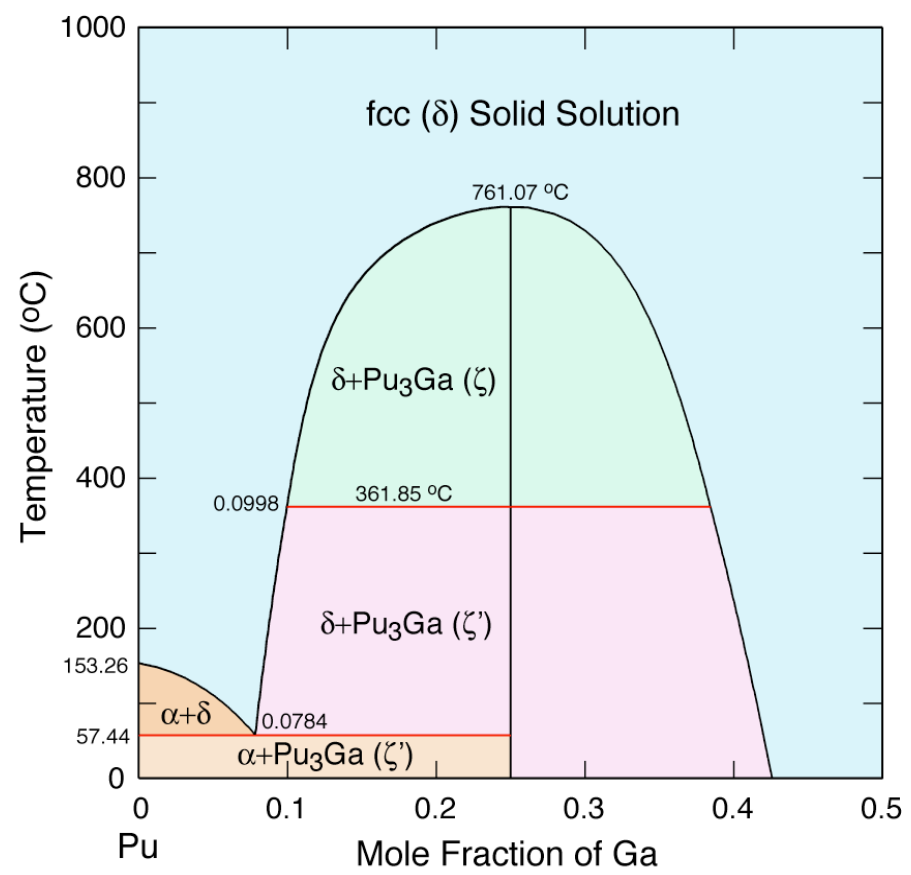

Figure 55. "Partial" phase diagram of the $\mathrm{Pu}-\mathrm{Ga}$ Alloy system. The $\alpha$ phase, the fcc $(\delta)$ solid solution and the two $\mathrm{Pu}_{3} \mathrm{Ga}$ ( $\zeta$ and ' $\zeta$ ') compounds are the only phases that have been considered for the determination of this phase diagram.

each phase is expected to vary smoothly with these two variables). Another representation that was not displayed in this report is the $\{$ temperature, chemical potential\} representation of a phase diagram. For example in Fig. 56 the Pu-Ga phase diagram is displayed with the chemical potential of $\mathrm{Ga}$ along the

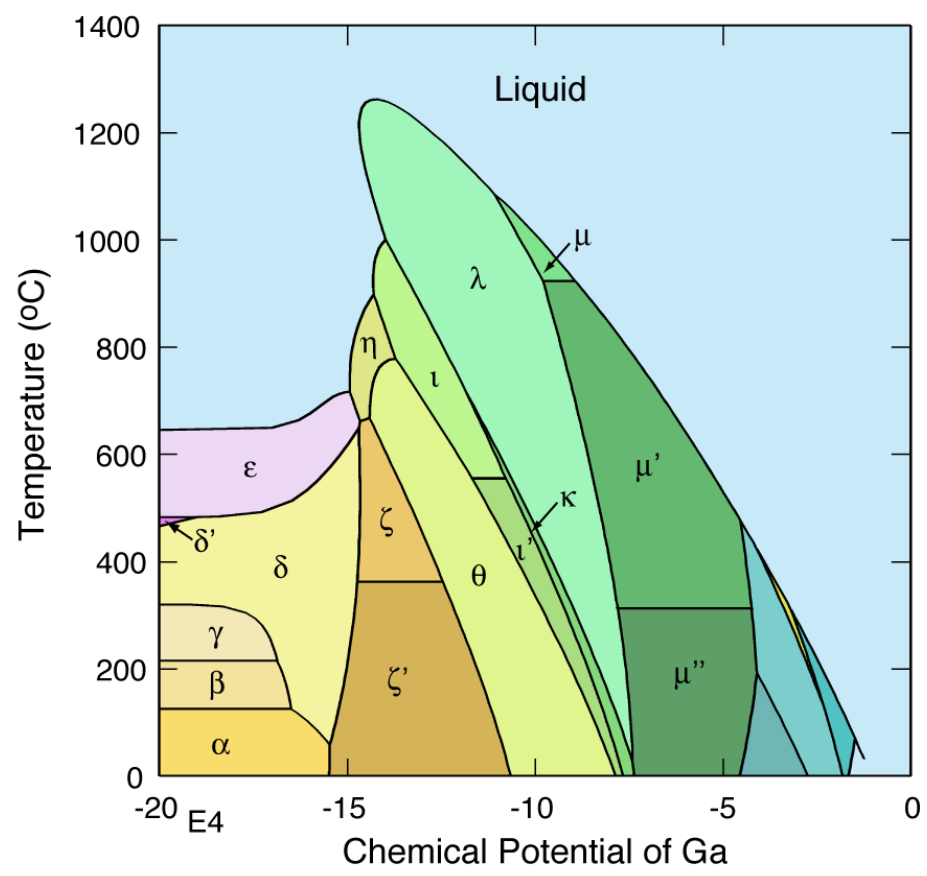

Figure 56. $\mathrm{Pu}-\mathrm{Ga}$ phase diagram in the \{temperature, chemical potential\} representation obtained under the same conditions as Fig. 8. Each Greek letter as defined in Table 5 refers to a phase. 
abscissa. Each domain in this diagram should be associated with a single phase. Note that the chemical potential $\mu_{i}$ of element $\mathrm{i}$ is related to the activity $a_{i}$ by the relation $\mu_{i}=R T \ln a_{i}$, and the activity itself is directly accessible experimentally by electromotive force (emf) measurements [20].

Kinetics of phase transformation has been studied for various reactions in $\mathrm{Pu}-\mathrm{Ga}$ alloys, in particular the precipitation of $\mathrm{Pu}_{3} \mathrm{Ga}$ and of $\alpha-\mathrm{Pu}$ in the fcc $(\delta)$ solid solution, and the eutectoid-phase decomposition. It was concluded that since the long-range atomic diffusion was inhibited in $\mathrm{Pu}-\mathrm{Ga}$ alloys at low temperatures and in the composition range where these transformations occur, the fcc matrix although thermodynamically unstable could be retained as a "metastable" phase at low temperatures for an infinite time (hundreds of thousand of years!), a situation similar to the one encountered in carbon steels. The predicted sluggish kinetics also implies that experimental phaseboundary determination becomes less accurate as temperature decreases, and the results of the calculations can be used advantageously to correct for these uncertainties.

Finally, the martensitic transformation that takes place at low temperatures in the $\mathrm{Pu}$-rich $\mathrm{Pu}-\mathrm{Ga}$ alloys has been fully analyzed, and predictions are in reasonnable agreement with the experimental observations made in the past. The Cohen-Kaufman model properly accounts for the change in time scale with alloy composition in the temperature-time-transformation (TTT) representation of the early stage of martensite nucleation. A rate control reaction at the highest Ga contents was proposed to explain the transition from double to single C-shape of the TTT curves with a decrease in Ga content. Materials parameters that have been selected in this study will be used in a near future to predict martensite microstructure with phase field modeling (cf. section XII.4).

The present work has shown that the tools are in place to properly describe the statics and kinetics of phase transformations in actinide alloys. Solidification (process and path) can also be studied with Thermo-Calc within the Scheil-Gulliver approximation or more accurately by solving the full problem of diffusion with DICTRA. The thermo-chemical and diffusion databases can be revisited and easily modified when additional experimental results are made available. Of special interest are those from DSC (differential scanning calorimetry) and DTA (differential thermal analysis) analysis. For example liquidus surfaces as predicted from CALPHAD could be "easily" validated by DTA at various alloy compositions.

It was recently shown that a natural interface between $a b$ initio (and tight-binding) and CALPHAD exists [119]. This interface can be used advantageously to test the validity of quantummechanical based predictions of heats of formation and transformation whenever available, and to study the impact quantum mechanical-based input on phase stability at finite temperature and on phase diagram. It was also shown that a similar interface exists between the thermodynamic output from molecular dynamic (MD) simulations based on EAM (embedded atom method) potentials and CALPHAD [120,121]. In this case, either the EAM results can be efficiently tested within the 
CALPHAD formalism and supplement the thermodynamic database when data are lacking, or conversely, the CALPHAD results can be used to improve the "quality" of the EAM potentials for subsequent MD simulations. On the kinetics side, the mobilities and energy barriers that make up the kinetic database are more difficult quantities to evaluate with a quantum mechanical-based approach. Indeed, if these quantities are well defined in a phenomenological context, their definition is more ambiguous within a first-principles framework. Although not yet reported, the input to the kinetic database from MD simulations based on empirical potentials for the purpose of studying the kinetics of transformation within CALPHAD can be of potential interest. A summary of the various interfaces is presented in Fig. 57.

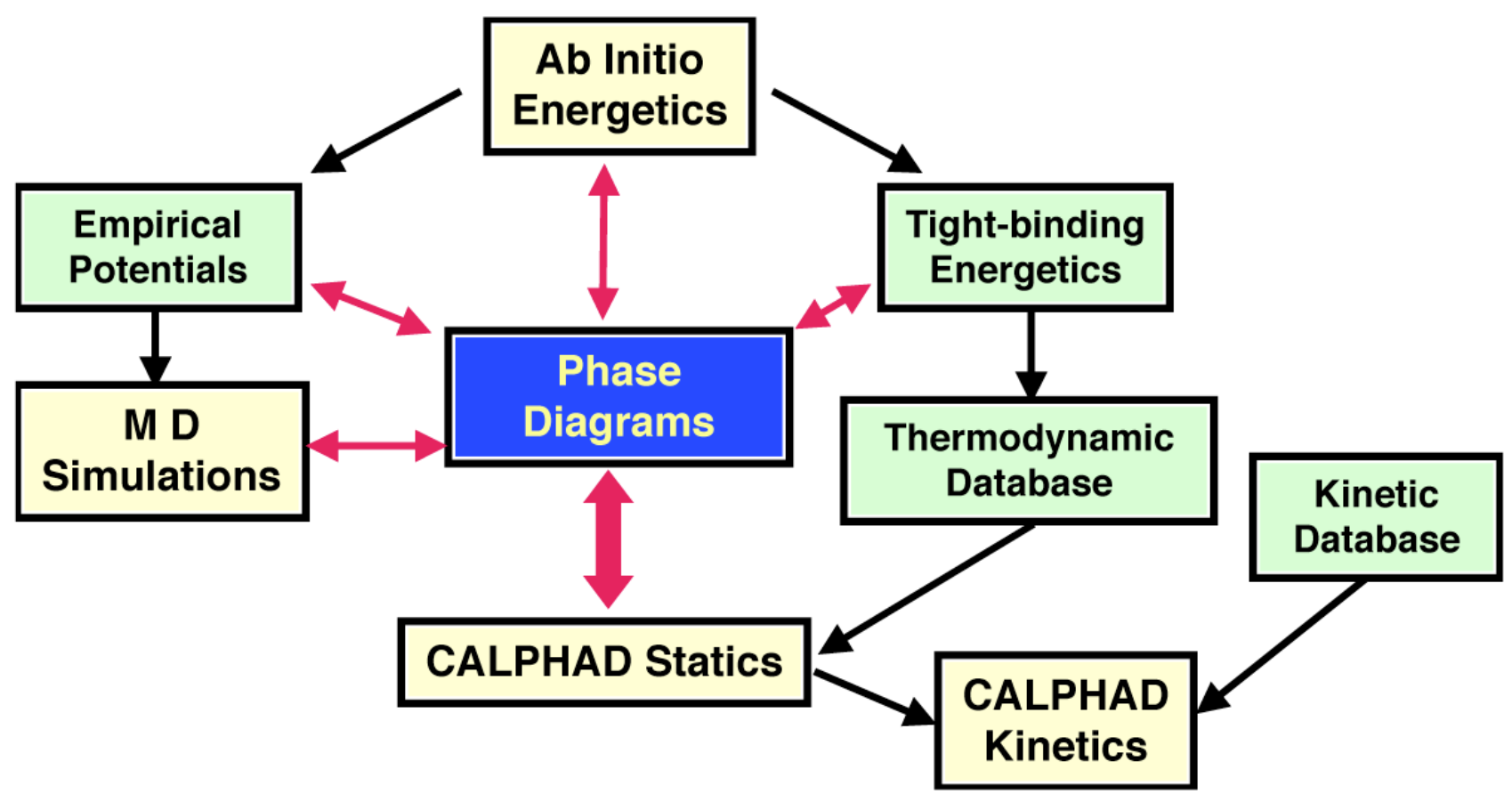

Figure 57. Linkage between thermodynamic properties of alloys (phase diagrams), CALPHAD statis and kinetics, electronic structure methods ( $a b$ initio and tight-binding), and molecular dynamic simulations based on empirical potentials. Interfaces are denoted by red arrows.

\section{PROSPECTS}

From this study several paths forward have been identified. They all correspond to natural extensions of the present work that can be modeled with either already existing technology or tools that have been developed in recent years by others in the scientific community.

\section{XII.1. Extension of the actinide thermodynamic database}

The first path forward is immediate and has been alluded to in section X: it corresponds to an extension of the existing thermo-chemical database to other actinides in a self-consistent manner. This will allow us to examine the role of diverse solutes in stabilizing phases in multi-component alloys. 
Examples of interest include the quaternary Fe-Ga-Ni-Pu system, and the role of decay products of $\mathrm{Pu}$, such as $\mathrm{Am}, \mathrm{Np}$, and $\mathrm{U}$, on the statics and kinetics of transformations in this quaternary alloy system. This study will require the thermodynamic analysis of a number of subsystems such as: Am$\mathrm{Pu}, \mathrm{Ni}-\mathrm{Pu}, \mathrm{Np}-\mathrm{Pu}$, and $\mathrm{U}-\mathrm{Pu}$ among which $\mathrm{U}-\mathrm{Pu}$ is the only binary system for which a full assessment is available [92,103-105]. This work (cf. also section X) would complement efforts conducted in Japan at the Central Research Institute of Electric Power Industry sponsored by the Japan Atomic Energy Research Institute, and in the European Community through the CIT (Corium Interaction and Thermochemistry) and ENTHALPY (European Nuclear Thermodynamic Database) projects. Both in Japan and Europe these efforts are geared toward modeling the thermochemistry of materials in usage in nuclear plants with the CALPHAD approach. These materials include all combinations of U (and the fuel $\left.\mathrm{UO}_{2}\right)$ and $\mathrm{Pu}$ with zircalloy $(\mathrm{Zr})$, steel structures $(\mathrm{Fe}, \mathrm{Cr}, \mathrm{Ni})$, control rods $(\mathrm{Ag}, \mathrm{Cd}, \mathrm{In}$, or $\mathrm{B}, \mathrm{C})$, selected fission products ( $\mathrm{Ba}, \mathrm{La}, \mathrm{Ru}, \mathrm{Sr})$, concrete $\left(\mathrm{Al}_{2} \mathrm{O}_{3}, \mathrm{CaO}, \mathrm{FeO}, \mathrm{Fe}_{2} \mathrm{O}_{3}, \mathrm{MgO}, \mathrm{SiO}_{2}\right)$, water and air $(\mathrm{H}, \mathrm{O})$.

\section{XII.2. Constitutive laws for transformation plasticity}

Secondly, constitutive relations for transformation plasticity will be derived to account for the transformation plasticity behavior in uni-axial compression as a function of composition, temperature and strain rate in plutonium-based alloys. Since the information gathered in the present work on the thermodynamics and kinetics of isothermal martensitic transformation in $\mathrm{Pu}-\mathrm{Ga}$ alloys represents a noticeable improvement on past evaluations [49,56,122], it is anticipated that the predictions on transformation plasticity in the stress-assisted transformation regime will be made more accurate [123]. The model put forward in Ref. [122] is based on the Patel-Cohen approximation for the stress dependence of the thermodynamic driving force, and on the assumption that the nucleation activation energy varies linearly with the driving force. This study will offer guidance on the control of phase stability for enhanced fracture toughness and tensile ductility.

\section{XII.3. Composition-pressure-temperature phase diagrams}

The third path forward concerns the study of concentration-pressure-temperature (CPT) phase diagrams [124]. It is usually assume that the pressure variable can be excluded from the Gibbs energy functions for solid-state transformations, since the magnitude of the PV term is small at atmospheric pressure. However with increase pressure, the extra contribution to the Gibbs energy which is given by

$$
G_{m}^{X \rightarrow Y}=\int_{0}^{P} V_{m}^{X \rightarrow Y} d P
$$

where $V_{m}^{X \rightarrow Y}$ is the change in molar volume associated with the transformation of $\mathrm{X}$ to $\mathrm{Y}$, cannot be ignored. Beyond the earlier treatments that were proposed, the volume is now made temperature and pressure dependent, and the expression given by Eq. (1) in section II.1 is rewritten as

$$
G_{m}^{P, T}-H_{m}^{S E R}=a+b T+c T \ln T+\sum d_{n} T^{n}+\int_{0}^{P} V_{m}^{P, T} d P
$$

where 


$$
\int_{0}^{P} V_{m}^{P, T} d P=V_{0}\left\{\left(1+n P \kappa_{P=0}^{T}\right)^{(n-1) / n}-1\right\} \frac{\exp \left(\alpha_{P=0}^{T}\right)}{(n-1) \kappa_{P=0}^{T}}
$$

where $\alpha_{P=0}^{T}$ is the thermal expansion at zero pressure given by

$$
\alpha_{P=0}^{T}=(\partial V / V \partial T)_{P}=\alpha_{0}+\alpha_{1} T+\alpha_{2} T^{2}+\alpha_{3} T^{-2}
$$

$\kappa$ is the isothermal compressibility also expressed as a function of temperature according to

$$
\kappa_{P=0}^{T}=-(\partial V / V \partial P)_{T}=\kappa_{0}+\kappa_{1} T+\kappa_{2} T^{2}
$$

and $\mathrm{V}_{0}$ is an empirical parameter with the dimension of a volume.

Hence, following the same CALPHAD methodology, assessment of existing data available for binary systems and extension to multi-component alloys can be done to predict CPT phase diagrams [125-128].

\section{XII.4. Phase-field modeling}

Finally the third extension of this work, and possibly the most promising one, pertains to the use of the thermo-chemical and diffusion databases to study microstructure evolution in alloys in the presence of defects and/or under applied stress. The most advanced method to study such properties is the phase-field method (PFM) [129]. It was recently realized that CALPHAD could be linked to PFM as shown in Fig. 58 to make the predictions both in time and length scales more relevant [130133]. PFM can also be used to study solidification under applied stress or not in complex alloys. This unified framework together with the thermodynamic and kinetic data that have been assessed in the present study will be used to address relevant issues in the meso-scale on solute effect on

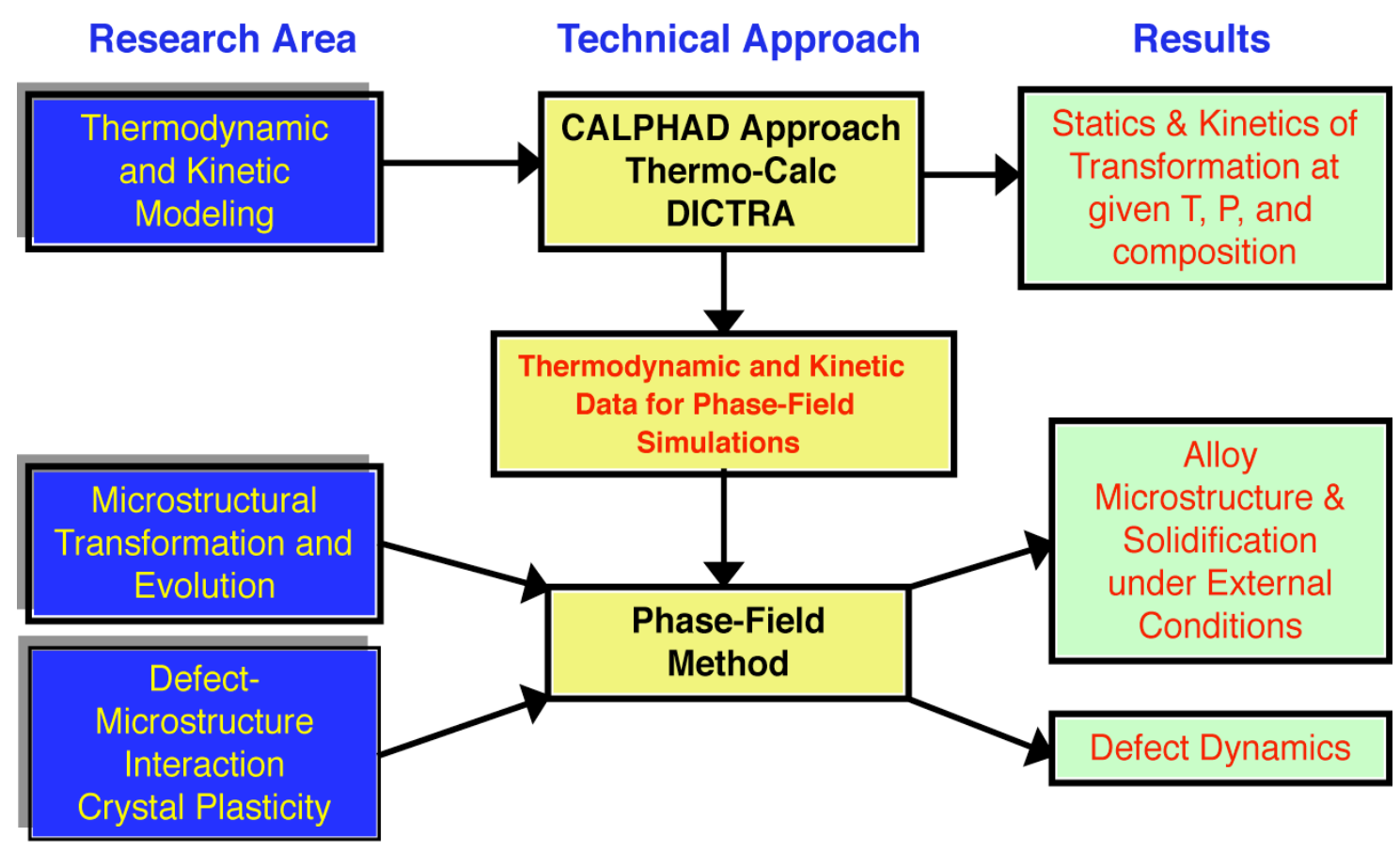

Figure 58. Linkage between CALPHAD and the phase-field method (PFM). Research areas and results are also indicated for CALPHAD and PFM. 
mechanical properties. Among the problems that could be addressed with PFM it is worth mentioning: modeling of the martensitic transformation in $\mathrm{Pu}-\mathrm{Ga}$ alloys and of the dynamics of dislocation motion in Pu-Ga alloys in the presence or not of an applied stress, microstructure evolution during eutectoid decomposition in $\mathrm{Pu}-\mathrm{Ga}$ alloys, and finally solidification of $\mathrm{Pu}$-rich $\mathrm{Pu}-\mathrm{Ga}$ alloys as a function of pressure.

In recent years, analytic and computational models have significantly contributed to a better understanding of the morphology and the kinetics of martensitic transformations. Since the initials studies performed with one- and two-dimensional models and mostly for mono-crystalline parent phase [134-136], computational tools based on phase-field microplasticity have been developed to accurately and efficiently model the kinetics of martensitic transformations in three dimensions [137] and for polycrystalline materials $[138,139]$. The understanding of the martensitic transformation in polycrystalline $\mathrm{Pu}-\mathrm{Ga}$ alloys will necessitate an extension of current modeling to account for the transformation from the parent fcc phase to the low-symmetry monoclinic product phase that is accompanied by a large volume change, a drastic change in the elastic properties, and a large elastic anisotropy. The information established in the recent past on the crystallography of the transformation $[48,140,141]$ will be used to extend phase-field microplasticity theory to the Pu-Ga case.

The microstructure evolution during the eutectoid precipitation of $\alpha-\mathrm{Pu}$ and $\mathrm{Pu}_{3} \mathrm{Ga}$ from the parent face centered cubic phase of $\mathrm{Pu}-\mathrm{Ga}$ is a problem that can also be formulated within PFM, in a way similar to what has been done in the case of the precipitation of ordered intermetallics [142]. Once again the thermodynamic data and the kinetic parameters that have been obtained in the present study will be used to perform realistic simulations.

Finally, in the case of solidification, the most recent multi-phase field approach interprets the phase fields as local phase fractions and assigns one field to each phase present [143,144]. Although simulations of eutectic growth to date have been carried out in two dimensions [144], calculations in three dimensions are now possible. Rapid solidification reduces the disparity of several orders of magnitude in length and time scales between the microstructural pattern formation and the width of the solid-liquid interface (nanometer scale) and the attachment kinetics of atoms at the interface (picosecond time scale). This reduction will render the simulations based on PFM computationally feasible, especially in the case of the rapid re-solidification of Pu-Ga alloys under pressure.

It has been alluded to in the three planned studies discussed above that the integration of phasefield micromechanics with the phase-field kinetics equations together with input thermodynamic and kinetic information gathered from the CALPHAD approach provides an efficient and versatile theoretical tool for predicting mesoscopic microstructures in the presence or not of defects and of an external stress.

\section{ACKNOWLEDGMENTS}

This work was performed under the auspices of the U. S. Department of Energy by the University of California Lawrence Livermore National Laboratory under Contract W-7405-ENG-48, 
supported by the LDRD office at LLNL from October 2000 to September 2003 ("Thermodynamics and Structure of Plutonium Alloys", LDRD project 01-ERD-030) and by the ASCI program on Dynamics of Metals. The Thermo-Calc and DICTRA programs are licensed by The Foundation for Computational Thermodynamics (Stockholm, Sweden). P. T. is grateful to Gil Gallegos, Tien Shen and Pat Allen (LLNL), Leo Brewer (UC Berkeley), Ted Massalski (Carnegie Mellon University), Sig Hecker (LANL), and Masaki Kurata (CRIEPI, Tokyo, Japan) for technical discussions during the various phases of this work. Thanks are also due to Tony Gonis, Bart Ebbinghaus, and Gil Gallegos for useful suggestions and comments, and for corrections made on early versions of the manuscript. Finally, P. T. owes a great debt of gratitude to Elaine Chandler who has been providing continuous encouragement and support in this venture beyond the three years of LDRD-ER.

\section{REFERENCES}

[1] F. L. Oetting, M. H. Rand, and R. J. Ackermann, The Chemical Thermodynamics of Actinide Elements and Compounds, Part 1: The Actinide Elements, F. L. Oetting, V. Medvedev, M. H. Rand, and E. F. Westrum, Jr., eds. (International Atomic Energy Agency, Vienna, 1976); and references therein.

[2] "Challenges in Plutonium and Actinide Materials Science", MRS Bulletin Vol. 26, No. 9, September 2001.

[3] F. H. Ellinger, "Crystal structure of delta-prime and the thermal expansion characteristics of delta, delta-prime, and epsilon plutonium”, Trans. AIME 206, 1256 (1956).

[4] W. H. Zachariasen and F. H. Ellinger, "The crystal structure of alpha plutonium metal", Acta Cryst. 16, 777 (1963).

[5] P. Söderlind, O. Eriksson, B. Johansson, and J. M. Wills, "Electronic properties of f-electron metals using the generalized gradient approximation”, Phys. Rev. B 50, 7291 (1994), and references therein.

[6] Olle Eriksson, L. E. Cox, B. R. Cooper, J. M. Wills, G. W. Fernando, Y. G. Hao, and A. M. Boring, "Possibility of a $\delta$-like surface for $\alpha$-Pu: Theory", Phys. Rev. B 46, 13576 (1992).

[7] M. Pénicaud, "Electron localization in the series of actinide metals. The cases of $\delta-\mathrm{Pu}$ and Es", J. Phys. Condens. Matter 9, 6341 (1997).

[8] J. van Ek, P. A. Sterne, and A. Gonis, "Phase stability of plutonium", Phys. Rev. B 48, 16280 (1993).

[9] P. Weinberger, A. M. Boring, and J. L. Smith, "Electronic structure of $\delta$-plutonium and of single

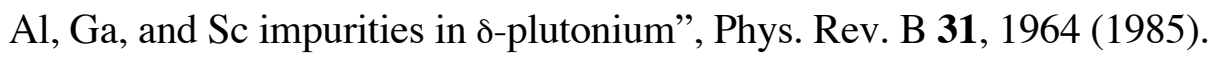

[10] P. Weinberger, A. Gonis, A. J. Freeman, and A. M. Boring, Electronic structure of Pu-rich $\mathrm{Pu}_{\mathrm{x}} \mathrm{Al}_{1-\mathrm{x}}$ alloys, Phys. Rev. B31, 1971 (1985).

[11] J. D. Becker, J. M. Wills, L. Cox, and B. R. Cooper, "Electronic structure of Pu compounds with group-IIIB metals: Two regimes of behavior", Phys. Rev. B 54, R17265 (1996). 
[12] J. D. Becker, B. R. Cooper, J. M. Wills, and L. Cox, "Calculated lattice relaxation in Pu-Ga alloys", J. Alloys Comp. 271-273, 367 (1998).

[13] J. D. Becker, J. M. Wills, L. Cox, and B. R. Cooper, "Calculated lattice relaxation in Pu-Ga", Phys. Rev. B 58, 5143 (1998).

[14] P. E. A. Turchi, A. Gonis, N. Kioussis, D. L. Price, and B. R. Cooper, "Correlation effects on stability in Pu metal and its alloys", published in the Proceedings of the International Workshop on “Electron Correlations and Materials Properties", ed. by A. Gonis, N. Kioussis, and M. Ciftan (Kluwer Academic/Plenum Publishers, New York and London, 1999), p. 531-537.

[15] P. Söderlind, “Ambient pressure phase diagram of plutonium: A unified theory for $\alpha-\mathrm{Pu}$ and $\delta$ Pu", Europhys. Lett. 55, 525-531 (2001).

[16] A. Georges, G. Kotliar, G. Krauth, and M. Rosenberg, "Dynamical mean-field theory of strongly correlated Fermion systems and the limit of infinite dimensions", Rev. Mod. Phys. 68, 13-125 (1996).

[17] S. Y. Savrasov, G. Kotliar, and E. Abrahams, "Correlated electrons in $\delta$-plutonium within a dynamical mean-field picture”, Nature 410, 793-795 (2001).

[18] X. Dai, S. Y. Savrasov, G. Kotliar, A. Migliori, H. Ledbetter, and E. Abrahams, "Calculated phonon spectra of plutonium at high temperatures", Science 300, 953-955 (2003).

[19] J. Wong, M. Krisch, D. L. Farber, F. Occelli, A. J. Schwartz, T.-C. Chiang, M. Wall, C. Boro, and R. Xu, "Phonon dispersions of fcc $\gamma$-plutonium-gallium by inelastic X-ray scattering", Science 301, 1078 (2003).

[20] N. Saunders and A. P. Miodownik, "CALPHAD, Calculation of Phase Diagrams: A Comprehensive Guide", Pergamon Press (1998).

[21] A. P. Miodownik, "Phenomenological calculations of phase equilibria: the CALPHAD approach", in NATO-ASI Proceedings, Series B: Physics, Vol. 319, eds. P. E. A. Turchi and A. Gonis (Plenum Press, NY, 1994), p. 45-79.

[22] MRS Bulletin, Vol. 24, No. 4 (April 1999), “Computer Simulations from Thermodynamic Data: Materials Production and Development”, p. 18-49.

[23] L. Kaufman and H. Bernstein, "Computer Calculation of Phase Diagrams with Special Reference to Refractory Metals" (Academic Press, New York, 1970).

[24] "CALPHAD and Alloy Thermodynamics", ed. by P. E. A. Turchi, A. Gonis, and R. D. Shull (TMS Publication, Warrendale, PA, 2002); and references therein.

[25] The Thermo-Calc and DICTRA applications software are products of Thermo-Calc AB; B. Sundman, B. Jansson, and J.-O. Andersson, “The Thermo-Calc Databank System”, CALPHAD 9 (4), 153 (1985); J.-O. Andersson, T. Helander, L. Höglund, Pingfang Shi, and B. Sundman, “THERMO-CALC \& DICTRA, computational tools for materials science”, CALPHAD 26 (2), 273312 (2002); cf. also http://www.thermocalc.se.

[26] I. Ansara and B. Sundman, "The Scientific Group Thermodata Europe", P. S. Glaeser ed., Computer Handling and Dissemination of Data, Elsevier Science Pub. Co., (1987). 
[27] A. Dinsdale, "SGTE Database for Pure Elements", CALPHAD 15, 317-425 (1991).

[28] B. Sundman and J. Agren, "A Regular solution model for phases with several components and sublattices, suitable for computer applications”, J. Phys. Chem. Sol. 42, 297-301 (1981).

[29] J. O. Andersson, A. F. Guillermet, M. Hillert, B. Jansson, and B. Sundman, "A CompoundEnergy Model of Ordering in a Phase with Sites of Different Coordination Numbers", Acta Metall. 34 (3), 437-445 (1986).

[30] I. Ansara, N. Dupin, and B. Sundman, "Reply to the paper: When is a compound energy not a compound energy? A critique of the 2-sublattice order/disorder model", CALPHAD 21, 535-542 (1997).

[31] O. Redlich and A. Kister, "Algebraic representation of the thermodynamic properties and the classification of solutions", Ind. Eng. Chem. 40, 345-348 (1948).

[32] Y. M. Muggianu, M. Gambino, and J. P. Bros, "Enthalpies de formation des alliages liquides bismuth-etain-gallium à $723 \mathrm{~K}$. Choix d'une représentation analytique des grandeurs d'excès intégrales et partielles de mélange”, J. Chem. Phys. 22, 83-88 (1975).

[33] E. Scheil, "Bemerkungen zur Schichtkristallbildung”, Zeitshrift für Metallkunde 34, 70-72 (1942).

[34] A. Engström, L. Höglund, and J. Agren, “Computer simulations of diffusion in multiphase systems", Metall. Mater. Trans. 25A, 1127-1134 (1994); A. Borgenstam, A. Engström, L. Höglund, and J. Agren, "DICTRA, a tool for simulation of diffusional transformations in alloys", J. of Phase Equil. 21 (3), 269-280 (2000).

[35] J. Agren, "Computer simulations of diffusional reactions in complex steels", ISIJ International 32, 291-296 (1992).

[36] P. G. Allen, unpublished results (January 2002).

[37] Hae-Geon Lee, "Chemical Thermodynamic for Metals and Materials" (Imperial College Press, London, 2000).

[38] Ira N. Levine, "Physical Chemistry", McGraw-Hill Book Company, New York, 1988), $3^{\text {rd }}$ edition.

[39] N. T. Cheboratev, E. S. Smotriskaya, M, A. Andrianov, and O. E. Kostyuk, "Some results of a study of the Pu-Al-Ga phase diagram", in "Plutonium 1975 and Other Actinides" (North-Holland Publishing Co., Amsterdam, 1976), pp. 37-45.

[40] F. H. Ellinger, C. C. Land, and V. O. Struebing, “The plutonium-gallium system”, J. Nucl. Mater. 12, 226-236 (1964).

[41] B. Hocheid, A. Tanon, S. Bedere, J. Despres, S. Hay, and F. Miard, in "Plutonium 1965" (Chapman and Hall, London, 1967), pp. 330-336.

[42] "Phase Diagram of Binary Actinide Alloys", Monograph Series on Alloy Phase Diagrams, vol. 11, M. E. Kassner and D. E. Peterson eds. (ASM International, Materials Park, OH, 1995).

[43] "The Actinide Binary Alloys", Part 5 of "The Chemical Thermodynamics of Actinides Elements and Compounds", ed. by P. Chiotti, V. V. Akhachinskij, I. Ansara, and M. H. Rand (IAEA, Vienna, 1981). 
[44] L. F. Timofeeva, "Low temperature equilibrium aging under self-irradiation in binary alloys of $\mathrm{Pu}$ with elements of group III-B", in Proceedings of the International Conference on "Aging studies and lifetime extension of Materials", ed. by L. G. Mallison (Kluwer Academic Publishers/Plenum, New York and Dordrecht, 2001), 13 pages.

[45] S. S. Hecker and L. F. Timofeeva, "A Tale of two diagrams", in Los Alamos Science, vol. 1, No. 26 (LANL, Los Alamos, NM, 2000), p. 244.

[46] S. S. Hecker, "The complex world of plutonium science”, MRS Bulletin, vol. 26, No. 9, 672-678 (2001).

[47] S. S. Hecker, "Plutonium: Coping with instability", JOM 55 (9), 13-18 (September 2003).

[48] S. S. Hecker, D. R. Harbur, and T. G. Zocco, "Phase stability and phase transformations in PuGa alloys", Preprint LA-UR-02-1976, to be published in the T. B. Massalski Festschrift Volume of Progress in Materials Science (2002), 59 pages.

[49] P. H. Adler, "Thermodynamic equilibrium in the low-solute regions of Pu-group IIIA metal binary systems", Metall. Trans. 22A, 2237-2246, 1991.

[50] C. W. Bale, A. D. Pelton, and W. T. Thompson: "FACT-Facility for the Analysis of Chemical Thermodynamics", users guides and supplements, $1^{\text {st }}$ ed. (McGill University/Ecole Polytechnique, Montréal, PQ, Canada, 1985). See also http://www.crct.polymtl.ca/fact/

[51] J. S. Dugdale, "Entropy and its Physical Meaning", (Taylor \& Francis, London, 1998); "Entropy" in Princeton series in Applied Mathematics, ed. by A. Greven, G. Keller, and G. Warnecke (Princeton University Press, Princeton, NJ, 2003); and references therein.

[52] Max Planck, "Treatise on Thermodynamics" (Dover Publications, Inc., New York, 1945), 3 rd edition.

[53] Cf. Ref. [43], pp. 236-7.

[54] V. V. Akhachinskii and L. M. Kopytin, "Heats of formation of intermetallic compounds of plutonium, with gallium and tin", Thermodynamics of Nuclear Materials, Proc. Symp. Vienna, 1967), IARA Vienna, 789-793.

[55] A. R. Miedema, "On the heat of formation of plutonium alloys", in "Plutonium 1975 and Other Actinides", ed. by H. Blank and R. Lindner (North-Holland Publishing Company, Amsterdam, 1976), pp. 3-20.

[56] P. H. Adler and G. B. Olson, "Thermodynamics and kinetics of $\alpha \rightarrow \delta$ martensitic transformation in Pu alloys", Metall. Trans. 19A, 2705-11, 1988.

[57] L. F. Timofeeva, "Eutectoid equilibria relationships in binary plutonium phase diagrams", JOM, 51-54 (September 2003).

[58] P. G. Mardon, M. A. Haines, J. H. Pearce, and M. B. Waldrom, J. Inst. Met. 86, 166 (1957).

[59] D. Ofte and L. J. Wittenberg, Trans. ASM 57, 916 (1964).

[60] M. Kurata, K. Nakamura, and T. Ogata, "Thermodynamic evaluation of the quaternary U-Pu-ZrFe system - assessment of cladding temperature limits of metallic fuel in a fast reactor", J. of Nucl. Mater. 294, 123-129 (2001). 
[61] F. W. Schonfeld, "Plutonium phase diagrams published by the Russians", in proceedings of the Conference on the Metal Plutonium, sponsored by ABC and ASM, ed. by A. S. Coffinberry and W. N. Miner (The University of Chicago Press, Chicago, IL, 1961), pp. 255-264.

[62] A. A. Bochvar, S. T. Konobeevsky, V. I. Kutaitsev, T. S. Menshikova, and N. T. Chebotarev, in Proceedings of the $2^{\text {nd }}$ United Nations International Conference on the Peaceful Uses of Atomic Energy, United Nations, Geneva, vol. 6, 184 (1958).

[63] F. H. Ellinger, C. C. Land, and W. N. Miner, "The solubility limits of Aluminum in delta Plutonium and some revisions of the Plutonium-Aluminum phase diagram", J. Nucl. Mater. 5, 165 172 (1962).

[64] F. H. Ellinger, W. N. Miner, D. R. O’Boyle, and F. W. Schonfeld, "Constitution of Plutonium Alloys", Los Alamos National Laboratory, Report LA-3870, Los Alamos, NM (1968).

[65] Cf. Ref. [43], p. 217.

[66] T. B. Massalski, ed., "Handbook of Alloy Phase Diagrams" (ASM International, Materials Park, $\mathrm{OH}, 1990), 3$ volumes.

[67] W. Koster and T. Godecke, "Uber den Aufbau des Systems eisen-Gallium zwischen 10 und 50 at.-\% Ga und dessen abhängigkeit von der wärmebehandlung”, Z. Mettallkd. 68 (10), 661-666 (1977).

[68] B. Predel and W. Vogelbein, “Thermodynamische untersuchung der systeme eisen-gallium und kobalt-gallium", Thermochimica Acta 13, 133-145 (1975).

[69] F. Wastin, J. C. Spirlet, and J. Rebizant, "Progress on solid compounds of actinides", J. of Alloys and Compounds 219, 232-237 (1995).

[70] W. Z. Wade, D. W. Short, J. C. Walden, and J. W. Magana, "Self-diffusion in plutonium metal”, Met. Trans. 9A, 965-972 (1978).

[71] A. L. Rafalski, M. R. Harvey, and D. H. Riefenberg, "Gallium diffusion in delta-stabilized Pu-Ga alloys", Transactions of the ASM 60, 721-723 (1967).

[72] W. Z. Wade, “The self-diffusion of plutonium in a Pu-1 wt.\% Ga alloy”, J. of Nucl. Mater. 38, 292-302 (1971).

[73] G. R. Edwards, R. E. Tate, and E. A. Hakkila, "Diffusion in stabilized delta plutonium, I. Gallium”, J. of Nucl. Mater. 25, 304-309 (1968).

[74] R. E. Tate, E. M. Cramer, and A. S. Goldman, "Self-diffusion studies of delta plutonium", Trans. of the Metallurgical Soc. of AIME 230, 639-644 (1964).

[75] M. E. Faiers, R. G. Loasby, B. J. Ward, J. T. Orme, and B. R. Spicer, “Transformation kinetics of the $\alpha-\beta$ and $\delta-\alpha$ transitions in pure and alloyed plutonium", in "Plutonium 1965", ed. by A. E. Kay and M. B. Waldron (Chapman and Hall, London, 1967), pp. 64-87.

[76] J. T. Orme, M. E. Faiers, and B. J. Ward, "The kinetics of the delta to alpha transformation in plutonium rich Pu-Ga alloys", in "Plutonium 1975 and Other Actinides", ed. by H. Blank and R. Lindner (North-Holland, Amsterdam, 1976), pp. 761-773.

[77] A. Borgenstam and M. Hillert, "Nucleation of isothermal martensite", Acta Mater. 48, 2777-2785 (2000). 
[78] G. B. Olson and M. Cohen, "Dislocations in Solids", vol. 7, 297-407 (North Holland, Amsterdam, 1986).

[79] "Martensite: A Tribute to Morris Cohen", ed. by G. B. Olson and W. S. Owen (ASM International, Materials Park, OH, 1992).

[80] Mats Hillert, "Phase Equilibrium, Phase Diagrams, and Phase Transformations: Their Thermodynamic Basis" (Cambridge University Press, Cambridge, UK, 1998).

[81] Larry Kaufman and Morris Cohen, "Thermodynamics and Kinetics of Martensitic Transformations", Progress in Metal Physics, vol. 7, 165-246 (Pergamon Press, London, 1958).

[82] P. Deloffre, J. L. Truffier, and A. Falanga, "Phase transformation in Pu-Ga alloys at low temperature and under pressure: limit stability of the $\delta$ phase”, J. of Alloys and Compounds 271-273, 370-373 (1998).

[83] M. Cohen, E. S. Machlin, and V. G. Paranjpe, "Thermodynamics of the martensitic transformation", in "Thermodynamics in Physical Metallurgy (ASM, 1950), pp. 242-270.

[84] S. S. Hecker, E. G. Zukas, J. R. Morgan, and R. A. Pereyra, "Temperature-induced transformation in a $\mathrm{Pu}-2.0$ at.\% Al alloy", in Proceedings of the International Conference on Solid $\rightarrow$ Solid Phase Transformations, ed. by H. I. Aaronson (Metallurgical Society of AIME, Warrendale, PA, 1982), pp. 1339-1343.

[85] Nathalie Dupin, "Contribution à l'évaluation thermodynamique des alliages polyconstitués à base de nickel", PhD Thesis, from the "Institut National Polytechnique de Grenoble" (29 March 1995, in french), unpublished.

[86] I. Ansara, N. Dupin, H. L. Lukas, and B. Sundman, “Thermodynamic assessment of the Al-Ni system”, J. of Alloys and Compounds 247, 20-30 (1997).

[87] Y. Du, Y. A. Chang, W. Gong, B. Huang, H. Xu, Z. Jin, F. Zhang, and S.-L. Chen, “Thermodynamic properties of the Al-Nb-Ni system", Intermetallics 11, 995-1013 (2003).

[88] H. Zhang, M. E. Huntelaar, R. J. M. Konings, and E. H. P. Cordfunke, "Melting behaviour of oxide systems for heterogeneous transmutation of actinides. I. The systems Pu-Al-O and Pu-Mg-O”, J. of Nucl. Mater. 249, 223-230 (1997).

[89] Ta. Wang, Z. Jin, and J.-C. Zhao, “Thermodynamic assessment of the Al-Zr binary system”, J. of Phase Equil. 22 (5), 544-551 (2001).

[90] M. Jiang, K. Oikawa, T. Ikeshoji, L. Wulff, and K. Ishida, "Thermodynamic calculations of Fe-Zr and Fe-Zr-C systems", J. of Phase Equil. 22 (4), 406-417 (2001).

[91] J. K. Gibson, R. G. Haire, E. C. Beahm, M. M. Gensini, A. Maeda, and T. Ogawa, "The neptunium-iron phase diagram”, J. of Nucl. Mater. 211, 215-222 (1994).

[92] K. Nakamura, M. Kurata, T. Ogata, T. Yokoo, and M. Mignanelli, "Phase relations in the Fe-PuU ternary system”, J. of Phase Equil. 22 (3), 259-264 (2001).

[93] K. Nakamura, M. Kurata, T. Ogata, A. Itoh, and M. Akabori, "Equilibrium phase relations in the U-Zr-Fe ternary system”, J. of Nucl. Mater. 275, 151-157 (1999).

[94] M. Kurata, T. Ogata, K. Nakamura, and T. Ogawa, “Thermodynamic assessment of the Fe-U, UZr and Fe-U-Zr systems", J. of Alloys and Compounds 271-273, 636-640 (1998). 
[95] S. Chatain, C. Guéneau, D. Labroche, J. Rogez, and O. Dugne, "Thermodynamic assessment of the Fe-U binary system”, J. of Phase Equil. 24 (20), 122-131 (2003).

[96] C. Servant, C. Gueneau, and I. Ansara, "Experimental and thermodynamic assessment of the FeZr system", J. of Alloys and Compounds 220, 19-26 (1995).

[97] J. Gröbner, R. Wenzel, G. G. Fisher, and R. Schmid-Fetzer, "Thermodynamic calculation of the binary systems M-Ga and investigation of ternary M-Ga-N phase equilibria (M=Ni, Co, Pd, Cr)", J. of Phase Equil. 20 (6), 615-630 (1999).

[98] W. Yuan, Z. Qiao, and H. Ipser, “Thermodynamic assessment of the Ni-Ga system”, preprint, to be published in J. of Phase Equil. (2004).

[99] H. Kinoshita, M. Uno, and S. Yamanaka, "Phase relation assessment of the O-Pu-Zr system by thermodynamic modeling”, J. of Alloys and Compounds 353, 129-137 (2003).

[100] R. G. Haire and J. M. Haschke, "Plutonium oxide systems and related corrosion products", MRS Bulletin, vol. 26, No. 9, 689-696 (2001).

[101] P. Y. Chevalier, E. Fischer, and B. Cheynet, "Progress in the thermodynamic modeling of the O-U-Zr ternary system”, CALPHAD 28, 15-40 (2004); and references therein.

[102] P. Y. Chevalier and E. Fischer, “Thermodynamic modelling of the O-U-Zr system”, J. of Nucl. Mater. 257, 213-255 (1998).

[103] T. Ogata, K. Nakamura, M. Kurata, T. Yokoo, and M. Mignanelli, "Reactions between U-Pu-Zr alloys and Fe at 923 K”, J. of Nucl. Sci. and Techn. 37 (3), 244-252 (2000).

[104] M. Kurata, "Thermodynamic assessment of the Pu-U, Pu-Zr, and Pu-U-Zr systems", CALPHAD 23 (3-4), 305-337 (1999).

[105] L. Leibowitz, E. Veleckis, R. A. Blomquist, and A. D. Pelton, "Solidus and liquidus temperatures in the Uranium-Plutonium-Zirconium system", J. of Nucl. Mater. 154, 145-153 (1988).

[106] V. Raghavan, “Al-Fe-U (Aluminium-Iron-Uranium)”, J. of Phase Equil. 24 (4), 349 (2003).

[107] V. Raghavan, "Fe-Pu-U (Iron-Plutonium-Uranium)”, J. of Phase Equil. 24 (4), 356-360 (2003).

[108] V. Raghavan, "Fe-Si-U (Iron-Silicon-Uranium)”, J. of Phase Equil. 24 (4), 361 (2003).

[109] V. Raghavan, "Fe-Sn-U (Iron-Tin-Uranium)”, J. of Phase Equil. 24 (4), 362-363 (2003).

[110] V. Raghavan, "Fe-U-Zr (Iron-Uranium-Zirconium)", J. of Phase Equil. 24 (4), 364-366 (2003).

[111] M. Kurata, K. Nakamura, and T. Ogata, "Thermodynamic evaluation of the quaternary U-Pu$\mathrm{Zr}$-Fe system - assessment of cladding temperature limits of metallic fuel in a fast reactor", J. of Nucl. Mater. 294, 123-129 (2001).

[112] V. Raghavan, "Fe-Pu-U-Zr (Iron-Plutonium-Uranium-Zirconium)”, J. of Phase Equil. 24 (4), 367-370 (2003).

[113] R. Ferro, G. Cacciamani, A. Saccone, and G. Borzone, "Systematics of lanthanide and actinide compound formation: remarks on the americium alloying behavior", J. of Alloys and Compounds 320, 326-340 (2001).

[114] O. Tougait, and H. Noël, "Stoichiometry of UAl ${ }_{4}$, Intermetallics 12, 219-223 (2004). 
[115] H. Noël, A. P. Gonçalves, and J. C. Waerenborgh, "Characterization of the ternary uraniumiron aluminide $\mathrm{UFe}_{2} \mathrm{Al}_{10}$ ", Intermetallics 12, 189-194 (2004).

[116] J. Gröbner, D. Kevorkov, R. Schmid-Fetzer, "Thermodynamic modeling of Al-Ce-Mg phase equilibria coupled with key experiments", Intermetallics 10, 415-422 (2002).

[117] A. M. Cardinale, G. Cacciamani, G. Borzone, and R. Ferro, "Experimental investigation of the Al-Ce-Nd system", CALPHAD 27, 221-226 (2003).

[118] G. Cacciamani, A. M. Cardinale, G. Borzone, and R. Ferro, “Thermodynamic modeling and optimization of the Al-Ce-Nd system”, CALPHAD 27, 227-233 (2003).

[119] Larry Kaufman, P. E. A. Turchi, Weiming Huang, and Zi-Kui Liu, "Thermodynamics of the Cr-Ta-W system by combining the ab initio and CALPHAD methods", CALPHAD 25 (3), 419-433 (2001).

[120] E. M. Lopasso, M. Caro, A. Caro, and P. E. A. Turchi, "The phase diagram of Fe-Cu as predicted by an empirical potential", Phys. Rev. B 68, 214205 (2003).

[121] A. Caro, P. E. A. Turchi, M. Caro, and E. M. Lopasso, "Thermodynamics of an embeddedatom-based description of Fe-Cu alloys", to be published in J. of Nucl. Mater. (2004).

[122] P. H. Adler, G. B. Olson, M. F. Stevens, and G. F. Gallegos, "On the constitutive relations for $\delta \rightarrow \alpha$ and $\alpha \rightarrow \delta$ martensitic transformation plasticity in plutonium alloys", Acta Metall. Mater. 40 (5), 1073-1082 (1992).

[123] A. Goldberg, R. L. Rose, and J. C. Shyne, "Effect of stress and plasticity deformation on the transformation of the delta phase in a Pu-1 at.\% Ga alloy", J. of Nucl. Mater. 55, 33-52 (1975).

[124] Y. Levinsky, "How to construct and how to use p-T-x phase diagrams", in "Pressure Dependent Phase Diagrams of Binary Alloys", ed. by G. Effenberg (ASM International, Metals Park, $\mathrm{OH}, 1997)$, pp. 1-71.

[125] L. Kaufman, in "Materials under Pressure", Honda Memorial series on Materials Science No. 2 (Maruzen, Tokyo, 174), p. 66.

[126] F. Guillermet, "An assessment of the thermodynamic properties and the (p,T) phase diagram of iron”, High Temp.-High Pres. 16, 591-610 (1985).

[127] "Pressure Dependent Phase Diagrams of Binary Alloys", ed. by G. Effenberg (ASM International, Metals Park, OH, 1997), 2 volumes.

[128] U. Benedict, "Study of actinide metals and actinide compounds under high pressure", J. of the Less-Common Met. 100, 153-170 (1984); and references therein.

[129] "Phase Transformations and Evolution in Materials", ed. by P. E. A. Turchi and A. Gonis (TMS, Warrendale, 2000); and references therein.

[130] J. Z. Zhu, Z. K. Liu, V. Vaithyanathan, and L. Q. Chen, "Linking phase-field model to CALPHAD: application to precipitate shape evolution in Ni-base alloys", Scripta Mater. 46, 401-406 (2002).

[131] R. S. Qin and E. R. Wallach, "A phase-field model coupled with a thermodynamic database”, Acta Mater. 51, 6199-6210 (2003). 
[132] J. Z. Zhu, T. Wang, S. H. Zhou, Z. K. Liu, and L. Q. Chen, "Quantitative interface model for simulating microstructure evolution”, Acta Mater. 52, 833-840 (2004).

[133] JOM issue on "Solidification and Microstructures", 56 (4), 16-68 (April 2004).

[134] P. H. Adler, G. B. Olson, and D. S. Margolies, "Kinematics of $\delta \rightarrow \alpha$ and $\alpha \rightarrow \delta$ martensitic transformation in plutonium alloys", Acta Metall. 34, 2053-2064 (1986).

[135] V. V. Bulatov and A. S. Argon, "A stochastic model for continuum elasto-plastic behavior: I. Numerical approach and strain localization", Model. Simul. Mater. Sci. Eng. 2 (2), 167-184 (1994); "II. A study of the glass-transition and structural relaxation", 185-202; "III. Plasticity in ordered versus disordered solids", 203-222.

[136] A. V. Idesman, V. I. Levitas, and E. Stein, "Elastoplastic materials with martensitic phase transition and twinning at finite strains: numerical solution with the finite element method", Comput. Methods Appl. Mech. Eng. 173, 71-98 (1999).

[137] Y. U. Wang and A. G. Khachaturyan, "Three-dimensional field model and computer modeling of martensitic transformations", Acta Mater. 45, 759-773 (1997).

[138] Y. M. Jin, A. Artemev, and A. G. Khachaturyan, "Three-dimensional phase field model of lowsymmetry martensitic transformation in polycrystal: Simulation of $\varsigma_{2}^{\prime}$ martensite in AuCd alloys", Acta Mater. 49, 2309-2320 (2001).

[139] Y. U. Wang, Y. M. Jin, and A. G. Khachaturyan, "The effects of free surfaces on martensite microstructures: 3D phase field microelasticity simulation study", Acta Mater. 52, 1039-1050 (2004). [140] G. B. Olson and P. H. Adler, "On the lattice correspondence of the $\delta \rightarrow \alpha$ displacive transformation in plutonium alloys", Scripta Metall. 18, 401-406 (1984).

[141] T. G. Zocco, M. F. Stevens, P. H. Adler, R. I. Sheldon, and G. B. Olson, "Crystallography of the $\delta \rightarrow \alpha$ phase transformation in a Pu-Ga alloy", Acta Metall. 38, 2275-2282 (1990).

[142] G. Rubin and A. G. Khachaturyan, "Three-dimensional model of precipitation of ordered intermetallics", Acta Mater. 47 (7), 1995-2002 (1999).

[143] A. Karma and M. Plapp, "New insights into the morphological stability of eutectic and peritectic coupled growth”, JOM 56 (4), 28-32 (April 2004).

[144] D. Lewis, T. Pusztai, L. Gránásy, J. Warren, and W. Boettinger, "Phase-field models for eutectic solidification”, JOM 56 (4), 34-39 (April 2004). 


\section{APPENDICES}

\section{Appendix A. Thermo-Calc Application Software}

Thermo-Calc version $\mathrm{N}$ is a commercially available software code that fulfills the need for critical modeling and analysis of data to:

- produce, refine, and analyze multi-component phase diagrams of alloys at relevant temperatures for predicting phase stability properties.

- determine the solidification path and long-term aging of alloys.

- generate isothermal sections of multi-component alloy phase diagrams at relevant temperatures, isopleths, and property diagrams (phase fractions as functions of temperature), and composition versus temperature for the all stable and metastable phases forming

- simulate phase transformations according to the Scheil-Gulliver model (for which local equilibria, infinite diffusion in the liquid phase, and no back diffusion in the solid phase are assumed).

Thermo-Calc is specially designed for systems with strongly non-ideal phases. It has gained a worldwide reputation as the best software application for calculation of multi-component phase diagrams. It is the only commercially available software that can calculate arbitrary phase diagram sections with up to five independent variables in multi-component systems. There are also modules to calculate many other types of properties, such as, Scheil-Gulliver solidification simulations, Pourbaix diagrams, partial pressures in gases, and more.

Data generated with the Thermo-Calc software also provide the basis for more accurate predictions of diffusion kinetics and ultimately TTT (temperature-time-transformations) diagrams with the DICTRA software by assuming diffusion both in the liquid and the solid phase. Note that the results of both equilibrium solidification and Scheil-Gulliver simulations generated by Thermo-Calc correspond to upper and lower bounds for the DICTRA results.

Input data files used by Thermo-Calc are: KP (Kaufman binary alloys database), SSOL (Scientific Group Thermodata Europe, or SGTE, solution database), from published journals, and/or from qualified sources.

\section{Appendix B. DICTRA Application Software}

DICTRA version 22 (DIffusion Controlled TRAnsformation) is a commercially available software that is used in conjunction with Thermo-Calc to calculate the rate at which the relevant phase transformations occur. DICTRA Version 22 is used to predict the kinetics of phase transformation and evolution in alloys. In particular, this software application predicts TTT (Temperature-TimeTransformation) diagrams, and therefore aging behavior of complex alloys.

DICTRA fulfills the need to provide critical modeling and analysis of data to: 1) Solve the diffusion equations; 2) Calculate thermodynamic equilibrium; and 3) Solve the flux-balance equations. The DICTRA software tracks the displacement of phase interface positions and adjusts grid points during simulation as a function of time. This software is particularly suited to analyze the kinetics of 
phase evolution in alloys selected by predicting TTT (Temperature-Time-Transformation) diagrams for relevant phases forming as functions of time.

DICTRA is interfaced to Thermo-Calc that handles all thermodynamic calculations needed by DICTRA. Data files used by Thermo-Calc and DICTRA are considered to be from accepted sources: KP (Kaufman binary alloys database), SSOL (Scientific Group Thermodata Europe, or SGTE, solution database), MOB (Mobility database), from published journals, and/or from qualified sources. The MOB database contains assessed self- and impurity diffusion data for a number of elements, as well as assessed data for some alloy systems. Diffusion data for the liquid phase is also presented in the database, but since no valid diffusion model exist for liquids, a rule of thumb value of $1 \mathrm{x} \cdot 10^{-9}$ $\left[\mathrm{m} / \mathrm{s}^{2}\right]$ is used for all diffusivities. Apart from the phases for which there are diffusion data, other phases can be included in the simulations. These will then be treated as diffusion "NONE", i.e. there is no diffusion considered in the phases. Phases for which there are no diffusion data will be entered as diffusion "NONE" if thermodynamic data for them has been retrieved previously to entering the mobility data.

The databases SSOL, KP, and MOB are in ASCII text format and can be reviewed or edited with any standard text editor. Custom generated input data can be created using any standard text editor to create an ASCII text file.

DICTRA uses the post-processor module from Thermo-Calc to generate output in graphical or tabular form that can be viewed on a monitor or printed as hardcopy output.

\section{Appendix C. Description of the Thermo-chemical Database C.1. Pure Elements}

Let us first describe the thermodynamics of the pure elements extracted from the SGTE database that have been compiled by Dinsdale [27]. The data not reported below are implicitly set to zero. The notations are those that have been introduced in section II.2.

\section{C.1.1. Plutonium}

The standard element reference (SER) is the monoclinic (or $\alpha$ ) phase of $\mathrm{Pu}(\mathrm{M}=244.0$ a.u.) with the following enthalpy and entropy at $298.15 \mathrm{~K}$ and $10^{5} \mathrm{~Pa}$ of pressure:

$\mathrm{H}_{\mathrm{Pu}}^{\mathrm{SER}}=6,902.0 \mathrm{~J} / \mathrm{mol}$

$\mathrm{S}_{\mathrm{Pu}}^{\mathrm{SER}}=54.4610 \mathrm{~J} / \mathrm{mol} . \mathrm{K}$

\section{$\alpha \mathrm{Pu}$}

$G_{P u}^{\alpha}(T)-H_{P u}^{S E R}=$

- $298.14 \mathrm{~K}<\mathrm{T}<400 \mathrm{~K}$

$-7,396.309+80.301382 * \mathrm{~T}-18.1258 * \mathrm{~T} * \mathrm{LN}(\mathrm{T})-.02241 * \mathrm{~T}^{2}$ 
- $400 \mathrm{~K}<\mathrm{T}<944 \mathrm{~K}$

$-16,605.962+236.786603 * \mathrm{~T}-42.4187 * \mathrm{~T} * \mathrm{LN}(\mathrm{T})-.00134493 * \mathrm{~T}^{2}+2.63443 \mathrm{E}-07 * \mathrm{~T}^{3}+579,325 * \mathrm{~T}^{-1}$

- $944 \mathrm{~K}<\mathrm{T}<3000 \mathrm{~K}$

$-14,462.156+232.961553 * \mathrm{~T}-42.248 * \mathrm{~T} * \mathrm{LN}(\mathrm{T})$

$\beta \mathbf{P u}$

$G_{P u}^{\beta}(T)-H_{P u}^{S E R}=$

- $298.14 \mathrm{~K}<\mathrm{T}<679.5 \mathrm{~K}$

$-4,873.654+123.249151 * \mathrm{~T}-27.416 * \mathrm{~T} * \mathrm{LN}(\mathrm{T})-.00653 * \mathrm{~T}^{2}$

- $679.5 \mathrm{~K}<\mathrm{T}<1464 \mathrm{~K}$

$+2,435.094+43.566585 * \mathrm{~T}-15.7351 * \mathrm{~T} * \mathrm{LN}(\mathrm{T})-.0154772 * \mathrm{~T}^{2}+1.524942 \mathrm{E}-06 * \mathrm{~T}^{3}-864,940 * \mathrm{~T}^{-1}$

- $1464 \mathrm{~K}<\mathrm{T}<3000 \mathrm{~K}$

$-13,959.062+228.221615 * \mathrm{~T}-42.248 * \mathrm{~T} * \mathrm{LN}(\mathrm{T})$

$\gamma \mathbf{P u}$

$G_{P u}^{\gamma}(T)-H_{P u}^{S E R}=$

- $298.14 \mathrm{~K}<\mathrm{T}<487.99 \mathrm{~K}$

$-16,766.303+419.402655 * \mathrm{~T}-77.5802 * \mathrm{~T} * \mathrm{LN}(\mathrm{T})+.0816415 * \mathrm{~T}^{2}-2.8103833 \mathrm{E}-05 * \mathrm{~T}^{3}+574825 * \mathrm{~T}^{-1}$

- $487.99 \mathrm{~K}<\mathrm{T}<593.90 \mathrm{~K}$

$-2,942.77+88.325069 * \mathrm{~T}-22.0233 * \mathrm{~T} * \mathrm{LN}(\mathrm{T})-.0114795 * \mathrm{~T}^{2}$

- $593.90 \mathrm{~K}<\mathrm{T}<1179.00 \mathrm{~K}$

$-9,336.967+160.314641 * \mathrm{~T}-32.3405 * \mathrm{~T} * \mathrm{LN}(\mathrm{T})-.0070383 * \mathrm{~T}^{2}+6.92887 \mathrm{E}-07 * \mathrm{~T}^{3}+630,600 * \mathrm{~T}^{-1}$

- $1179 \mathrm{~K}<\mathrm{T}<3000 \mathrm{~K}$

$-12,435.75+226.131617 * \mathrm{~T}-42.248 * \mathrm{~T} * \mathrm{LN}(\mathrm{T})$

$\delta \mathrm{Pu}$

$G_{P u}^{\delta}(T)-H_{P u}^{S E R}=$

- $298.14 \mathrm{~K}<\mathrm{T}<990 \mathrm{~K}$

$-3,920.781+127.586536 * \mathrm{~T}-28.4781 * \mathrm{~T} * \mathrm{LN}(\mathrm{T})-.0054035 * \mathrm{~T}^{2}$

- $990 \mathrm{~K}<\mathrm{T}<1464 \mathrm{~K}$

$+3,528.208+41.52572 * \mathrm{~T}-15.7351 * \mathrm{~T} * \mathrm{LN}(\mathrm{T})-.0154772 * \mathrm{~T}^{2}+1.524942 \mathrm{E}-06 * \mathrm{~T}^{3}-864,940 * \mathrm{~T}^{-1}$

- $1464 \mathrm{~K}<\mathrm{T}<3000 \mathrm{~K}$

$-12,865.948+226.18075 * \mathrm{~T}-42.248 * \mathrm{~T} * \mathrm{LN}(\mathrm{T})$

$\delta ’ \mathbf{P u}$

$G_{P u}^{\delta^{\prime}}(T)-H_{P u}^{S E R}=$

- $298.14 \mathrm{~K}<\mathrm{T}<736 \mathrm{~K}$

$-496.178+54.586547 * \mathrm{~T}-16.43 * \mathrm{~T} * \mathrm{LN}(\mathrm{T})-.024006 * \mathrm{~T}^{2}+5.166667 \mathrm{E}-06 * \mathrm{~T}^{3}-158,470 * \mathrm{~T}^{-1}$

- $736 \mathrm{~K}<\mathrm{T}<757 \mathrm{~K}$

$-6,122.307+173.35008 * \mathrm{~T}-35.56 * \mathrm{~T} * \mathrm{LN}(\mathrm{T})$

- $757 \mathrm{~K}<\mathrm{T}<2157 \mathrm{~K}$

$+3,982.078+63.890352 * \mathrm{~T}-19.756 * \mathrm{~T} * \mathrm{LN}(\mathrm{T})-.00937295 * \mathrm{~T}^{2}+6.59882 \mathrm{E}-07 * \mathrm{~T}^{3}-1,112,565 * \mathrm{~T}^{-1}$ 
- $2157 \mathrm{~K}<\mathrm{T}<3000 \mathrm{~K}$

$-15,200.539+228.05641 * \mathrm{~T}-42.248 * \mathrm{~T} * \mathrm{LN}(\mathrm{T})$

$\varepsilon \mathbf{P u}$

$G_{P u}^{\varepsilon}(T)-H_{P u}^{S E R}=$

- $298.14 \mathrm{~K}<\mathrm{T}<745 \mathrm{~K}$

$-1,358.984+116.603882 * \mathrm{~T}-27.094 * \mathrm{~T} * \mathrm{LN}(\mathrm{T})-.009105 * \mathrm{~T}^{2}+2.061667 \mathrm{E}-06 * \mathrm{~T}^{3}+20,863 * \mathrm{~T}^{-1}$

- $745 \mathrm{~K}<\mathrm{T}<956 \mathrm{~K}$

$-2,890.817+156.878957 * \mathrm{~T}-33.72 * \mathrm{~T} * \mathrm{LN}(\mathrm{T})$

- $956 \mathrm{~K}<\mathrm{T}<2071 \mathrm{~K}$

$+29,313.619-132.788248 * \mathrm{~T}+6.921 * \mathrm{~T} * \mathrm{LN}(\mathrm{T})-.02023305 * \mathrm{~T}^{2}+1.426922 \mathrm{E}-06 * \mathrm{~T}^{3}-4,469,245^{*} \mathrm{~T}^{-1}$

- $2071 \mathrm{~K}<\mathrm{T}<3000 \mathrm{~K}$

$-15,400.585+227.421855 * \mathrm{~T}-42.248 * \mathrm{~T} * \mathrm{LN}(\mathrm{T})$

Liquid Pu

$G_{P u}^{L i q}(T)-H_{P u}^{S E R}=+6,608.1-12.5133 * \mathrm{~T}+\mathrm{G}_{\mathrm{Pu}}^{\alpha}(\mathrm{T})-\mathrm{H}_{\mathrm{Pu}}^{\mathrm{SER}}$

\section{C.1.2. Gallium}

The standard element reference (SER) is the orthorhombic (Cmca or A11) phase of Ga (M=69.723 a.u.) with the following enthalpy and entropy at $298.15 \mathrm{~K}$ and $10^{5} \mathrm{~Pa}$ of pressure:

$\mathrm{H}_{\mathrm{Ga}}^{\mathrm{SER}}=5573.1 \mathrm{~J} / \mathrm{mol}$

$\mathrm{S}_{\mathrm{Ga}}^{\mathrm{SER}}=40.828 \mathrm{~J} / \mathrm{mol} . \mathrm{K}$

\section{Orthorhombic (Cmca or A11) Ga}

$G_{G a}^{o r t h}(T)-H_{G a}^{S E R}=$

- $200 \mathrm{~K}<\mathrm{T}<302.92 \mathrm{~K}$

$-21,312.331+585.263691 * \mathrm{~T}-108.228783 * \mathrm{~T} * \mathrm{LN}(\mathrm{T})+.227155636 * \mathrm{~T}^{2}-1.18575257 \mathrm{E}-04 * \mathrm{~T}^{3}$

$+439954 * \mathrm{~T}^{-1}$

- $302.92 \mathrm{~K}<\mathrm{T}<4000 \mathrm{~K}$

$-7,055.646+132.7302 * \mathrm{~T}-26.0692906 * \mathrm{~T} * \mathrm{LN}(\mathrm{T})+1.506 \mathrm{E}-04 * \mathrm{~T}^{2}-4.0173 \mathrm{E}-08 * \mathrm{~T}^{3}-118,332 * \mathrm{~T}^{-1}$

$+1.64554 \mathrm{E}+23 * \mathrm{~T}^{-9}$

\section{Liquid Ga}

$G_{G a}^{L i q}(T)-H_{G a}^{S E R}=$

- $200 \mathrm{~K}<\mathrm{T}<302.92 \mathrm{~K}$

$+5,491.31-18.073718 * \mathrm{~T}-7.0154 \mathrm{E}-17 * \mathrm{~T}^{7}+\mathrm{G}_{\mathrm{Ga}}^{\mathrm{orth}}(\mathrm{T})-\mathrm{H}_{\mathrm{Ga}}^{\mathrm{SER}}$

- $302.92 \mathrm{~K}<\mathrm{T}<4000 \mathrm{~K}$

$+5,666.446-18.680788 * \mathrm{~T}-1.64554 \mathrm{E}+23 * \mathrm{~T}^{-9}+\mathrm{G}_{\mathrm{Ga}}^{\text {orth }}(\mathrm{T})-\mathrm{H}_{\mathrm{Ga}}^{\mathrm{SER}}$

bec Ga

$G_{G a}^{b c c(\varepsilon)}(T)-H_{G a}^{S E R}=+4500-11.7 * \mathrm{~T}+\mathrm{G}_{\mathrm{Ga}}^{\mathrm{orth}}(\mathrm{T})-\mathrm{H}_{\mathrm{Ga}}^{\mathrm{SER}}$

bet (A5) Ga 
$G_{G a}^{b c t}(T)-H_{G a}^{S E R}=+3,846-9.8 * \mathrm{~T}+\mathrm{G}_{\mathrm{Ga}}^{\mathrm{orth}}(\mathrm{T})-\mathrm{H}_{\mathrm{Ga}}^{\mathrm{SER}}$

\section{fec $\mathbf{G a}$}

$G_{G a}^{f c c(\delta)}(T)-H_{G a}^{S E R}=+3,800-10.2 * \mathrm{~T}+\mathrm{G}_{\mathrm{Ga}}^{\mathrm{orth}}(\mathrm{T})-\mathrm{H}_{\mathrm{Ga}}^{\mathrm{SER}}$

$(\alpha-\mathbf{P u}) \mathbf{G a}$

$G_{G a}^{\alpha}(T)-H_{G a}^{S E R}=+2,000+\mathrm{G}_{\mathrm{Ga}}^{\mathrm{orth}}(\mathrm{T})-\mathrm{H}_{\mathrm{Ga}}^{\mathrm{SER}}$

$(\gamma-\mathbf{P u}) \mathbf{G a}$

$G_{G a}^{\gamma}(T)-H_{G a}^{S E R}=+2,500+\mathrm{G}_{\mathrm{Ga}}^{\mathrm{orth}}(\mathrm{T})-\mathrm{H}_{\mathrm{Ga}}^{\mathrm{SER}}$

$\gamma \mathbf{G a}$

$G_{G a}^{\gamma}(T)-H_{G a}^{S E R}=+3,089.8-8.71535^{*} \mathrm{~T}+\mathrm{G}_{\mathrm{Ga}}^{\mathrm{orth}}(\mathrm{T})-\mathrm{H}_{\mathrm{Ga}}^{\mathrm{SER}}$

\section{hep Ga}

$G_{G a}^{h c p}(T)-H_{G a}^{S E R}=+4,500-9.5 * \mathrm{~T}+\mathrm{G}_{\mathrm{Ga}}^{\mathrm{orth}}(\mathrm{T})-\mathrm{H}_{\mathrm{Ga}}^{\mathrm{SER}}$

tetragonal ( $\delta$ ' or A6) Ga

$G_{G a}^{\delta^{\prime}}(T)-H_{G a}^{S E R}=+3,500-10 * \mathrm{~T}+\mathrm{G}_{\mathrm{Ga}}^{\mathrm{orth}}(\mathrm{T})-\mathrm{H}_{\mathrm{Ga}}^{\mathrm{SER}}$

\section{C1.3. Aluminum}

The standard element reference (SER) is the fcc (or A1) phase of $\mathrm{Al}$ (M=26.982 a.u.) with the following enthalpy and entropy at $298.15 \mathrm{~K}$ and $10^{5} \mathrm{~Pa}$ of pressure:

$H_{A l}^{S E R}=4,577.3 \mathrm{~J} / \mathrm{mol}$

$S_{A l}^{S E R}=28.322 \mathrm{~J} / \mathrm{mol} . \mathrm{K}$

\section{fec (or A1) Al}

${ }^{0} G_{A l}^{f c c}(T)-H_{A l}^{S E R}(298.15)=$

- $298.15 \mathrm{~K}<\mathrm{T}<700 \mathrm{~K}$

$-7,976.15+137.071542 * \mathrm{~T}-24.3671976 * \mathrm{~T}^{*} \mathrm{LN}(\mathrm{T})-0.001884662 * \mathrm{~T}^{2}-8.77664 \mathrm{E}-07 * \mathrm{~T}^{3}+74,092 * \mathrm{~T}^{-1}$

- $700 \mathrm{~K}<\mathrm{T}<933.6 \mathrm{~K}$

$-11,276.24+223.02695 * \mathrm{~T}-38.5844296 * \mathrm{~T}^{*} \mathrm{LN}(\mathrm{T})+0.018531982 * \mathrm{~T}^{2}-5.764227 \mathrm{E}-06 * \mathrm{~T}^{3}+74,092 * \mathrm{~T}^{-1}$

- $933.6 \mathrm{~K}<\mathrm{T}<2900 \mathrm{~K}$

$-11,277.683+188.661987 * \mathrm{~T}-31.748192 * \mathrm{~T} * \mathrm{LN}(\mathrm{T})-1.234264 \mathrm{E}+28 * \mathrm{~T}^{-9}$

\section{Liquid Al}

${ }^{0} G_{A l}^{L i q}(T)=$

- $298.14 \mathrm{~K}<\mathrm{T}<933.6 \mathrm{~K}$

$+11,005.553-11.840873 * \mathrm{~T}+7.9401 \mathrm{E}-20 * \mathrm{~T}^{7}+{ }^{0} G_{A l}^{f c c}(T)$

- $933.6 \mathrm{~K}<\mathrm{T}<2900 \mathrm{~K}$

$+10,481.974-11.252014 * \mathrm{~T}+1.23426 \mathrm{E}+28 * \mathrm{~T}^{-9}+{ }^{0} G_{A l}^{f c c}(T)$

bcc Al

${ }^{0} G_{A l}^{b c c}(T)=+10,083-4.813 * \mathrm{~T}+{ }^{0} G_{A l}^{f c c}(T)$ 


\section{hep Al}

${ }^{0} G_{A l}^{h c p}(T)=+5,481-1.8 * \mathrm{~T}+{ }^{0} G_{A l}^{f c c}(T)$

( $\alpha$-Pu) Al

${ }^{0} G_{A l}^{\alpha}(T)=+5,000+{ }^{0} G_{A l}^{f c c}(T)$

$(\boldsymbol{\beta}-\mathbf{P u}) \mathrm{Al}$

${ }^{0} G_{A l}^{\beta}(T)=+5,000+{ }^{0} G_{A l}^{f c c}(T)$

$(\gamma-\mathbf{P u}) \mathrm{Al}$

${ }^{0} G_{A l}^{\gamma}(T)=+4,900+{ }^{0} G_{A l}^{f c c}(T)$

( $\delta^{\prime}$-Pu) Al

${ }^{0} G_{A l}^{\delta^{\prime}}(T)=+5,000+{ }^{0} G_{A l}^{f c c}(T)$

\section{C1.4. Iron}

The standard element reference (SER) is the bcc (or A2) phase of Fe (M=55.847 a.u.) with the following enthalpy and entropy at $298.15 \mathrm{~K}$ and $10^{5} \mathrm{~Pa}$ of pressure:

$H_{A l}^{S E R}=4,489.0 \mathrm{~J} / \mathrm{mol}$

$S_{A l}^{S E R}=27.280 \mathrm{~J} / \mathrm{mol} . \mathrm{K}$

The thermodynamic data for iron are given in Ref. [27].

\section{C.2. Binary Alloys}

In alphabetical order, the thermodynamic properties of the following alloys that have been assessed:

$\mathrm{Al}-\mathrm{Ga}, \mathrm{Al}-\mathrm{Fe}, \mathrm{Al}-\mathrm{Pu}, \mathrm{Fe}-\mathrm{Ga}, \mathrm{Fe}-\mathrm{Pu}, \mathrm{Ga}-\mathrm{Pu}$, are reported below.

\section{C2.1. Al-Ga}

fcc (Al,Ga) solid solution

${ }^{0} L_{A l, G a}^{f c c}=+9,195.8+8.18764 * \mathrm{~T}$

${ }^{1} L_{A l, G a}^{f c c}=-7,678.5$

Liquid (Al,Ga)

${ }^{0} L_{A l, G a}^{L i q}=+2,613.3-2.94533 * \mathrm{~T}$

${ }^{1} L_{A l, G a}^{L i q}=+692.4-0.09271 * \mathrm{~T}$

${ }^{2} L_{A l, G a}^{L i q}=+319.5$

\section{C2.2 Al-Fe}

fec $(\mathrm{Al}, \mathrm{Fe})$ solid solution

${ }^{0} L_{A l, F e}^{f c c}=-76,066.1+18.6758 * \mathrm{~T}$

${ }^{1} L_{A l, F e}^{f c c}=-21,167.4+1.3398 * \mathrm{~T}$

bcc $(\mathrm{Al}, \mathrm{Fe})$ solid solution

${ }^{0} L_{A l, F e}^{b c c}=-122,960+31.9888 * \mathrm{~T}$

${ }^{1} L_{A l, F e}^{b c c}=+2,945.2$

$T_{c A l, F e}^{b c c}=+504$

Liquid (Al,Fe) 
${ }^{0} L_{A l, F e}^{L i q}=-91,976.5+22.1414 * \mathrm{~T}$

${ }^{1} L_{A l, F e}^{L i q}=-5,672.58+4.8728 * \mathrm{~T}$

${ }^{2} L_{A l, F e}^{L i q}=+121.9$

$\mathrm{Al}_{13} \mathrm{Fe}_{\mathbf{4}}:(\mathrm{Al})_{.6275}(\mathrm{Fe})_{.235}(\mathrm{Al}, \mathrm{Va})_{.1375}$

${ }^{0} G_{A l: F e: A l}^{A l_{1} F e_{4}}-.765{ }^{0} G_{A l}^{f c c}-.235{ }^{0} G_{F e}^{b c c}=-30,714.4+7.44 * \mathrm{~T}$

${ }^{0} G_{A l: F e: V a}^{A l_{1} F e_{4}}-.6275{ }^{0} G_{A l}^{f c c}-.235{ }^{0} G_{F e}^{b c c}=-27781.3+7.2566 * \mathrm{~T}$

$\mathrm{Al}_{5} \mathbf{F e}_{2}$

${ }^{0} G^{A l_{5} F e_{2}}-.714{ }^{0} G_{A l}^{f c c}-.286{ }^{0} G_{F e}^{b c c}=-32653.7+6.99929 * \mathrm{~T}$

$\mathrm{Al}_{2} \mathbf{F e}$

${ }^{0} G^{A l_{2} F e}-.663{ }^{0} G_{A l}^{f c c}-.337{ }^{0} G_{F e}^{b c c}=-32836.3+6.2501 * \mathrm{~T}$

$\mathrm{Al}_{5} \mathbf{F e}_{4}$

${ }^{0} G_{A l}^{A l_{5} F e_{4}}-{ }^{0} G_{A l}^{f c c}=+12,084.8-4.813 * \mathrm{~T}$

${ }^{0} G_{F e}^{\mathrm{Al}_{5} \mathrm{Fe}_{4}}-{ }^{0} G_{\mathrm{Fe}}^{b c c}=+5,009.03$

${ }^{0} L_{\mathrm{Al}, \mathrm{Fe}}^{\mathrm{Al}_{\mathrm{Fe}}}=-131649+29.4833 * \mathrm{~T}$

${ }^{1} L_{A l, F e}^{\mathrm{Al}_{5} \mathrm{Fe}_{4}}=-18619.5$

\section{C2.3 Al-Pu}

$\alpha(\mathrm{Al}, \mathrm{Pu})$ solid solution

${ }^{0} L_{A l, P u}^{\alpha}=+31,500$

$\delta(\mathrm{Al}, \mathrm{Pu})$ solid solution

${ }^{0} L_{A l, P u}^{\delta}=-94,000+18 * \mathrm{~T}$

${ }^{1} L_{A l, P u}^{\delta}=-10,000-8 * \mathrm{~T}$

$\varepsilon(\mathrm{Al}, \mathrm{Pu})$ solid solution

${ }^{0} L_{A l, P u}^{\varepsilon}=-98,000+10 * \mathrm{~T}$

${ }^{1} L_{A l, P u}^{\varepsilon}=-3,500-28 * \mathrm{~T}$

Liquid (Al,Pu)

${ }^{0} L_{A l, P u}^{L i q}=-50,000-23 * \mathrm{~T}$

${ }^{1} L_{A l, P u}^{\mathrm{Liq}}=-4,000-36 * \mathrm{~T}$

${ }^{2} L_{A l, P u}^{L i q}=-24,000+10 * \mathrm{~T}$

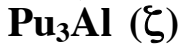

${ }^{0} G^{P u_{3} A l(\zeta)}-.75{ }^{0} G_{P u}^{\alpha}-.25{ }^{0} G_{A l}^{f c c}=-16,375-5.35 * \mathrm{~T}$

PuAl ( $\eta)$

${ }^{0} G^{P u A l(\eta)}-.5{ }^{0} G_{P u}^{\alpha}-.5{ }^{0} G_{A l}^{f c c}=-34,128-2.159 * \mathrm{~T}$

$\mathbf{P u A l}_{2}(\boldsymbol{\theta})$

${ }^{0} G^{P u A l_{2}(\theta)}-.33{ }^{0} G_{P u}^{\alpha}-.67{ }^{0} G_{A l}^{f c c}=-46,000+0.667 * \mathrm{~T}$

$\mathbf{P u A l}_{\mathbf{3}}(\mathbf{l}-\mathbf{9 H}, \mathbf{L T})$

${ }^{0} G^{\text {PuAl }_{3}\left(i-9 H_{\alpha}\right)}-.25{ }^{0} G_{P u}^{\alpha}-.75{ }^{0} G_{A l}^{f c c}=-45,000+7.5 * \mathrm{~T}$

$\mathbf{P u A l}_{3}\left(\mathbf{l}-9 \mathrm{H}_{\beta}, \mathbf{M T}_{1}\right)$

${ }^{0} G^{P u A l_{3}\left(i-9 H_{\beta}\right)}-.25{ }^{0} G_{P u}^{\alpha}-.75{ }^{0} G_{A l}^{f c c}=-28,200-6.5 * \mathrm{~T}$

$\mathrm{PuAl}_{3}$ (l-6H, $\mathrm{MT}_{2}$ )

${ }^{0} G^{\text {PuAl }_{3}(\iota-6 H)}-.25{ }^{0} G_{P u}^{\alpha}-.75{ }^{0} G_{A l}^{f c c}=-25,600-8.5^{*} \mathrm{~T}$

$\mathbf{P u A l}_{3}$ ((l-3H, HT)

${ }^{0} G^{\text {PuAl }_{3}(l-3 H)}-.25{ }^{0} G_{P u}^{\alpha}-.75{ }^{0} G_{A l}^{f c c}=-24,150-9.5^{*} \mathrm{~T}$

$\mathrm{PuAl}_{4}$ (к)

${ }^{0} G^{P u A l_{4}(\kappa)}-.2{ }^{0} G_{P u}^{\alpha}-.8{ }^{0} G_{A l}^{f c c}=-36,000+5 * \mathrm{~T}$ 


\section{C2.4. Fe-Ga}

fcc (Fe,Ga) solid solution

${ }^{0} L_{F e, G a}^{f c c}=-100,500+28 * \mathrm{~T}$

${ }^{1} L_{F e, G a}^{f c c}=+21,000-24 * \mathrm{~T}$

bcc (Fe,Ga) solid solution

${ }^{0} L_{F e, G a}^{b c c}=-112,000+28 * \mathrm{~T}$

${ }^{1} L_{F e, G a}^{b c c}=+31,000-24 * \mathrm{~T}$

Liquid (Fe,Ga)

${ }^{0} L_{F e, G a}^{L i q}=-92,000+18 * \mathrm{~T}$

${ }^{1} L_{\mathrm{Fe}, \mathrm{Ga}}^{\mathrm{Liq}}=-10,000+3 * \mathrm{~T}$

$\mathrm{Fe}_{3} \mathbf{G a}$

${ }^{0} G^{F e_{3} G a}-.75^{0} G_{F e}^{b c c}-.25{ }^{0} G_{G a}^{o r t h}=-25,100+3.7 * \mathrm{~T}$

$\mathrm{Fe}_{6} \mathbf{G a}_{5}$

${ }^{0} G^{F e_{6} G a_{5}}-.546{ }^{0} G_{F e}^{b c c}-.454{ }^{0} G_{G a}^{o r t h}=-33,500+3.3 * \mathrm{~T}$

$\mathrm{Fe}_{3} \mathbf{G a}_{4}$

${ }^{0} G^{F e_{3} G a_{4}}-.429^{0} G_{F e}^{b c c}-.571^{0} G_{G a}^{o r t h}=-35,000+2.7 * \mathrm{~T}$

$\mathrm{FeGa}_{3}$

${ }^{0} G^{F e G a_{3}}-.25{ }^{0} G_{F e}^{b c c}-.75{ }^{0} G_{G a}^{o r t h}=-28,000+0.1 * \mathrm{~T}$

\section{C2.5. Fe-Pu}

fec $(\mathrm{Fe}, \mathrm{Pu})$ solid solution

${ }^{0} L_{F e, P u}^{f c c}=+5,000$

bec $(\mathrm{Fe}, \mathrm{Pu})$ solid solution

${ }^{1} L_{F e, P u}^{b c c}=+5,000$

Liquid (Fe,Pu)

${ }^{0} L_{\mathrm{Fe}, P u}^{\mathrm{Liq}}=-24,000+3 * \mathrm{~T}$

${ }^{1} L_{F e, P u}^{L i q}=-4,000$

$\mathrm{FePu}_{6}:(\mathrm{Fe}, \mathrm{Pu})_{1 / 7}(\mathrm{Fe}, \mathrm{Pu})_{6 / 7}$

${ }^{0} G_{F e}^{F e P u_{6}}-{ }^{0} G_{F e}^{b c c}=+2,142.9$

${ }^{0} G_{P u}^{F e P u_{6}}-{ }^{0} G_{P u}^{\alpha}=+11,571.4-12.571 * \mathrm{~T}$

${ }^{0} G_{F e: P u}^{F e P u_{6}}-0.143^{0} G_{F e}^{b c c}-0.857^{0} G_{P u}^{\alpha}=-1,739-5.286 * \mathrm{~T}$

${ }^{0} G_{P u: F e}^{\mathrm{FePu}_{6}}-0.857^{0} G_{\mathrm{Fe}}^{b c c}-0.143^{0} G_{P u}^{\alpha}=+34,285.7+0.857 * \mathrm{~T}$

${ }^{0} L_{\mathrm{Fe}, \mathrm{Pu}: \mathrm{Fe}}^{\mathrm{FePu}}={ }^{0} L_{\mathrm{Fe}, \mathrm{Pu}: \mathrm{Pu}}^{\mathrm{FePu}}=+1,428.6$

${ }^{0} L_{\mathrm{Fe}: \mathrm{Fe}, \mathrm{Pu}}^{\mathrm{FePu}}={ }^{0} L_{\mathrm{Pu}: \mathrm{Fe}, \mathrm{Pu}}^{\mathrm{FePu}}=+8,571.4$

$\mathbf{F e}_{2} \mathbf{P u}:(\mathbf{F e}, \mathbf{P u})_{2 / 3}(\mathbf{F e}, \mathbf{P u})_{1 / 3}$

${ }^{0} G_{F e} \mathrm{Fe}_{2} P u-{ }^{0} G_{\mathrm{Fe}}^{b c c}=+5,000$

${ }^{0} G_{P u}^{F e_{2} P u}-{ }^{0} G_{P u}^{\alpha}=+11,666.7-5.429 * \mathrm{~T}$

${ }^{0} G_{F e: P u}^{F e_{2} P u}-0.667^{0} G_{F e}^{b c c}-0.333^{0} G_{P u}^{\alpha}=-8,000-4.85^{*} \mathrm{~T}$

${ }^{0} G_{P u: F e}^{F e_{2} P u}-0.333^{0} G_{F e}^{b c c}-0.667^{0} G_{P u}^{\alpha}=+33,333.3-10 * \mathrm{~T}$

${ }^{0} L_{\mathrm{Fe}, \mathrm{Pu}: \mathrm{Fe}}^{\mathrm{Fe}_{2} \mathrm{Pu}}={ }^{0} L_{\mathrm{Fe}, \mathrm{Pu}: \mathrm{Pu}}^{\mathrm{Fe} P \mathrm{Pu}_{\mathrm{Fe}}}=+20,000$

${ }^{0} L_{\mathrm{Fe}: \mathrm{Fe}, \mathrm{Pu}}^{\mathrm{Fe}}={ }^{0} L_{\mathrm{Pu}: \mathrm{Fe}, \mathrm{Pu}}^{\mathrm{Fe}}=+10,000$

\section{C2.6. Ga-Pu}

$\alpha(\mathrm{Ga}, \mathrm{Pu})$ solid solution

${ }^{1} L_{G a, P u}^{\alpha}=+66,500$ 
$\gamma(\mathbf{G a}, \mathbf{P u})$ solid solution $(0 \mathrm{~K}<\mathrm{T}<593 \mathrm{~K})$

${ }^{0} L_{G a, P u}^{\gamma}=+12 * \mathrm{~T}$

${ }^{1} L_{G a, P u}^{\gamma}=+321,000-580 * \mathrm{~T}$

$\delta(\mathbf{G a}, \mathbf{P u})$ solid solution

${ }^{0} L_{G a, P u}^{\delta}=-182,428+58.42 * \mathrm{~T}$

${ }^{1} L_{G a, P u}^{\delta}=+19,215-79.062 * \mathrm{~T}$

$\boldsymbol{\varepsilon}$ (Ga,Pu) solid solution

${ }^{0} L_{G a, P u}^{\varepsilon}=-126,805+18.8 * \mathrm{~T}$

${ }^{1} L_{G a, P u}^{\varepsilon}=-10,489-26.68 * \mathrm{~T}$

${ }^{2} L_{G a, P u}^{\varepsilon}=-10,000+10 * \mathrm{~T}$

\section{$\boldsymbol{\eta}(\mathbf{G a}, \mathbf{P u})$ solid solution}

${ }^{0} L_{G a, P u}^{\eta}=-183,945+31.388 * \mathrm{~T}$

${ }^{1} L_{G a, P u}^{\eta}=-68,327-10 * \mathrm{~T}$

${ }^{2} L_{G a, P u}^{\eta}=-2,516.3+0.1 * \mathrm{~T}$

Liquid (Ga,Pu)

${ }^{0} L_{G a, P u}^{L i q}=-121,696+18.762 * \mathrm{~T}$

${ }^{1} L_{G a, P u}^{L i q}=-31,927-5.288 * \mathrm{~T}$

${ }^{2} L_{G a, P u}^{L i q}=+12,711-7.134 * \mathrm{~T}$

$\mathbf{P u}_{\mathbf{3}} \mathbf{G a}(\boldsymbol{\zeta}, \mathbf{L T})$

${ }^{0} G^{P u_{3} G a\left(\xi^{\prime}\right)}-.75^{0} G_{P u}^{\alpha}-.25{ }^{0} G_{G a}^{\text {orth }}=-38,934+11.093 * \mathrm{~T}$

$\mathbf{P u}_{3} \mathbf{G a}(\zeta$, HT)

${ }^{0} G^{P u_{3} G a(\zeta)}-.75{ }^{0} G_{P u}^{\alpha}-.25^{0} G_{G a}^{o r t h}=-38,775+10.843 * \mathrm{~T}$

$\mathbf{P u}_{5} \mathbf{G a}_{3}$

${ }^{0} G^{\mathrm{Pu}_{5} \mathrm{Ga} a_{3}}-.625{ }^{0} G_{P u}^{\alpha}-.375{ }^{0} G_{G a}^{\text {orth }}=-48,394+9.5 * \mathrm{~T}$

PuGa (, LT)

${ }^{0} G^{P u G a(\iota)}-.5{ }^{0} G_{P u}^{\alpha}-.5{ }^{0} G_{G a}^{o r t h}=-51,489+5.037 * \mathrm{~T}$

\section{PuGa (ı', HT)}

${ }^{0} G^{P u G a\left(\iota^{\prime}\right)}-.5^{0} G_{P u}^{\alpha}-.5{ }^{0} G_{G a}^{\text {orth }}=-50,289+3.61 * \mathrm{~T}$

$\mathbf{P u}_{\mathbf{2}} \mathbf{G a}_{3}$

${ }^{0} G^{P u_{2} G a_{3}}-.4^{0} G_{P u}^{\alpha}-.6^{0} G_{G a}^{\text {orth }}=-54,260+4.0 * \mathrm{~T}$

\section{$\mathbf{P u G a}_{2}$}

${ }^{0} G^{P u G a_{2}}-.33{ }^{0} G_{P u}^{\alpha}-.67{ }^{0} G_{G a}^{\text {orth }}=-55,327+2.67 * \mathrm{~T}$

$\operatorname{PuGa}_{3}(\mu$ ', LT)

${ }^{0} G^{\mathrm{PuGa}_{3}\left(\mu^{\prime \prime}\right)}-.25{ }^{0} G_{P u}^{\alpha}-.75{ }^{0} G_{G a}^{\text {orth }}=-59,714+11.249 * \mathrm{~T}$

$\operatorname{PuGa}_{3}(\mu$ ', MT)

${ }^{0} G^{P u G a_{3}\left(\mu^{\prime}\right)}-.25{ }^{0} G_{P u}^{\alpha}-.75^{0} G_{G a}^{\text {orth }}=-59,713+11.247 * \mathrm{~T}$

$\operatorname{PuGa}_{3}(\boldsymbol{\mu}, \mathbf{H T})$

${ }^{0} G^{P u G a_{3}(\mu)}-.25{ }^{0} G_{P u}^{\alpha}-.75{ }^{0} G_{G a}^{\text {orth }}=-48,682+2.025 * \mathrm{~T}$

\section{$\mathbf{P u}_{\mathbf{2}} \mathbf{G a}_{7}$}

${ }^{0} G^{P u_{2} G a_{7}}-.222^{0} G_{P u}^{\alpha}-.778^{0} G_{G a}^{o r t h}=-59,000+17.8^{*} \mathrm{~T}$

PuGa $_{3.7}$

${ }^{0} G^{P u G a_{3.7}}-.213{ }^{0} G_{P u}^{\alpha}-.787{ }^{0} G_{G a}^{\text {orth }}=-57,000+16.1 * \mathrm{~T}$

$\mathrm{PuGa}_{4}$

${ }^{0} G^{P u G a_{4}}-.2^{0} G_{P u}^{\alpha}-.8{ }^{0} G_{G a}^{\text {orth }}=-53,820+14.9 * \mathrm{~T}$

\section{PuGa $_{6}$}

${ }^{0} G^{P u G a_{6}}-.143{ }^{0} G_{P u}^{\alpha}-.857^{0} G_{G a}^{\text {orth }}=-41,000+12.4 * \mathrm{~T}$ 


\section{$\mathbf{P u}_{2} \mathbf{G a}_{15}$}

${ }^{0} G^{P u_{2} G a_{15}}-.118{ }^{0} G_{P u}^{\alpha}-.882{ }^{0} G_{G a}^{o r t h}=-38,000+22.0 * \mathrm{~T}$

\section{C.3. AlFePu Compound}

$$
{ }^{0} G^{A l F e P u}-.333{ }^{0} G_{A l}^{f c c}-.333{ }^{0} G_{F e}^{b c c}-.333{ }^{0} G_{P u}^{\alpha}=-40,000+1.333 * \mathrm{~T}
$$

\section{Appendix D. Description of the Mobility Database}

The MOB database, produced by the Thermo-Calc group, contains assessed data for the diffusion coefficients and the mobilities of concentrated alloys. All phase names and thermodynamic factors are compatible with the SGTE solution database (SSOL).

The standard kinetic calculations for the formation of the $\mathrm{Pu}_{3} \mathrm{Ga}$ compound in a fcc $(\delta)$ matrix of $\mathrm{Pu}-\mathrm{Ga}$ alloy performed using DICTRA required input data on mobilities and activation energies. The available data from the scientific literature on the subject is summarized in Fig. D.1, together with the input selected for subsequent DICTRA calculations. Note that except for the data from Ref. a (see Fig. D.1), all the other data pertain to $\delta$-stabilized $\mathrm{Pu}$ with $\mathrm{Ga}$. The results described in sections IX.2-4 are based on the updated mobility database called pugamob1.TDB. Since a single-sublattice model is considered for the diffusion of $\mathrm{Pu}$ and $\mathrm{Ga}$ in a fcc ( $\delta) \mathrm{Pu}-\mathrm{Ga}$ matrix, the expression for the activity Gibbs energies of $\mathrm{Pu}$ and Ga take the simpler form (to be compared with Eq. (9) in section II.3):

$$
\begin{aligned}
& \Delta G_{P u}^{f c c}=x_{P u} Q_{P u}^{P u}+x_{G a} Q_{P u}^{G a}+x_{P u} x_{G a} Q_{P u}^{P u, G a} \\
& \Delta G_{G a}^{f c c}=x_{P u} Q_{G a}^{P u}+x_{G a} Q_{G a}^{G a}+x_{G a} x_{P u} Q_{G a}^{G a, P u}
\end{aligned}
$$

The composition-dependent atomic mobilities of $\mathrm{Ga}$ and $\mathrm{Pu}$ in the fcc $(\delta)$ solid solution are represented by the following Arrhenius-type equation:

$$
M_{i}=\frac{M_{i}^{0}}{R T} \exp \left(-\frac{Q_{i}}{R T}\right)
$$

where $M_{i}$ is the atomic mobility of species $\mathrm{i}$ in the fcc phase, $M_{i}^{0}$ is the frequency factor (in $\left.\mathrm{m}^{2} / \mathrm{s}\right)$, and $Q_{i}$ is the activation energy (in $\mathrm{J} / \mathrm{mol}$ ). Let us define $\Phi_{i}$ as

$$
\Phi_{i}=-Q_{i}-R T \ln M_{i}^{0}
$$

then the mobility can also be written as

$$
M_{i}=\frac{1}{R T} \exp \left(\frac{\Phi_{i}}{R T}\right)
$$

In the spirit of the CALPHAD methodology, the composition dependence of $\Phi_{i}$ is given by the following expression

$$
\Phi_{i}=x_{G a} \Phi_{i}^{G a}+x_{P u} \Phi_{i}^{P u}+x_{G a} x_{P u} \sum_{k=0}^{p}{ }^{k} \Phi_{i}^{G a, P u}\left(x_{G a}-x_{P u}\right)^{k}
$$

where $\Phi_{i}^{j}$ is the mobility parameter of element i in pure $\mathrm{j}$ (as given by the mobility database), and ${ }^{k} \Phi_{i}^{G a, P u}$ are the interaction parameters for element $\mathrm{i}$ and are set to zero for both $\mathrm{Ga}$ and $\mathrm{Pu}$. 


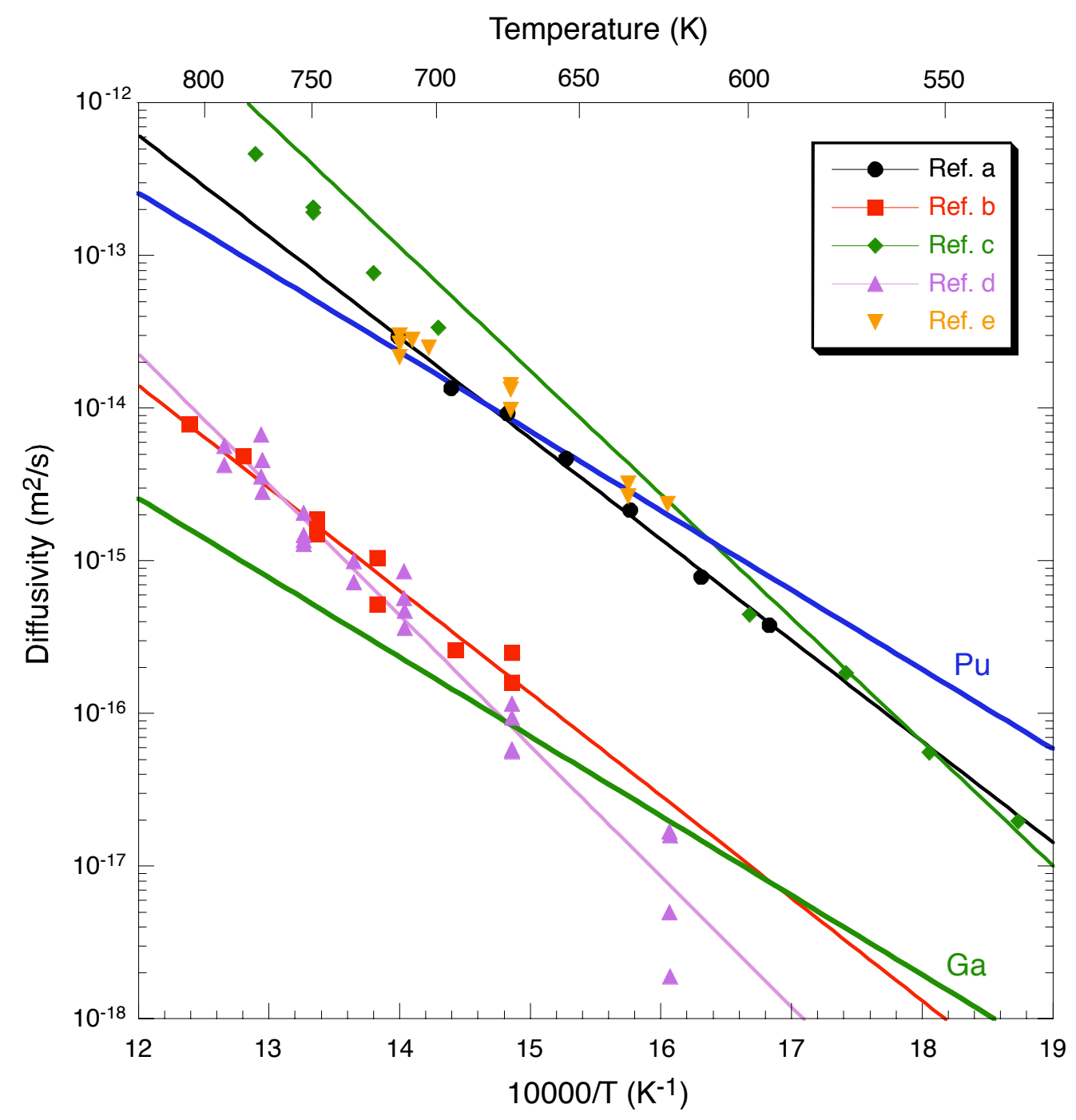

Figure D.1. Plot of plutonium diffusivity in the fcc $(\delta)$ phase versus the reciprocal absolute temperature. The four types of symbol correspond to four sources of data, and each line associated with the symbols of the same color is the result of a fit. The thicker blue and green lines correspond to the data selected for the mobility database of Pu (Ref. e) and Ga, respectively, used to perform DICTRA calculations.

${ }^{a}$ Ref. [70]. The results pertain to unalloyed $\mathrm{Pu}$. The fit to the data is given by the equation: $\mathrm{D}=5.17 \mathrm{x} 10-5 \exp \left(-126,400 / \mathrm{RT}\right.$ ) in $\mathrm{m}^{2} / \mathrm{s}$ (with the gas constant $\mathrm{R}=8.31451 \mathrm{~J} / \mathrm{mol} . \mathrm{K}$ ).

${ }^{\mathrm{b}}$ Ref. [71]. The results are obtained from two set of couples: one with 0.73 and $1.97 \mathrm{wt} . \% \mathrm{Ga}$, and the other with $1.15 \mathrm{wt} . \%$ and $1.68 \mathrm{wt} . \% \mathrm{Ga}$. The fit to the data is given by the equation: $\mathrm{D}=9.80 \times 10^{-6}$ $\exp \left(-139,420 / \mathrm{RT}\right.$ ) in $\mathrm{m}^{2} / \mathrm{s}$ (with the gas constant $\mathrm{R}=8.31451 \mathrm{~J} / \mathrm{mol} . \mathrm{K}$ ).

${ }^{\text {c}}$ Ref. [72]. As indicated in the title of the paper, the results pertain to an alloy with $1 \mathrm{wt} \% \mathrm{Ga}$. The fit to the data is given by the equation: $\mathrm{D}=7.64 \times 10^{-5} \exp (-151,981 / \mathrm{RT}$ ) (with the gas constant $\mathrm{R}=8.31451$ $\mathrm{J} / \mathrm{mol} . \mathrm{K})$.

${ }^{\mathrm{d}}$ Ref. [73]. The results pertain to two alloy compositions: 3.0 and 7.9 at.\% Ga. The fit to the data is given by the equation: $\mathrm{D}=1.30 \times 10^{-4} \exp (-156,377 / \mathrm{RT}$ ) (with the gas constant $\mathrm{R}=8.31451 \mathrm{~J} / \mathrm{mol}$.K). 
${ }^{\text {e}}$ Ref. [74]. The results are based on tracer isotope experiments of unalloyed $\mathrm{Pu}$. The fit to the data is given by the equation: $\mathrm{D}=4.5 \times 10^{-7} \exp (-96,646 / \mathrm{RT}$ ) (with the gas constant $\mathrm{R}=8.31451 \mathrm{~J} / \mathrm{mol} . \mathrm{K}$ ), and corresponds to the blue line associated with pure Pu in Fig. D.1.

The composition-dependent interdiffusion coefficients in the fcc phase can then be calculated using Darken's equation

$$
\tilde{D}=\left(x_{G a} M_{P u}+x_{P u} M_{G a}\right) x_{G a} x_{P u} \frac{d^{2} G_{m}^{f c c}}{d x_{P u}^{2}}
$$

Diffusion in the $\alpha$ phase and the $\mathrm{Pu}_{3} \mathrm{Ga}$ compounds are neglected in all DICTRA calculations.

Hence, the mobility (see Eq. 8, section II.3) and Q parameters for Pu and Ga that pertain to the diffusion in the fcc matrix take the following values (the $\mathrm{Q}$ parameters not listed below are set to zero):

$$
\begin{array}{ll}
M_{G a}^{0}=4.5 \times 10^{-9} \mathrm{~m}^{2} / \mathrm{s} & M_{P u}^{0}=4.5 \times 10^{-7} \mathrm{~m}^{2} / \mathrm{s} \\
Q_{G a}^{G a}=Q_{G a}^{P u}=Q_{P u}^{P u}=Q_{P u}^{G a}=-99,600 \mathrm{~J} / \mathrm{mol} &
\end{array}
$$

Note that the mobility $\mathrm{M}_{\mathrm{i}}$ associated with species $\mathrm{i}$ is directly related to the tracer diffusivity by means of the Einstein relation: $\mathrm{D}_{\mathrm{i}}^{*}=\mathrm{RTM}_{\mathrm{i}}$.

In the pugamob1.TDB mobility database the data take the following form:

$$
\begin{aligned}
& \text { MQ(FCC_A1\&GA, } *: V A)=-99600+R * T * L O G(4.5 E-9) \\
& \text { MQ(FCC_A1\&PU, *:VA) }=-99600+R * T * L O G(4.5 E-7)
\end{aligned}
$$

These input data are the result of available data that are summarized in Fig. D.1. One should note that the activation energy has been related to the melting point of the diffusing system according to

$$
Q=3 b^{2} R T_{m}
$$

where $\mathrm{R}$ is the gas constant, $b^{2}$ is a constant equal to about 2 , and $T_{m}$ is the melting point (in $\mathrm{K}$ ). However as noted by Le Claire, the values calculated by this equation are consistently lower than the measured values. The same remark also applies to the Nachtrieb et al. correlation

$$
Q=16.5 L_{m}
$$

where $L_{m}$ is the latent heat of fusion. With the information gathered in Table 2 of section III, Eqs. (D.9) and (D.10) give for $Q$ values equal to 41,911 and 63,309 $\mathrm{J} / \mathrm{mol}$, respectively, which are indeed way smaller than those determined experimentally.

\section{Appendix E. Details of the DICTRA Results}

In this appendix we report the results of DICTRA calculations in a set of figures generated as output of the simulations, and summarized in a table to produce the figures presented in section IX.2. The DICTRA calculations are performed for a given alloy composition and a specific temperature. Each DICTRA calculation gives as output the phase fraction of product phase as a function of time. 


\section{E.1. Fec ( $\delta$ ) to $\mathrm{Pu}_{3} \mathrm{Ga}$ Transformation in Pu-Ga Alloys}

The property diagram of four Pu-Ga alloys presented in Fig. 35 (section IX.2) shows for each of the four phases, namely the fcc ( $\delta$ ) solid solution, the $\alpha$ phase, and the $\mathrm{Pu}_{3} \mathrm{Ga}$ ( $\zeta$ and $\zeta$ ') compounds, the maximum phase fraction that can be reached at a specific temperature and for a given alloy composition. This information can be directly obtained by the lever rule, e.g., in the case $\delta-\mathrm{Pu}_{3} \mathrm{Ga}$, according to

$$
f^{P u_{3} G a}=\left(x_{G a}-x_{1}\right) /\left(.25-x_{1}\right)
$$

where $f^{P u_{3} G a}$ is the phase fraction of $\mathrm{Pu}_{3} \mathrm{Ga}, x_{G a}$ and $x_{1}$ represent the alloy composition and the equilibrium composition of the alloy that corresponds to the location of the two-phase region $\delta+\mathrm{Pu}_{3} \mathrm{Ga}$ as calculated from Eq. (23), respectively.

Table E.1 presents in numerical form the results displayed in Fig. 38 (cf. section IX.2). Typical examples of DICTRA results are shown in Fig. E.1 from which the values reported in Table E.1 have been determined.

$\mathrm{Pu}-12$ at. $\% \mathrm{Ga}$

\begin{tabular}{|c|c|r|r|r|r|r|r|r|r|}
\hline $\mathrm{T}(\mathrm{K})$ & $\mathrm{T}\left({ }^{\circ} \mathrm{C}\right)$ & $\begin{array}{c}\mathrm{t}(\mathrm{hrs}) \\
5 \%\end{array}$ & $\begin{array}{c}\mathrm{t}(\mathrm{yrs}) \\
5 \%\end{array}$ & $\begin{array}{c}\mathrm{t}(\mathrm{hrs}) \\
10 \%\end{array}$ & $\begin{array}{c}\mathrm{t}(\mathrm{yrs}) \\
10 \%\end{array}$ & $\begin{array}{c}\mathrm{t}(\mathrm{hrs}) \\
15 \%\end{array}$ & $\begin{array}{c}\mathrm{t}(\mathrm{yrs}) \\
15 \%\end{array}$ & $\begin{array}{c}\mathrm{t}(\mathrm{hrs}) \\
20 \%\end{array}$ & $\begin{array}{c}\mathrm{t}(\mathrm{yrs}) \\
20 \%\end{array}$ \\
\hline 673 & 400 & 108 & 0.01 & 556 & 0.06 & & & & \\
\hline 593 & 320 & 489 & 0.06 & 2133 & 0.24 & 8306 & 0.95 & & \\
\hline 573 & 300 & 833 & 0.10 & 3500 & 0.40 & 11111 & 1.27 & & \\
\hline 543 & 270 & 2133 & 0.24 & 8944 & 1.02 & 23889 & 2.72 & & \\
\hline 443 & 170 & 158333 & 18.07 & 611111 & 69.76 & 1416667 & 161.72 & 4305555 & 491.5 \\
\hline 343 & 70 & 2222224 & 25368 & 861111104 & 98300 & 1977777792 & 225774 & 4361111040 & 497843 \\
\hline
\end{tabular}

$\mathrm{Pu}-15$ at. $\% \mathrm{Ga}$

\begin{tabular}{|c|c|r|r|r|r|r|r|r|r|}
\hline $\mathrm{T}(\mathrm{K})$ & $\mathrm{T}\left({ }^{\circ} \mathrm{C}\right)$ & \multicolumn{1}{c}{$\begin{array}{c}\mathrm{t}(\mathrm{hrs}) \\
5 \%\end{array}$} & $\begin{array}{c}\mathrm{t}(\mathrm{yrs}) \\
5 \%\end{array}$ & $\begin{array}{c}\mathrm{t}(\mathrm{hrs}) \\
10 \%\end{array}$ & $\begin{array}{c}\mathrm{t}(\mathrm{yrs}) \\
10 \%\end{array}$ & $\begin{array}{c}\mathrm{t}(\mathrm{hrs}) \\
15 \%\end{array}$ & $\begin{array}{c}\mathrm{t}(\mathrm{yrs}) \\
15 \%\end{array}$ & $\begin{array}{c}\mathrm{t}(\mathrm{hrs}) \\
20 \%\end{array}$ & $\begin{array}{c}\mathrm{t}(\mathrm{yrs}) \\
20 \%\end{array}$ \\
\hline 873 & 600 & 1.1 & 0.0001 & 4.9 & 0.0006 & 14.1 & 0.0016 & & \\
\hline 773 & 500 & 1.8 & 0.0002 & 7.1 & 0.0008 & 16.4 & 0.0019 & 168.3 & 0.019 \\
\hline 673 & 400 & 8.3 & 0.0009 & 34 & 0.0038 & 76.9 & 0.0088 & 135.6 & 0.016 \\
\hline 593 & 320 & 61.1 & 0.007 & 248 & 0.028 & 544.4 & 0.062 & 955.5 & 0.11 \\
\hline 573 & 300 & 102.5 & 0.01 & 475 & 0.054 & 986.1 & 0.11 & 1753 & 0.20 \\
\hline 543 & 270 & 277.8 & 0.03 & 1167 & 0.13 & 2575.0 & 0.29 & 4888.8887 & 0.56 \\
\hline 443 & 170 & 27778 & 3.17 & 113056 & 12.91 & 234722 & 26.79 & 436111 & 49.78 \\
\hline 343 & 70 & 43611112 & 4978 & 170000000 & 19406 & 402777792 & 45979 & 741666688 & 84665 \\
\hline
\end{tabular}

$\mathrm{Pu}-17$ at. $\% \mathrm{Ga}$

\begin{tabular}{|c|c|r|r|r|r|r|r|r|r|}
\hline $\mathrm{T}(\mathrm{K})$ & $\mathrm{T}\left({ }^{\circ} \mathrm{C}\right)$ & $\begin{array}{c}\mathrm{t}(\mathrm{hrs}) \\
5 \%\end{array}$ & $\begin{array}{c}\mathrm{t}(\mathrm{yrs}) \\
5 \%\end{array}$ & $\begin{array}{c}\mathrm{t}(\mathrm{hrs}) \\
10 \%\end{array}$ & $\begin{array}{c}\mathrm{t}(\mathrm{yrs}) \\
10 \%\end{array}$ & $\begin{array}{c}\mathrm{t}(\mathrm{hrs}) \\
15 \%\end{array}$ & $\begin{array}{c}\mathrm{t}(\mathrm{yrs}) \\
15 \%\end{array}$ & $\begin{array}{r}\mathrm{t}(\mathrm{hrs}) 20 \% \\
\mathrm{t}(\mathrm{yrs})\end{array}$ & $\begin{array}{c}1 \\
20 \%\end{array}$ \\
\hline 873 & 600 & 0.20 & 0.0000 & 0.77 & 0.0001 & 1.77 & 0.0002 & 3.36 & 0.0004 \\
\hline 773 & 500 & 0.51 & 0.0001 & 2.05 & 0.0002 & 4.53 & 0.0005 & 7.69 & 0.0009 \\
\hline 673 & 400 & 2.8 & 0.0003 & 11.22 & 0.0013 & 25.75 & 0.0029 & 45.28 & 0.0052 \\
\hline 593 & 320 & 20.5 & 0.002 & 86.11 & 0.0098 & 190.56 & 0.022 & 347.22 & 0.040 \\
\hline 573 & 300 & 36.1 & 0.004 & 157.78 & 0.018 & 361.11 & 0.041 & 613.89 & 0.070 \\
\hline 543 & 270 & 104.2 & 0.01 & 436.11 & 0.50 & 1002.78 & 0.11 & 1766.67 & 0.20 \\
\hline 443 & 170 & 8083 & 0.92 & 43611.11 & 4.98 & 90278 & 10.31 & 158333 & 18.07 \\
\hline 343 & 70 & 18333334 & 2092 & 74166664 & 8467 & 157777776 & 18011 & 277777792 & 31710 \\
\hline
\end{tabular}


Pu-20 at.\% Ga

\begin{tabular}{|c|c|r|r|r|r|r|r|r|r|}
\hline $\begin{array}{c}\mathrm{T} \\
(\mathrm{K})\end{array}$ & $\begin{array}{c}\mathrm{T} \\
\left({ }^{\circ} \mathrm{C}\right)\end{array}$ & $\begin{array}{c}\mathrm{t}(\mathrm{hrs}) \\
5 \%\end{array}$ & $\begin{array}{c}\mathrm{t}(\mathrm{yrs}) \\
5 \%\end{array}$ & $\begin{array}{c}\mathrm{t}(\mathrm{hrs}) \\
10 \%\end{array}$ & $\begin{array}{c}\mathrm{t}(\mathrm{yrs}) \\
10 \%\end{array}$ & $\begin{array}{c}\mathrm{t}(\mathrm{hrs}) \\
15 \%\end{array}$ & $\begin{array}{c}\mathrm{t}(\mathrm{yrs}) \\
15 \%\end{array}$ & $\begin{array}{c}\mathrm{t}(\mathrm{hrs}) \\
20 \%\end{array}$ & \multicolumn{1}{c|}{$\begin{array}{c}\mathrm{t}(\mathrm{yrs}) \\
20 \%\end{array}$} \\
\hline 873 & 600 & 0.0278 & 0.0000 & 0.14 & 0.0000 & 0.34 & 0.0000 & 0.56 & 0.0001 \\
\hline 773 & 500 & 0.0983 & 0.0000 & 0.45 & 0.0001 & 0.93 & 0.0001 & 1.67 & 0.0002 \\
\hline 673 & 400 & 0.5556 & 0.0001 & 2.78 & 0.0003 & 6.17 & 0.0007 & 11.19 & 0.0013 \\
\hline 593 & 320 & 5.4444 & 0.0006 & 20.97 & 0.002 & 51.39 & 0.0059 & 90.28 & 0.0103 \\
\hline 573 & 300 & 11.1111 & 0.0013 & 40.83 & 0.005 & 92.22 & 0.011 & 166.67 & 0.019 \\
\hline 543 & 270 & 27.7778 & 0.0032 & 111.11 & 0.013 & 267.50 & 0.031 & 452.78 & 0.052 \\
\hline 443 & 170 & 2222.2222 & 0.25 & 11111 & 1.27 & 25000 & 2.85 & 47222 & 5.39 \\
\hline 343 & 70 & 3472222.2500 & 396.3724 & 19777778 & 2258 & 45277776 & 5168.6961 & 83333336 & 9512.9375 \\
\hline
\end{tabular}

Table E.1. Time (in hours and years) for 5-10-15-20\% transformation-rate from fcc-based ( $\delta$ ) solid solution to $\mathrm{Pu}_{3} \mathrm{Ga}$ at various temperatures (in $\mathrm{K}$ and ${ }^{\circ} \mathrm{C}$ ) in $\mathrm{Pu}-\mathrm{Ga}$ alloys.
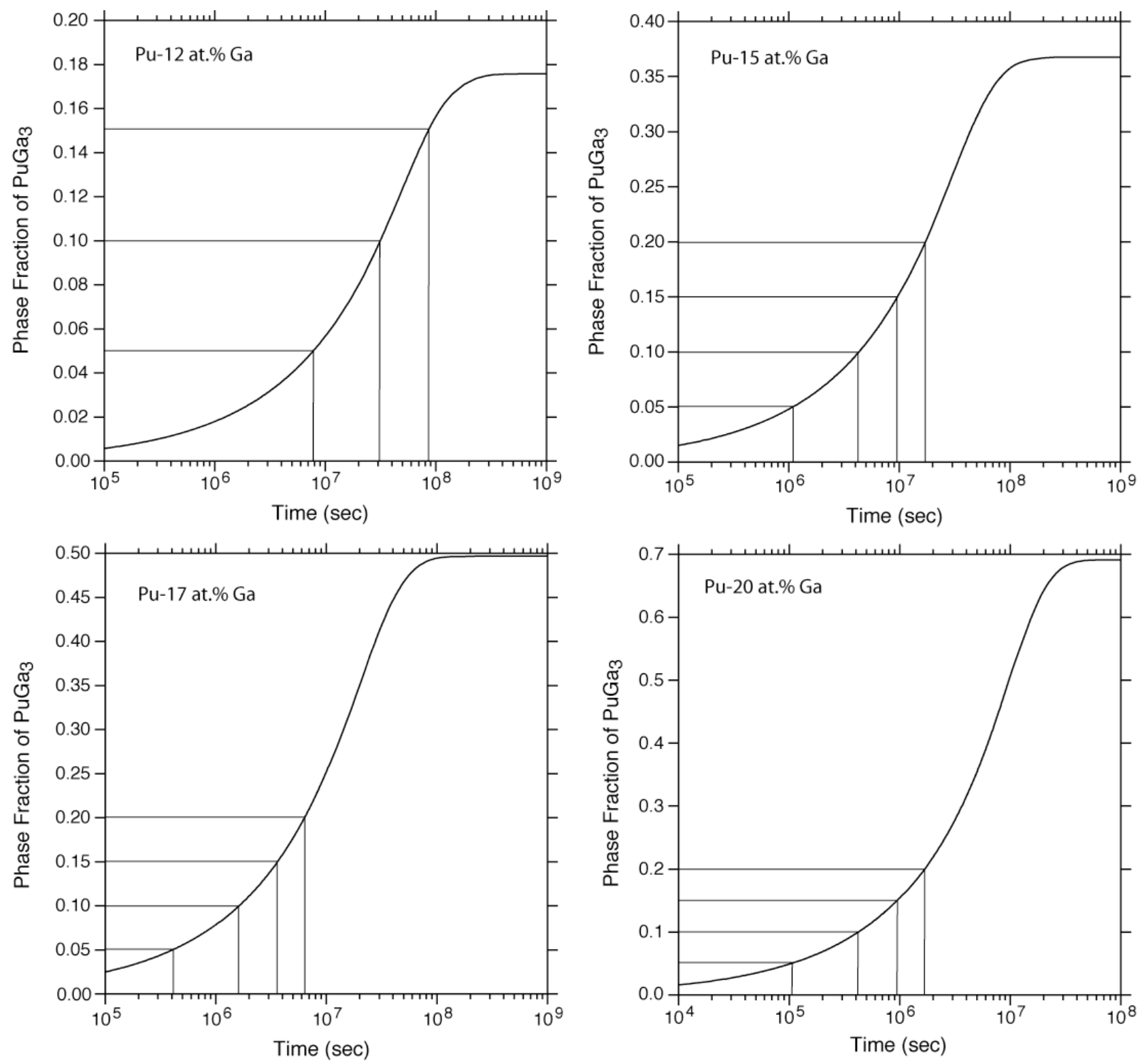

Figure E.1. Calculated phase fraction of $\mathrm{Pu}_{3} \mathrm{Ga}$ formed from a fcc $(\delta)$ matrix for $\mathrm{Pu}_{1-\mathrm{x}}-\mathrm{Ga}_{\mathrm{x}}$ $(\mathrm{x}=.12, .15, .17, .20)$ versus time (in sec) at $543 \mathrm{~K}$. The horizontal and vertical lines indicate 5, 10, 15, and $20 \%$-transformation rates from $\delta$ to $\mathrm{Pu}_{3} \mathrm{Ga}$ and their corresponding times, respectively 


\section{E.2. Fec $(\delta)$ to $\alpha$ Transformation in Pu-rich Pu-Ga Alloys}

The phase fraction of $\alpha$ can be directly obtained by the lever rule according to

$$
f^{\alpha}=\left(x_{2}-x_{G a}\right) / x_{2}
$$

where $f^{\alpha}$ is the phase fraction of $\alpha, x_{G a}$ and $x_{2}$ represent the alloy composition and the equilibrium composition of the alloy that corresponds to the location of the two-phase region $\alpha+\delta$ as calculated from Eq. (24), respectively.

Table E. 2 presents in numerical form the results displayed in Fig. 42 (cf. section IX.3). Typical examples of DICTRA results are shown in Fig. E.2 from which the values reported in Table E.2 have been determined.

$\mathrm{Pu}-2$ at.\% Ga

\begin{tabular}{|c|c|c|c|c|r|r|r|r|r|}
\hline $\mathrm{T}(\mathrm{K})$ & $\mathrm{T}\left({ }^{\circ} \mathrm{C}\right)$ & $\begin{array}{c}\mathrm{t}(\mathrm{hrs}) \\
5 \%\end{array}$ & $\begin{array}{c}\mathrm{t}(\mathrm{yrs}) \\
5 \%\end{array}$ & $\begin{array}{c}\mathrm{t}(\mathrm{hrs}) \\
10 \%\end{array}$ & $\begin{array}{c}\mathrm{t}(\mathrm{yrs}) \\
10 \%\end{array}$ & $\begin{array}{c}\mathrm{t}(\mathrm{hrs}) \\
15 \%\end{array}$ & $\begin{array}{c}\mathrm{t}(\mathrm{yrs}) \\
15 \%\end{array}$ & $\begin{array}{c}\mathrm{t}(\mathrm{hrs}) \\
20 \%\end{array}$ & $\begin{array}{c}\mathrm{t}(\mathrm{yrs}) \\
20 \%\end{array}$ \\
\hline 393 & 120 & 1666667 & 190.3 & 5083333 & 580.3 & 16694444 & 1905.8 & 29444444 & 3361.2 \\
\hline 373 & 100 & 3361111 & 383.7 & 13888889 & 1585.5 & 27777778 & 3171.0 & 55555556 & 6342.0 \\
\hline 363 & 90 & 5083333 & 580.3 & 22222222 & 2536.8 & 50000000 & 5707.8 & 93055556 & 10622.8 \\
\hline 353 & 80 & 10027778 & 1144.7 & 41944444 & 4788.2 & 89444444 & 10210.6 & 166666667 & 19025.9 \\
\hline 343 & 70 & 25000000 & 2853.9 & 93055556 & 10622.8 & 205277778 & 23433.5 & 347222222 & 39637.2 \\
\hline
\end{tabular}

$\mathrm{Pu}-3$ at.\% Ga

\begin{tabular}{|c|c|c|c|c|c|c|c|c|c|}
\hline $\mathrm{T}(\mathrm{K})$ & $\mathrm{T}\left({ }^{\circ} \mathrm{C}\right)$ & $\begin{array}{c}\mathrm{t}(\mathrm{hrs}) \\
5 \%\end{array}$ & $\begin{array}{c}\mathrm{t}(\mathrm{yrs}) \\
5 \%\end{array}$ & $\begin{array}{c}\mathrm{t}(\mathrm{hrs}) \\
10 \%\end{array}$ & $\begin{array}{c}\mathrm{t}(\mathrm{yrs}) \\
10 \%\end{array}$ & $\begin{array}{c}\mathrm{t}(\mathrm{hrs}) \\
15 \%\end{array}$ & $\begin{array}{c}\mathrm{t}(\mathrm{yrs}) \\
15 \%\end{array}$ & $\begin{array}{c}\mathrm{t}(\mathrm{hrs}) \\
20 \%\end{array}$ & $\begin{array}{c}\mathrm{t}(\mathrm{yrs}) \\
20 \%\end{array}$ \\
\hline 393 & 120 & 7861111 & 897.4 & 30277778 & 3456.4 & 68333333 & 7800.6 & 116388889 & 13286.4 \\
\hline 373 & 100 & 8333333 & 951.3 & 32222222 & 3678.3 & 74166667 & 8466.5 & 130555556 & 14903.6 \\
\hline 363 & 90 & 13888889 & 1585.5 & 55555556 & 6342.0 & 111111111 & 12683.9 & 197777778 & 22577.4 \\
\hline 353 & 80 & 19444444 & 2219.7 & 93055556 & 10622.8 & 194444444 & 22196.9 & 347222222 & 39637.2 \\
\hline 343 & 70 & 41388889 & 4724.8 & 183333333 & 20928.5 & 416666667 & 47565.0 & 700000000 & 79908.7 \\
\hline
\end{tabular}

$\mathrm{Pu}-4$ at.\% Ga

\begin{tabular}{|c|c|c|c|c|c|c|c|r|r|}
\hline $\mathrm{T}(\mathrm{K})$ & $\mathrm{T}\left({ }^{\circ} \mathrm{C}\right)$ & $\begin{array}{c}\mathrm{t}(\mathrm{hrs}) \\
5 \%\end{array}$ & $\begin{array}{c}\mathrm{t}(\mathrm{yrs}) \\
5 \%\end{array}$ & $\begin{array}{c}\mathrm{t}(\mathrm{hrs}) \\
10 \%\end{array}$ & $\begin{array}{c}\mathrm{t}(\mathrm{yrs}) \\
10 \%\end{array}$ & $\begin{array}{c}\mathrm{t}(\mathrm{hrs}) \\
15 \%\end{array}$ & $\begin{array}{c}\mathrm{t}(\mathrm{yrs}) \\
15 \%\end{array}$ & $\begin{array}{c}\mathrm{t}(\mathrm{hrs}) \\
20 \%\end{array}$ & $\begin{array}{c}\mathrm{t}(\mathrm{yrs}) \\
20 \%\end{array}$ \\
\hline 393 & 120 & 158333328 & 18074.6 & & & & & & \\
\hline 373 & 100 & 23472222 & 2679.5 & 101111112 & 11542.4 & 198333328 & 22640.8 & 388888896 & 44393.7 \\
\hline 363 & 90 & 33055556 & 3773.5 & 133888888 & 15284.1 & 277777792 & 31709.8 & 513888896 & 58663.1 \\
\hline 353 & 80 & 54444444 & 6215.1 & 198333328 & 22640.8 & 486111104 & 55492.1 & 808333312 & 92275.5 \\
\hline 343 & 70 & 85277776 & 9734.9 & 366666656 & 41856.9 & 852777792 & 97349.1 & 1416666624 & 161720.0 \\
\hline
\end{tabular}

$\mathrm{Pu}-5$ at. $\% \mathrm{Ga}$

\begin{tabular}{|c|c|c|r|c|c|c|c|c|c|}
\hline $\mathrm{T}(\mathrm{K})$ & $\mathrm{T}\left({ }^{\circ} \mathrm{C}\right)$ & $\begin{array}{c}\mathrm{t}(\mathrm{hrs}) \\
5 \%\end{array}$ & $\begin{array}{c}\mathrm{t}(\mathrm{yrs}) \\
5 \%\end{array}$ & $\begin{array}{c}\mathrm{t}(\mathrm{hrs}) \\
10 \%\end{array}$ & $\begin{array}{c}\mathrm{t}(\mathrm{yrs}) \\
10 \%\end{array}$ & $\begin{array}{c}\mathrm{t}(\mathrm{hrs}) \\
15 \%\end{array}$ & $\begin{array}{c}\mathrm{t}(\mathrm{yrs}) \\
15 \%\end{array}$ & $\begin{array}{c}\mathrm{t}(\mathrm{hrs}) \\
20 \%\end{array}$ & $\begin{array}{c}\mathrm{t}(\mathrm{yrs}) \\
20 \%\end{array}$ \\
\hline 393 & 120 & & & & & & & & \\
\hline 373 & 100 & 167500000 & 19121 & 722222208 & 82446 & & & & \\
\hline 363 & 90 & 119722224 & 136667 & 436111104 & 49784 & 1011111104 & 115424 & 2777777664 & 317098 \\
\hline 353 & 80 & 166388896 & 18994 & 577777792 & 65956 & 1266666624 & 144597 & 2219444480 & 253361 \\
\hline 343 & 70 & 209722224 & 23941 & 902777792 & 103057 & 1983333376 & 226408 & 3666666752 & 418569 \\
\hline
\end{tabular}

Table E.2. Time (in hours and years) for 5-10-15-20\% transformation-rate from fcc-based $(\delta)$ solid solution to $\alpha-\mathrm{Pu}$ at various temperatures (in $\mathrm{K}$ and ${ }^{\circ} \mathrm{C}$ ) in $\mathrm{Pu}-\mathrm{Ga}$ alloys. 

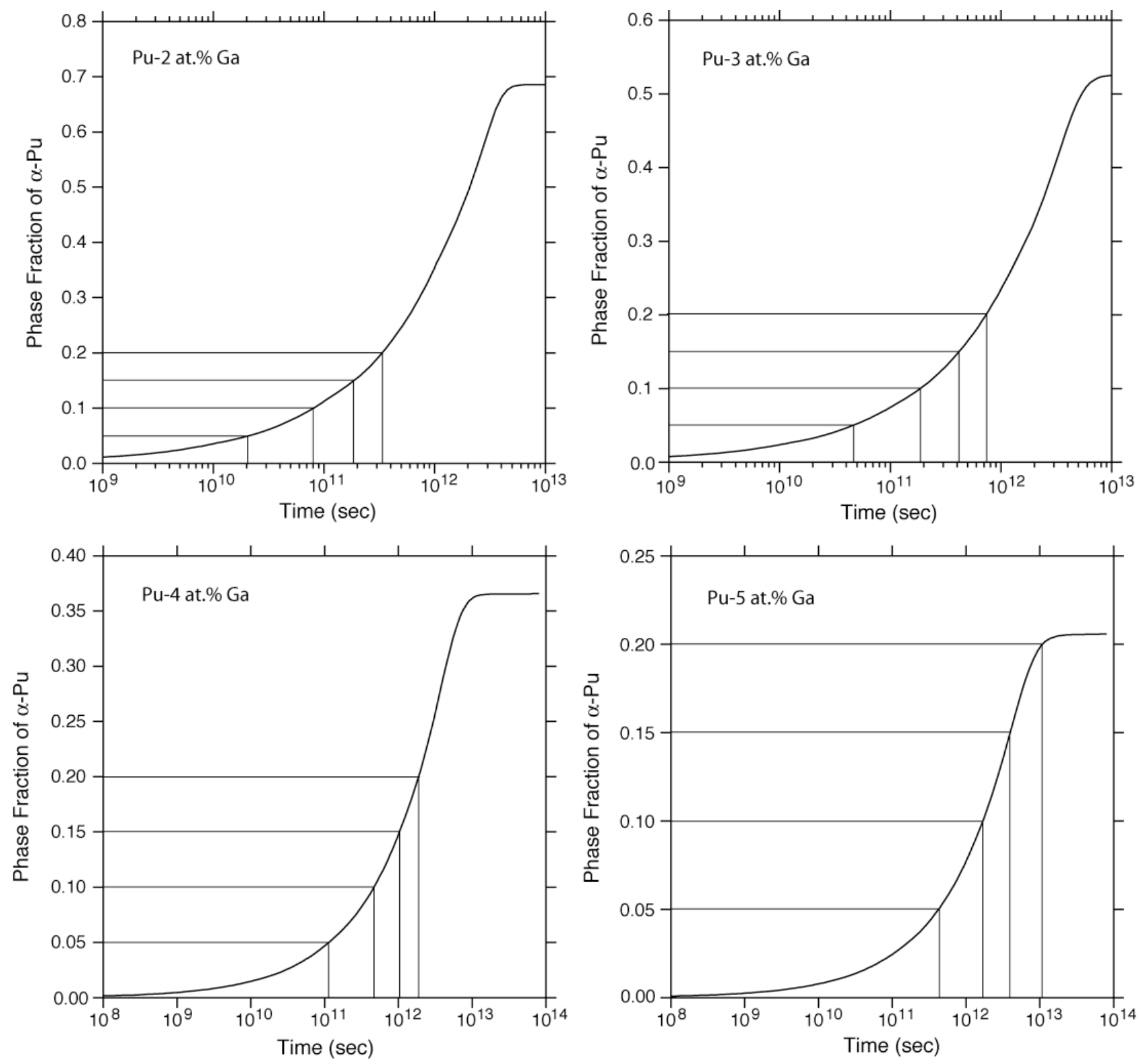

Figure E.2. Calculated phase fraction of $\alpha$-Pu formed from a fcc $(\delta)$ matrix for $\mathrm{Pu}_{1-\mathrm{x}}-\mathrm{Ga}_{\mathrm{x}}(\mathrm{x}=.02$, $.03, .04, .05$ ) versus time (in sec) at $363 \mathrm{~K}$. The horizontal and vertical lines indicate $5,10,15$, and 20 $\%$-transformation rates from $\delta$ to $\alpha$-Pu and their corresponding times, respectively

\section{E.3. Fcc ( $\delta$ ) to $\alpha$ and to $\mathrm{Pu}_{3} \mathrm{Ga}$ Transformations in Pu-rich Pu-Ga Alloys at an Equilibrium Rate of Transformation of $5 \%$}

We consider here the kinetics of transformation from the fcc-based (d) solid solution to a-Pu and to $\mathrm{Pu}_{3} \mathrm{Ga}$, separately, at a fixed maximum equilibrium transformation rate of $5 \%$. As in the previous subsection, the Ga content that corresponds to $\mathrm{f}=0.05$ is calculated according to Eq. (E.2) with the help of Eq. (24) for the determination of $x_{2}$ for $\delta \rightarrow \delta+\alpha$ and to Eq. (E.1) and Eq. (23) for the determination of $x_{1}$ for $\delta \rightarrow \delta+\mathrm{Pu}_{3}$ Ga. Table E.3 presents in numerical form the results displayed in Fig. 44 (cf. section IX.4). Typical examples of DICTRA results are shown in Fig. E.3 from which the values reported in Table E. 3 have been determined. 


\begin{tabular}{|c|c|c|r||c|c|c|r|}
\hline & \multicolumn{3}{|c||}{$\delta-\alpha$} & \multicolumn{4}{|c|}{$\delta-\mathrm{Pu}_{3} \mathrm{Ga}$} \\
\hline $\mathrm{T}\left({ }^{\circ} \mathrm{C}\right)$ & $\mathrm{T}(\mathrm{K})$ & $\mathrm{x}_{\mathrm{Ga}}$ & \multicolumn{1}{|c|}{ time $(\mathrm{yrs})$} & $\mathrm{T}\left({ }^{\circ} \mathrm{C}\right)$ & $\mathrm{T}(\mathrm{K})$ & $\mathrm{x}_{\mathrm{Ga}}$ & \multicolumn{1}{c|}{ time $(\mathrm{yrs})$} \\
\hline 70 & 343 & 0.0686 & 2536783.36 & 70 & 343 & 0.0872 & 2536783.36 \\
\hline 90 & 363 & 0.0595 & 634195.84 & 170 & 443 & 0.0941 & 951.29 \\
\hline 100 & 373 & 0.0546 & 285388.13 & 270 & 543 & 0.1003 & 7.55 \\
\hline 120 & 393 & 0.0418 & 95129.38 & 300 & 573 & 0.1022 & 2.85 \\
\hline & & & & 320 & 593 & 0.1113 & 1.59 \\
\hline
\end{tabular}

Table E.3. Time (in years) for a maximum equilibrium transformation rate of $5 \%$ for the fcc $(\delta)$ solid solution to $\alpha-\mathrm{Pu}$ and to $\mathrm{Pu}_{3} \mathrm{Ga}$ transformations at various temperatures (in ${ }^{\circ} \mathrm{C}$ and $\mathrm{K}$ ) in $\mathrm{Pu}-\mathrm{Ga}$ alloys.
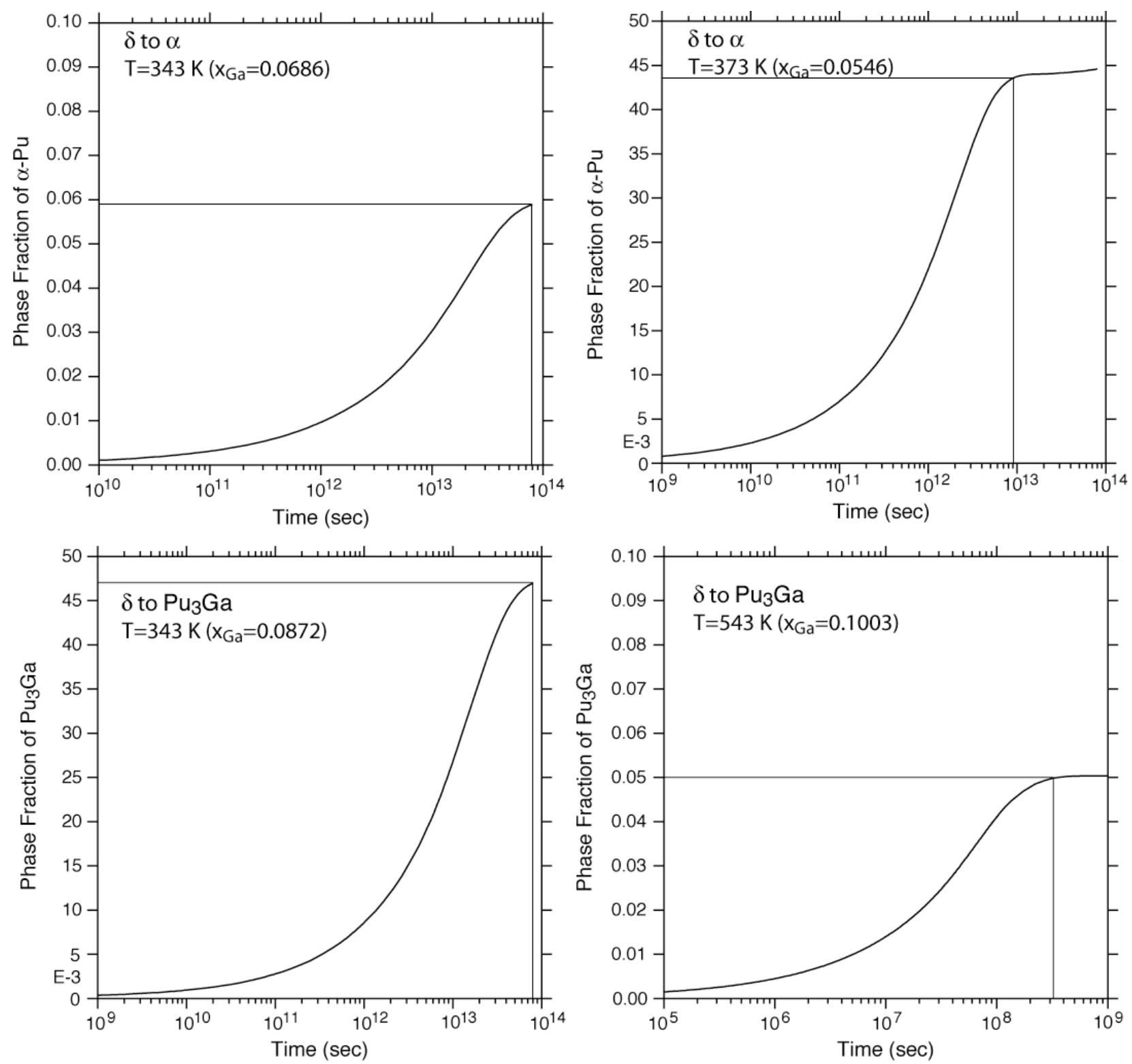

Figure E.3. Calculated phase fraction of $\alpha-\mathrm{Pu}$ (top figures) and $\mathrm{Pu}_{3} \mathrm{Ga}$ (bottom figures) formed from a fcc $(\delta)$ matrix for $\mathrm{Pu}_{1-\mathrm{x}}-\mathrm{Ga}_{\mathrm{x}}$ alloys versus time (in sec) at specific temperatures. Each alloy composition corresponds to an equilibrium phase fraction of product phase of about $5 \%$. 